\title{
A Novel Approach to Experimental Studies of Mineral Dissolution Kinetics
}

\section{Final Technical Report}

Performance Period September 1, 2004 - August 31, 2008

\author{
CHEN ZHU \\ Indiana University
}

January 14, 2009

Award Number

DE-FG26-04NT42125

Department of Geological Sciences, Indiana University, Bloomington, IN 47401. Phone: (812) 855-5582, FAX: (812) 855-7899, e-mail: chenzhu@indiana.edu 


\section{Disclaimer}

This report was prepared as an account of work sponsored by an agency of the United States Government. Neither the United States Government nor any agency thereof, nor any of their employees, makes any warranty, express or implied, or assumes any legal liability or responsibility for the accuracy, completeness, or usefulness of any information, apparatus, product, or process disclosed, or represents that its use would not infringe privately owned rights. Reference herein to any specific commercial product, process, or service by trade name, trademark, manufacture, or otherwise does not necessarily constitute or imply its endorsement, recommendation, or favoring by the United States Government or any agency thereof. The views and opinions of authors expressed herein do not necessarily state or reflect those of the United States Government or any agency thereof. 


\section{Abstract}

Currently, DOE is conducting pilot $\mathrm{CO}_{2}$ injection tests to evaluate the concept of geological sequestration. The injected $\mathrm{CO}_{2}$ is expected to react with the host rocks and these reactions can potentially alter the porosity, permeability, and mechanical properties of the host or cap rocks. Reactions can also result in precipitation of carbonate-containing minerals that favorably and permanently trap $\mathrm{CO}_{2}$ underground. Many numerical models have been used to predict these reactions for the carbon sequestration program. However, a firm experimental basis for predicting silicate reaction kinetics in $\mathrm{CO}_{2}$ injected geological formations is urgently needed to assure the reliability of the geochemical models used for the assessments of carbon sequestration strategies. The funded experimental and theoretical study attempts to resolve this outstanding scientific issue by novel experimental design and theoretical interpretation of silicate dissolution rates at conditions pertinent to geological carbon sequestration.

In this four year research grant (three years plus a one year no cost extension), seven (7) laboratory experiments of $\mathrm{CO}_{2}$-rock-water interactions were carried out. An experimental design allowed the collection of water samples during experiments in situ and thus prevented back reactions. Analysis of the in situ samples delineated the temporal evolution of aqueous chemistry because of $\mathrm{CO}_{2}$-rock-water interactions. The solid products of the experiments were retrieved at the end of the experimental run, and analyzed with a suite of advanced analytical and electron microscopic techniques (i.e., atomic resolution transmission electron microscopy (TEM), scanning electron microscopy (SEM), electron microprobe, X-ray diffraction, X-ray photoelectron spectroscopy (XPS)). As a result, the research project probably has produced one of the best data sets for $\mathrm{CO}_{2}$-rock-water interactions in terms of both aqueous solution chemistry and solid characterization. Three experiments were performed using the Navajo sandstone. Navajo sandstone is geologically equivalent to the Nugget sandstone, which is a target formation for a regional partnership injection project. Our experiments provided the experimental data on the potential $\mathrm{CO}_{2}$-rock-water interactions that are likely to occur in the aquifer. Geochemical modeling was performed to interpret the experimental results.

Our single mineral (feldspar) experiments addressed a basic research need. i.e., the coupled nature of dissolution and precipitation reactions, which has universal implication to the reaction kinetics as it applied to $\mathrm{CO}_{2}$ sequestration. Our whole rock experiments (Navajo sandstone) addressed the applied research component, e.g., reacting Navajo sandstone with brine and $\mathrm{CO}_{2}$ has direct relevance on the activities of a number of regional partnerships.

The following are the major findings from this project:

1. The project generated a large amount of experimental data that is central to evaluating $\mathrm{CO}_{2}$-water-rcok interactions and providing ground truth to predictive models, which have been used and will inevitably be increasingly more used in carbon sequestration.

2. Results from the feldspar experiments demonstrated stronger coupling between dissolution and precipitation reactions. We show that the partial equilibrium assumption did not hold in the feldspar hydrolysis experiments (Zhu and Lu, submitted, Appendix 
A-2). The precipitation of clay minerals influenced dissolution of primary silicate in a much stronger way as previously envisioned. Therefore, our experimental data indicated a much more complex chemical kinetics as it has been applied to carbon sequestration program in terms of preliminary predictive models of $\mathrm{CO}_{2}$-rock-water interactions. Adopting this complexity (strong coupling) may influence estimates of mineral trapping and porosity/permeability for geological carbon sequestration. In general, our knowledge of the coupling of different reactions is poor, and we must consider the uncertainties resulting from our poor knowledge on this regard.

3. Our experimental results concur with previous findings that the role of dissolved $\mathrm{CO}_{2}$ is mostly to acidify the brine, but not change the mechanisms of reactions. This conclusion is based on careful paired experiments with and without $\mathrm{CO}_{2}$.

4. We observed strong chemical reactions between $\mathrm{CO}_{2}$ acidified brine with the Navajo sandstone. The laboratory experiments were conducted at a higher temperature $\left(200{ }^{\circ} \mathrm{C}\right)$ than that in the field $\left(\sim 90{ }^{\circ} \mathrm{C}\right)$ in order to induce measurable chemical changes in the laboratory. However, field conditions are more acidic and reaction time is much longer (1000 years versus $10-80$ days in the laboratory). Therefore, the conclusions on extensive reactions are relevant. We observed extensive dissolution of feldspars, and precipitation of clay minerals. However, the clay coatings on the sediment grains, which were a concern whether it would come off and clog the pores, were intact. The precipitation of secondary minerals can potentially clog pore throats and reduce permeability. Additional experiments are needed to quantify the amount of secondary mineral precipitation, and the results of batch reactor experiments need to be compared to the flooded core experiments to be performed by NETL in house.

Throughout this project, we endeavored to disseminate the research results in a timely fashion, worked closely with NETL in-house research, and communicated our results to the regional partnerships. To reach the carbon capture and storage (CCS) community in the broadest possible sense, we have published our first set of experimental results in a highly regarded journal Chemical Geology, with proper DOE approval, acknowledgement to this grant, and required disclaimer (see Appendix A-1). Note the publication at this peer-referred journal had gone through rigorous peer review. A second publication on geochemical modeling interpretation of experimental data was submitted to the top ranked journal Geochimica et Cosmochimica Acta, and is currently under peer review. A third publication on the experimental data of Navajo sandstone was completed and submitted to the Journal of Greenhouse Gas Control for peer review.

In January 2008, the PI (Dr. Chen Zhu) gave presentations at the Lawrence Berkeley National Laboratory and Lawrence Livermore National Laboratory. Most in the audience are funded by DOE to work on various carbon sequestration programs. Presentations are also given at the annual convention of the American Association of Petroleum Geologist (2008), Seventh Annual Conference Carbon Capture \& Sequestration Conference (2008), Geological Society of America annual meeting (2008), and AAPG Eastern Section Meeting (2007). Because a large amount of experimental data was generated and has not been fully digested, some of our findings will be further analyzed and ideas will be refined. We will continue to communicate the results 
to the carbon sequestration community through open literature publications and presentations at national and international meetings with proper acknowledgement of this grant. 


\section{Table of Contents}

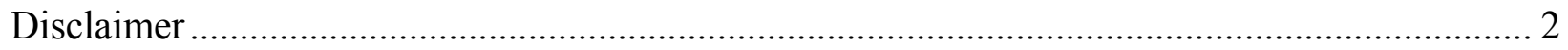

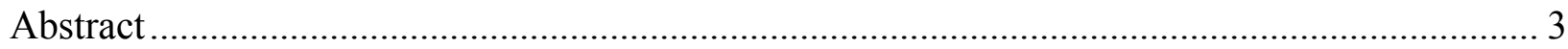

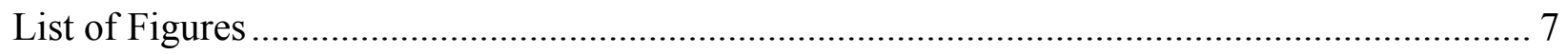

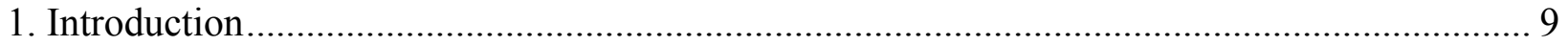

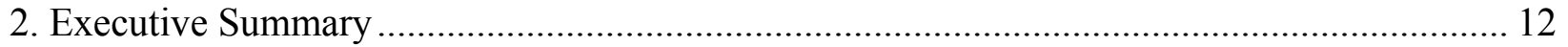

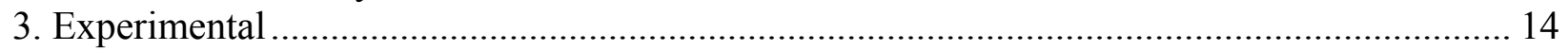

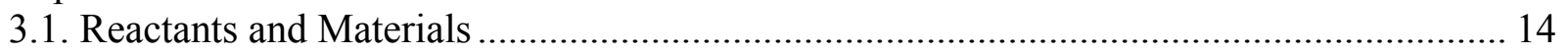

3.2. Batch and Flow-through Experiments .................................................................... 14

3.3. Electron Micro Beam and X-ray Characterization of Reactants and Products................ 16

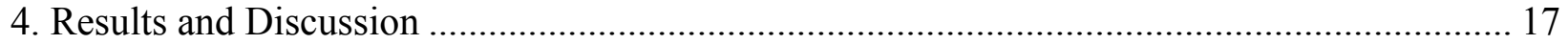

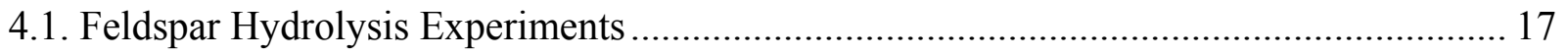

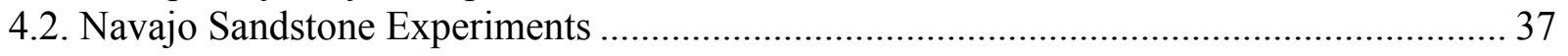

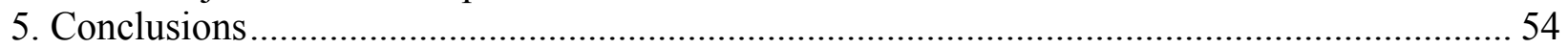

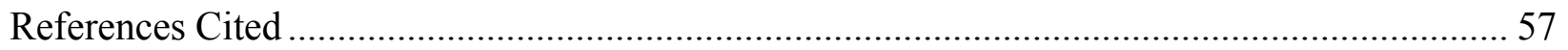

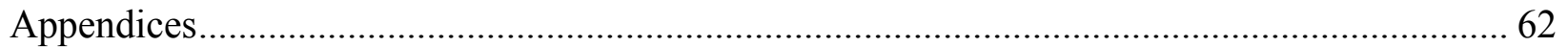

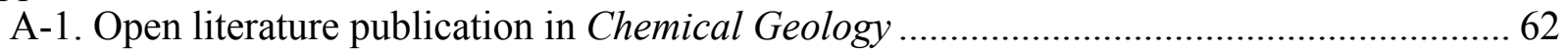

A-2. Manuscript submitted to Geochimica et Cosmochimica Acta ........................................ 62

A-3. Manuscript submitted to Journal of Greenhouse Gas Control ....................................... 62 


\section{List of Figures}

Figure 1. Chemical compositions and nomenclature of feldspars.

Figure 2. Schematic illustration of the flexible cell reaction system

Figure 3. Changes in the dissolved concentrations of selected aqueous constituents with time for the perthitic alkali-feldspar dissolution experiments (Experiment 2) at $200^{\circ} \mathrm{C}$ and 300 bars.

Figure 4. SEM backscatter images of alkali-feldspar dissolution effects following reaction (Experiment 2).

Figure 5. X-ray diffraction patterns of mineral products following the experiment (Experiment 2).

Figure 6. TEM images and SAED patterns of mineral products from alkali-feldspar dissolution experiments at $200^{\circ} \mathrm{C}$ and 300 bars (Experiment 2).

Figure 7. Activity - activity diagrams showing the phase relations in the system $\mathrm{K}_{2} \mathrm{O}-\left(\mathrm{Al}_{2} \mathrm{O}_{3}\right)$ $\mathrm{SiO}_{2}-\mathrm{H}_{2} \mathrm{O}-\mathrm{HCl}$ at $200{ }^{\circ} \mathrm{C}$ and 300 bars (Experiment 2).

Figure 8. Changes in the dissolved concentrations of selected aqueous constituents with time for the perthitic alkali-feldspar dissolution experiments with the presence of $\mathrm{CO}_{2}$ at $200{ }^{\circ} \mathrm{C}$ and 300 bars (Experiment 1).

Figure 9. SEM backscatter micrograph of alkali-feldspars after $5 \mathrm{~d}$ reaction in Experiment 1.

Figure 10. TEM images of alkali-feldspars after $120 \mathrm{~h}$ 's dissolution experiment with the presence of $\mathrm{CO}_{2}$ using ultrasonication sample preparation method (Experiment 1).

Figure 11. X-ray diffraction pattern of mineral products recovered following 648-h experiment (Experiment 1).

Figure 12. Changes in the dissolved concentrations of selected aqueous constituents with time for the alkali-feldspar dissolution experiments with the presence of $\mathrm{CO}_{2}$ at $200{ }^{\circ} \mathrm{C}$ and 300 bars (Experiment 1).

Figure 13. SEM micrograph of products from Experiment 6.

Figure 14. Changes in the dissolved concentrations of selected aqueous constituents with time for the albite dissolution experiments with the presence of $\mathrm{CO}_{2}$ at $150{ }^{\circ} \mathrm{C}$ and 300 bars (Experiment 7).

Figure 15. SEM micrographs of Experiment 7. 
Figure 16. X-ray diffraction pattern of mineral products following albite dissolution experiment (Experiment 7).

Figure 17. TEM images (a) kaolinite like clay particle with a d-spacing $\sim 0.7 \mathrm{~nm}$; (b) A and B are Al-containing particles, probably boehmite; (c) EDS that shows A and B contain mainly Al (Experiment 7).

Figure 18. Activity-activity diagram depicting mineral stability fields in the system $\mathrm{Na}_{2} \mathrm{O}-\mathrm{Al}_{2} \mathrm{O}_{3}$ $\mathrm{SiO}_{2}-\mathrm{CO}_{2}-\mathrm{H}_{2} \mathrm{O}$ at $150{ }^{\circ} \mathrm{C}$ (Experiment 7).

Figure 19. X-ray diffraction patterns of the clay fraction in Navajo Sandstone before (grey line) and after reactions with $\mathrm{CO}_{2}$-imprenanted brine (black line).

Figure 20. SEM micrographs of Navajo Sandstone before reactions.

Figure 21. SEM micrographs of Navajo Sandstone after Experiment 3.

Figure 22. SEM micrographs of Navajo Sandstone after Experiment 4.

Figure 23. SEM micrographs of Navajo Sandstone after Experiment 5. 


\section{Introduction}

There has been a great deal of concern over global climate change, and its link to growing atmospheric concentrations of carbon dioxide $\left(\mathrm{CO}_{2}\right)$. An ever-increasing amount of scientific evidence suggests that anthropogenic release of $\mathrm{CO}_{2}$ has led to a rise in global temperatures over the past several hundred years (BRADLEY, 2001; CROWLEY, 2000). This "global warming" is a trend that, if unabated, can lead to significant and possibly catastrophic alteration of climate throughout the world.

In order to decrease the impact of $\mathrm{CO}_{2}$ on global climate, several strategies are under development that will potentially remove $\mathrm{CO}_{2}$ from the atmosphere or decrease $\mathrm{CO}_{2}$ emission (DOE, 1999; HERZOG et al., 1997). One such strategy that has received a great deal of attention involves the capture of $\mathrm{CO}_{2}$ from large point sources (such as fossil fuel-fired power plants) and the long-term storage of $\mathrm{CO}_{2}$ underground. In fact, such a technique is currently in practice in Norway. Statoil's Sleipner plant separates about 2,800 tons of $\mathrm{CO}_{2}$ from a natural gas stream daily and injects it into a saline aquifer below the North Sea (Hammerstad, 2000).

For geological carbon sequestration programs that inject $\mathrm{CO}_{2}$ into deep saline formations, the injected $\mathrm{CO}_{2}$ can react with brine and solid matrix, resulting in an increase of $\mathrm{pH}$ and precipitation of carbonates. The rate of this reaction with respect to fluid flow is important to determine the mechanism of trapping, either by hydrodynamics $\left(\mathrm{CO}_{2}\right.$ dissolved in slow moving brine or remains to be in a separate liquid phase) or mineral trapping (carbon precipitation). Such processes are currently being evaluated at NETL sponsored pilot test sites in the Frio sandstone in the Texas Gulf Coast (Hovorka et al., 2002), at Statoil's Sleipner project in North Sea (Johnson et al., 2002), and at the Weyburn $\mathrm{CO}_{2}$-enhanced oil recovery site, Canada (Perkins et al., 2002).

Recently, STRAZISAR et al. (2006) performed one-dimensional transport modeling of $\mathrm{CO}_{2}$ in the Alberta basin, with the chemical reaction aspect of the model resembling that presented by GUNTER et al. (2000) as a first approximation. The ultimate goal of this modeling effort is to develop reservoir or basin scale models that include flow, mass and heat transport, multi-phases, and chemical reaction processes at field pilot test and $\mathrm{CO}_{2}$ injection sites. Such a model is valuable for evaluating the suitability of a geological formation as $\mathrm{CO}_{2}$ storage, optimal injection operations, and monitoring and management of injection operations.

One outcome of this modeling study is the demonstrated importance of mineral reaction kinetics. However, one of the fundamental problems in modern geochemistry is the persistent two to five orders of magnitude discrepancy between laboratory-measured and field derived feldspar dissolution rates (see reviews by Blum and Stillings, 1995; Drever and Clow, 1995; White, 1995). This discrepancy is huge. For example, the laboratory rates indicate that a $0.1 \mathrm{~mm}$ feldspar sphere should weather away in $\sim 250$ years, whereas the field rates predict a feldspar lifetime of millions of years (calculations followed Lasaga, 1998). Such a large discrepancy illustrates our inability to move forward with the quantitative assessment of mineral trapping as a sequestration strategy. Feldspar is the most abundant mineral in the earth's crust. Most sandstones that have been proposed as sequestration target formations contain several percent to tens of percent of feldspars. In addition to the geological carbon sequestration program, kinetically controlled reactions, including glauconite dissolution (Gunter et al., 1997), iron carbonate precipitation (NRC, 2003), and olivine and serpentine carbonation (Carey et al., 2003, 
and reports published by the Albany Research Center), are also important to other carbon sequestration programs.

To date, there is no real guidance as to how to predict in situ reaction rates for use in reactive transport models. Models for geological carbon sequestration have generally opted to use laboratory rates (e.g., Gunter et al., 1997; Xu et al., 2004). In general, we know little about the proper rates and rate laws that are applicable to geological systems (Lasaga, 1998). However, a firm scientific basis for predicting reaction kinetics in natural environments is urgently needed to assure the reliability of the geochemical models used for the carbon sequestration program.

The funded research here attempts to resolve this outstanding scientific issue. The chemical, physical, and biological processes in the deep geological formation are complex and inter-related. Monitoring subsurface activities is costly. Thus, the results of the funded research represents a necessary step in reducing cost associated with geological carbon sequestration by developing mathematical models for evaluating and optimizing the injection program. Over the long-term, geological carbon sequestration will go through performance assessment evaluation processes, and as time progresses, the reaction kinetics problem is likely to occupy a more prominent position. Our results will provide crucial parameters for the performance assessment.

Feldspars (Fig. 1) are the most abundant silicate minerals and comprise over $50 \%$ of the volume of the earth's crust. When $\mathrm{CO}_{2}$ is injected into geological formations, $\mathrm{CO}_{2}$ will react with silicate minerals in the aquifers (such as in the case of the Frio sandstone, Texas, Weyburn, Canada, and the Sleipner projects mentioned above). The reactions will increase the $\mathrm{pH}$ of the brine, resulting in an enhanced solubility of $\mathrm{CO}_{2}$ in brine, which is a desirable effect because it reduces the chance of $\mathrm{CO}_{2}$ leakage to the surface.

Dissolution of feldspars can also release $\mathrm{Ca}^{2+}$, which can form carbonate precipitates. This is the most desired consequence of $\mathrm{CO}_{2}$ injection because carbonate solids are immobile and are permanently stored in deep geological formations without the risk of seeping back to the surface. As

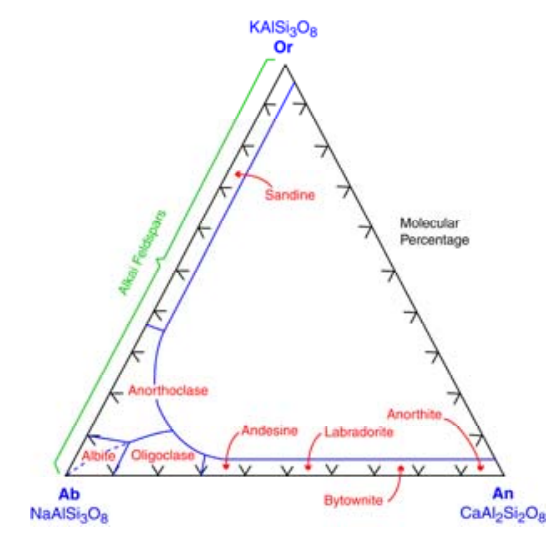

Fig. 1. Chemical compositions and nomenclature of feldspars. pointed out by the NRC workshop report (NRC, 2003), this is a natural process of weathering. However, the key to the carbon sequestration program is an understanding of the reaction kinetics and how to accelerate the process.

Another consequence of silicate reaction after $\mathrm{CO}_{2}$ injection is the change of porosities in the geological formation, which can alter the patterns of fluid flow and cause formation damage. STRAZISAR et al. (2006) again demonstrated that the magnitudes of porosity changes are closely related to the kinetic parameters used in the model.

In addition to the long-term controversy between field and laboratory rates, there is a general lack of experimental data at conditions pertinent to the geological carbon sequestration program. The reactions pertinent to geological carbon sequestration occur in about 50 to $150{ }^{\circ} \mathrm{C}$, high $\mathrm{CO}_{2}$ pressure, and in saline brines. Although high $\mathrm{CO}_{2}$ concentrations might suggest $\mathrm{pH}$ lowering and more rapid dissolution of primary aluminosilicates, these conditions may enhance 
further the stability of clay minerals and carbonate minerals, with attendant effects on the overall reaction rate schemes. Moreover, it is not at all clear from available data whether high $\mathrm{CO}_{2}$ concentrations in fluids act to catalyze or inhibit mineral dissolution/precipitation processes typical of or likely to be found in geologic terrains impacted by carbon sequestration.

\section{There is a dearth of kinetic data relevant to geological carbon sequestration, and} hence the need for experimental measurements.

This report summarizes both single mineral and whole rock experiments. The single mineral feldspar experiments were targeted to evaluate some basic scientific questions in chemical kinetics such as the partial equilibrium assumption. The classical reaction path model of feldspar hydrolysis (HELGESON, 1968; HelGESON, 1971; HELGESON, 1979; HELGESON et al., 1969) states that: (1) dissolution of primary feldspar is the rate-limiting irreversible reaction and the driver of all processes in the system; (2) precipitation of all secondary minerals is instantaneous; (3) the aqueous solution is at equilibrium with or undersaturated with respect to all secondary minerals at all times; (4) fluid chemistry evolves along the boundaries of the mineral phases on equilibrium activity-activity diagrams (abbreviated as $a-a$ diagrams hereafter); and (5) secondary minerals dissolve and precipitate in a paragenesis sequence as aqueous chemistry evolves. Because secondary clay minerals are at equilibrium with the aqueous solution while the overall system does not reach equilibrium, it is called partial equilibrium systems.

Our whole rock experiments used the target geological formation materials to react with $\mathrm{CO}_{2}$ and brine and tested the reactivity of the rocks with $\mathrm{CO}_{2}$ impregnated brines. The combination of the two categories of experiments addresses the needs of both fundamental and applied sciences in support of geological carbon sequestration. 


\section{Executive Summary}

Currently, DOE is conducting pilot $\mathrm{CO}_{2}$ injection tests to evaluate the concept of geological sequestration. One strategy that potentially enhances $\mathrm{CO}_{2}$ solubility and reduces the risk of $\mathrm{CO}_{2}$ leak back to the surface is dissolution of indigenous minerals in the geological formation and precipitation of secondary carbonate phases, which increases the brine $\mathrm{pH}$ and immobilizes $\mathrm{CO}_{2}$. Clearly, the rates at which these dissolution and precipitation reactions occur directly determine the efficiency of this strategy. Therefore, a firm scientific basis for predicting silicate reaction kinetics in $\mathrm{CO}_{2}$ injected geological formations is urgently needed to assure the reliability of the geochemical models used for the assessments of carbon sequestration strategies. This research project addresses this critical and urgent need of the carbon sequestration program.

In this four year research grant (three years plus a one year no cost extension), seven (7) laboratory experiments of $\mathrm{CO}_{2}$-rock-water interactions were carried out. An experimental design allowed the collection of water samples during experiments in situ and thus prevented back reactions. Analysis of the in situ samples delineated the temporal evolution of aqueous chemistry because of $\mathrm{CO}_{2}$-roick-water interactions. The solid products of the experiments were retrieved at the end of the experimental run, and analyzed with a suite of advanced analytical and electron microscopic techniques (i.e., atomic resolution transmission electron microscopy (TEM), scanning electron microscopy (SEM), electron microprobe, X-ray diffraction, XPS). Geochemical modeling was also performed to interpret the experimental results. As a result, the research project probably has produced one of the most comprehensive data sets for $\mathrm{CO}_{2}$-rockwater interactions in terms of both aqueous solution chemistry and solid characterization.

Our single mineral (feldspar) experiments addressed a basic research need. i.e., the coupled nature of dissolution and precipitation reactions, which has universal implication to the reaction kinetics as it applied to $\mathrm{CO}_{2}$ sequestration. Our whole rock experiments (Navajo sandstone) addressed the applied research component, e.g., reacting Navajo sandstone with brine and $\mathrm{CO}_{2}$ has direct relevance on the activities of a number of regional partnerships.

The following are the major findings from this project:

1. The project generated a large amount of experimental data that is central to evaluating $\mathrm{CO}_{2}$-water-rcok interactions and providing ground truth to predictive models, which have been used and will inevitably be increasingly more used in carbon sequestration.

2. Results from the feldspar experiments demonstrated stronger coupling between dissolution and precipitation reactions. We show that the partial equilibrium assumption did not hold in the feldspar hydrolysis experiments (Zhu and Lu, submitted, Appendix A-2). The precipitation of clay minerals influenced dissolution of primary silicate in a much stronger way as previously envisioned. Therefore, our experimental data indicated a much more complex chemical kinetics as it has been applied to carbon sequestration program in terms of preliminary predictive models of $\mathrm{CO}_{2}$-rock-water interactions. Adopting this complexity (strong coupling) may influence estimates of mineral trapping and porosity/permeability for geological carbon sequestration. In general, our 
knowledge of the coupling of different reactions is poor, and we must consider the uncertainties resulting from our poor knowledge on this regard.

3. Our experimental results concur with previous findings that the role of dissolved $\mathrm{CO}_{2}$ is mostly to acidify the brine, but not change the mechanisms of reactions. This conclusion is based on careful paired experiments with and without $\mathrm{CO}_{2}$.

4. We observed strong chemical reactions between $\mathrm{CO}_{2}$ acidified brine with the Navajo sandstone. The laboratory experiments were conducted at a higher temperature $\left(200{ }^{\circ} \mathrm{C}\right)$ than that in the field $\left(\sim 90{ }^{\circ} \mathrm{C}\right)$ in order to induce measurable chemical changes in the laboratory. However, field conditions are more acidic and reaction time is much longer (1000 years versus $10-80$ days in the laboratory). Therefore, the conclusions on extensive reactions are relevant. We observed extensive dissolution of feldspars, and precipitation of clay minerals. However, the clay coatings on the sediment grains, which were a concern whether it would come off and clog the pores, were intact. The precipitation of secondary minerals can potentially clog pore throats and reduce permeability. Additional experiments are needed to quantify the amount of secondary mineral precipitation, and the results of batch reactor experiments need to be compared to the flooded core experiments to be performed by NETL in house.

Throughout this project, we endeavored to disseminate the research results in a timely fashion, worked closely with NETL in-house research, and communicated our results to the regional partnerships. To reach the carbon capture and storage (CCS) community in the broadest possible sense, we have published our first set of experimental results in a highly regarded journal Chemical Geology, with proper DOE approval, acknowledgement to this grant, and required disclaimer (see Appendix A-1). Note the publication at this peer-referred journal had gone through rigorous peer review.

A second publication on geochemical modeling interpretation of experimental data was submitted to the top ranked journal Geochimica et Cosmochimica Acta, and is currently under peer review. A third publication on the experimental data of Navajo sandstone was completed and submitted to the Journal of Greenhouse Gas Control for peer review.

In January 2008, the PI (Dr. Chen Zhu) gave presentations at the Lawrence Berkeley National Laboratory and Lawrence Livermore National Laboratory. Most in the audience are funded by DOE to work on various carbon sequestration programs. Presentations are also given at the annual convention of the American Association of Petroleum Geologist (2008), Seventh Annual Conference Carbon Capture \& Sequestration Conference (2008), Geological Society of America annual meeting (2008), and AAPG Eastern Section Meeting (2007). Because a large amount of experimental data was generated and has not been fully digested, some of our findings will be further analyzed and ideas will be refined. We will continue to communicate the results to the carbon sequestration community through open literature publications and presentations at national and international meetings with proper acknowledgement of this grant. 


\section{Experimental}

\subsection{Reactants and Materials}

"Orthoclase" crystals and Amelia albite crystals having an average size of $\sim 0.5 \mathrm{~cm}$ were purchased from the WARD'S Natural Sciences Establishments, Inc. These crystals were handpicked, ground with an agate mortar and pestle, and subsequently dry sieved to retain the fraction between 50 and $100 \mu \mathrm{m}$ in size. For the freshly ground material, there were a large number of submicron-to-micron particles that adhered to the surface of large grains. Dissolution of these ultrafine particles will result in initially non-linear rates of reaction or parabolic kinetics (HOLDREN and BERNER, 1979). To remove these particles, the sample was first ultrasonically cleaned using analytical grade acetone. This was performed eight times on each aliquot for about $20 \mathrm{~min}$ per treatment. The cleaned alkali-feldspar grains were finally rinsed with deionized water and then freeze-dried. Before experiments, alkali-feldspar sample was kept in an oven at $105^{\circ} \mathrm{C}$ overnight to exclude possible organic contamination. Amelia albite is commonly used in experiments because it is a compositionally pure end-member albite (e.g., see Smith and Brown, 1988). Its chemical composition is close to $\mathrm{NaAlSi}_{3} \mathrm{O}_{8}$ (microprobe results available from literature).

Reddish Navajo Sandstones were collected from $\mathrm{N}$ aquifer, Black Mesa, Arizona. The major mineral component of Navajo Sandstone is quartz, with $2 \%$ feldspars (DULANEY, 1989; HARSHBARGER et al., 1957; ZHU, 2005). A sandstone sample (MSE 136.5137 ) is crushed and ground with an agate mortar and pestle, and then dry sieved to obtain the fraction between 50 and $100 \mu \mathrm{m}$. Ten grams of the resulting powder and $150 \mathrm{~mL}$ deionized water are placed into a $200-\mathrm{mL}$ polyethylene bottle and ultrasonic-cleaned with a sonic probe five times, for 10 minutes per treatment. The bottle is immersed into a water bath to keep cool when ultrasonicating. The supernatant is disposed of and the remaining solid is freezedried.

\subsection{Batch and Flow-through Experiments}

\subsubsection{Experimental apparatus for batch} experiment.

The prepared grains were placed in a flexible gold reaction cell with detachable Ticlosure (Seyfried et al., 1987). This arrangement allows easy access to the reactants at the end of an experiment. More importantly, the flexible cell permits on-line sampling of the aqueous phase at constant temperature and pressure simply by adding water,

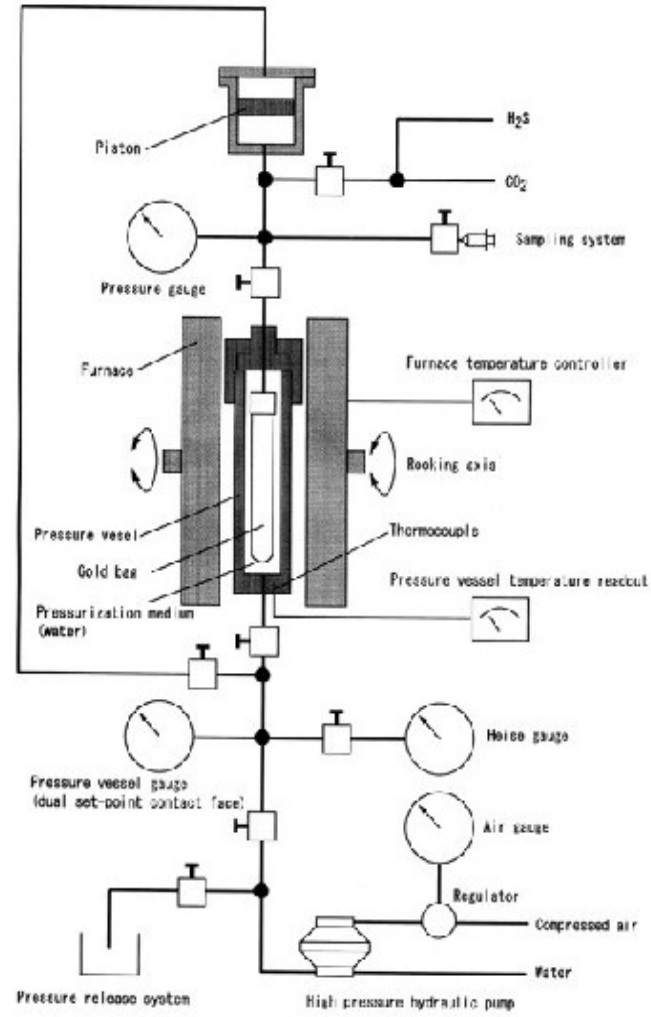

Fig. 2. Schematic illustration of the flexible cell reaction system (Seyfried et al., 1987), which is being used for the mineral dissolution/precipitation rate studies. 
in an amount equivalent to the sampled fluid, to the region surrounding the reaction cell (Fig. 2). These experimental data are generally superior to those derived from samples collected after the reactors are cooled down because backward reactions may occur during cooling.

The experiments using the flexible cell system were conducted at temperature of $150{ }^{\circ} \mathrm{C}$ and 300 bars. Fluid samples taken from the reactor at regular intervals were analyzed for all major and some minor dissolved components. Dissolved cations were analyzed by inductively coupled plasma mass spectrometry (ICP-MS) or AA with graphite furnace (for aluminum), while anions were analyzed by ion chromatography.

\subsubsection{Experimental apparatus for flow-through experiment.}

The flow-through dissolution experiment of the Navajo Sandstone was performed using a hydrothermal flow system. A fixed volume $(\sim 100 \mathrm{ml})$ Ti reactor represents the central unit of the flow system. It connects to a high-pressure fluid delivery system (Shimadzu 10A HPLC pump) that keeps the rate of fluid flow at pre-selected values. The outlet side of the reactor is connected to a computer-controlled regulating valve that serves to maintain the total pressure at fixed values. Temperature control is provided by a series of Watlow band heaters external to the Ti reactor. The reactor is also equipped with a magnetic stirrer (Parr Instrument, A1120HC), which allows reactants to remain suspended in the fluids during the experiment.

Seven completed experiments are listed in Table 1. Experiments 1,2 and 6 were carried out in the first year and experiments 3,4 and 5 were carried out in the second year. Experiment 7 was carried out in the third year.

Table 1. Summary of Experiments in 3 years

\begin{tabular}{|c|c|c|c|}
\hline & Time & Materials & conditions \\
\hline Exp. 1 & Year $1 *$ & $\begin{array}{l}\text { Alkali-feldspar from Wards. } \\
35 \% \text { low albite }\left(\mathrm{Ca}_{0.04} \mathrm{Na}_{0.95} \mathrm{~K}_{0.01} \mathrm{Al}_{1.04} \mathrm{Si}_{2.96} \mathrm{O}_{8}\right) \text {, } \\
60 \% \text { orthoclase }\left(\mathrm{K}_{0.85} \mathrm{Na}_{0.15} \mathrm{Al}_{1.04} \mathrm{Si}_{2.97} \mathrm{O}_{8}\right) \text {, and } 5 \% \\
\text { of quartz. }\end{array}$ & $\begin{array}{l}200{ }^{\circ} \mathrm{C}, 300 \text { bars } \\
0.2 \mathrm{M} \mathrm{KCl} \text { with } 0.05 \mathrm{M} \mathrm{CO}_{2}, \mathrm{pH} 4\end{array}$ \\
\hline Exp. 2 & Year $1^{*}$ & $\begin{array}{l}\text { Alkali-feldspar from Wards. } \\
35 \% \text { low albite }\left(\mathrm{Ca}_{0.04} \mathrm{Na}_{0.95} \mathrm{~K}_{0.01} \mathrm{Al}_{1.04} \mathrm{Si}_{2.96} \mathrm{O}_{8}\right) \text {, } \\
60 \% \text { orthoclase }\left(\mathrm{K}_{0.85} \mathrm{Na}_{0.15} \mathrm{Al}_{1.04} \mathrm{Si}_{2.97} \mathrm{O}_{8}\right) \text {, and } 5 \% \\
\text { of quartz. }\end{array}$ & $\begin{array}{l}200^{\circ} \mathrm{C}, 300 \text { bars } \\
0.2 \mathrm{M} \mathrm{KCl} \text { without } \mathrm{CO}_{2}, \mathrm{pH} 3\end{array}$ \\
\hline Exp.3 & Year 2 & Navajo sandstone & $\begin{array}{l}200^{\circ} \mathrm{C}, 300 \text { bars } \\
0.2 \mathrm{M} \mathrm{KCl} \text { with } 0.02 \mathrm{M} \mathrm{CO}_{2}, \mathrm{pH} \\
5.5 \text { (in-situ) }\end{array}$ \\
\hline Exp. 4 & Year 2 & Navajo sandstone 2 . & $\begin{array}{l}20{ }^{\circ} \mathrm{C}, 300 \text { bars } \\
0.2 \mathrm{M} \mathrm{KCl} \text { without } \mathrm{CO}_{2}, \mathrm{pH} 5.5 \\
\text { (in-situ) }\end{array}$ \\
\hline Exp. 5 & Year 2 & Navajo sandstone 3. (flow through reactor) & $200^{\circ} \mathrm{C}, 250$ bars \\
\hline
\end{tabular}




\begin{tabular}{|l|l|l|l|}
\hline & & & $0.2 \mathrm{M} \mathrm{KCl}$ without $\mathrm{CO}_{2}, \mathrm{pH} 3.9(25$ \\
& & & $\left.{ }^{\circ} \mathrm{C}\right)$ \\
\hline Exp. 6 & Year 1 & $\begin{array}{l}\text { “K-feldspar” from } \mathrm{IU} . \\
30 \% \text { low albite }\left(\mathrm{NaAl}_{1.04} \mathrm{Si}_{2.96} \mathrm{O}_{8}\right),\end{array}$ & $\begin{array}{l}200{ }^{\circ} \mathrm{C}, 300 \text { bars } \\
0.05 \mathrm{M} \mathrm{NaCl} \text { with } 6 \mathrm{mM} \mathrm{CO}\end{array}$ \\
& & $70 \%$ microcline $\left(\mathrm{K}_{0.94} \mathrm{Na}_{0.06} \mathrm{Al}_{1.03} \mathrm{Si}_{2.97} \mathrm{O}_{8}\right)$. & 6.1 (in-situ) \\
\hline Exp. 7 & Year 3 & Dawsonite precipitation & $150{ }^{\circ} \mathrm{C}, 300$ bars \\
& & & $0.2 \mathrm{M} \mathrm{NaCl}$ with $13.3 \mathrm{mM} \mathrm{CO}_{2}, \mathrm{pH}$ \\
& & $3.7\left(25^{\circ} \mathrm{C}\right)$ \\
\hline
\end{tabular}

*In the second year, we performed additional 5-day alkali-feldspar dissolution experiments under the same conditions as experiments 1 and 2 to check the validation of the experiments and analysis.

\subsection{Electron Micro Beam and X-ray Characterization of Reactants and Products}

Reactants and products were investigated by an array of sophisticated techniques: gas adsorption (B.E.T surface area), SEM (phase relationships and surface morphology), electron microprobe, and XPS (surface chemistry), as well as High-resolution TEM (structure and chemistry).

A Beckman Coulter SA-3100 surface area analyzer was used for BET surface area analysis of alkali-feldspar sample before experiments. The sample was degassed at $250^{\circ} \mathrm{C}$ for several hours prior to measurements. The instrument was periodically calibrated before and during measurements, using National Institute of Standards and Technology reference material 1900 , a silicon nitrite powder with surface area of $2.85 \mathrm{~m}^{2} / \mathrm{g}$. Multipoint $\mathrm{N}_{2}$ gas adsorption isotherms were measured to obtain the specific surface area of $0.13 \mathrm{~m}^{2} / \mathrm{g}$ for alkali-feldspar with estimated error of $\pm 5 \%$.

Scanning Electron Microscopy (SEM) was conducted with a Quanta 400 Field Emission Gun (FEG). The Energy Dispersive X-ray Spectrometer (EDS) system has an EDAX thin window and CDU LEAP detector. The low energy X-ray detection with FEG provided high spatial resolution for microanalysis down to $\sim 0.1 \mu \mathrm{m}^{2}$ under optimum conditions.

TEM observations were performed using a Philips CM 200UT microscope with a spherical aberration coefficient (Cs) of $0.5 \mathrm{~mm}$ and a point-to-point resolution of $0.19 \mathrm{~nm}$. Data reduction was carried out using the standard Cliff-Lorimer method implemented in the DTSA.

The samples were prepared with ultrasonic method. A fraction of the reaction products were immersed into absolute ethanol and ultrasonicated for several minutes to disengage the secondary minerals from feldspar surfaces. A drop of the resulting suspension (with grains of feldspar as well as secondary minerals) was mounted onto a holey-carbon film supported by a standard $\mathrm{Cu}$ TEM grid and air-dried for $\sim 10 \mathrm{~min}$. 


\section{Results and Discussion}

\subsection{Feldspar Hydrolysis Experiments}

\subsubsection{Experiment 2.}

This experiment was conducted to establish the baseline so that the results could be compared to Experiment 1, for which $\mathrm{CO}_{2}$ was introduced. It was hoped that with the establishment of the baseline, the role of $\mathrm{CO}_{2}$ in reactions with minerals can be deduced. Time series changes in fluid chemistry from both the 78-day and the 5-day experiments are listed in Table 2 and illustrated in Fig. 3. As anticipated from the relative abundances of fluid and mineral components used for the experiments, dissolved $\mathrm{Cl}^{-}$concentrations remained relatively constant. The concentration of dissolved $\mathrm{K}^{+}$, however, tended to decrease, although the extent of this represents a small fraction of that initially available in the fluid $(200 \mathrm{mmol} / \mathrm{kg})$. Changes in dissolved concentrations of $\mathrm{Na}^{+}, \mathrm{Ca}^{2+}, \mathrm{Al}^{3+}$ and $\mathrm{SiO}_{2}$ during the 78-day experiment were significant as alkali-feldspar dissolution proceeded. For example, dissolved $\mathrm{SiO}_{2}$ increased slowly to approximately $1.70 \mathrm{mmol} / \mathrm{kg}$ after $456 \mathrm{~h}$ of reaction, then, surprisingly, decreased to $1.35 \mathrm{mmol} / \mathrm{kg}$ during the next $360 \mathrm{~h}$ of reaction, before again increasing to $4.18 \mathrm{mmol} / \mathrm{kg}$ at 1368 $\mathrm{h}$. During the remaining $504 \mathrm{~h}$ of the experiment, dissolved $\mathrm{SiO}_{2}$ decreased by $0.43 \mathrm{mmol} / \mathrm{kg}$ to a final value of $3.75 \mathrm{mmol} / \mathrm{kg}$ (Table 2). Dissolved concentrations of $\mathrm{Na}^{+}$and $\mathrm{Ca}^{2+}$ generally tracked with $\mathrm{SiO} 2$, suggesting the possible involvement of non-stoichiometric dissolution of minor accessory components in albite in the moderately acidic fluids. $\mathrm{Al}^{3+}$ concentration decreased sharply during the first $216 \mathrm{~h}$, then increased to $0.08 \mathrm{mmol} / \mathrm{kg}$ by $456 \mathrm{~h}$ before decreasing gradually throughout the remainder of the experiment. Dissolved concentrations of $\mathrm{Na}^{+}, \mathrm{Ca}^{2+}, \mathrm{Al}^{3+}$ and $\mathrm{SiO}_{2}$ from the 5-day experiment at $120 \mathrm{~h}$ were largely consistent with changes in fluid chemistry of the 78-day experiment at a similar time of reaction (Fig. 3).

Table 2. Time-dependent changes in the composition of major dissolved constituents in aqueous fluid coexisting with alkali-feldspar at $200{ }^{\circ} \mathrm{C}$ and 300 bars

\begin{tabular}{|c|c|c|c|c|c|c|c|c|c|}
\hline $\begin{array}{c}\text { Sample } \\
\#\end{array}$ & $\begin{array}{c}\text { Time } \\
\text { (Hours) }\end{array}$ & $\mathrm{Cl}^{-}$ & $\mathrm{K}^{+}$ & $\begin{array}{l}\mathrm{SiO}_{2} \\
(\mathrm{~mm}\end{array}$ & $\begin{array}{l}\mathrm{Na}^{+} \\
/ \mathrm{kg})\end{array}$ & $\mathrm{Ca}^{2+}$ & $\mathrm{Al}^{3+}$ & $\begin{array}{c}\mathrm{pH} \\
\left(25^{\circ} \mathrm{C}\right) \\
\end{array}$ & $\begin{array}{c}\text { In situ } \mathrm{pH} \\
\left(200^{\circ} \mathrm{C}\right)\end{array}$ \\
\hline \multicolumn{10}{|c|}{ 78-day experiment } \\
\hline & 0 & 198.3 & 204.0 & - & - & 3.72 & - & 3.0 & 3.1 \\
\hline 1 & 24 & 197.5 & 202.8 & 0.31 & 0.42 & 0.12 & 0.01 & 3.2 & 3.3 \\
\hline 2 & 216 & 198.7 & 201.1 & 1.46 & 1.13 & 0.21 & 0.003 & 3.5 & 3.6 \\
\hline 3 & 456 & 196.8 & 197.8 & 1.70 & 2.04 & 0.43 & 0.08 & 4.1 & 3.7 \\
\hline 4 & 816 & 197.9 & 204.3 & 1.35 & 1.86 & 0.16 & 0.03 & 4.2 & 4.0 \\
\hline 5 & 1368 & 199.5 & 197.0 & 4.18 & 3.72 & 0.30 & 0.01 & 4.9 & 4.5 \\
\hline 6 & 1872 & 199.4 & 196.5 & 3.75 & 1.91 & 0.35 & 0.001 & 4.9 & 4.7 \\
\hline \multicolumn{10}{|c|}{ 5-day experiment } \\
\hline 1 & 120 & n.a. ${ }^{1}$ & n.a. & 1.31 & 0.88 & 0.35 & 0.005 & n.a. & 3.4 \\
\hline
\end{tabular}




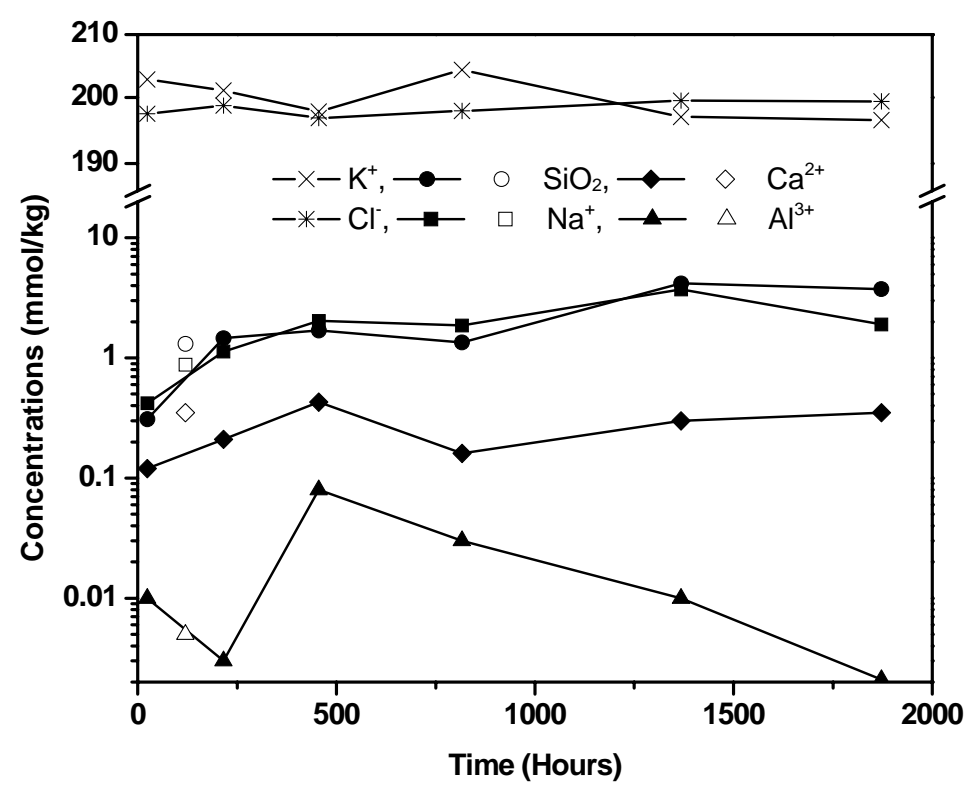

Fig. 3. Changes in the dissolved concentrations of selected aqueous constituents with time for the perthitic alkali-feldspar dissolution experiments at $200{ }^{\circ} \mathrm{C}$ and 300 bars. Dissolved concentrations of $\mathrm{K}^{+}, \mathrm{Cl}^{-}, \mathrm{Na}^{+}, \mathrm{Ca}^{2+}, \mathrm{Al}^{3+}$ and $\mathrm{SiO}_{2}$ for the 78-day experiment (solid symbols) and $\mathrm{Na}^{+}, \mathrm{Ca}^{2+}, \mathrm{Al}^{3+}$ and $\mathrm{SiO}_{2}$ for the 5-day experiment (open symbols). Time series changes for $\mathrm{K}^{+}, \mathrm{Cl}^{-}$concentrations for the 5-day experiment are not available beyond the start of the experiment (Table 2).

It is well known from results of numerous studies of reaction kinetics of silicate minerals in aqueous fluids that $\mathrm{pH}$ plays a particularly important role in the rate of mineral dissolution/precipitation processes. This is the case during the present study as well. To examine $\mathrm{pH}$ effects, the $\mathrm{pH}$ value measured for the fluid sample at ambient conditions $\left(25^{\circ} \mathrm{C}, 1 \mathrm{bar}\right)$ (bench $\mathrm{pH}$ ) was re-calculated at experimental conditions $\left(200^{\circ} \mathrm{C}, 300\right.$ bars) by taking account of the effect of temperature and pressure on the distribution of aqueous species. Accordingly, $\mathrm{pH}$ (in situ) was calculated for each sample taken during the course of experiments (Table 2). Owing to the relatively low experimental temperature, however, $\mathrm{pH}$ (in situ) was close to that measured, with an offset that ranged from approximately 0.1 to 0.4 units. During the 78 -day experiment, $\mathrm{pH}$ values increased from 3.1 to 4.7 (Table 2).

SEM photomicrographs of alkali-feldspar following the 78-day (Fig. 4a, b) and 5-day experiments (Fig. 4c, d) reveal channels and etch pits demonstrating dissolution heterogeneity, with albite lamellae preferentially dissolved. The presence of these mineral dissolution features was less obvious from results of the 5-day experiment. 

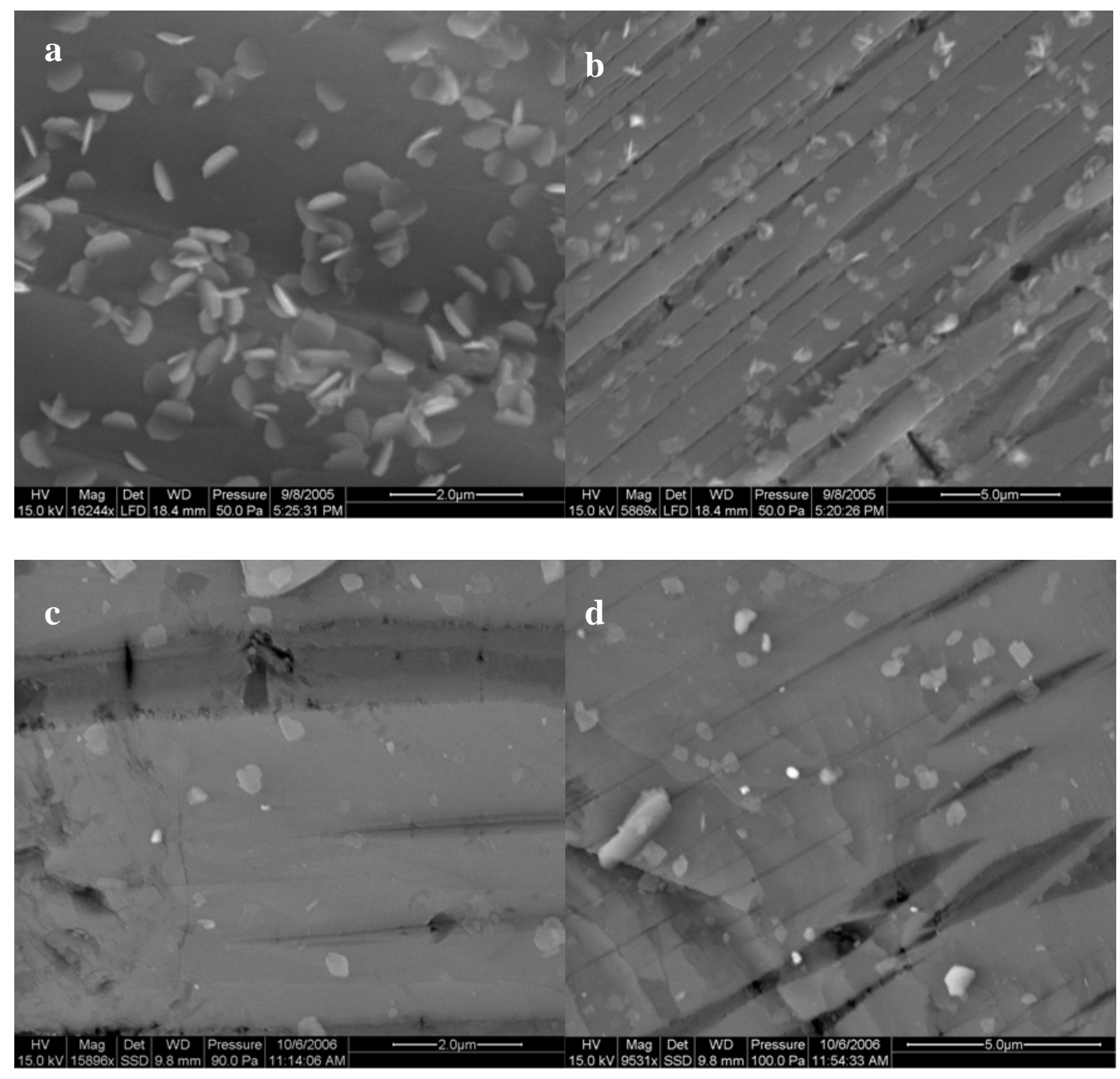

Fig. 4. SEM backscatter images of alkali-feldspar dissolution effects following reaction after 78 days $(\mathrm{a}, \mathrm{b})$ and 5 days $(\mathrm{c}, \mathrm{d})$. Reacted feldspar from the 78-day experiment reveal small $(\sim 0.5 \mu \mathrm{m})$ hexagon-shaped secondary minerals covering approximately $20 \%$ of the feldspar surface. In the 5-day experiment, secondary minerals cover only about $5 \%$ of the feldspar surface. The relative abundance of surface mineralization on the feldspars from each experiment is consistent with observed distribution of mineral dissolution features, such as laminar channels and etch pits on Na-rich lamina.

Secondary minerals, with cross sectional diameter $(d)$ of less than $0.5 \mu \mathrm{m}$ and height $(h)$ of approximately $0.1 \mu \mathrm{m}$, covered approximately $20 \%$ of total alkali-feldspar surface from the 78 day experiment. Alteration products also exhibited hexagonal shape. In the 5-day experiment, however, secondary minerals covered much less $(\sim 5 \%)$ of feldspar surface (Fig. 4$)$. In both cases, secondary minerals were evenly distributed on the feldspar surface, suggesting no structural inheritance from the alkali-feldspar precursor. Feldspar dissolution and secondary mineral formation are likely coupled in the overall mass transfer process. 
XRD patterns of mineral products in both experiments showed the presence of kaolinite as well as boehmite (Fig. 5 a, b). The high peak intensities of boehmite in the XRD patterns likely result from preferential orientation of boehmite, and are not directly proportional to abundance.

Due to relatively low magnification of the JEOL 1010 operated at low voltage $(100 \mathrm{kV})$, secondary mineral products (kaolinite and boehmite) from the 78-day experiment were manifest as a transparent phase with hexagonal shape and sizes of 200-300 nm (Fig. 6a). Selected area electron diffraction (SAED) patterns indicated that most alteration minerals are sheet silicates (Fig. 6b). The existence of boehmite crystals with rounded shapes, however, was confirmed by HRTEM observation with JEOL FEG 2100F (Fig. 6c). TEM images also showed "seesaw" edges of reacted alkali-feldspar from the experiment (Fig. 6d), suggesting preferential dissolution of Na lamellae, which is consistent with SEM observations. In the 5-day experiment, boehmite with distinctly sharp edges was observed on alkali-feldspar as the lone secondary mineral (Fig. 6e), which was confirmed by [010] SAED patterns, showing two dimensions for the Al octahedral structure (Fig. 6f). In contrast with boehmite from the 5-day experiment, boehmite following the 78-day experiment showed dissolution features characterized by more rounded grain boundaries (Fig. 6c).

Recently, Zhu et al. (2004; 2006) observed an amorphous layer on naturally weathered feldspar, typically a few tens of nanometers thick. In the 78-day experiment, HRTEM observation also indicated that the alkali-feldspar grains were rimmed with an apparently amorphous layer (Fig. 6c). The amorphous nature of the edges was confirmed by the absence of electron diffraction pattern. It is still controversial whether an amorphous layer is caused by leaching (NesBitT and SKInNER, 2001; NugENT et al., 1998) or is the result of silica reprecipitation effects (HELLMANN et al., 2003; 2004).

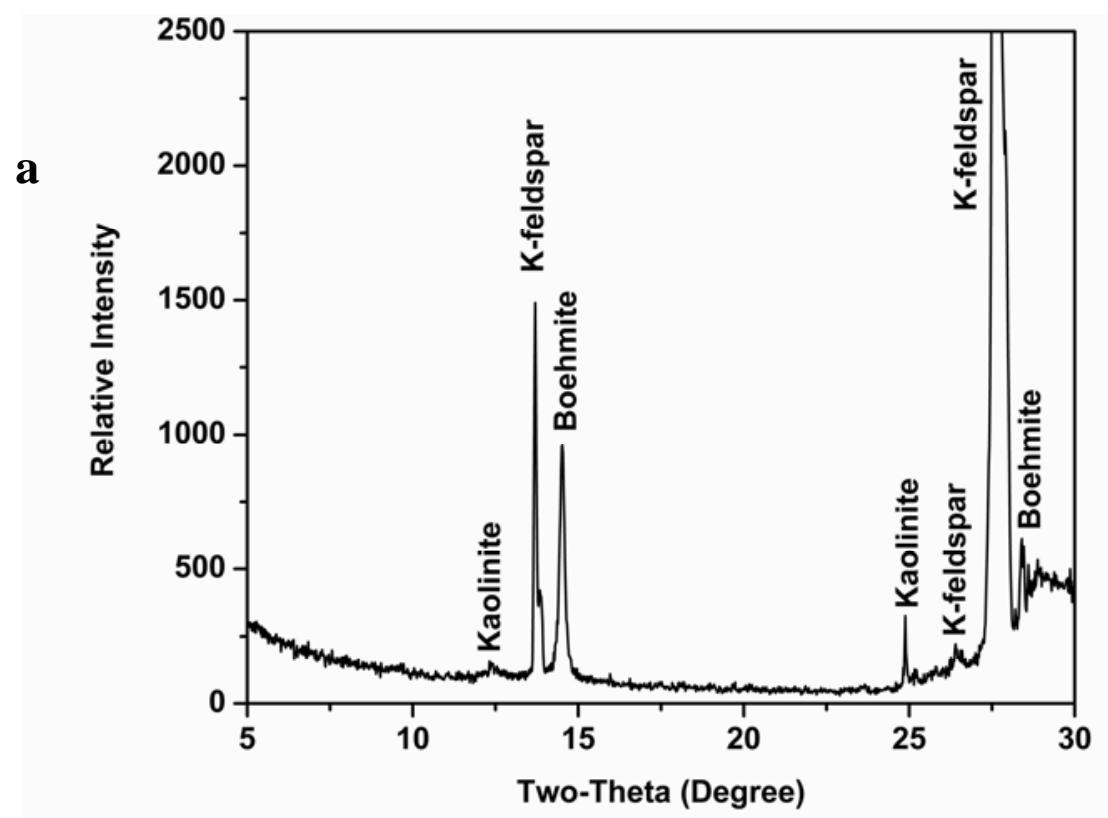




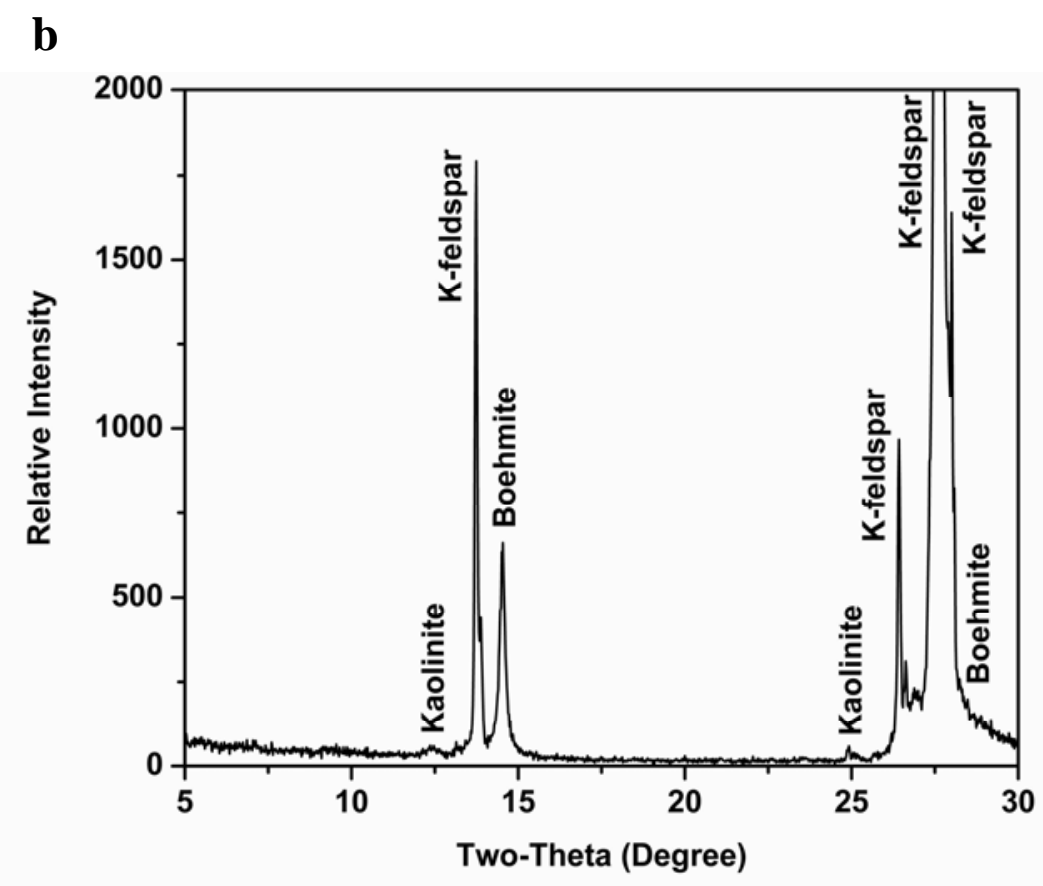

Fig. 5. X-ray diffraction patterns of mineral products following the 5-day experiment (a) and 78day experiment (b). Kaolinite, boehmite, and K-feldspar were identified. The high peak intensity of boehmite is not a reflection of its abundance, but rather the result of preferential orientation.
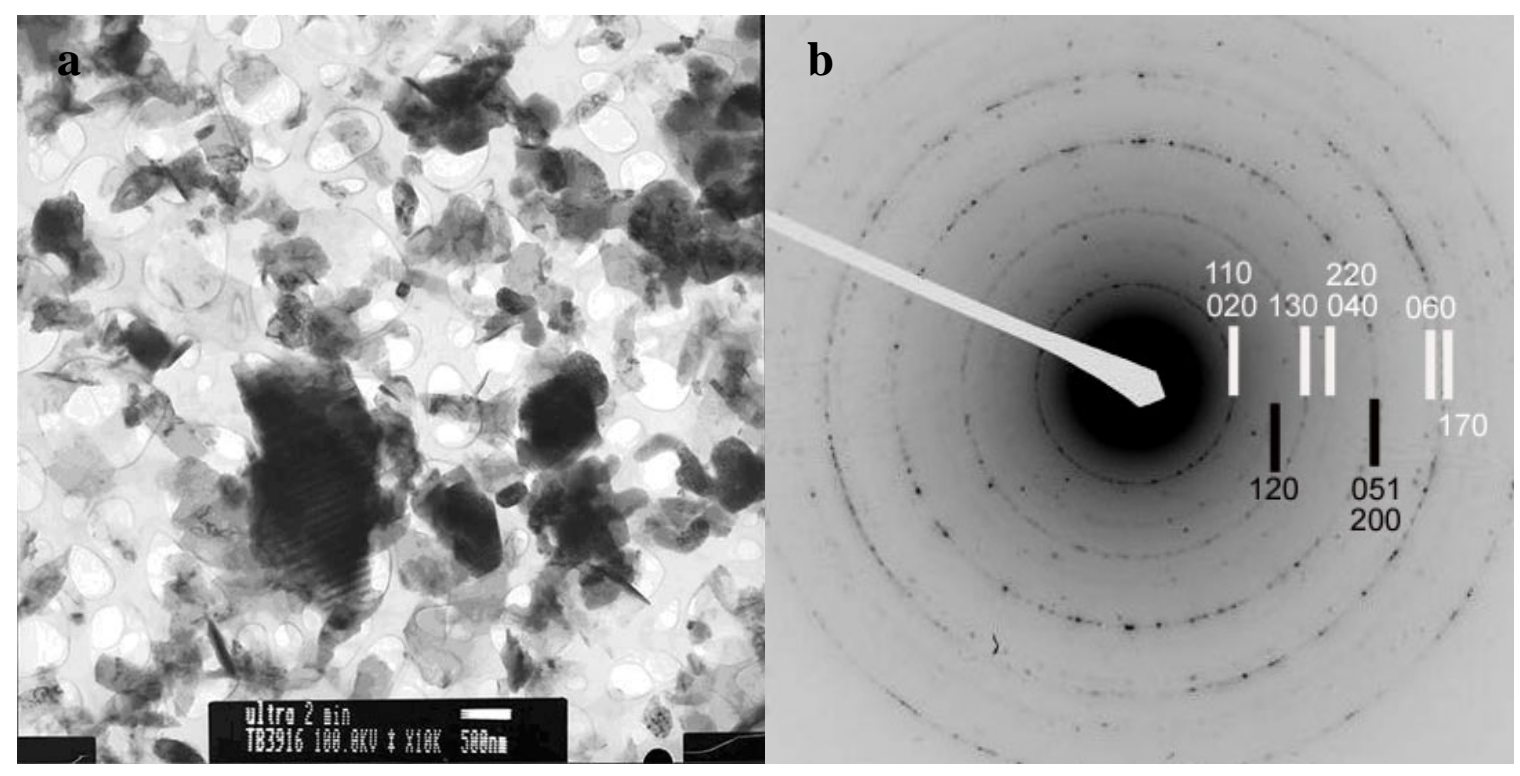


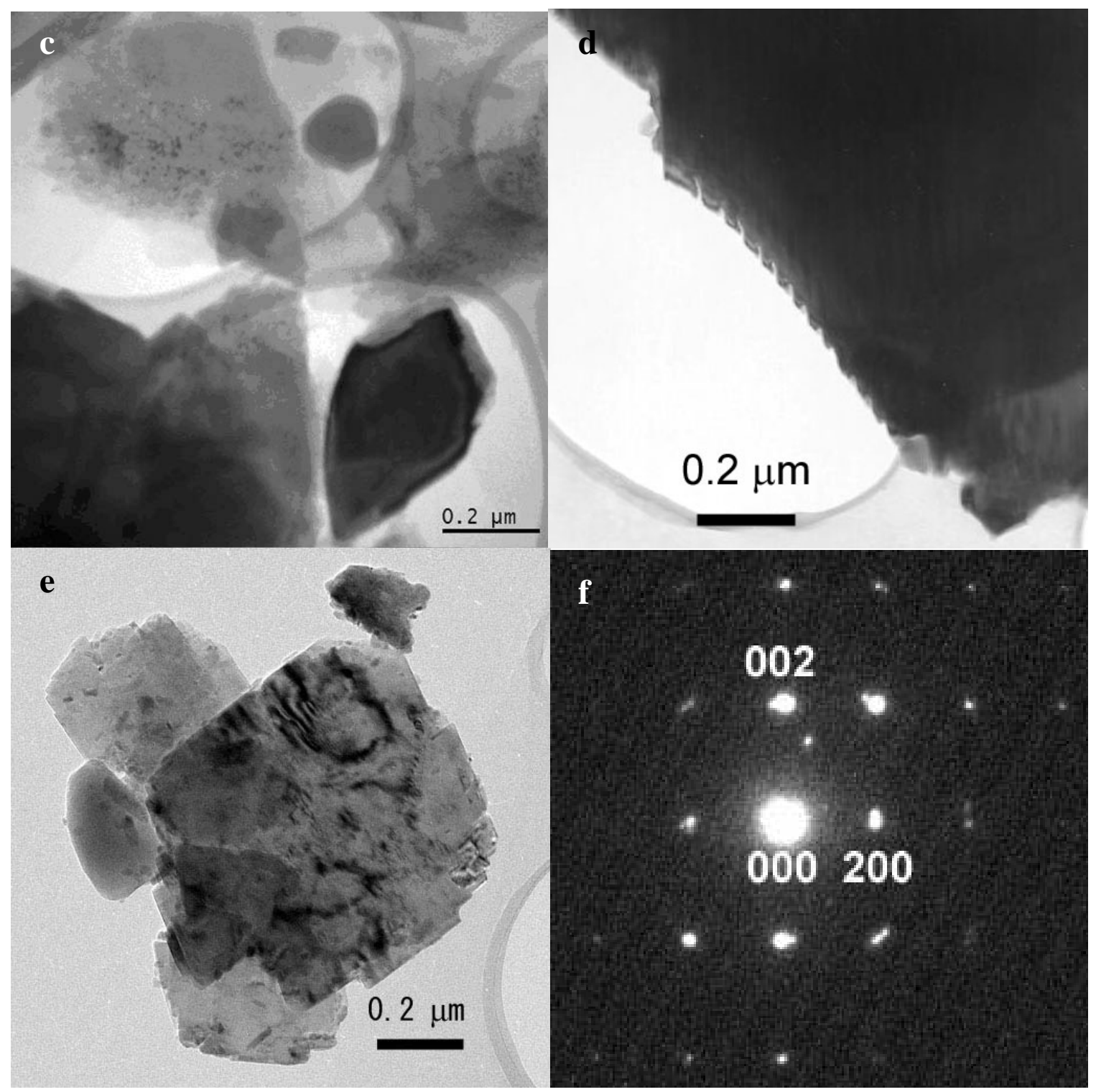

Fig. 6. TEM images and SAED patterns of mineral products from alkali-feldspar dissolution experiments at $200{ }^{\circ} \mathrm{C}$ and 300 bars. (a) Feldspar (large grains) and hexagonal secondary minerals (200-300 nm sized grains); (b) SAED pattern of mineral products labeled with Miller Indices for kaolinite (upper layer) and boehmite (lower layer); (c) Bright-field TEM image showing secondary minerals, with an alkali-feldspar grain at lower-right corner; (d) TEM image showing alkali-feldspar grain (dark color), seesaw edges indicate preferential dissolution of $\mathrm{Na}$ laminae; (e) TEM image showing alkali-feldspar grains with alteration mineral phases from the 5-day experiment; (f) [010] SAED pattern showing the octahedral structure of boehmite in the 5day experiment. Unless otherwise noted, all samples were from the 78-day experiment. Image (a) was obtained by JEOL 1010 at $100 \mathrm{kV}$ and (b)-(f) by JEOL $2100 \mathrm{~F}$ at higher operating voltage.

XPS data for the alkali-feldspar before the 78-day experiment indicate $\mathrm{K} / \mathrm{Al}$ and $\mathrm{Al} / \mathrm{Si}$ mole ratios of 0.66 and 0.37 , respectively. These data are in good agreement with the surface chemistry of the fresh feldspar used for the 5-day experiment in spite of the fact that two different instruments were utilized to acquire the data (Table 3). Following the 78-day 
experiment, however, the $\mathrm{Al} / \mathrm{Si}$ mole ratio increased significantly to 0.57 , while $\mathrm{K} / \mathrm{Al}$ decreased to 0.37 . These data confirm the existence of secondary mineral phases, such as kaolinite and boehmite, where $\mathrm{Al}$ has a greater compositional percentage than for K-feldspar or albite. Results from the 5-day experiment also indicate an increase of $\mathrm{Al} / \mathrm{Si}$ mole ratio to 0.41 , while the $\mathrm{K} / \mathrm{Al}$ remained constant at 0.61 , which can best be accounted for by formation of aluminous secondary minerals, but in less abundance than for the 78-day experiment.

Table 3. XPS surface composition results $^{1}$ of alkali-feldspar from both experiments in comparison with theoretical values for K-feldspar and kaolinite

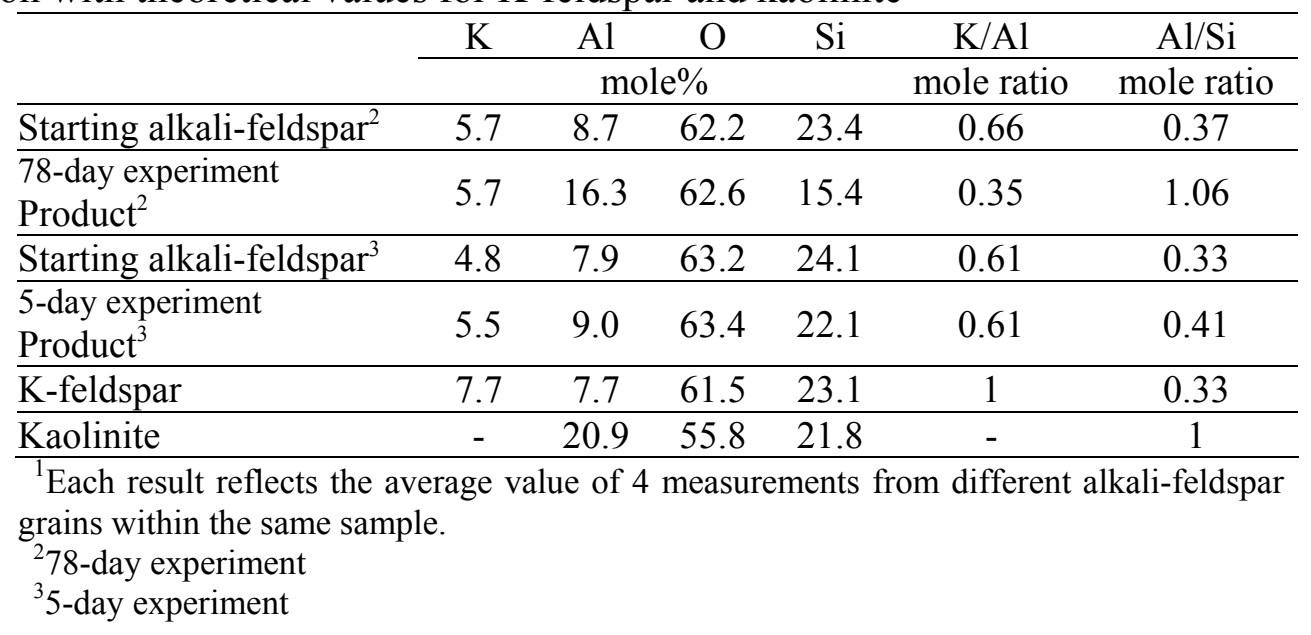

Based on distribution of aqueous species calculations at experimental conditions, mineral saturation states during the experiments were determined (Table 4). The calculated saturation indices (SI, SI $=\log \mathrm{Q} / \mathrm{K})$ indicate that throughout the experiments, the SI of albite is always negative, whereas the SI of K-feldspar becomes positive between 216 and $456 \mathrm{~h}$ of reaction (78day experiment). Therefore, albite hydrolysis is predicted to occur throughout the experiment, while K-feldspar incrementally approaches saturation and then supersaturation. This is consistent with SEM and TEM observations of mineral products showing preferential dissolution of $\mathrm{Na}$ lamellae during the study (Fig. 4 and Fig. 6d), an observation consistent with results of earlier studies (BusenBerg and ClemenCy, 1976; LAGACHE, 1976; LEE and PARSONS, 1995; RAFAL'SKIY et al., 1990).

Table 4. Changes of mineral saturation state $(\log \mathrm{Q} / \mathrm{K})$ with time in alkali-feldspar dissolution experiments at $200^{\circ} \mathrm{C}$ and 300 bars

\begin{tabular}{ccccccc}
\hline \multirow{2}{*}{ Sample \# } & Time & \multicolumn{5}{c}{ Minerals } \\
\cline { 3 - 7 } & (Hours) & K-feldspar & Albite & Boehmite & Kaolinite & Muscovite \\
\hline 78-day experiment & & & & & \\
1 & 24 & -2.82 & -6.85 & 1.17 & 1.27 & 1.60 \\
2 & 216 & -0.82 & -4.42 & 0.85 & 1.98 & 2.96 \\
3 & 456 & 0.96 & -2.38 & 2.34 & 5.10 & 7.73 \\
4 & 816 & 0.68 & -2.71 & 2.04 & 4.31 & 6.86 \\
5 & 1368 & 2.00 & -1.07 & 1.41 & 4.02 & 6.91 \\
6 & 1872 & 1.40 & -1.95 & 0.75 & 2.61 & 5.00 \\
5 5-day experiment & & & & & \\
\multicolumn{1}{l}{1} & 120 & -1.14 & -4.84 & 0.87 & 1.93 & 2.69 \\
\hline
\end{tabular}


The time evolution of aqueous chemistry in the system $\mathrm{Na}_{2} \mathrm{O}-\mathrm{K}_{2} \mathrm{O}-\left(\mathrm{Al}_{2} \mathrm{O}_{3}\right)-\mathrm{SiO}_{2}-\mathrm{H}_{2} \mathrm{O}-$ $\mathrm{HCl}$ system is traced on $a-a$ diagrams (Fig. 7). The solution chemistry fell within the boehmite stability field after $24 \mathrm{~h}$. The $120 \mathrm{~h}$ sample showed that the aqueous fluid crossed the boehmitekaolinite boundary and entered into the kaolinite stability field. Fluid chemistry fell in the muscovite stability field from 216 to $1872 \mathrm{~h}$, but muscovite was not detected in the products. Dissolution of the microcline should have stopped at $456 \mathrm{~h}$ because the microcline was supersaturated at this point (Table 4), but the fluid chemistry did not reach the microcline stability field even at the end of the experiment.
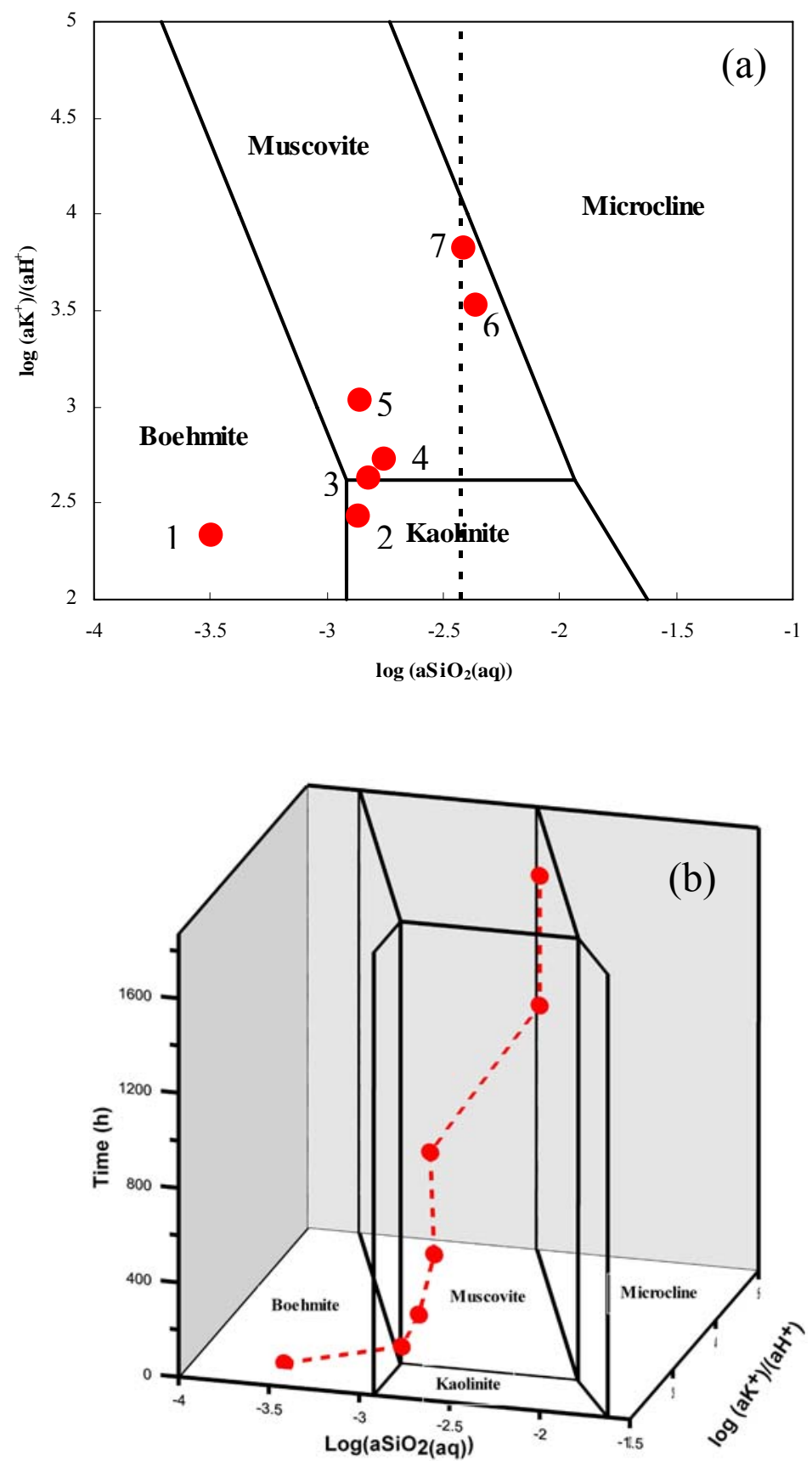
Fig. 7. Activity - activity diagrams showing the phase relations in the system $\mathrm{K}_{2} \mathrm{O}-\left(\mathrm{Al}_{2} \mathrm{O}_{3}\right)-\mathrm{SiO}_{2}-$ $\mathrm{H}_{2} \mathrm{O}-\mathrm{HCl}$ at $200{ }^{\circ} \mathrm{C}$ and 300 bars. The dashed line in (a) denotes quartz saturation. Symbols represent experimental results of alkali feldspar dissolution in $0.2 \mathrm{~m} \mathrm{KCl}$ solution at $200{ }^{\circ} \mathrm{C}$ and 300 bars (Fu et al., 2008, see Sec. 3.1). The activity and activity ratios were obtained from speciation modeling of the experimental system $\mathrm{Na}_{2} \mathrm{O}-\mathrm{K}_{2} \mathrm{O}-\left(\mathrm{Al}_{2} \mathrm{O}_{3}\right)-\mathrm{SiO}_{2}-\mathrm{H}_{2} \mathrm{O}-\mathrm{HCl}$, based on the experimental solution chemistry data of Table 2 . Points 1 through 7 represent experiment solutions at reaction time of $24,120,216,456,816,1368$, and $1872 \mathrm{~h}$, respectively. The red dashed line in (b) connecting experimental data is for visualization of fluid chemical evolution.

\subsubsection{Results from the Experiment 1}

With the baseline experiment discussed above, we conducted the experiment with $\mathrm{CO}_{2}$ to evaluate the role of $\mathrm{CO}_{2}$ in reaction kinetics (see Table 1 on page 13). Time series changes in fluid chemistry from the experiments are listed in Table 5 and shown in Fig. 8. The changes in dissolved concentrations of $\mathrm{Na}^{+}, \mathrm{Al}^{3+}$, and $\mathrm{SiO}_{2}$ are consistent with albite dissolution. Calculated in situ $\mathrm{pH}$ values increased from 4.5 to 5.7.
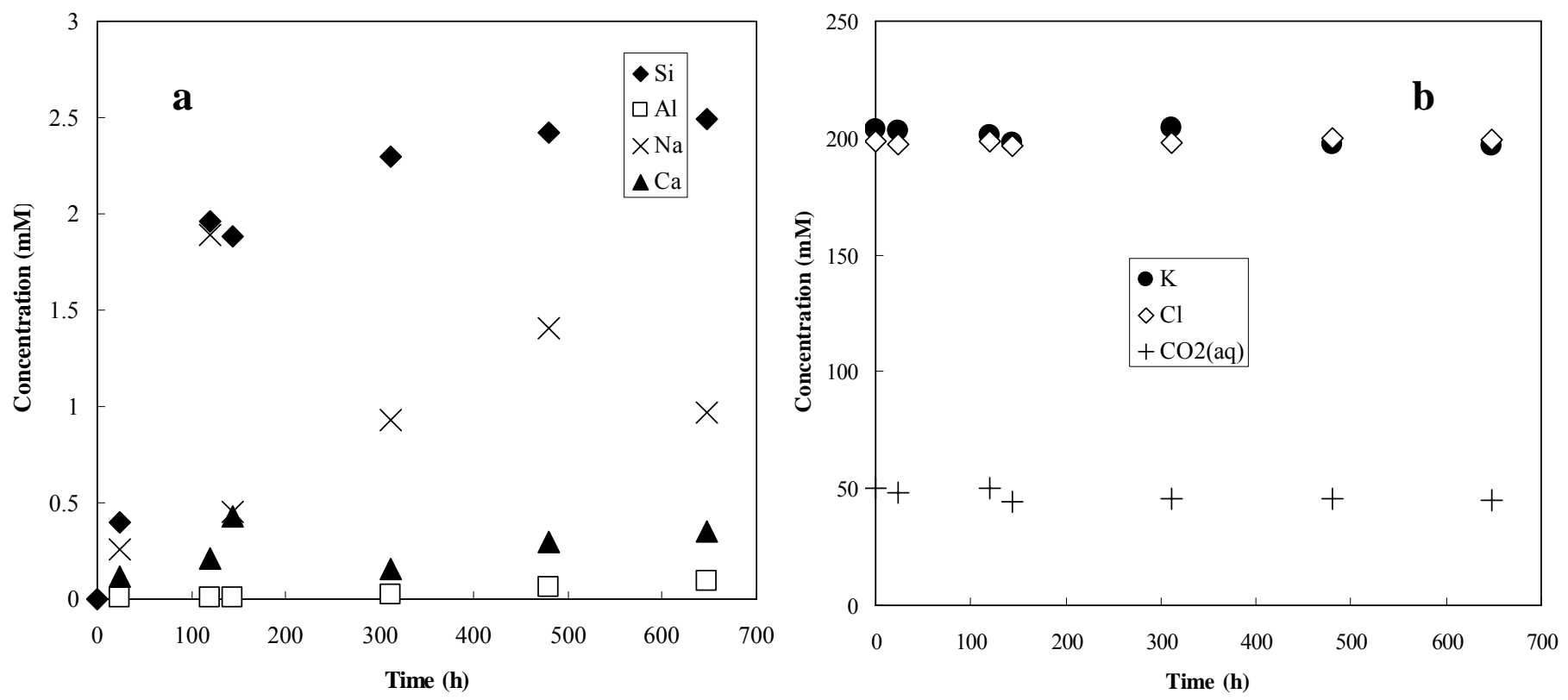

Fig. 8. Changes in the dissolved concentrations of selected aqueous constituents with time for the perthitic alkali-feldspar dissolution experiments with the presence of $\mathrm{CO}_{2}$ at $200{ }^{\circ} \mathrm{C}$ and 300 bars.

SEM photomicrographs of the feldspar grains following experiments (Fig. 9) revealed laminar channels and etch pits, demonstrating dissolution heterogeneities, with albite laminae preferentially dissolved. The presence of these mineral dissolution features was less extensive in the 5-day experiment than the 27-day experiment. Secondary minerals covered approximately $20 \%$ of total alkali-feldspar surface in 27 -day experiment. But only $5 \%$ of feldspar surface in 5 - 
day experiment. Secondary minerals were mostly evenly distributed on feldspar surface, but aggregates at kinks were also observed. TEM studies showed that the platelets are boehmite (Fig. 10). The presence of boehmite in the products was confirmed with XRD studies (see below).
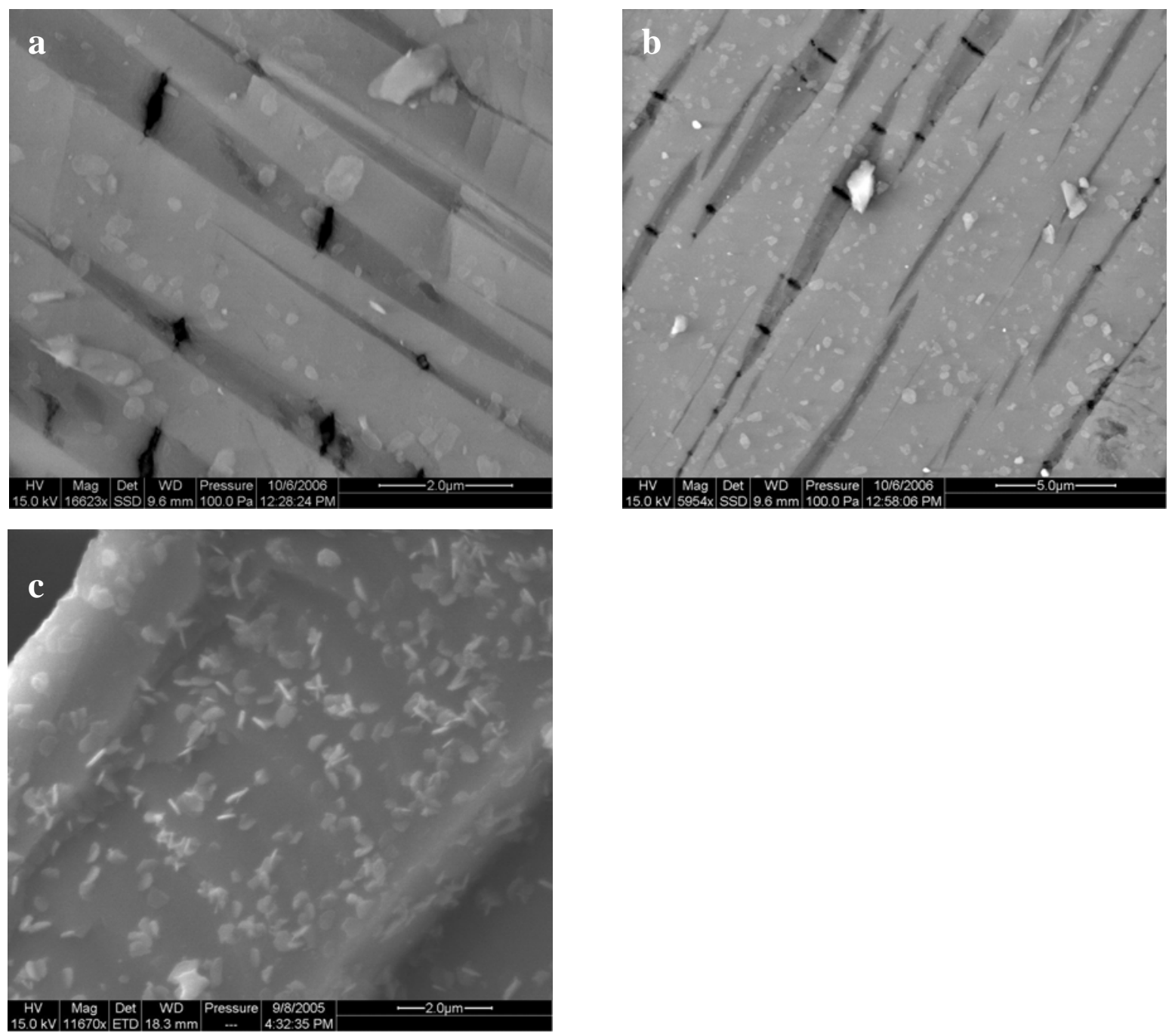

Fig. 9. (a) and (b) SEM backscatter micrograph of alkali-feldspars after $5 \mathrm{~d}$ reaction in Experiment 1 . Feldspar shows pitted surface. The coverage of secondary minerals on feldspar surface is less than $5 \%$. (c) SEM micrograph of alkali-feldspars after $27 \mathrm{~d}$ or $648 \mathrm{~h}$ reaction. Secondary mineral platelets (boehmite?) with the size of $<0.5$ micron and aggregated. 
Table 5. Major dissolved constituents in aqueous fluid ( $\mathrm{mmol} / \mathrm{kg}$, except for $\mathrm{pH}$ ) coexisting with alkali feldspar and reaction products at $200{ }^{\circ} \mathrm{C}$ and 300 bars

\begin{tabular}{|c|c|c|c|c|c|c|c|c|}
\hline $\begin{array}{c}\text { Time } \\
(\mathrm{h})\end{array}$ & $\mathrm{SiO}_{2}$ & $\mathrm{Na}^{+}$ & $\mathrm{Al}^{3+}$ & $\mathrm{K}^{+}$ & $\mathrm{Cl}^{-}$ & $\mathrm{CO}_{2}(\mathrm{aq})$ & $\begin{array}{c}\text { Measured } \\
\mathrm{pH}(25 \\
\left.{ }^{\circ} \mathrm{C}\right)\end{array}$ & $\begin{array}{c}\text { Calculated } \\
\text { in situ pH } \\
\left(200{ }^{\circ} \mathrm{C}\right)\end{array}$ \\
\hline 0 & - & - & - & 200.0 & 200.0 & 50.0 & 4.0 & 4.5 \\
\hline 24 & 0.40 & 0.26 & 0.01 & 196.31 & 199.22 & 47.90 & 4.3 & 4.9 \\
\hline $120^{*}$ & 1.96 & 1.89 & 0.006 & $200.0^{\#}$ & $200.0^{\#}$ & $50.0^{\#}$ & 4.0 & 5.0 \\
\hline 144 & 1.88 & 0.45 & 0.01 & 194.30 & 196.51 & 44.47 & 4.5 & 5.1 \\
\hline 312 & 2.30 & 0.93 & 0.02 & 195.35 & 197.48 & 45.83 & 5.0 & 5.6 \\
\hline 480 & 2.42 & 1.41 & 0.06 & 196.19 & 199.40 & 45.35 & 5.1 & 5.7 \\
\hline 648 & 2.49 & 0.97 & 0.09 & 195.40 & 198.77 & 45.17 & 5.1 & 5.7 \\
\hline
\end{tabular}

*Terminated after 5 days. " Assumed, not measured concentrations.

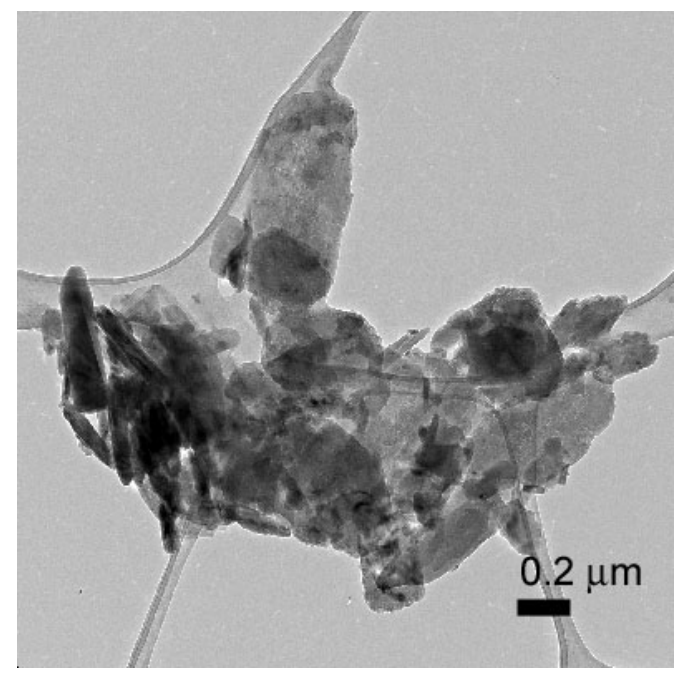

Fig. 10. TEM images of alkali-feldspars after $120 \mathrm{~h}$ 's dissolution experiment with the presence of $\mathrm{CO}_{2}$ using ultrasonication sample preparation method. The sample with $\mathrm{CO}_{2}$ shows bohemite (plates) and un-identified phase (rod-like).

XRD pattern of the clay fraction of mineral products in the 27-day experiment showed the presence of kaolinite, boehmite, and muscovite (Fig. 11). Geochemical modeling results show that the experimental solutions were undersaturated with respect to albite, but supersaturated with respect to microcline with exception of the first sample, and supersaturated with respect to boehmite, kaolinite, and muscovite (Table 6). 


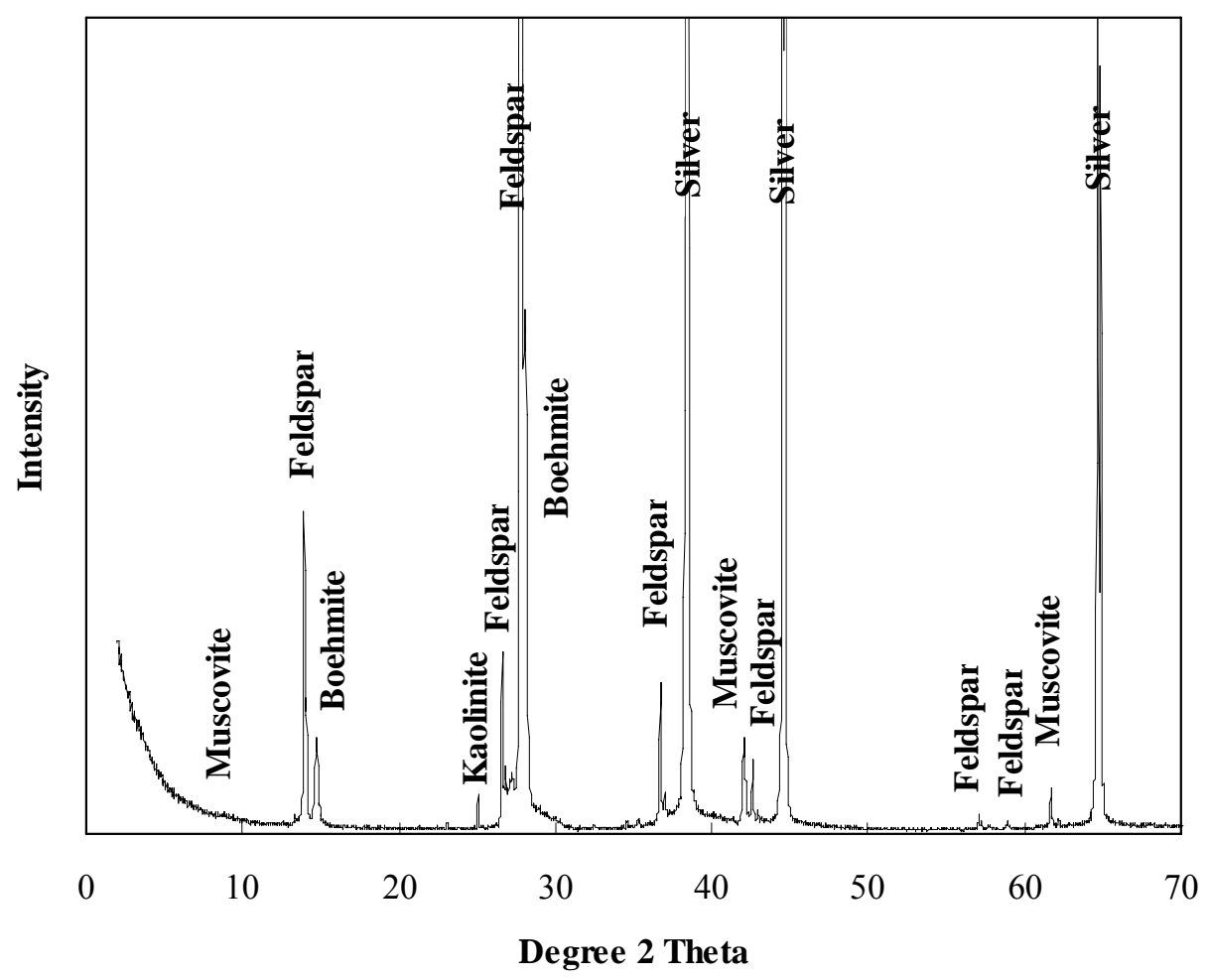

Fig 11. X-ray diffraction pattern of mineral products recovered following 648-h experiment (Experiment 1 (St. Paul)). Boehmite (ICDD card number: 21-1307), Muscovite (ICDD card number: 6-263), Kaolinite (ICDD card number: 14-164) and feldspar were identified.

Table 6. Mineral saturation indices at each sampling time in experiments for the alkali feldspar dissolution in $0.2 \mathrm{~m} \mathrm{KCl}$ and $0.05 \mathrm{~m} \mathrm{CO}_{2}$ solution at $200^{\circ} \mathrm{C}$ and 300 bars $^{\dagger}$.

\begin{tabular}{|c|c|c|c|c|c|c|c|c|c|c|}
\hline Time (h) & In situ pH & Albite & Boehmite & Diaspore & Kaolinite & Microcline & Muscovite & Paragonite & Pyrophyllite & Quartz \\
\hline 24 & 4.9 & -5.13 & 1.18 & 1.40 & 1.43 & -0.88 & 3.44 & -1.04 & -0.96 & -0.96 \\
\hline (120) & 5.0 & -2.41 & 0.87 & 1.09 & 2.18 & 0.99 & 4.69 & 1.06 & 1.19 & -0.27 \\
\hline 144 & 5.1 & -2.85 & 1.00 & 1.22 & 2.42 & 1.16 & 5.13 & 0.88 & 1.38 & -0.29 \\
\hline 312 & 5.6 & -1.94 & 0.83 & 1.05 & 2.25 & 1.75 & 5.37 & 1.44 & 1.39 & -0.20 \\
\hline 480 & 5.7 & -1.22 & 1.21 & 1.43 & 3.05 & 2.30 & 6.68 & 2.93 & 2.23 & -0.18 \\
\hline (648) & 5.7 & -1.17 & 1.38 & 1.61 & 3.43 & 2.51 & 7.25 & 3.33 & 2.63 & -0.16 \\
\hline
\end{tabular}

${ }^{\dagger}$ The parentheses on time in the first column on left denote to the time that the experiment was terminated and solids were recovered for characterization. In situ $\mathrm{pH}$ was calculated from the speciation modeling. 


\subsubsection{Results from the Experiment 6}

In this experiment, we intended to evaluate feldspar- $\mathrm{CO}_{2}$ interactions using a different feldspar (see Table 1 on p.13). The temporal evolution of the aqueous chemistry was shown in Table 7 and Fig. 12. SEM micrographs show dissolution features and precipitation of secondary minerals on the feldspar surfaces (Fig. 13). Geochemical modeling calculations show that the experimental solutions were supersaturated with respect to albite with the exception of the first sample, undersaturated with respect to microcline, and supersaturated with respect to boehmite, kaolinite, and paragonite (Table 8).
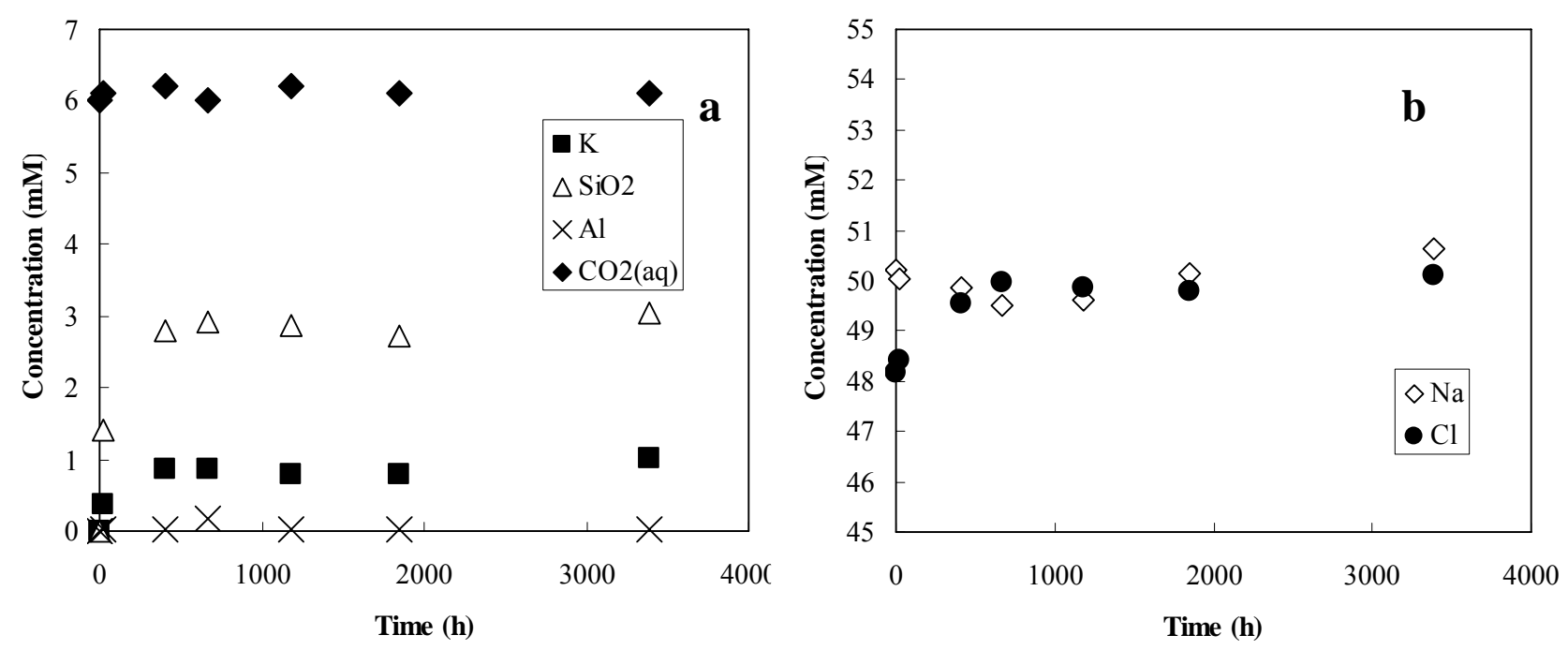

Fig. 12. Changes in the dissolved concentrations of selected aqueous constituents with time for the alkali-feldspar dissolution experiments with the presence of $\mathrm{CO}_{2}$ at $200{ }^{\circ} \mathrm{C}$ and 300 bars.

Table 7. "Experiment 6": Time-dependent changes in the composition of major dissolved species in aqueous fluid coexisting with $\mathrm{K}$-feldspar at $200{ }^{\circ} \mathrm{C}$ and 300 bars.

\begin{tabular}{|c|c|c|c|c|c|c|c|c|c|c|c|c|c|}
\hline Sample & $\begin{array}{c}\text { Time } \\
\text { (h) }\end{array}$ & $\mathrm{Na}^{+}$ & $\mathrm{Mg}^{2+}$ & $\mathrm{K}^{+}$ & $\mathrm{SiO}_{2}$ & $\begin{array}{r}\mathrm{Al}^{3+} \\
(\mathrm{m}\end{array}$ & $\begin{array}{c}\mathrm{Ca}^{2+} \\
\mathrm{mol} / \mathrm{kg}\end{array}$ & $\mathrm{Li}^{+}$ & $\mathrm{NH}_{4}^{+}$ & $\mathrm{Cl}^{-}$ & $\mathrm{CO}_{2}(\mathrm{aq})$ & $25^{\circ} \mathrm{C}$ & $\begin{array}{l}\mathrm{pH} \\
200{ }^{\circ} \mathrm{C} \\
\text { calculated }\end{array}$ \\
\hline starting & 0 & 50.22 & 0.01 & 0 & 0 & 0 & 0.03 & 0 & 0.01 & 48.18 & 6.0 & 5.0 & 5.7 \\
\hline \#1 & 24 & 50.03 & 0.01 & 0.37 & 1.40 & 0.02 & 0.03 & 0.01 & 0.05 & 48.41 & 6.1 & 5.3 & 5.9 \\
\hline$\# 2$ & 408 & 49.87 & 0.01 & 0.87 & 2.80 & 0.03 & 0.03 & 0.01 & 0.05 & 49.53 & 6.2 & 5.4 & 6.0 \\
\hline \#3 & 672 & 49.50 & 0.05 & 0.87 & 2.92 & 0.18 & 0.13 & 0.01 & 0.04 & 49.97 & 6.0 & 5.5 & 5.7 \\
\hline$\# 4$ & 1176 & 49.63 & 0.01 & 0.80 & 2.86 & 0.02 & 0.17 & 0.01 & 0.05 & 49.85 & 6.2 & 5.6 & 6.2 \\
\hline$\# 5$ & 1848 & 50.13 & 0.02 & 0.79 & 2.72 & 0.03 & 0.05 & 0.01 & 0.18 & 49.80 & 6.1 & 5.4 & 6.0 \\
\hline \#6 & 3384 & 50.65 & 0.02 & 1.01 & 3.04 & 0.02 & 0.05 & 0.01 & 0.14 & 50.11 & 6.1 & 5.7 & 6.3 \\
\hline
\end{tabular}

Note: For K-feldspar dissolution in $50 \mathrm{mmol} / \mathrm{kg} \mathrm{NaCl}$ solution and $6 \mathrm{mmol} / \mathrm{kg} \mathrm{CO}_{2}$ (aq) at $200{ }^{\circ} \mathrm{C}$ and 300 bars experiment. The overall analytical error for dissolved species is $\pm 5 \%$. In-situ $\mathrm{pH}$ is calculated from distribution of aqueous species calculations at the temperature and pressure of the experiment using constraints imposed by major element concentrations and $\mathrm{pH}$ values measured at $25^{\circ} \mathrm{C}$. 

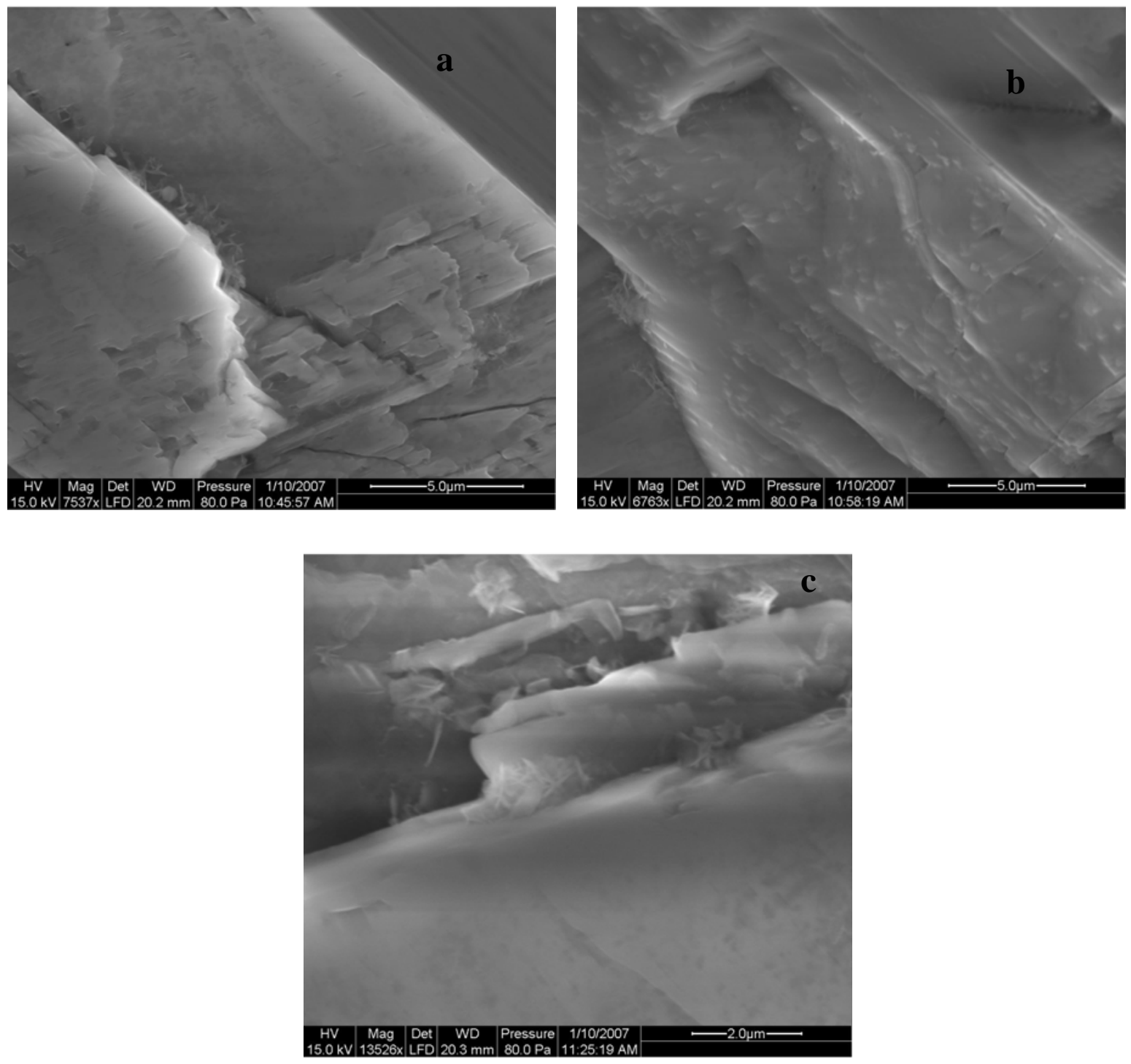

Fig. 13 . SEM micrograph of products from Experiment 6. (a) typical Alkali feldspar heterogeneous surface after dissolution experiment. Dissolution features of terraces, kinks, and steps are visible. Small amount of secondary minerals are deposited either near kinks (a,c) or evenly on the surface (b).

Table 8. Mineral saturation indices (SI) at each sampling time of Experiment $6^{\dagger}$.

\begin{tabular}{|c|c|c|c|c|c|c|c|c|c|c|}
\hline Time (h) & In-situ $\mathrm{pH}$ & Albite & Boehmite & Diaspore & Kaolinite & Microcline & Muscovite & Paragonite & Pyrophyllite & Quartz \\
\hline 24 & 5.9 & -0.83 & 0.52 & 0.74 & 1.18 & -1.56 & 1.45 & 1.95 & -0.14 & -0.43 \\
\hline 408 & 6.0 & 0.25 & 0.60 & 0.82 & 1.94 & -0.11 & 3.06 & 3.18 & 1.22 & -0.13 \\
\hline 672 & 5.7 & 1.08 & 1.67 & 1.89 & 4.12 & 0.72 & 6.03 & 6.15 & 3.44 & -0.11 \\
\hline 1176 & 6.2 & 0.10 & 0.23 & 0.45 & 1.21 & -0.30 & 2.12 & 2.28 & 0.50 & -0.12 \\
\hline 1848 & 6.0 & 0.22 & 0.60 & 0.82 & 1.91 & -0.19 & 2.97 & 3.14 & 1.17 & -0.14 \\
\hline 3384 & 6.3 & 0.19 & 0.12 & 0.35 & 1.06 & -0.12 & 2.10 & 2.16 & 0.41 & -0.09 \\
\hline
\end{tabular}

${ }^{\dagger}$ For IUB-AF dissolution in $50 \mathrm{mmol} / \mathrm{kg} \mathrm{NaCl}$ solution and $6 \mathrm{mmol} / \mathrm{kg} \mathrm{CO}_{2}(\mathrm{aq})$ at $200{ }^{\circ} \mathrm{C}$ and 300 bars. 


\subsubsection{Results from the Experiment 7 ("Dawsonite Precipitation")}

In this experiment, we let albite to react with $\mathrm{CO}_{2}$-impregnated brine for a long duration (Table 1 on p. 13) in order to evaluate whether dawsonite can be precipitated. Dawsonite is a relatively rare mineral, but in recent years, it has been proposed as a good candidate for mineral trapping. The time series changes in fluid chemistry from the dissolution of Amelia albite are listed in Table 9 and shown in Fig. 14. Dissolved $\mathrm{SiO}_{2}$ increased, reaching $0.85 \mathrm{mM}$ after $960 \mathrm{~h}$ of reaction (Table 9). The solution chemistry is consistent with characterization of solid products. Solids were recovered at the end of the experiment $(275 \mathrm{~d}$ or $6600 \mathrm{~h})$. Typical dissolution features (e.g., terraces, kinks, steps) are visible on the surface of the albite particles (Fig. 15c, d, e), indicating that dissolution is heterogeneous. The results indicate that secondary minerals are clay minerals (Fig. 15d, f). XRD pattern shows that the clay minerals are paragonite and minor kaolinite (Fig. 16). The presence of kaolinite was confirmed with TEM micrograph (Fig. 17a). TEM also shows presence of an Al-bearing phase probably boehmite (Fig. 17b,c).

Table 9. Time-dependent changes in the composition of major ions in aqueous fluid

\begin{tabular}{cccccccccccc}
\hline Sample & Time & $\mathrm{Na}^{+}$ & $\mathrm{SiO}_{2}$ & $\mathrm{Al}^{3+}$ & $\mathrm{K}^{+}$ & $\mathrm{Mg}^{2+}$ & $\mathrm{Ca}^{2+}$ & $\mathrm{Cl}^{-}$ & $\mathrm{CO}_{2}(\mathrm{aq})$ & $\mathrm{pH}$ & $\mathrm{pH}$ \\
\hline \multicolumn{3}{c}{ (hours) } & & & \multicolumn{7}{c}{$(\mathrm{mmol} / \mathrm{kg})$} \\
starting & 0 & 198.66 & 0 & 0 & 0 & 0 & 0 & 195.43 & 13.3 & 3.70 & 3.76 \\
$\# 1$ & 24 & 199.78 & 0.47 & 0.047 & 0.11 & 0.13 & 0.20 & 194.89 & 13.1 & 4.13 & 4.02 \\
$\# 2$ & 456 & 200.28 & 0.64 & 0.039 & 0 & 0 & 0.18 & 192.02 & 11.5 & 4.53 & 4.51 \\
$\# 3$ & 960 & 197.14 & 0.85 & 0.019 & 0 & 0 & 0.17 & 190.74 & 10.3 & 4.79 & 4.94 \\
$\# 4$ & 2472 & 198.98 & 0.99 & 0.052 & 0.12 & 0 & 0 & 189.57 & 9.7 & 4.88 & 4.91 \\
$\# 5$ & 4392 & 196.50 & 1.00 & 0.045 & 0.24 & 0.15 & 0.21 & 191.43 & 9.3 & 5.00 & 5.09 \\
$\# 6$ & 5568 & 194.03 & 0.91 & 0.066 & 0.16 & 0.12 & 0 & 191.50 & 9.2 & 5.02 & 5.04 \\
$\# 7$ & 6600 & 205.01 & 0.85 & 0.071 & 0.15 & 0.27 & 0.29 & 194.72 & 9.2 & 5.07 & 5.10 \\
\hline
\end{tabular}



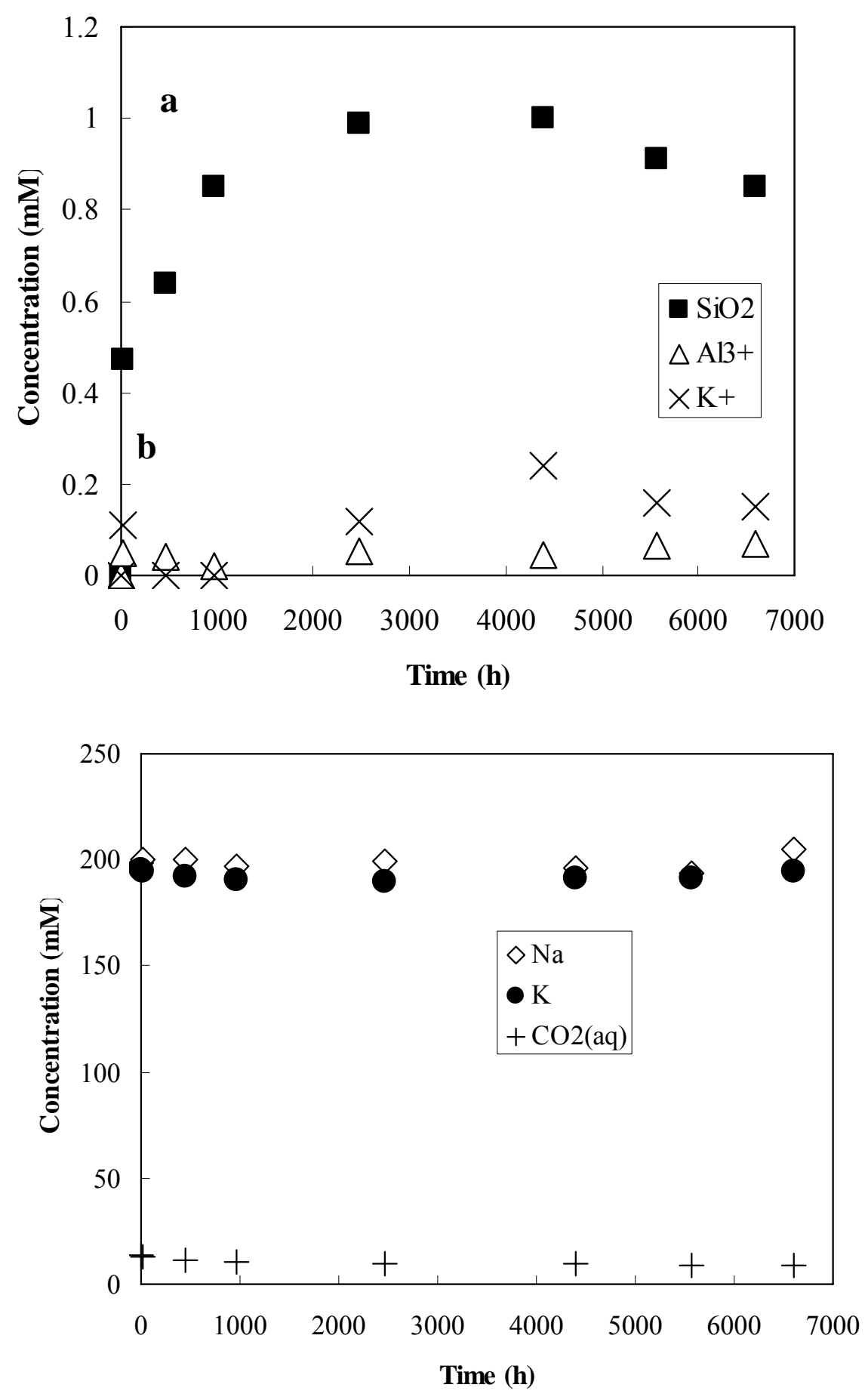

Fig. 14. Changes in the dissolved concentrations of selected aqueous constituents with time for the albite dissolution experiments with the presence of $\mathrm{CO}_{2}$ at $150{ }^{\circ} \mathrm{C}$ and 300 bars. 

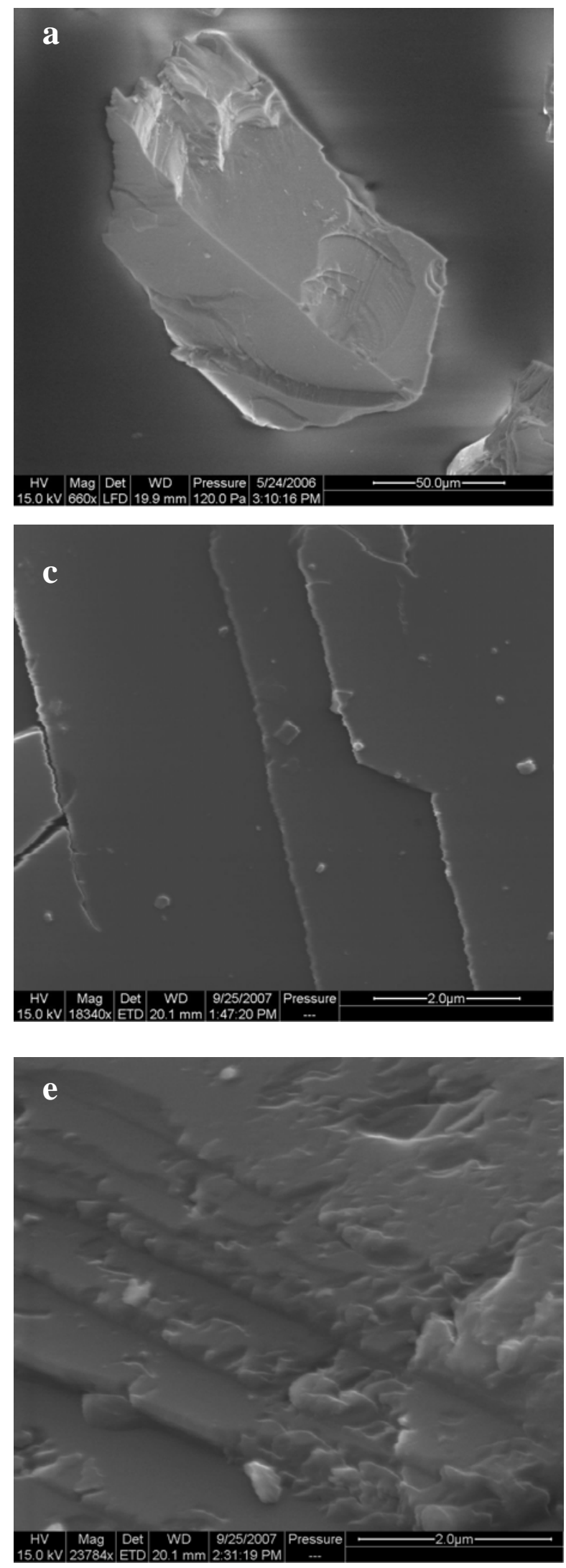

Zhu
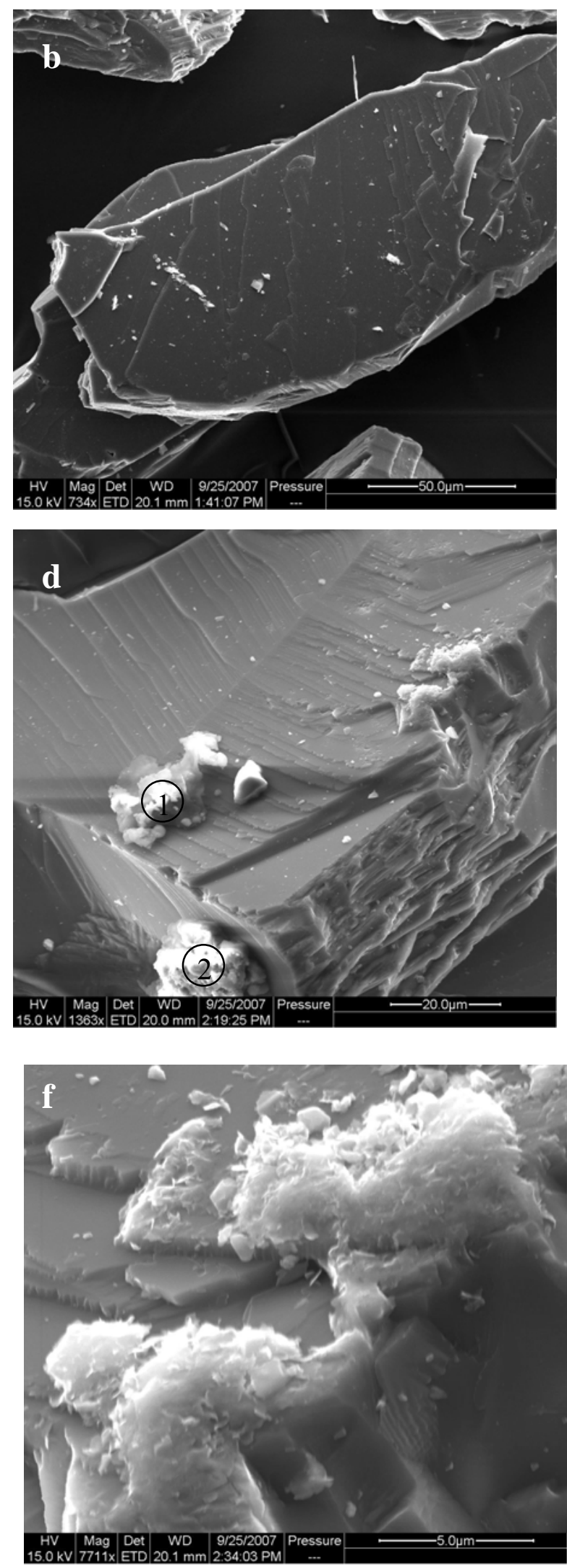

DE-FG26-04NT42125 
Fig. 15. SEM micrographs of (Experiment 7 (Dawsonite)) show (a) albite grains before the hydrothermal experiments, which are free from extra-fine particles and have angular shapes. This morphology is to be compared to reacted feldspars; (b) an albite particle after dissolution experiment. Surface topography consists of irregular, blocky terraces. The foreign objects are possibly debris of albite; (c) Enlargement of (b). Seesaw edges of dissolution terraces. Terraces covered by barely visible surface precipitates $(<0.5 \mu \mathrm{m})$ in the form of platy crystals. The total coverage is about $1 \%$; (d) surface of an albite particle after reaction showing dissolution stepwaves on twinned crystals. Precipitate is made of aggregates of secondary crystals; (e) an albite particle after dissolution experiment. Surface topography of dissolution terraces with irregular edges and irregular etch pits (with the size of $<0.1 \mu \mathrm{m}-1 \mu \mathrm{m}$ ). The dissolution was intensive; (f) Clusters of small secondary crystal aggregates and dissolution terraces with seesaw edges; or 6600 hours). SEM micrographs show that albite exhibits irregular and pitted surface

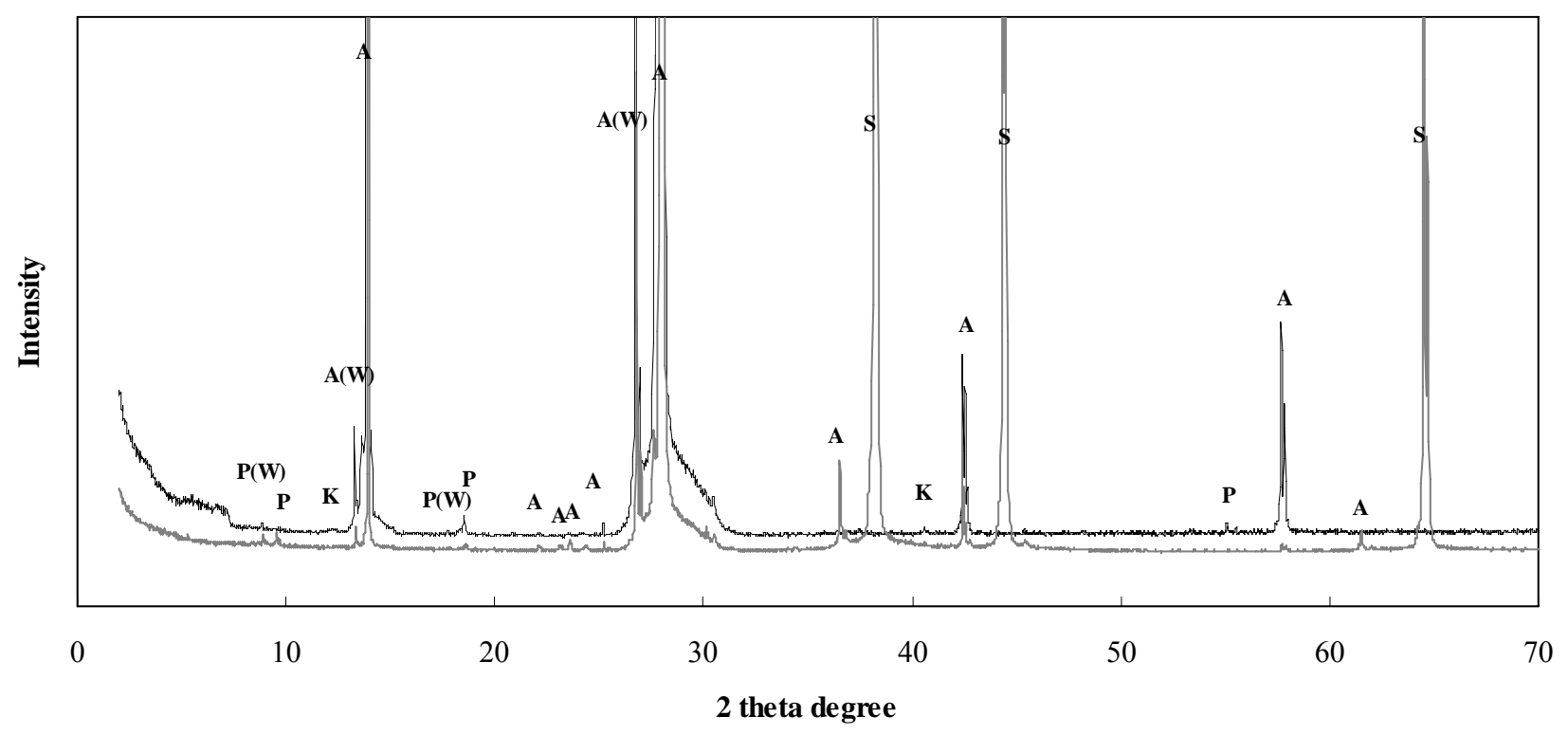

Fig. 16. X-ray diffraction pattern of mineral products following albite dissolution experiment (Experiment 7 dawsonite). A- Albite, ordered (ICDD: 9-466), P-Paragonite-1M (ICDD: 241047), K-Kaolinite (ICDD: 14-164), and S-silver (ICDD: 4-783) was from silver filter membrane. Note that $\mathrm{A}(\mathrm{W})$ and $\mathrm{P}(\mathrm{W})$ represent tungsten radiation (due to aged XRD tube) peaks of Albite and Paragonite, respectively. Grey line: "filtering-slurry mount" method. Black line: "slurry mount" method. 


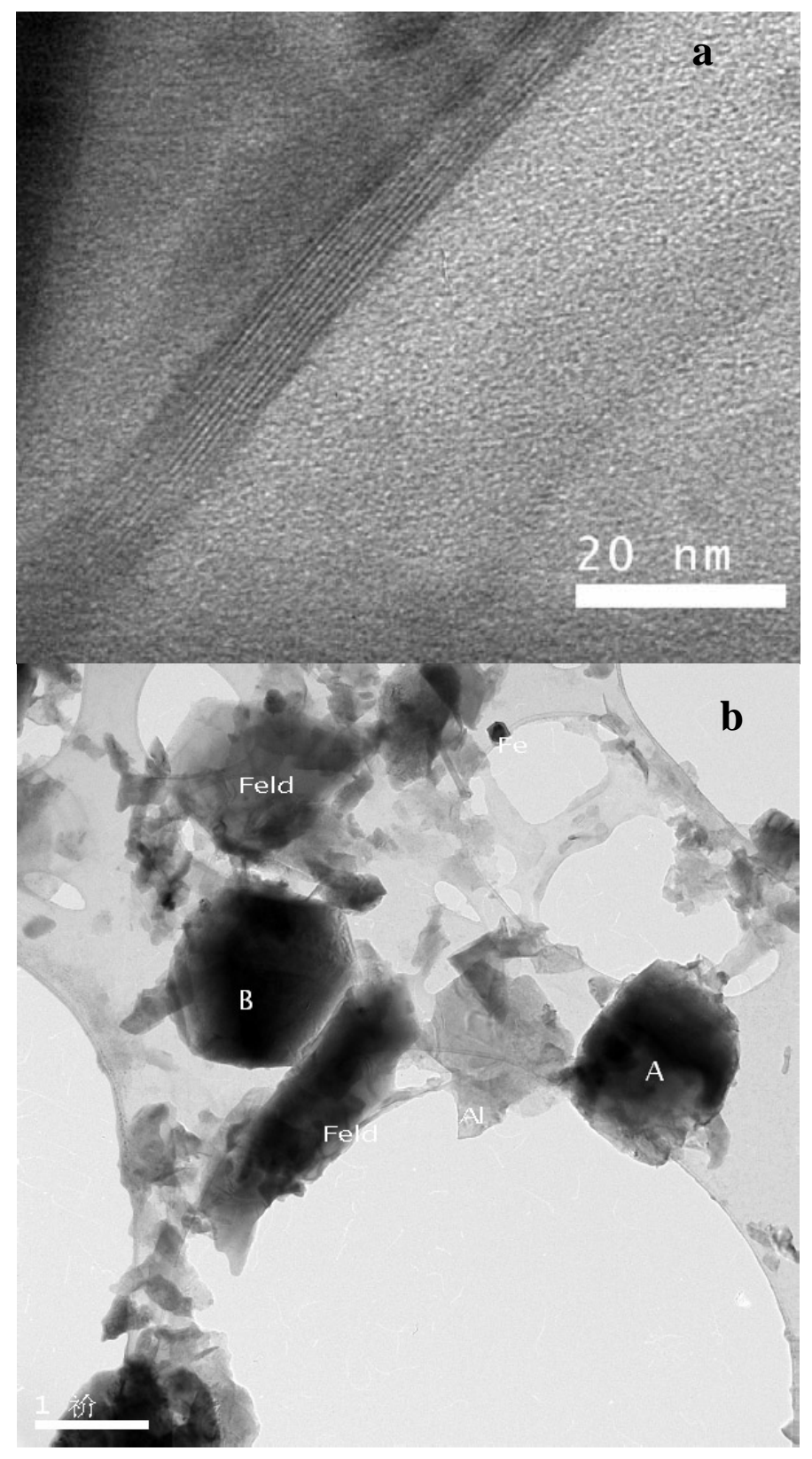




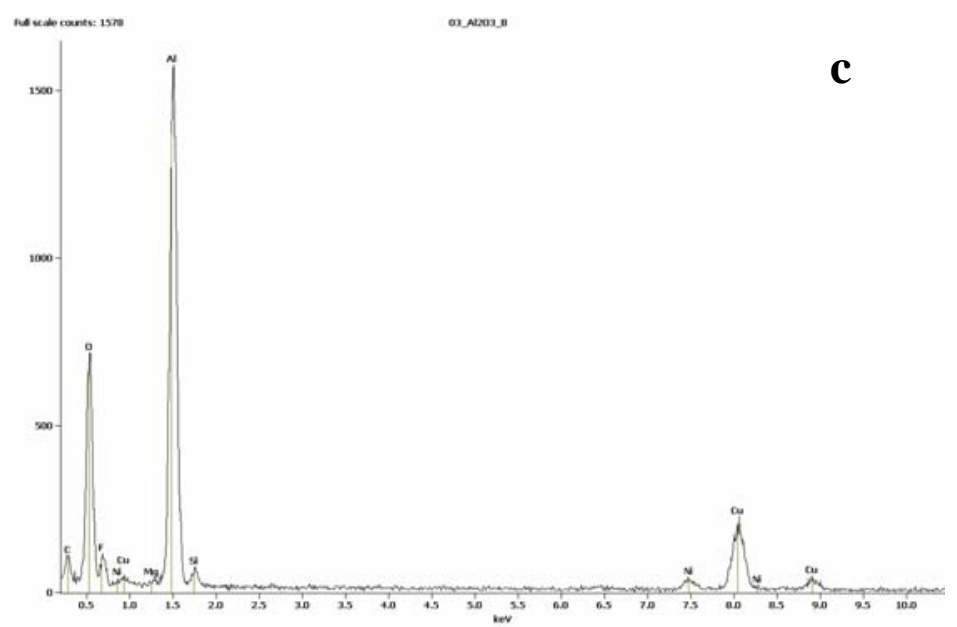

Fig. 17. TEM images (a) kaolinite like clay particle with a d-spacing $\sim 0.7 \mathrm{~nm}$; (b) A and B are Al-containing particles, probably boehmite; (c) EDS that shows A and B contain mainly Al.

The concentrations of dissolved $\mathrm{CO}_{2}{ }^{\circ}(\mathrm{aq})$ decreased from 13.3 to $9.2 \mathrm{mM}$. The decrease of $\mathrm{CO}_{2}{ }^{\circ}$ (aq) concentrations with time suggests possible precipitation of a carbon-containing phase such as dawsonite $\left[\mathrm{NaAlCO}_{3}(\mathrm{OH})_{2}\right]$. However, XRD pattern (Fig. 16) did not show discernable the peaks of dawsonite. Geochemical modeling, using the solubility product for dawsonite, described by the reaction at $150{ }^{\circ} \mathrm{C}$,

$$
\mathrm{NaAlCO}_{3}(\mathrm{OH})_{2}+2 \mathrm{H}_{2} \mathrm{O}=\mathrm{Na}^{+}+\mathrm{Al}(\mathrm{OH})_{4}^{-}+\mathrm{HCO}_{3}^{-}+\mathrm{H}^{+}
$$

was calculated from equation 15 of Benezeth et al. (2007), which is based on their solubility measurement of dawsonite at $50-200{ }^{\circ} \mathrm{C}$. The results showed that the experimental solutions were undersaturated with respect to dawsonite, which corroborates with the XRD results. Geochemical modeling results also show that boehmite, kaolinite, and paragonite were supersaturated. Alternatively, the decrease of $\mathrm{CO}_{2}(\mathrm{aq})$ could have resulted from degassing of the samples.

One of the better outcomes in terms of the fate of injected $\mathrm{CO}_{2}$ in deep geological formation is "mineral trapping" - the precipitation of carbonate-containing minerals that are immobile (Gunter et al., 1997). The mineral dawsonite $\left[\mathrm{NaAlCO}_{3}(\mathrm{OH})_{2}\right]$ was predicted to form in significant quantities as a $\mathrm{CO}_{2}$ mineral trap in numerical reactive transport simulations of $\mathrm{CO}_{2}$ injection into the Sleipner aquifers, North Sea (JOHNSON and NITAO, 2002; JOHNSON et al., 2001), into the Navajo sandstone on the Colorado Plateau (White et al., 2005), into the Rose Run sandstone aquifer in Ohio (Zerai et al., 2006), and into sandstone aquifers resembling the Frio Formation in Texas (Xu et al., 2003; Xu et al., 2004). However, there is a lack of experimental data to support these computer model predictions. Such approximations may result in significant uncertainties in numerical predictions. Dawsonite is a naturally occurring mineral. Its main geological occurrences are as hydrothermal alteration product of igneous rocks, in saline, alkaline lacustrine basins (e.g., Green River Formation, Hay, 1963) and the Bowen-GunnedahSyndney basin in Eastern Australia. The most prominent argument of dawsonite as a mineral trap 
was put forwarded by Moore et al. (2005), who showed pore filling dawsonite in the Springerville-St. Johns $\mathrm{CO}_{2}$ field.

Our experiment of Amelia albite with $\mathrm{CO}_{2}$ and $\mathrm{NaCl}$ did not precipitate dawsonite. It could be that dawsonite does not form readily by reacting with albite (Kaszuba, 2007), but Figure 18 shows the dawsonite stability field under typical reservoir conditions of $150{ }^{\circ} \mathrm{C}$ and 300 bars. At $150{ }^{\circ} \mathrm{C}$ and 300 bars, $\mathrm{CO}_{2}$ solubility in a $2 \mathrm{~m} \mathrm{NaCl}$ solution is approximately $0.95 \mathrm{~m}$ (DUAN et al., 2006). Our conclusion is thus in agreement with that of Hellevang et al. (2005) that dawsonite is not stable in typical formation waters.

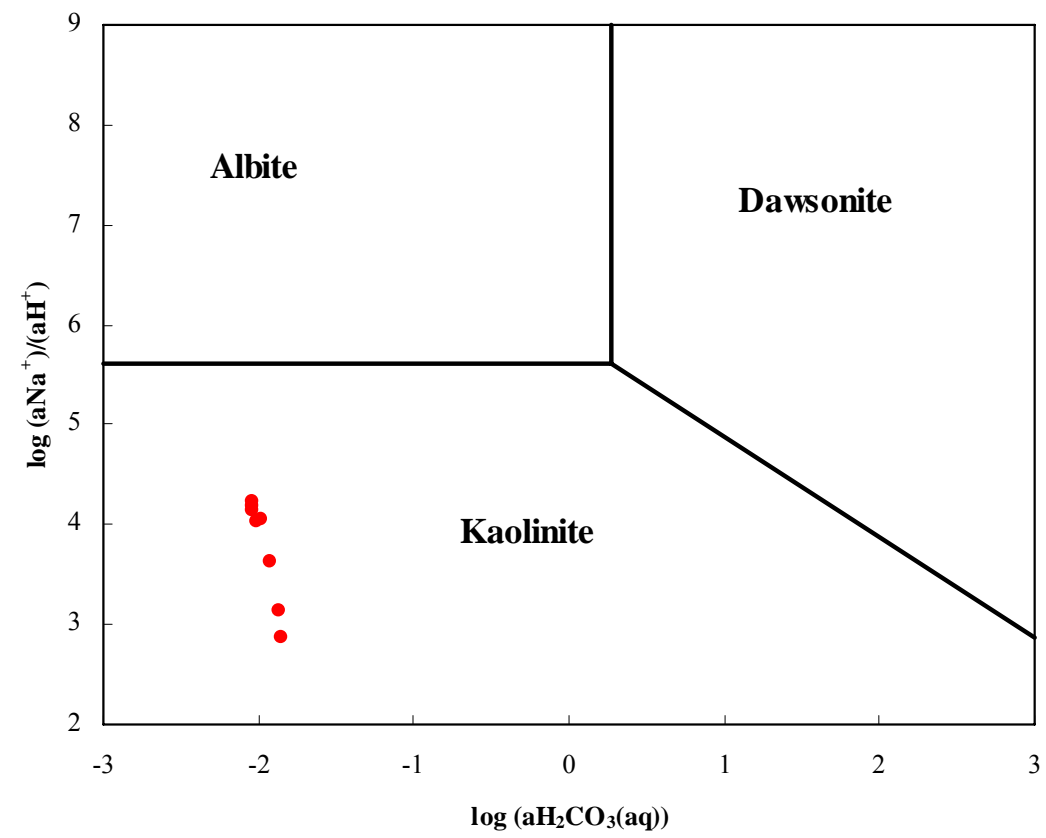

Fig. 18. Activity-activity diagram depicting mineral stability fields in the system $\mathrm{Na}_{2} \mathrm{O}-\mathrm{Al}_{2} \mathrm{O}_{3}-$ $\mathrm{SiO}_{2}-\mathrm{CO}_{2}-\mathrm{H}_{2} \mathrm{O}$ at $150{ }^{\circ} \mathrm{C}$. $\mathrm{SiO}_{2}$ activity is fixed by quartz saturation. Dots stand for experimental data from Experiment 7.

\subsection{Navajo Sandstone Experiments}

A total of three hydrothermal experiments have been conducted to assess the primary mineral dissolution and secondary mineral precipitation kinetics and to test the feasibility of using the Navajo Sandstone saline aquifer for $\mathrm{CO}_{2}$ storage. The first batch experiment exposes the Navajo Sandstone to $\mathrm{CO}_{2}$-impregnant brine and assesses the mineral reactivity as it affects permeability, porosity, and permanent sequestration via precipitation of carbonates and dissolution/precipitation of silicates and clay. These data will provide input for further simulation studies and direct evidence for answering the question "is the Navajo Sandstone a viable formation for geologic carbon sequestration?" The second batch experiment dissolves the Navajo Sandstone in acidic brine without $\mathrm{CO}_{2}$ and serves as a base case to be compared with experiment 
\#1. Finally, a flow-through experiment (experiment \#3) is performed to measure the sandstone dissolution rates based on variations of $\mathrm{Si}$ concentration as a function of time. Our experimental pressures (250-300 bars) are similar to the pressure of the target formation studied by the Big Sky Carbon Sequestration Partnership (265.4 bars), but the experimental temperature is higher $\left(200^{\circ} \mathrm{C}\right)$ than that of the Big Sky study $\left(\sim 98^{\circ} \mathrm{C}\right)$. Our pressure and temperature conditions are comparable with those in Kuszuba et al. $\left(2003\right.$; 2005) $\left(200\right.$ bars and $\left.200^{\circ} \mathrm{C}\right)$. Gunter et al. (1997) also used higher temperature $\left(105^{\circ} \mathrm{C}\right)$ than that of the corresponding aquifer $\left(54^{\circ} \mathrm{C}\right)$ because experiments at $54^{\circ} \mathrm{C}$ did not produce observable reactions. The higher temperature in this study is necessary to accelerate the reactions to measurable rates in the laboratory. The higher temperature is justifiable because performance assessments are on the orders of thousands of years or longer (WILDENBORG and VAN DER MEER, 2002).

\subsubsection{Navajo sandstone before hydrothermal reactions.}

Detailed studies of untreated Navajo Sandstone were described in Zhu et al. (2006). XRD analysis of the bulk Navajo Sandstone shows $\sim 90 \%$ by weight quartz, with minor amounts of Kfeldspar and smectite, and trace amounts of kaolinite and illite/mica (ZHU et al., 2006). Feldspar grains are covered with an inner layer of kaolin and an outer layer of smectite (ZHU et al., 2006). Smectite coatings occur not only on feldspar grains but also on quartz and Fe-Ti oxides (ZHU et al., 2006). X-ray diffraction results confirmed Zhu et al.'s (2006) findings that the clay coating on the Navajo Sandstone is mainly composed of smectite and kaolinite (Fig. 19).

Fig. 19 shows SEM microphotographs of the Navajo Sandstone after ultrasonication removed the clay coatings. These images are to be compared with the images after the experiments. After ultrasonication, the smectite coating is largely removed (Fig. 20). However, the kaolinite coating persists on the K-feldspar surface (Figs. 20b and 20c).

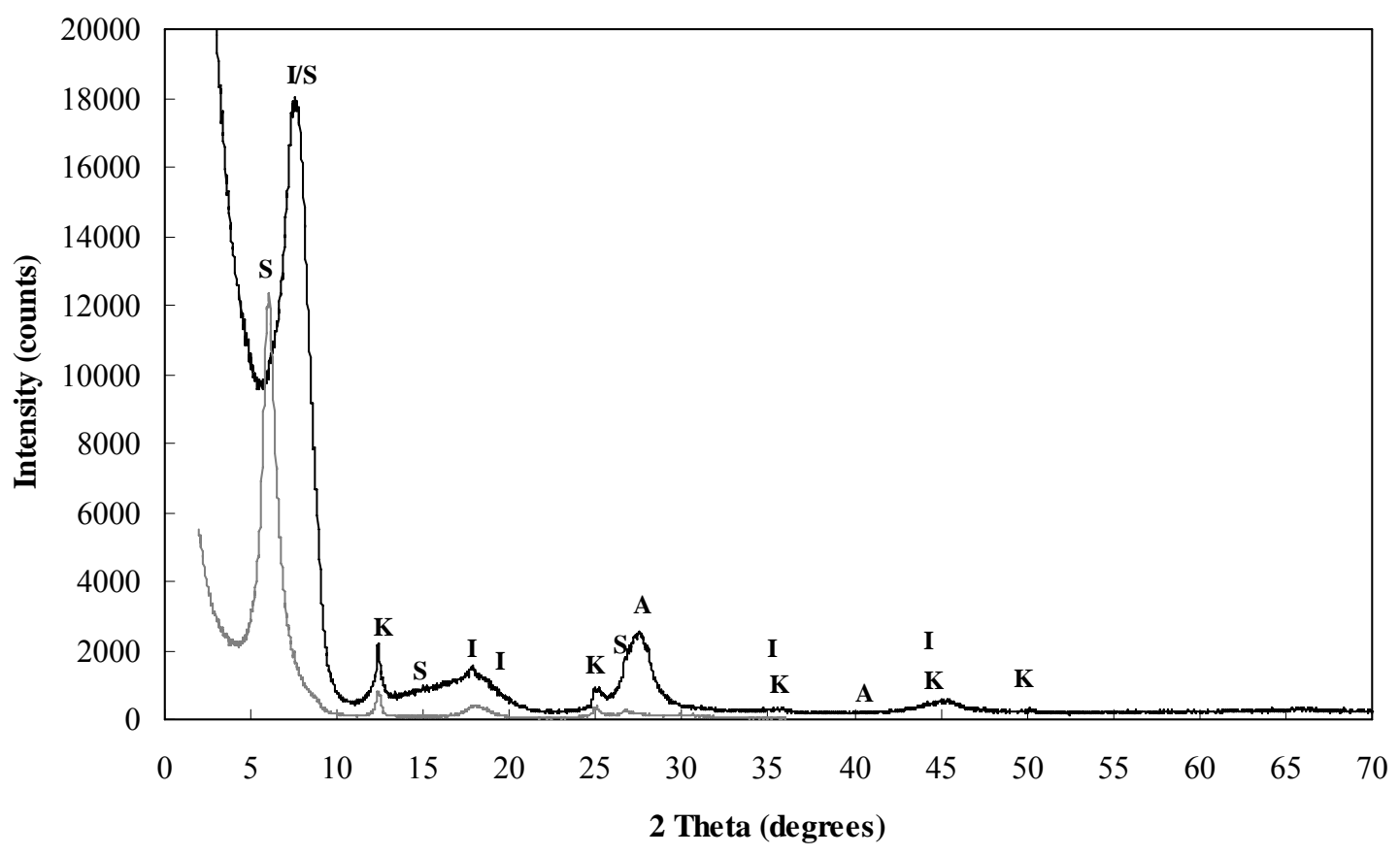


Fig. 19. X-ray diffraction patterns of the clay fraction in Navajo Sandstone before (grey line) and after reactions with $\mathrm{CO}_{2}$-imprenanted brine (black line). Before reaction the clay fraction is mainly composed of smectite (with the (001) reflection between 14-15 angstroms) and kaolinite (K, ICDD: 14-164). The clays of the reacted sandstone shows an (001) reflection of 11-12 angstroms (illite/smectite), suggesting illitization of smectite due to hydrothermal reactions. Kaolinite and allophane were also identified. "I" Illite (ICDD: 29-1496), "A" Allophane (ICDD: 38-499), "I/S" illite/smectite. 

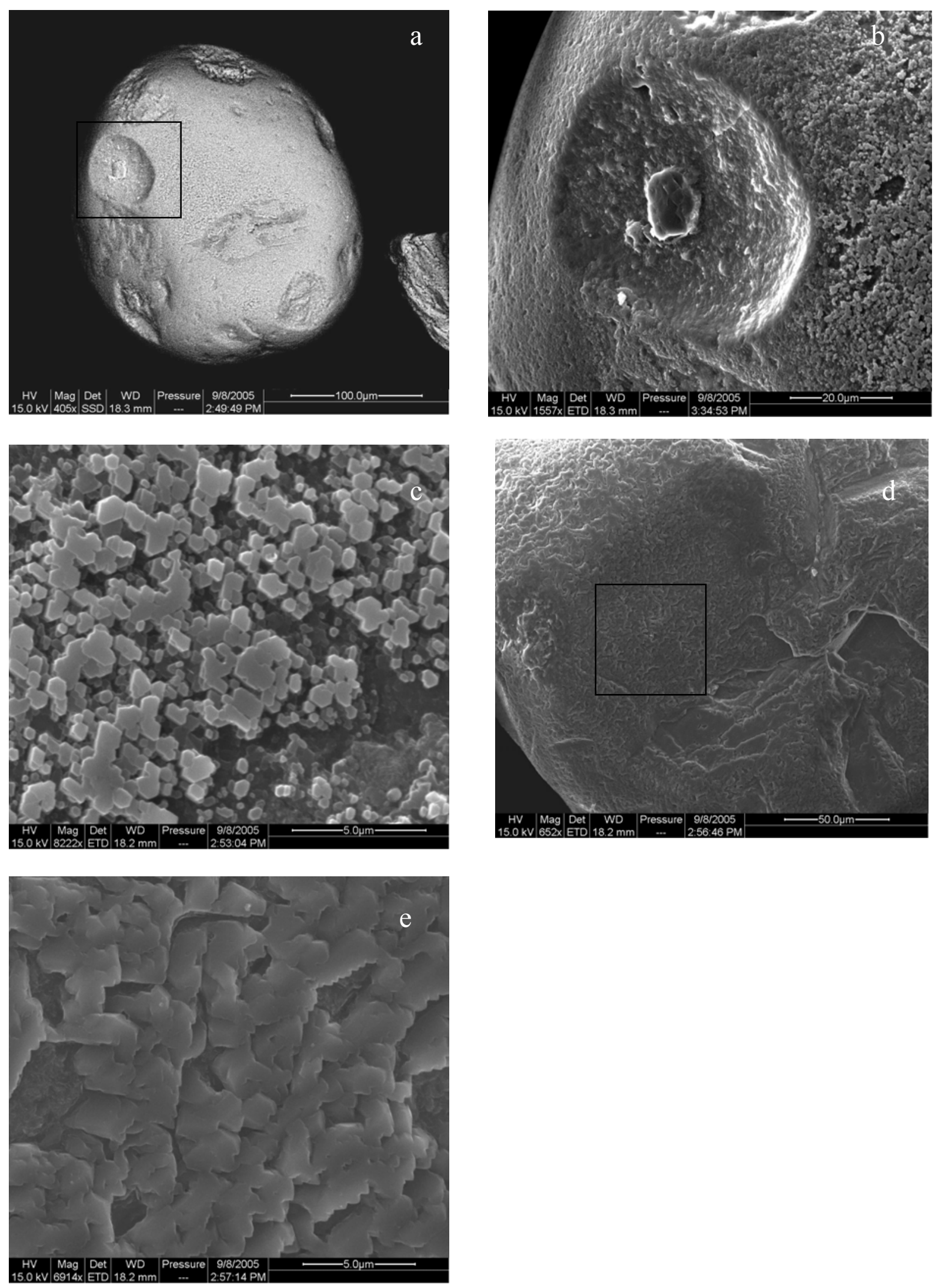
Fig. 20. (a) A K-feldspar particle image after sonication with a sonic probe. The K-feldspar is rounded with pitted surface topography. The identification of K-feldspar was confirmed by EDS; (b) Enlargement of one of the etch-pits outlined by the black box in (a), showing dissolution features. A kaolinite coating is visible to the right of the etch-pit; (c) Enlarged view of the kaolinite coating. The kaolinite is euhedral to semi-euhedral hexagonal platelets, with a size of $0.5 \mu \mathrm{m}$. These platelets are aggregated and well-oriented, but do not form a continuous cover. The basal plane always faces the feldspar surface; (d) A typical quartz particle after the ultrasonication treatment and before the dissolution experiment. The surface of the quartz is coated with incipient quartz overgrowth; (e) High resolution view of an area outlined by the black box in (d), showing incipient quartz overgrowth.

\subsubsection{Batch experiment 1: Navajo sandstone dissolution in $\mathrm{CO}_{2}$-impregnanted brine.}

The first Navajo Sandstone dissolution experiment is a batch experiment at $200{ }^{\circ} \mathrm{C}$ and 300 Bars and $\mathrm{pH} 4.1$ (measured at $25^{\circ} \mathrm{C}$ ). Four grams of Navajo sandstone were reacted with 40 grams $200 \mathrm{mmol} / \mathrm{kg} \mathrm{KCl}$ solution in the presence of $20 \mathrm{mmol} / \mathrm{kg} \mathrm{CO}_{2}$ (aq). X-ray diffraction results (Fig. 19) indicate that our experiment produced secondary clay minerals after 552 hours of reaction. Hydrothermal reactions led to the illitization of smectite minerals (Fig. 19). The peak at 11-12 angstroms is illite/smectite. Illitization of smectite has been widely documented by XRD studies and continues to draw the attention of researchers all over the world. From the time of the pioneering study of Hower et al. (1976), there has been general agreement that illitization of smectite involves interstratified intermediates, with the proportion of illite in mixed-layer illite/smectite increasing as a function of increasing temperature, time and burial depth of basin sediments (e.g., BAULUZ et al., 2002; CUADROS and LinARES, 1996). Kaolinite and allophane were also identified (Fig. 19). While kaolinite was present before the experiment, allophane was newly precipitated as a reaction product in the experiment. Allophane $\left(\mathrm{Al}_{2} \mathrm{Si}_{2} \mathrm{O}_{5} \cdot 3 \mathrm{H}_{2} \mathrm{O}\right)$ is a poorly crystallized hydrous aluminum silicate clay mineral and has a composition similar to kaolinite $\left(\mathrm{Al}_{2} \mathrm{Si}_{2} \mathrm{O}_{5}(\mathrm{OH})_{2}\right)$. Rhombohedra-shaped carbonate grains were occasionally found on quartz particles (Fig. 21f). However, there are not sufficient quantities of carbonate minerals to be successfully identified with XRD.

SEM images show that the morphology of the sandstone change during the course of the experiment. The reacted sandstone displays evidence of participating in fluid-rock interactions, which has also been observed in Kaszuba et al.(2003; 2005). Solution chemistry data (Si concentrations increase with time) suggests silicate dissolution (Table 10), although dissolution features on sandstones are not evident. Abundant clay minerals adhere to quartz and K-feldspars after the reaction and commonly bridge the pores. Product minerals observed with SEM are consistent with XRD results. Newly formed allophane aggregates fill the pores (Fig. 21a and 21c). These allophanes are poorly crystallized. XRD (Fig. 19) and SEM with X-ray microanalysis (SEM/EDS) analysis (Fig. 20d) confirm the identity of allophane. SEM observations confirmed the illtization of smectite. The morphologies range from the typical "corn-flake," "maple leaf," or "honeycomb" habit of smectite to the typical platy or scalloped (with curled points) habit of illite, as described by Keller et al. (1986). Elongated fabric, platy or ribbon-like illite/smectite is shown in Figs. 20a-20g. This morphology of illite/smectite has also been observed in Keller et al. (1986), Nadeau (1998), Nadeau et al. (2002), and Celik et al. 
(1999). Illite, as interwoven ribbons, is intimately associated with the smectite (Fig. 21g). The smectite and kaolinite coatings persisted on the K-feldspar grains, indicating that the chemical reactions did not remove the coatings (Fig. 21h-j).

The solution chemistry results are presented in Tables 10 and 11. During the experiment, dissolved $\mathrm{K}^{+}$and $\mathrm{Cl}^{-}$concentrations remained relatively constant (Table 10). Dissolved $\mathrm{SiO}_{2}$ increased, reaching $2.20 \mathrm{mmol} / \mathrm{kg}$ by the end of experiment. The smectite-to-illite conversion generally consumes $\mathrm{K}^{+}$and releases $\mathrm{SiO}_{2}$ (CUADROS and LINARES, 1996). This conversion is likely to be a source of increased $\mathrm{SiO}_{2}$. Another source of $\mathrm{SiO}_{2}$ is dissolution of feldspars. Saturation index calculations indicate that the solution is undersaturated with respect to albite and anorthite during the entire course of the reaction (see below), suggesting the dissolution of plagioclase. The dissolved concentrations of $\mathrm{Mg}^{2+}$ and $\mathrm{Ca}^{2+}$ also increased with time. $\mathrm{Mg}^{2+}$ and $\mathrm{Ca}^{2+}$ are probably from $\mathrm{K}^{+}$cation exchange with $\mathrm{Mg}^{2+}$ and $\mathrm{Ca}^{2+}$ in smectite. There was only a slight decrease in dissolved $\mathrm{CO}_{2}$ concentration during the experiment (which suggests the formation of carbonates) while $\mathrm{pH}$ values increased slowly with reaction progress. Generally, the dissolved concentrations of most minor and trace elements approached steady-state values within the first 48 hours (Table 11). Fe, Sr, and $\mathrm{Ba}$ are probably from $\mathrm{K}^{+}$cation exchange with $\mathrm{Fe}, \mathrm{Sr}$, and $\mathrm{Ba}$ in smectite.

Table 10. Time-dependent changes in the composition of major dissolved species in $\mathrm{CO}_{2}$-bearing aqueous fluid coexisting with Navajo sandstone at $200{ }^{\circ} \mathrm{C}$ and 300 bars. The overall analytical error for dissolved species is $\pm 5 \%$.

\begin{tabular}{|c|c|c|c|c|c|c|c|c|c|c|c|c|}
\hline Sample & $\begin{array}{l}\text { Time } \\
\text { (h) }\end{array}$ & $\mathrm{K}^{+}$ & $\mathrm{SiO}_{2}$ & $\mathrm{Al}^{3+}$ & $\mathrm{Na}^{+}$ & $\begin{array}{c}\mathrm{Mg}^{2+} \\
(\mathrm{mmo})\end{array}$ & $\begin{array}{l}\mathrm{Ca}^{2+} \\
\mathrm{kg})\end{array}$ & $\mathrm{Cl}^{-}$ & $\mathrm{SO}_{4}{ }^{2-}$ & $\mathrm{CO}_{2}(\mathrm{aq})$ & $25^{\circ} \mathrm{C}$ & $\begin{array}{l}\mathrm{pH} \\
\text { In-situ* }\end{array}$ \\
\hline starting & 0 & 197.26 & - & - & 0.17 & - & - & 200.77 & 0.04 & 20.3 & 4.1 & 4.4 \\
\hline$\# 1$ & 48 & 195.00 & 0.89 & 0.01 & 0.26 & 0.09 & 0.29 & 193.33 & 0.16 & 19.2 & 4.7 & 5.2 \\
\hline$\# 2$ & 144 & 190.42 & 1.70 & 0.01 & 0.08 & 0.11 & 0.26 & 197.76 & 0.05 & 19.7 & 4.8 & 5.4 \\
\hline \#3 & 336 & 193.32 & 2.03 & 0.10 & 0.14 & 0.17 & 0.34 & 192.38 & - & 19.5 & 4.9 & 5.3 \\
\hline \#4 & 552 & 199.60 & 2.20 & 0.02 & 0.05 & 0.19 & 0.33 & 193.66 & 0.18 & 19.6 & 4.9 & 5.6 \\
\hline
\end{tabular}

In-situ $\mathrm{pH}$ is calculated from distribution of aqueous species calculations at the temperature and pressure of the experiment using constraints imposed by major element concentrations and $\mathrm{pH}$ values measured at $25^{\circ} \mathrm{C}$.

Table 11. Time-dependent changes in the composition of minor and trace dissolved species in $\mathrm{CO}_{2}$-bearing aqueous fluid coexisting with Navajo Sandstone at $200{ }^{\circ} \mathrm{C}$ and 300 bars. The overall analytical error for concentration measurements is $\pm 5 \%$.

\begin{tabular}{cccccccccccccc}
\hline Sample & $\begin{array}{c}\text { Time } \\
(\mathrm{h})\end{array}$ & $\mathrm{Li}$ & $\mathrm{Cr}$ & $\mathrm{Fe}$ & $\mathrm{Mn}$ & $\mathrm{Co}$ & $\begin{array}{c}\mathrm{Ni} \\
(\mathrm{ppm})\end{array}$ & $\mathrm{Cu}$ & $\mathrm{Rb}$ & $\mathrm{Sr}$ & $\mathrm{Cs}$ & $\mathrm{Ba}$ \\
\hline Starting & 0 & - & - & - & - & - & - & 0.10 & 0.24 & 0.29 & 0.01 & 0.01 & 0.01 \\
$\# 1$ & 48 & - & - & 1.70 & 0.09 & 0.01 & - & 0.06 & 0.32 & 0.27 & 0.36 & 0.01 & 0.22 \\
$\# 2$ & 144 & - & - & - & 0.08 & - & - & 0.13 & 0.20 & 0.27 & 0.36 & 0.01 & 0.30 \\
$\# 3$ & 336 & 0.04 & 0.01 & 6.63 & 0.13 & 0.01 & 0.25 & 0.27 & 0.38 & 0.43 & 0.36 & 0.08 & 0.25 \\
$\# 4$ & 552 & 0.05 & - & 0.67 & 0.12 & - & 0.18 & 0.09 & 0.17 & 0.32 & 0.35 & 0.02 & 0.24 \\
\hline
\end{tabular}



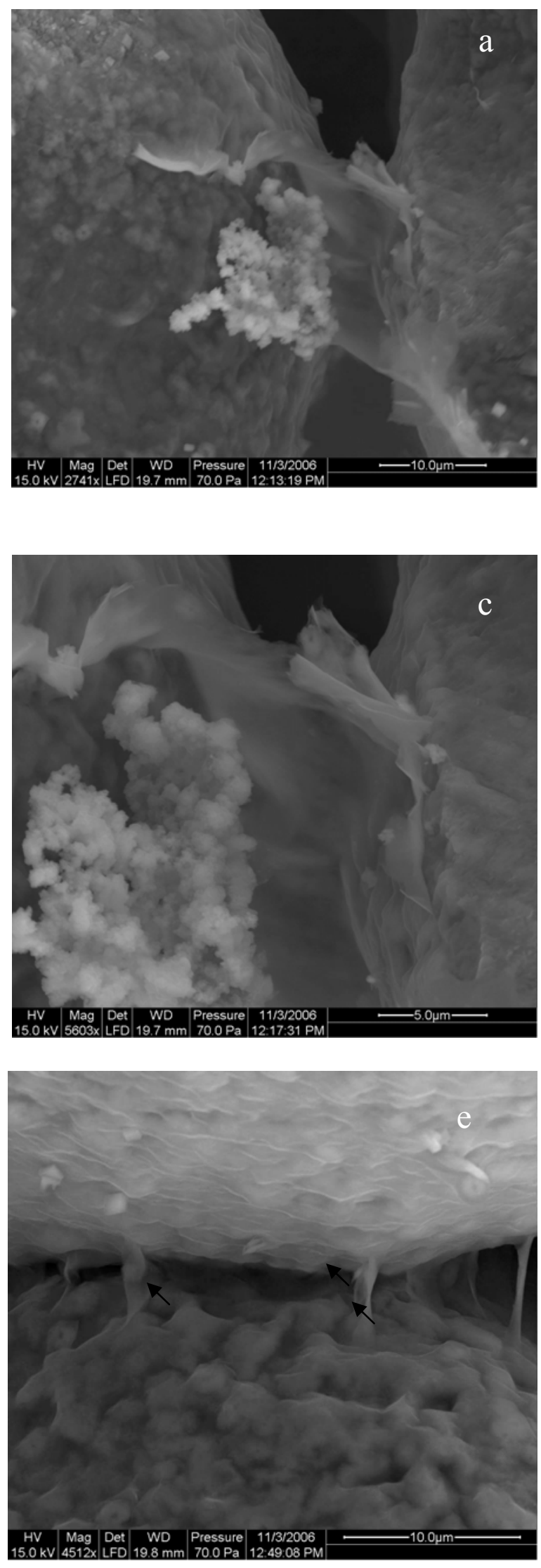
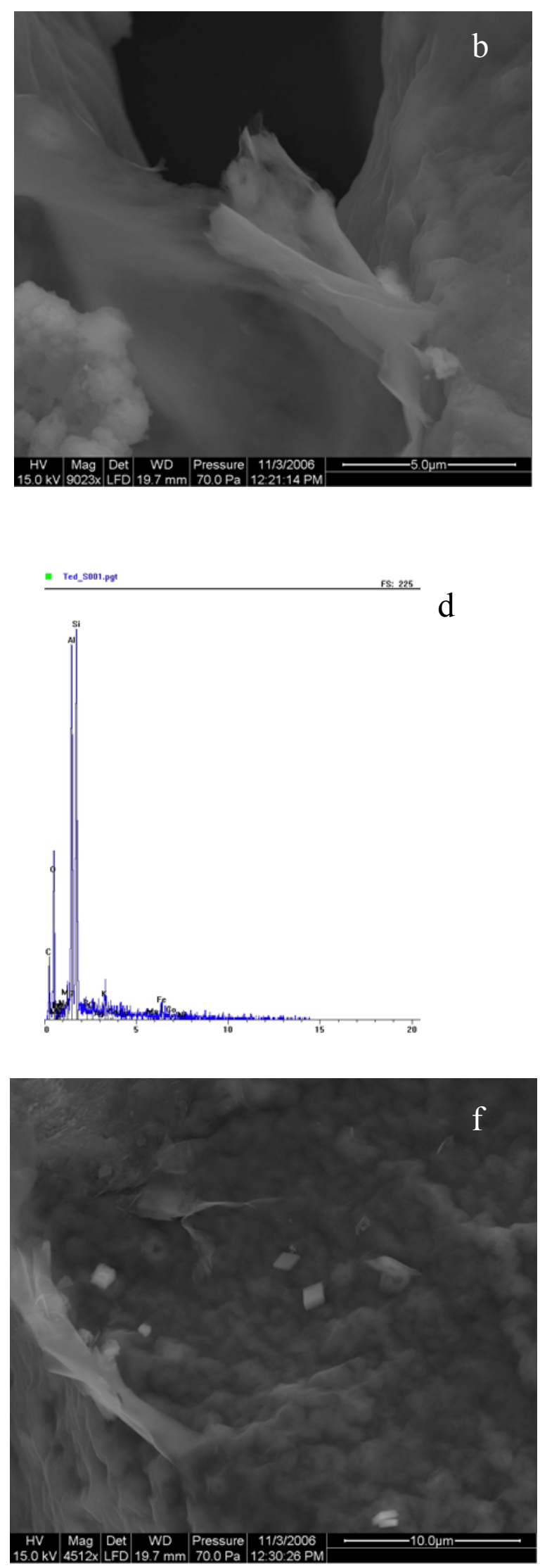

43 

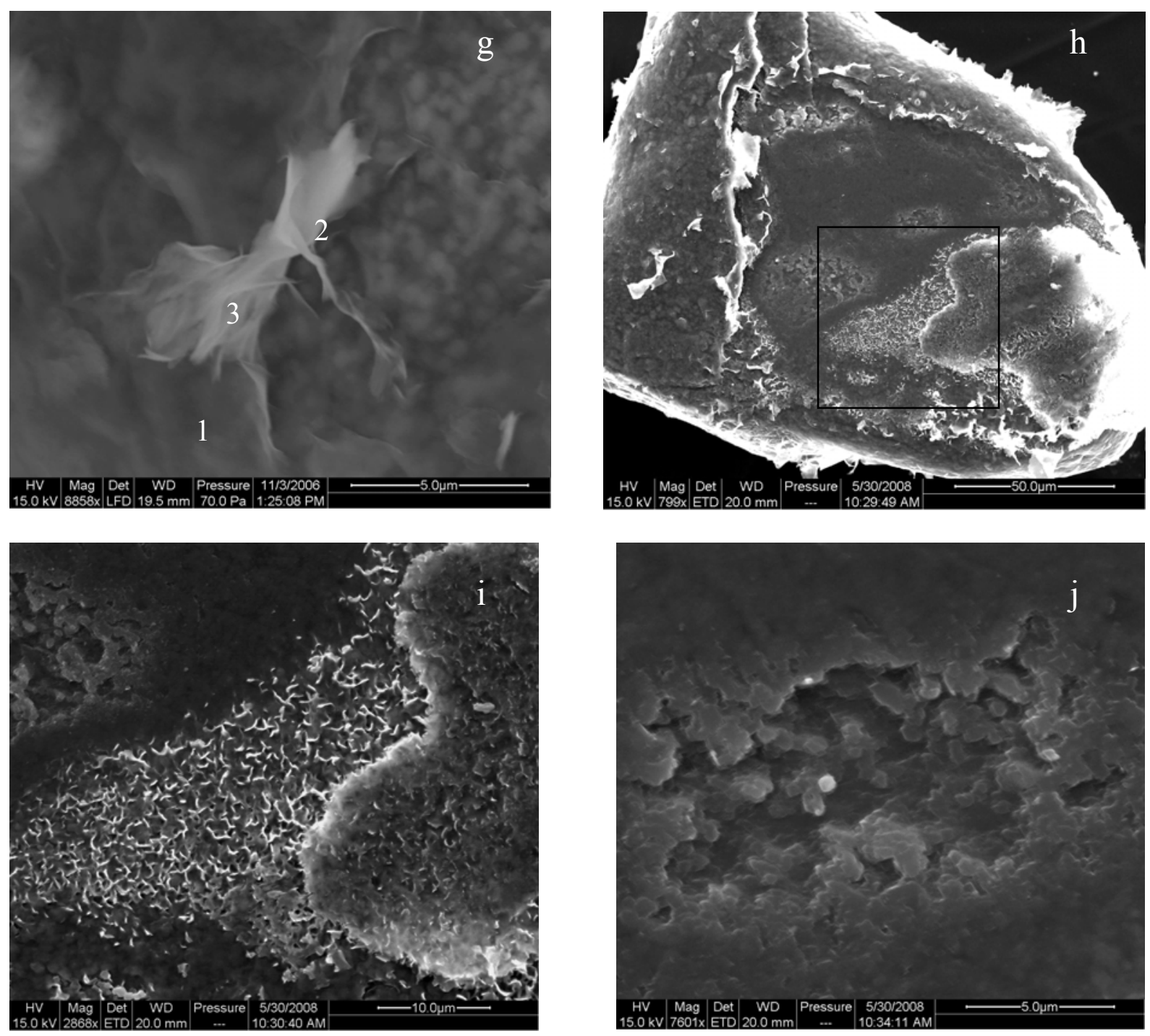

Fig. 21. (a) SEM microphotograph shows a ribbon-like secondary mineral bridging two quartz particles and aggregated secondary minerals filling the pore between the quartz particles; (b) Enlarged view of the platy, flaky secondary mineral (approximately $8 \mu \mathrm{m}$ wide) shown in (a) with slightly scalloped, curled edges. This morphology looks similar to the reference illite shown in Keller et al. (1986). It is likely to be illite/smectite, with the chemical composition close to the illite end member; (c) Enlarged view of the aggregated secondary mineral. Poorly-crystallized allophane partly fills pores. Allophane has not been observed in the sandstone reactant and thus is newly formed; (d) EDS analysis yielding nearly equal peak heights of Si and Al suggests the minerals are probably allophane; (e) SEM microphotograph shows the smooth, flaky secondary mineral filling the pore and bridging two quartz particles. Similar morphology of illite/smectite was also shown in Keller et al. (1986), Nadeau (1998), Nadeau et al. (2002), and Celik et al. (1999); (f) SEM microphotograph shows rhombohedra-shaped secondary minerals (indicated by black arrows), approximately $1 \mu \mathrm{m}$ in size. These minerals are likely to be carbonates. However, it was difficult to confirm with EDS due to their small size. The flaky secondary mineral (approximately $3 \mu \mathrm{m}$ wide) to the left is illite/smectite; (g) SEM microphotograph shows secondary minerals on a quartz surface. The smooth, flaky secondary minerals (marked as "1" 
and "2") are illite/smectite. The interwoven ribbons feature is a typical morphology of illite (marked as " 3 "). The length of a single ribbon is about $2 \mu \mathrm{m}$. The existence of illite was confirmed by XRD (Figure 1); (h) SEM microphotograph shows a K-feldspar particle after reaction. A massive, webby smectite aggregate covers the right-hand part of the K-feldspar; (i) Enlarged view of an area outlined by the box in (h). Well-developed, highly crenulated smectite formed a thin, webby crust. The webby morphology is a common crystal habit of smectite. The morphology of the webby smectite is similar to that shown in Zhu et al. (2006), but it is much denser; (j) SEM microphotograph shows pore-filling kaolinite on a K-feldspar particle. The kaolinite particles are semi-euhedral platelets. These platelets are aggregated and well-oriented, but do not form a continuous cover. The basal plane always faces the feldspar surface.

The measured fluid chemistry and $\mathrm{pH}$, when considered alongside aqueous speciation distribution, and taking explicit account of mass balance, mass action and charge balance constraints, together with constraints imposed by the revised HKF equation of state, (JOHNSON et al., 1992; SHOCK and HelgeSON, 1988; SHOCK et al., 1989; SHOCK et al., 1992; SVERJENSKY et al., 1997) permit calculation of ion activities of dissolved species. Speciation-solubility calculations were facilitated with the geochemical modeling code PHREEQC (PARKHURST and APPELLO, 1999). Thermodynamic data used in the speciation-solubility calculations are listed in Table 12.

Mineral saturation indices (SI) calculations (Table 13) show that the solution is supersaturated with respect to microcline and undersaturated with respect to albite during the entire course of the reaction; the solution changes from undersaturated $(144 \mathrm{~h})$ to supersaturated $(336 \mathrm{~h})$ back to undersaturated $(552 \mathrm{~h})$ with respect to anorthite; the solution is supersaturated with respect to calcite and magnesite and slightly undersaturated with respect to quartz. SI calculations indicate that the formation of carbonate minerals (e.g., calcite and magnesite) is thermodynamically favored. As for the clay minerals, the solution is supersaturated with respect to kaolinite and illite during the entire course of the reaction and changes from undersaturated to supersaturated with respect to beidellite-K (a type of smectite) and montmorillonite- $\mathrm{K}$ (a type of smectite) at $144 \mathrm{~h}$ and $336 \mathrm{~h}$, respectively. 
Table 12. Thermodynamic data used in this report, calculated with the computer code of SUPCRT92 (JOHNSON et al., 1992).

\begin{tabular}{|c|c|c|c|c|}
\hline Aqueous reactions & $\begin{array}{l}\log \mathrm{K} \\
25^{\circ} \mathrm{C}\end{array}$ & $\begin{array}{c}\log \mathrm{K} \\
200^{\circ} \mathrm{C} 300 \text { bar }\end{array}$ & $\begin{array}{c}\log \mathrm{K} \\
200^{\circ} \mathrm{C} 250 \text { bar }\end{array}$ & Ref \\
\hline$\overline{\mathrm{H}_{2} \mathrm{O}=\mathrm{OH}^{-}+\mathrm{H}^{+}}$ & -13.995 & -11.163 & -11.183 & (1) \\
\hline $\mathrm{H}_{2} \mathrm{O}+\mathrm{Al}^{+3}=\mathrm{AlOH}^{+2}+\mathrm{H}^{+}$ & -4.964 & -1.446 & -1.438 & (2) \\
\hline $2 \mathrm{H}_{2} \mathrm{O}+\mathrm{Al}^{+3}=\mathrm{Al}(\mathrm{OH})_{2}^{+}+2 \mathrm{H}^{+}$ & -10.921 & -3.630 & -3.614 & (2) \\
\hline $3 \mathrm{H}_{2} \mathrm{O}+\mathrm{Al}^{+3}=\mathrm{Al}(\mathrm{OH})_{3}{ }^{\circ}+3 \mathrm{H}^{+}$ & -17.044 & -7.301 & -7.281 & (2) \\
\hline $4 \mathrm{H}_{2} \mathrm{O}+\mathrm{Al}^{+3}=\mathrm{Al}(\mathrm{OH})_{4}^{-}+4 \mathrm{H}^{+}$ & -22.851 & -11.572 & -11.557 & (2) \\
\hline $\mathrm{Na}^{+}+4 \mathrm{H}_{2} \mathrm{O}+\mathrm{Al}^{+3}=\mathrm{NaAl}(\mathrm{OH})_{4}{ }^{\circ}+4 \mathrm{H}^{+}$ & -22.9 & -10.748 & -10.724 & (2) \\
\hline $\mathrm{SiO}_{2}+2 \mathrm{H}_{2} \mathrm{O}+\mathrm{Al}^{+3}=\mathrm{AlH}_{3} \mathrm{SiO}_{4}^{+2}+\mathrm{H}^{+}$ & -2.357 & 1.86 & 1.858 & (2) \\
\hline $\mathrm{Na}^{+}+\mathrm{H}_{2} \mathrm{O}=\mathrm{NaOH}^{\mathrm{o}}+\mathrm{H}^{+}$ & -14.205 & -11.087 & -11.095 & (3) \\
\hline $\mathrm{Na}^{+}+\mathrm{Cl}^{-}=\mathrm{NaCl}^{\circ}$ & -0.777 & 0.019 & .031 & (4) \\
\hline $\mathrm{K}^{+}+\mathrm{Cl}^{-}=\mathrm{KCl}^{\circ}$ & & 0.456 & 0.464 & (5) \\
\hline $\mathrm{H}^{+}+\mathrm{Cl}^{-}=\mathrm{HCl}^{\circ}$ & -0.710 & -0.15 & -0.15 & (6) \\
\hline $\mathrm{K}^{+}+\mathrm{H}_{2} \mathrm{O}=\mathrm{KOH}^{\mathrm{o}}+\mathrm{H}^{+}$ & -14.439 & -10.939 & -10.946 & (3) \\
\hline $\mathrm{Na}^{+}+\mathrm{HCO}_{3}^{-}=\mathrm{NaHCO}_{3}$ & 0.1541 & -1.213 & & (7) \\
\hline $\mathrm{Na}^{+}+\mathrm{HCO}_{3}^{-}=\mathrm{NaCO}_{3}^{-}+\mathrm{H}^{+}$ & -9.8144 & -12.632 & & (7) \\
\hline $\mathrm{K}^{+}+\mathrm{HCO}_{3}^{-}=\mathrm{KHCO}_{3}$ & 0.1541 & -1.213 & & (8) \\
\hline $\mathrm{K}^{+}+\mathrm{HCO}_{3}^{-}=\mathrm{KCO}_{3}^{-}+\mathrm{H}^{+}$ & -9.8144 & -12.632 & & (8) \\
\hline $\mathrm{Cl}^{-}+\mathrm{Ca}^{+2}=\mathrm{CaCl}^{+}$ & -0.292 & 1.146 & 1.159 & (4) \\
\hline $2 \mathrm{Cl}^{-}+\mathrm{Ca}^{+2}=\mathrm{CaCl}_{2}{ }^{\circ}$ & -0.644 & 0.672 & 0.700 & (4) \\
\hline $\mathrm{H}_{2} \mathrm{O}+\mathrm{Ca}^{+2}=\mathrm{CaOH}^{+}+\mathrm{H}^{+}$ & -12.833 & -7.961 & -7.956 & (3) \\
\hline $\mathrm{Ca}^{+2}+\mathrm{HCO}_{3}{ }^{-}=\mathrm{CaCO}_{3}{ }^{\circ}+\mathrm{H}^{+}$ & -7.002 & -5.05 & & (3) \\
\hline $\mathrm{Ca}^{+2}+\mathrm{HCO}_{3}^{-}=\mathrm{Ca}\left(\mathrm{HCO}_{3}\right)^{+}$ & 1.047 & 2.305 & & (4) \\
\hline $\mathrm{HCO}_{3}{ }^{-}+\mathrm{H}^{+}=\mathrm{CO}_{2}{ }^{\circ}+\mathrm{H}_{2} \mathrm{O}$ & 6.345 & 7.067 & & (3) \\
\hline $\mathrm{CO}_{3}^{-2}+\mathrm{H}^{+}=\mathrm{HCO}_{3}^{-}$ & 10.329 & 10.298 & & (3) \\
\hline $\mathrm{NH}_{3}{ }^{\mathrm{o}}+\mathrm{H}^{+}=\mathrm{NH}_{4}^{+}$ & 9.241 & 5.825 & & (3) \\
\hline $\mathrm{Mg}^{+2}+\mathrm{HCO}_{3}^{-}=\mathrm{MgHCO}_{3}^{+}$ & 1.036 & 2.288 & & (9) \\
\hline $\mathrm{Mg}^{+2}+\mathrm{HCO}_{3}^{-}=\mathrm{MgCO}_{3}+\mathrm{H}^{+}$ & -7.35 & -5.92 & & (4) \\
\hline $\mathrm{Ca}^{+2}+\mathrm{SO}_{4}^{-2}=\mathrm{CaSO}_{4}$ & 2.111 & 3.291 & 3.313 & (3) \\
\hline $\mathrm{Mg}^{+2}+\mathrm{Cl}^{-}=\mathrm{MgCl}^{+}$ & -0.135 & 0.911 & .924 & (4) \\
\hline $\mathrm{Mg}^{+2}+\mathrm{H}_{2} \mathrm{O}=\mathrm{Mg}(\mathrm{OH})^{+}+\mathrm{H}^{+}$ & -11.682 & -7.424 & -7.419 & (4) \\
\hline $\mathrm{H}^{+}+\mathrm{SO}_{4}^{-2}=\mathrm{HSO}_{4}^{-}$ & 1.979 & 4.350 & 4.369 & (4) \\
\hline $\mathrm{K}_{+}+\mathrm{SO}_{4}^{-2}=\mathrm{KSO}_{4}^{-}$ & 0.88 & 1.854 & 1.864 & (4) \\
\hline $\mathrm{K}^{+}+\mathrm{HSO}_{4}^{-}=\mathrm{KHSO}_{4}$ & -3.474 & -1.366 & -1.355 & (4) \\
\hline $\mathrm{Mg}^{+2}+\mathrm{SO}_{4}^{-2}=\mathrm{MgSO}_{4}$ & 2.23 & 3.383 & 3.408 & (4) \\
\hline $\mathrm{Na}^{+}+\mathrm{SO}_{4}^{-2}=\mathrm{NaSO}_{4}^{-}$ & 0.7 & 1.666 & 1.683 & (4) \\
\hline $\mathrm{SiO}_{2}+\mathrm{H}_{2} \mathrm{O}=\mathrm{HSiO}_{3}^{-}+\mathrm{H}^{+}$ & -9.585 & -8.707 & -8.728 & (4) \\
\hline $\mathrm{SiO}_{2}+\mathrm{H}_{2} \mathrm{O}+\mathrm{Na}^{+}=\mathrm{NaHSiO}_{3}{ }^{\circ}+\mathrm{H}^{+}$ & -7.754 & -7.767 & -7.775 & (4) \\
\hline \multicolumn{5}{|l|}{ Mineral reactions } \\
\hline $\mathrm{KAlSi}_{3} \mathrm{O}_{8}$ (microcline) $+4 \mathrm{H}^{+}=\mathrm{Al}^{+3}+\mathrm{K}^{+}+2 \mathrm{H}_{2} \mathrm{O}+3 \mathrm{SiO}_{2}(\mathrm{aq})$ & -1.050 & -3.923 & -3.975 & $(10)$ \\
\hline $\mathrm{NaAlSi}_{3} \mathrm{O}_{8}$ (albite) $+4 \mathrm{H}^{+}=\mathrm{Al}^{+3}+\mathrm{Na}^{+}+2 \mathrm{H}_{2} \mathrm{O}+3 \mathrm{SiO}_{2}(\mathrm{aq})$ & 2.065 & -2.508 & -2.561 & (10) \\
\hline $\mathrm{CaAl}_{2} \mathrm{Si}_{2} \mathrm{O}_{8}$ (anorthite) $+8 \mathrm{H}^{+}=\mathrm{Ca}^{+2}+2 \mathrm{Al}^{+3}+2 \mathrm{SiO}_{2}(\mathrm{aq})+4 \mathrm{H}_{2} \mathrm{O}$ & 23.68 & 4.042 & 3.954 & $(10)$ \\
\hline $\mathrm{AlO}_{2} \mathrm{H}$ (diaspore) $+3 \mathrm{H}^{+}=\mathrm{Al}^{+3}+2 \mathrm{H}_{2} \mathrm{O}$ & 7.191 & 0.02 & -0.005 & $(10)$ \\
\hline $\mathrm{AlO}_{2} \mathrm{H}$ (boehmite) $+3 \mathrm{H}^{+}=\mathrm{Al}^{+3}+2 \mathrm{H}_{2} \mathrm{O}$ & 7.595 & 0.242 & 0.217 & (11) \\
\hline $\mathrm{CaCO}_{3}$ (calcite) $+\mathrm{H}^{+}=\mathrm{Ca}^{+2}+\mathrm{HCO}_{3}^{-}$ & 1.816 & -0.438 & & $(10)$ \\
\hline $\mathrm{MgCO}_{3}$ (magnesite) $+\mathrm{H}^{+}=\mathrm{Mg}^{+2}+\mathrm{HCO}_{3}^{-}$ & 2.29 & -1.066 & & $(10)$ \\
\hline $\mathrm{NaAlCO}_{3}(\mathrm{OH})_{2}$ (Dawsonite) $+3 \mathrm{H}^{+}=\mathrm{Al}^{+3}+\mathrm{HCO}_{3}^{-}+\mathrm{Na}^{+}+2 \mathrm{H}_{2} \mathrm{O}$ & 4.3464 & -0.4756 & -0.4756 & $(12)$ \\
\hline $\mathrm{CaMg}\left(\mathrm{CO}_{3}\right)_{2}$ (Dolomite) $+2 \mathrm{H}^{+}=\mathrm{Ca}^{+2}+\mathrm{Mg}^{+2}+2 \mathrm{HCO}_{3}^{-}$ & 3.240 & -2.018 & & $(10)$ \\
\hline $\mathrm{SiO}_{2}($ quartz $)=\mathrm{SiO}_{2}(\mathrm{aq})$ & -4.047 & -2.424 & -2.431 & (10) \\
\hline $\mathrm{CO}_{2}(\mathrm{~g})=\mathrm{CO}_{2}{ }^{\circ}$ & -1.473 & -2.132 & & $(10)$ \\
\hline $\mathrm{Al}_{2} \mathrm{Si}_{2} \mathrm{O}_{5}(\mathrm{OH})_{4}$ (kaolinite) $+6 \mathrm{H}^{+}=2 \mathrm{Al}^{+3}+2 \mathrm{SiO}_{2}(\mathrm{aq})+5 \mathrm{H}_{2} \mathrm{O}$ & 4.501 & -5.354 & -5.415 & $(10)$ \\
\hline $\mathrm{KAl}_{3} \mathrm{Si}_{3} \mathrm{O}_{10}(\mathrm{OH})_{2}$ (muscovite) $+10 \mathrm{H}^{+}=\mathrm{K}^{+}+3 \mathrm{Al}^{+3}+3 \mathrm{SiO}_{2}(\mathrm{aq})+6 \mathrm{H}_{2} \mathrm{O}$ & 11.22 & -5.407 & -5.506 & $(10)$ \\
\hline $\mathrm{NaAl}_{3} \mathrm{Si}_{3} \mathrm{O}_{10}(\mathrm{OH})_{2}$ (paragonite) $+10 \mathrm{H}^{+}=\mathrm{Na}^{+}+3 \mathrm{Al}^{+3}+3 \mathrm{SiO}_{2}(\mathrm{aq})+6 \mathrm{H}_{2} \mathrm{O}$ & 14.397 & -3.753 & -3.852 & (10) \\
\hline $\mathrm{Al}_{2} \mathrm{Si}_{4} \mathrm{O}_{10}(\mathrm{OH})_{2}($ pyrophyllite $)+6 \mathrm{H}^{+}=2 \mathrm{Al}^{+3}+4 \mathrm{H}_{2} \mathrm{O}+4 \mathrm{SiO}_{2}(\mathrm{aq})$ & -1.724 & -9.733 & -9.809 & $(10)$ \\
\hline $\begin{array}{l}\mathrm{K}_{0.6} \mathrm{Mg}_{0.25} \mathrm{Al}_{2.3} \mathrm{Si}_{3.5} \mathrm{O}_{10}(\mathrm{OH})_{2}(\mathrm{illite})+8 \mathrm{H}^{+}=0.25 \mathrm{Mg}^{+2}+0.6 \mathrm{~K}^{+}+2.3 \mathrm{Al}^{+3}+ \\
\text { 3.5 } \mathrm{SiO}_{2}(\mathrm{aq})+5 \mathrm{H}_{2} \mathrm{O}\end{array}$ & 9.0260 & -4.6120 & -4.6120 & (13) \\
\hline $\begin{array}{l}\mathrm{K}_{0.33} \mathrm{Al}_{2.33} \mathrm{Si}_{3.67} \mathrm{O}_{10}(\mathrm{OH})_{2}(\text { Beidellite- } \mathrm{K})+7.32 \mathrm{H}^{+}=0.33 \mathrm{~K}^{+}+2.33 \mathrm{Al}^{+3}+3.67 \\
\mathrm{SiO}_{2}(\mathrm{aq})+4.66 \mathrm{H}_{2} \mathrm{O}\end{array}$ & 5.252 & -6.559 & -6.644 & $(10)$ \\
\hline $\begin{array}{l}\mathrm{K}_{0.33} \mathrm{Mg}_{0.33} \mathrm{Al}_{1.67} \mathrm{Si}_{4} \mathrm{O}_{10}(\mathrm{OH})_{2}(\text { Montmorillonite- } \mathrm{K})+6 \mathrm{H}^{+}=0.33 \mathrm{Mg}^{+2}+0.33 \mathrm{~K}^{+}+ \\
1.67 \mathrm{Al}^{+3}+4 \mathrm{H}_{2} \mathrm{O}+4 \mathrm{SiO}_{2}(\mathrm{aq})\end{array}$ & 2.102 & -5.766 & -5.839 & $(10)$ \\
\hline
\end{tabular}

(1) Haar et al.(1984); (2) Tagirov and Schott (2001); (3) Shock et al. (1997); (4) Sverjensky et al. (1997); (5) Ho et al., (2000); (6) McCollom and Shock (1997); (7)Wagman et al. (1982), $200{ }^{\circ} \mathrm{C}, \mathrm{P}_{\text {sat }}$; (8) Assumed log $\mathrm{K}$ as same as Na species; (9) Shock and Koretsky (1995); (10) Holland and Powell (1998); (11) Hemingway et al. (1991) for boehmite; (12) Robie and Hemingway (1995), $200{ }^{\circ} \mathrm{C}, \mathrm{P}_{\text {sat }}$; (13) Wolery (1978), $200{ }^{\circ} \mathrm{C}, \mathrm{P}_{\text {sat }}$. 
Table 13. Saturation indices calculation for sandstone experiment \#1.

\begin{tabular}{lrrrr}
\hline Minerals & $48(\mathrm{~h})$ & $144(\mathrm{~h})$ & $336(\mathrm{~h})$ & $552(\mathrm{~h})$ \\
\hline Quartz & -0.61 & -0.33 & -0.25 & -0.22 \\
Microcline & 0.19 & 1.04 & 2.27 & 1.70 \\
Albite & -4.05 & -3.71 & -2.24 & -3.27 \\
Diaspore & 1.13 & 0.94 & 2.04 & 1.05 \\
Boehmite & 0.91 & 0.72 & 1.82 & 0.83 \\
Kaolinite & 1.58 & 1.77 & 4.11 & 2.21 \\
Muscovite & 3.98 & 4.45 & 7.87 & 5.33 \\
Paragonite & -0.51 & -0.54 & 3.12 & 0.12 \\
Pyrophyllite & -0.10 & 0.65 & 3.14 & 1.31 \\
Calcite & 7.78 & 8.14 & 8.05 & 8.62 \\
Anorthite & -1.87 & -1.33 & 0.93 & -0.40 \\
Magnesite & 7.95 & 8.45 & 8.43 & 9.06 \\
Illite & 0.54 & 1.33 & 4.06 & 2.26 \\
Beidellite-K & -0.50 & 0.15 & 2.96 & 0.89 \\
Montmorillonite-K & -1.25 & -0.21 & 1.89 & 0.69 \\
\hline
\end{tabular}

\subsubsection{Batch experiment 2: Navajo sandstone dissolution in acidic brine.}

The second Navajo Sandstone dissolution experiment is a batch experiment at $200{ }^{\circ} \mathrm{C}$ and 300 Bars without the presence of $\mathrm{CO}_{2}$ (aq). Four grams of Navajo sandstone are reacted with 40 grams $200 \mathrm{mmol} / \mathrm{kg} \mathrm{KCl}$ solution at $\mathrm{pH} 2.8\left(25^{\circ} \mathrm{C}\right)$. The solution chemistry results are presented in Tables 14 and 15. During the experiment, dissolved $\mathrm{K}^{+}$and $\mathrm{Cl}^{-}$concentrations remain relatively constant (Table 14). Dissolved $\mathrm{SiO}_{2}$ continuously increases, reaching $4.93 \mathrm{mmol} / \mathrm{kg}$ at $696 \mathrm{~h}$ and then approaches steady-state. The sandstone dissolves much faster in this experiment than in Experiment $\# 1$ because the initial pH of experiment $\# 2\left(2.8\right.$ at $\left.25^{\circ} \mathrm{C}\right)$ is much lower than that of experiment \#1 (4.1 at $\left.25^{\circ} \mathrm{C}\right)$. The release of $\mathrm{SiO}_{2}$ is possibly due to both dissolution of feldspars (albite, plagioclase, and anorthite; see SI calculations below) and the conversion of smectite to illite. Dissolved $\mathrm{Al}^{3+}$ reaches a maximum value of $0.14 \mathrm{mmol} / \mathrm{kg}$ at $24 \mathrm{~h}$ and decreases thereafter. The dissolved concentrations of $\mathrm{Mg}^{2+}$ and $\mathrm{Ca}^{2+}$ also increase with time. $\mathrm{Mg}^{2+}$ and $\mathrm{Ca}^{2+}$ are probably from $\mathrm{K}^{+}$cation exchange with $\mathrm{Mg}^{2+}$ and $\mathrm{Ca}^{2+}$ in smectite. $\mathrm{pH}$ values increase rapidly with reaction progress during the first $360 \mathrm{~h}$ and remain almost constant during the rest of the reaction time. Generally, the dissolved concentrations of most minor and trace elements approach steady-state values within the first 24 hours (Table 15). Fe, $\mathrm{Sr}$ and $\mathrm{Ba}$ are probably from $\mathrm{K}^{+}$cation exchange with $\mathrm{Fe}, \mathrm{Sr}$ and $\mathrm{Ba}$ in smectite.

SEM images show that after reaction with acidic brine, the dissolution features are much more intensive than in experiment \#1. Although the surface of K-feldspar grains used as starting material have some rounded and angular pits (Fig. 20a), those observed on K-feldspar after reaction are more numerous and deep (Fig. $22 \mathrm{~h}$ and $22 \mathrm{i}$ ) and sometimes with dissolution features in the pits (Fig. 22i). The development of dissolution features (pits, steps and channels) shows that the dissolution is heterogeneous (e.g., Fig. 22e-i). The smectite coatings remain, indicating that the chemical reactions did not remove coatings (Fig. 22a). Abundant clay minerals adhere to 
quartz and K-feldspars after the reaction and stretch across pores and open fractures. The smooth, flaky illite/smectite fills the pore and bridges particles (e.g., Figs. 22c and 22d). Illite, as interwoven ribbons, displays intergrowth with the smectite (Fig. 22b). No carbonate minerals are found.

Table 14. Time-dependent changes in the composition of major dissolved species in aqueous fluid coexisting with Navajo sandstone at $200{ }^{\circ} \mathrm{C}$ and 300 bars. The overall analytical error for dissolved species is $\pm 5 \%$.

\begin{tabular}{|c|c|c|c|c|c|c|c|c|c|c|}
\hline Sample & Time & $\mathrm{K}^{+}$ & $\mathrm{SiO}_{2}$ & $\mathrm{Al}^{+3}$ & $\mathrm{Na}^{+}$ & $\mathrm{Mg}^{2+}$ & $\mathrm{Ca}^{2+}$ & $\mathrm{Cl}^{-}$ & & $\mathrm{H}$ \\
\hline & (h) & \multicolumn{7}{|c|}{$(\mathrm{mmol} / \mathrm{kg})$} & $25^{\circ} \mathrm{C}$ & In-situ* \\
\hline starting & 0 & 203.86 & - & - & 0.11 & - & - & 188.25 & 2.8 & 2.9 \\
\hline$\# 1$ & 24 & 197.28 & 1.63 & 0.14 & 1.42 & 0.77 & 1.15 & 184.91 & 3.6 & 3.4 \\
\hline$\# 2$ & 168 & 200.07 & 4.00 & 0.03 & 0.14 & 1.03 & 1.17 & 182.93 & 4.6 & 4.1 \\
\hline$\# 3$ & 360 & 193.05 & 4.55 & 0.02 & 0.21 & 1.01 & 1.20 & 202.32 & 4.9 & 4.3 \\
\hline$\# 4$ & 696 & 208.74 & 4.93 & 0.02 & 0.30 & 1.36 & 1.28 & 200.96 & 5.0 & 4.3 \\
\hline \#5 & 1392 & 198.67 & 4.49 & 0.02 & 0.24 & 0.86 & 1.09 & 198.78 & 5.1 & 4.2 \\
\hline
\end{tabular}

*In-situ $\mathrm{pH}$ is calculated from distribution of aqueous species calculations at the temperature and pressure of the experiment using constraints imposed by major element concentrations and $\mathrm{pH}$ values measured at $25^{\circ} \mathrm{C}$.

Table 15. Time-dependent changes in the composition of minor and trace dissolved species in aqueous fluid coexisting with Navajo sandstone at $200{ }^{\circ} \mathrm{C}$ and 300 bars. The overall analytical error for concentration measurements is $\pm 5 \%$.

\begin{tabular}{ccccccccccccc}
\hline Sample & $\mathrm{Li}$ & $\mathrm{Cr}$ & $\mathrm{Fe}$ & $\mathrm{Mn}$ & $\mathrm{Co}$ & $\begin{array}{c}\mathrm{Ni} \\
(\mathrm{ppm})\end{array}$ & $\mathrm{Cu}$ & $\mathrm{Zn}$ & $\mathrm{Rb}$ & $\mathrm{Sr}$ & $\mathrm{Cs}$ & $\mathrm{Ba}$ \\
\hline Starting & - & - & - & - & - & - & - & 0.04 & 0.12 & 0.01 & 0.01 & 0.04 \\
$\# 1$ & - & - & 1.57 & 0.94 & - & - & 6.07 & 0.52 & 0.12 & 0.54 & 0.01 & 0.41 \\
$\# 2$ & - & - & 0.10 & 0.75 & - & 0.09 & 0.10 & 0.20 & 0.13 & 0.54 & 0.01 & 0.30 \\
$\# 3$ & 0.10 & - & 0.12 & 0.37 & 0.02 & 0.21 & 0.14 & 0.06 & 0.14 & 0.53 & 0.01 & 0.30 \\
$\# 4$ & - & - & 0.34 & 0.28 & - & - & 0.11 & 0.05 & 0.18 & 0.56 & 0.02 & 0.45 \\
$\# 5$ & 0.24 & - & 0.27 & 0.28 & - & - & 0.2 & 0.32 & 0.15 & 0.55 & 0.01 & 0.35 \\
\hline
\end{tabular}

Mineral saturation indices (SI) calculations (Table 16) show that the solution is supersaturated with respect to microcline and undersaturated with respect to albite during the entire course of the reaction; the solution changes from undersaturated ( $24 \mathrm{~h})$ to slightly supersaturated (168 h) with respect to anorthite; the solution is supersaturated with respect to boehmite, muscovite, paragonite and pyrophyllite; slightly undersaturated (before $24 \mathrm{~h}$ ) to supersaturated with respect to quartz $(168 \mathrm{~h})$. As for the clay minerals, the solution is supersaturated with respect to kaolinite, illite, beidellite- $K$ and montmorillonite- $K$ during the entire course of the reaction. 

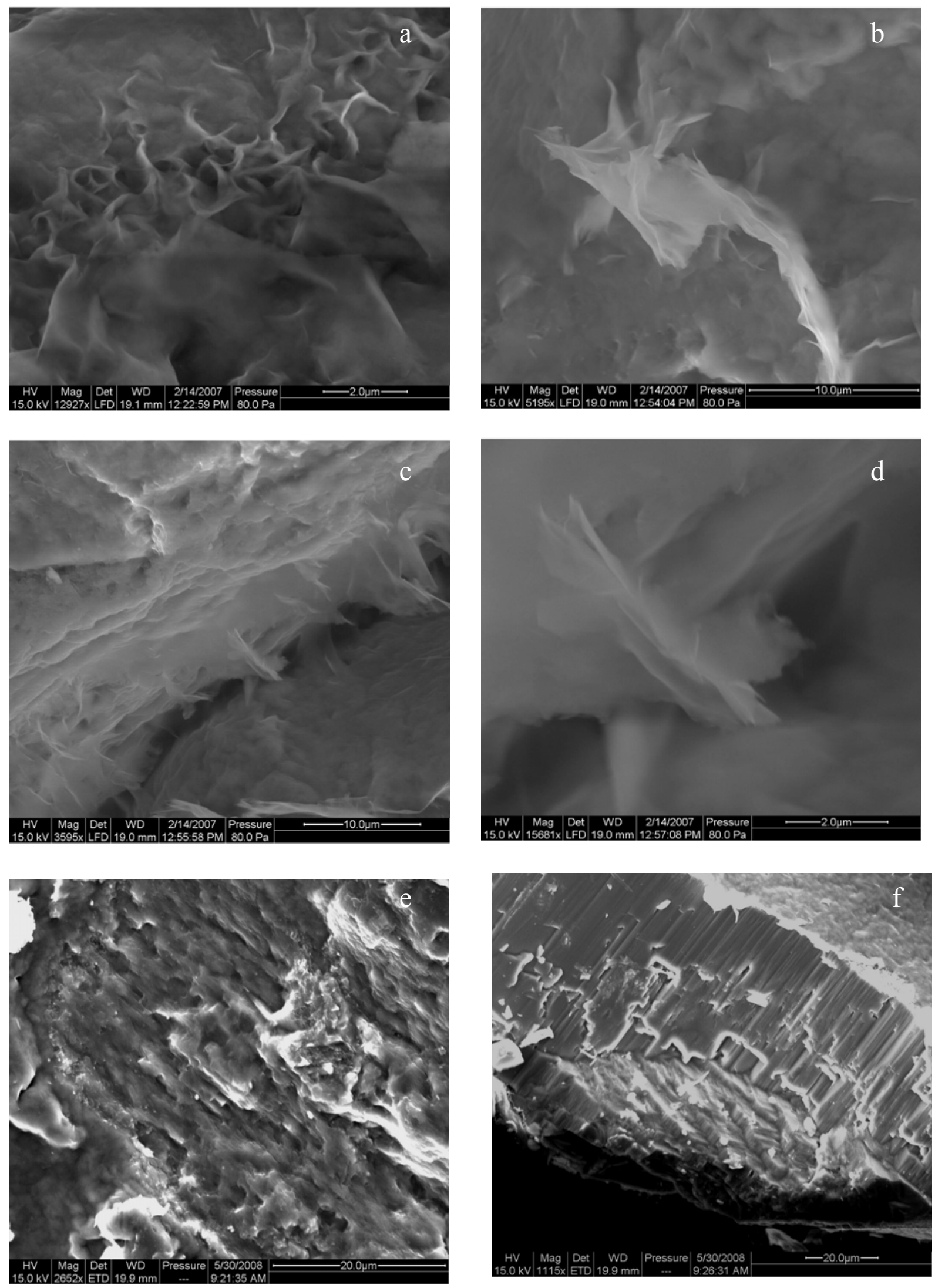

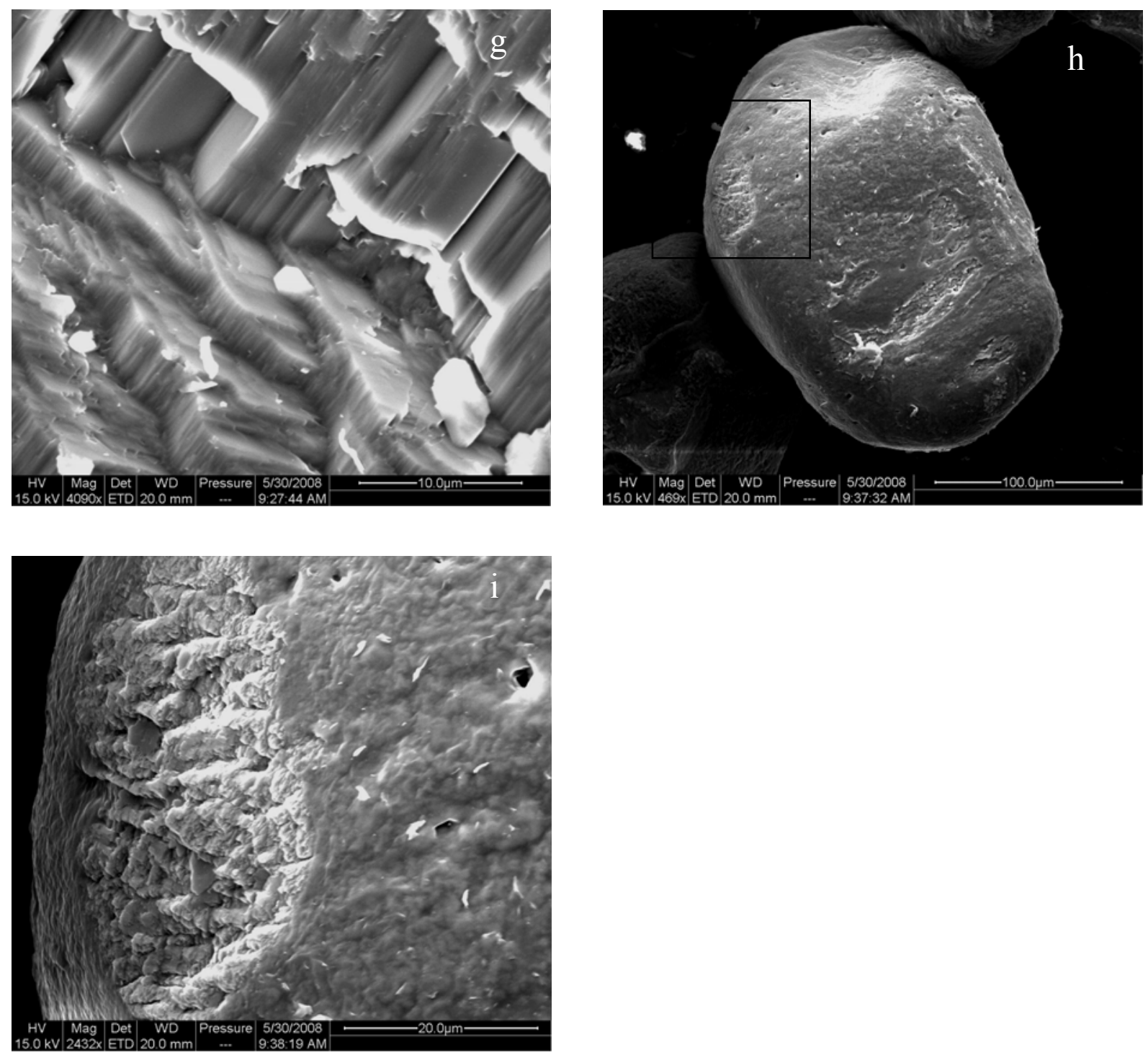

Fig. 22. (a) SEM microphotograph shows secondary minerals on a quartz surface. The cornflakeshaped smectites at the upper part have a similar morphology to those in Zhu et al. (2006). These smectites possibly existed before the dissolution experiment. However, the smooth, flaky illite/smectite at the lower part is much larger and is possibly formed during the dissolution experiment. (b) SEM microphotograph shows secondary minerals on another quartz surface. The secondary minerals are likely to be illite (ribbons) intergrown with smectite, which suggests the progressive illitization of smectite; (c) SEM microphotograph shows secondary minerals (illite/smectite) filling the pore and bridging two quartz particles. Some smooth, flaky illite/smectite minerals are visible (indicated by arrows). These minerals are also likely to be newly formed; (d) Enlarged view of an area outlined by the black box in (c), showing one of the particle-bridging secondary minerals. The smooth, flaky mineral $(\sim 5 \mu \mathrm{m})$ is illite/smectite; (e) SEM microphotograph shows dissolution features on a K-feldspar particle; (f) SEM microphotograph shows dissolution features on a K-feldspar particle; (g) Close-up of dissolution features on the K-feldspar particle showed in (f). The feldspar has angular and prismatic features at the micron scale. Dissolution steps are visible along the c-axis of the cleavages and dissolution 
channels along the b-axis of the cleavages; (h) SEM microphotograph shows surface morphology of a K-feldspar particle after reaction; (i) Enlarged view of an area outlined by the black box in (h), showing dissolution feature in an etch pit.

Table 16. Saturation indices calculation.

\begin{tabular}{lrrrrr}
\hline Minerals & $24(\mathrm{~h})$ & $168(\mathrm{~h})$ & $360(\mathrm{~h})$ & $696(\mathrm{~h})$ & $1392(\mathrm{~h})$ \\
\hline Quartz & -0.36 & 0.04 & 0.10 & 0.14 & 0.09 \\
Microcline & 0.59 & 2.24 & 2.38 & 2.51 & 2.30 \\
Albite & -2.92 & -2.29 & -1.96 & -1.70 & -1.99 \\
Diaspore & 2.57 & 2.30 & 2.09 & 2.09 & 2.12 \\
Boehmite & 2.35 & 2.08 & 1.87 & 1.87 & 1.89 \\
Kaolinite & 4.97 & 5.24 & 4.92 & 4.99 & 4.96 \\
Muscovite & 7.25 & 8.37 & 8.08 & 8.21 & 8.05 \\
Paragonite & 3.50 & 3.60 & 3.51 & 3.76 & 3.53 \\
Pyrophyllite & 3.78 & 4.86 & 4.65 & 4.79 & 4.68 \\
Anorthite & -1.49 & 0.18 & 0.29 & 0.36 & 0.08 \\
Illite & 2.99 & 4.59 & 4.50 & 4.67 & 4.42 \\
Beidellite-K & 3.18 & 4.27 & 4.04 & 4.17 & 4.05 \\
Montmorillonite-K & 0.69 & 2.59 & 2.65 & 2.83 & 2.55 \\
\hline
\end{tabular}

\subsubsection{Flow-through experiment: Navajo sandstone dissolution in acidic brine.}

The third Navajo Sandstone dissolution experiment is a flow-through experiment at $200{ }^{\circ} \mathrm{C}$ and 250 Bars. Five grams of Navajo sandstone are reacted with $200 \mathrm{mmol} / \mathrm{kg} \mathrm{KCl}$ fluid. The $\mathrm{KCl}$ fluid is acidified to $\mathrm{pH} 3.9$ before the experiment at ambient temperature and pressure by addition of dilute $\mathrm{HCl}$. The rate of fluid input is kept at $0.82 \mathrm{ml} / \mathrm{min}$ for the whole experiment of 23.5 hours. The results are presented in Table 17. During the experiment, dissolved $\mathrm{K}^{+}$and $\mathrm{Cl}^{-}$ concentrations remain relatively constant (Table 17). The dissolved concentrations of $\mathrm{Si}$ and $\mathrm{Mg}$ approach steady-state values within the first 4 hours. $\mathrm{pH}$ values remained essentially the same with reaction progress.

Table 17. Time-dependent changes in the composition of major dissolved species in aqueous fluid coexisting with Navajo sandstone at $200{ }^{\circ} \mathrm{C}$ and 250 bars. The overall analytical error for dissolved species is $\pm 5 \%$.

\begin{tabular}{ccccccccccc}
\hline $\begin{array}{c}\text { Sample Time } \\
\text { (hours) }\end{array}$ & $\mathrm{K}^{+}$ & $\mathrm{SiO}_{2}$ & $\mathrm{Al}^{3+}$ & $\begin{array}{c}\mathrm{Na}^{+} \\
\text {(mmol/kg) }\end{array}$ & $\mathrm{Mg}^{2+} \mathrm{Ca}^{2+}$ & $\mathrm{Cl}^{-}$ & \multicolumn{2}{c}{$\begin{array}{c}\mathrm{pH} \\
25^{\circ} \mathrm{C}\end{array}$} \\
\hline$\# 1$ & 0.5 & 196.35 & 0.02 & - & 0.22 & 0.01 & 0.02 & 201.43 & 5.2 & 5.2 \\
$\# 2$ & 4 & 209.45 & 0.26 & - & 0.02 & 0.04 & - & 198.79 & 5.3 & 5.2 \\
$\# 3$ & 13 & 207.01 & 0.24 & - & 0.05 & 0.03 & 0.01 & 197.34 & 5.3 & 5.2 \\
$\# 4$ & 23.5 & 204.83 & 0.18 & - & 0.30 & 0.05 & 0.02 & 196.78 & 5.5 & 5.3 \\
\hline
\end{tabular}

*In-situ $\mathrm{pH}$ is calculated from distribution of aqueous species calculations at the temperature and pressure of the experiment using constraints imposed by major element concentrations and $\mathrm{pH}$ values measured at $25^{\circ} \mathrm{C}$. 
SEM images show that after dissolution in a flow-through reactor, the dissolution features are less intensive than those in experiment \#2. The K-feldspar grains partially preserved the "three layer onion" structure of unreacted sandstones (see Fig. 23d). Newly formed smectite/illite, observed in the products of experiment \#1 are also found (e.g., Figs. 23b, 23e, 23e, and 23f).

The Al concentrations are under the detection limit. Saturation states for aluminosilicates are thus unknown. The solution is also undersaturated with respect to quartz (Table 18).

Table 18. Saturation indices calculation.

\begin{tabular}{lcccc}
\hline Minerals & $0.5(\mathrm{~h})$ & $4(\mathrm{~h})$ & $13(\mathrm{~h})$ & $23.5(\mathrm{~h})$ \\
\hline Quartz & -2.25 & -1.14 & -1.17 & -1.30 \\
\hline
\end{tabular}

Dissolution rate (as per mole of $\mathrm{Si}$ ) was calculated according to the following formula based on time-series Si concentrations:

$$
r=\frac{\left(C_{\text {out }}\right)\left(\vartheta_{0}\right)\left(10^{-6}\right)}{M \delta A}
$$

where $C_{\text {out }}$ is the output concentration of $\mathrm{Si}$ in $\mathrm{mg} / \mathrm{L}, \vartheta_{0}$ is the input flow rate in $\mathrm{ml} / \mathrm{s}, M$ is the atomic weight $(\mathrm{g} / \mathrm{mol})$ of Si, $\delta$ is the stoichiometric coefficient of Si (set to 1), and $A$ is the total surface area in $\mathrm{m}^{2}$. The average dissolution rate is $6.85 \times 10^{-10} \mathrm{~mol} \mathrm{~m}^{-2} \mathrm{~s}^{-1}$ as per mole of Si (Table 19).

Table 19. Dissolution rates of Navajo sandstone in the experiment with flow-through apparatus at $200{ }^{\circ} \mathrm{C}$ and 250 bars. The total surface area of 5 gram Navajo sandstone is assumed to be 3.5 $\mathrm{m}^{2}$. The input flow rate is $0.82 \mathrm{ml} / \mathrm{min}$.

\begin{tabular}{cc}
\hline Sample & Dissolution Rate $\left(\mathrm{mol} \mathrm{m}^{-2} \mathrm{~s}^{-1}\right)^{*}$ \\
\hline$\# 1$ & $7.81 \times 10^{-11}$ \\
$\# 2$ & $1.02 \times 10^{-9}$ \\
$\# 3$ & $9.37 \times 10^{-10}$ \\
$\# 4$ & $7.03 \times 10^{-10}$ \\
\hline Average & $6.85 \times 10^{-10}$ \\
\hline
\end{tabular}

As per mole of $\mathrm{Si}$ 

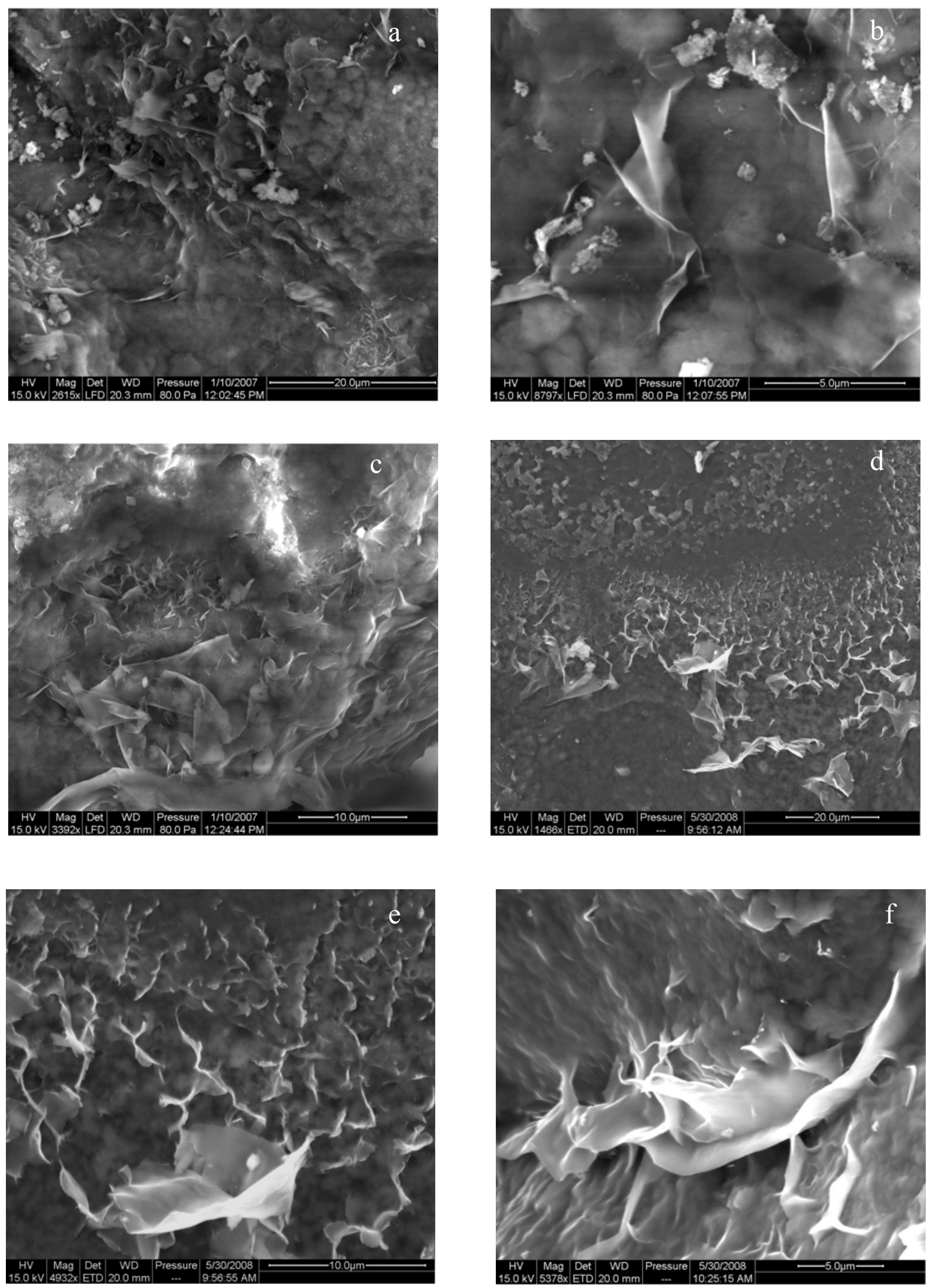
Fig. 23. (a) SEM microphotograph shows the quartz surface after reaction. Secondary minerals (possibly illite) are visible; (b) Enlarged view of upper right corner of (a). The large smooth, flaky smectite/illite is possibly formed during the dissolution experiment; (c) SEM microphotograph shows the quartz surface after the hydrothermal experiment. Similar to Fig. 4a, the corn-flake-shaped smectites in the upper part have a similar morphology as those in Zhu et al. (2006). These smectites possibly existed before the hydrothermal reaction. However, the smooth, flaky smectite/illite at the lower part is much larger than authigenic smectite in the center of the image and possibly formed during the dissolution experiment; (d) SEM microphotograph shows the "three layer onion" described in Zhu et al. (2006). The grain is K-feldspar, and is coated with a layer of kaolinite. Smectite in turn covers kaolinite; (e) Close-up of the smectite shown in (d). The smooth, flaky, slightly crenulated smectite/illite at the lower part is much larger than authigenic smectite shown in this image and is possibly formed during the dissolution experiment; (f) The smooth, flaky illite/smectite with scalloped, curled edges is much larger than authigenic smectite shown in this image and is possibly formed during the dissolution experiment.

\subsubsection{Fate of $\mathrm{CO}_{2}$ and sandstone responses to $\mathrm{CO}_{2}$ injection.}

In experiment $\# 1$, the $\mathrm{CO}_{2}$ is mainly trapped in aqueous solution as carbonate species. Carbonate mineral precipitation is observed with SEM, and supported by calculated SI values, but the amount precipitated is small judging from the decrease of $\mathrm{CO}_{2}$ in solution chemistry data and absence in XRD patterns. However, in actual injection cases, the carbonate concentrations would be much higher and the reaction time would be in years to thousands of years. The formation of carbonate minerals (i.e., mineral trapping) is thus expected and thermodynamically favored.

The dissolution of silicates is likely to increase porosity, but permeability is probably inversely affected by the formation of clay minerals in the pore space. Open, interconnected pores lined with ribbons, coating grain surfaces and also bridging the pores between grains will create permeability barriers to fluid flow (e.g., Figs. 21a, 21b, 21c, 21e, 22c, 22d, and 23f). Neasham (1977) demonstrated that this clay texture severely reduces permeability without affecting porosity.

\section{Conclusions}

We conducted seven (7) laboratory experiments to simulate the interactions of minerals and rocks after $\mathrm{CO}_{2}$ is injected into geological formations for the carbon sequestration program. Four (4) experiments used the mineral feldspar, which is usually a few percent to a few tens of percent in geological formations designated for $\mathrm{CO}_{2}$ storage. Three (3) experiments used the Navajo (Nugget) sandstone, a sandstone designated for field injection test in the BigSky regional project partnership, and a geological formation deemed to have large potential for $\mathrm{CO}_{2}$ storage in the western USA. 
An experimental design allowed the collection of water samples during experiments in situ and thus prevented back reactions. Analysis of the in situ samples delineated the temporal evolution of aqueous chemistry because of $\mathrm{CO}_{2}$-rock-water interactions. The solid products of the experiments were retrieved at the end of the experimental run, and analyzed with a suite of advanced analytical and electron microscopic techniques (i.e., atomic resolution transmission electron microscopy (TEM), scanning electron microscopy (SEM), electron microprobe, X-ray diffraction, X-ray photoelectron spectroscopy (XPS)). As a result, the research project probably has produced one of the best data sets for $\mathrm{CO}_{2}$-rock-water interactions in terms of both aqueous solution chemistry and solid characterization.

The single mineral (feldspar) experiments were intended to answer some basic scientific questions (the kinetic rate law, nature of the coupling between dissolution and precipitation reactions), which has broad applications to the carbon sequestration program as well as energy sciences (diagenesis in oil and gas exploration, enhanced oil recovery). The targeted geological formation (Navajo Sandstone) experiments were intended to answer region-specific questions whether chemical reactions after $\mathrm{CO}_{2}$ is injected into the targeted geological formation need to be of concern.

The following are the major findings from this project:

1. The project generated a large amount of experimental data that is central to evaluating $\mathrm{CO}_{2}$-water-rcok interactions and providing ground truth to predictive models, which have been used and will inevitably be increasingly more used in carbon sequestration.

2. Results from the feldspar experiments demonstrated stronger coupling between dissolution and precipitation reactions. We show that the partial equilibrium assumption did not hold in the feldspar hydrolysis experiments (Zhu and Lu, submitted, Appendix A-2). The precipitation of clay minerals influenced dissolution of primary silicate in a much stronger way as previously envisioned. Therefore, our experimental data indicated a much more complex chemical kinetics as it has been applied to carbon sequestration program in terms of preliminary predictive models of $\mathrm{CO}_{2}$-rock-water interactions. Adopting this complexity (strong coupling) may influence estimates of mineral trapping and porosity/permeability for geological carbon sequestration. In general, our knowledge of the coupling of different reactions is poor, and we must consider the uncertainties resulting from our poor knowledge on this regard.

3. Our experimental results concur with previous findings that the role of dissolved $\mathrm{CO}_{2}$ is mostly to acidify the brine, but not change the mechanisms of reactions. This conclusion is based on careful paired experiments with and without $\mathrm{CO}_{2}$.

4. We observed strong chemical reactions between $\mathrm{CO}_{2}$ acidified brine with the Navajo sandstone. The laboratory experiments were conducted at a higher temperature $\left(200{ }^{\circ} \mathrm{C}\right)$ than that in the field $\left(\sim 90^{\circ} \mathrm{C}\right)$ in order to induce measurable chemical changes in the laboratory. However, field conditions are more acidic and reaction time is much longer (1000 years versus $10-80$ days in the laboratory). Therefore, the conclusions on extensive reactions are relevant. We observed extensive dissolution of feldspars, and 
precipitation of clay minerals. However, the clay coatings on the sediment grains, which was a concern whether it would come off and clog the pores, were intact. The precipitation of secondary minerals can potentially clog pore throats and reduce permeability. Additional experiments are needed to quantify the amount of secondary mineral precipitation, and the results of batch reactor experiments need to be compared to the flooded core experiments to be performed by NETL in house.

Throughout this project, we endeavored to disseminate the research results in a timely fashion and worked closely with NETL in-house research and communicated our results to the regional partnerships. To reach the carbon capture and storage (CCS) community in the broadest possible sense, we have published our first set of experimental results in a highly regarded journal Chemical Geology, with proper DOE approval, acknowledgement to this grant, and required disclaimer (see Appendix A-1). Note the publication at this peer-referred journal had gone through rigorous peer review.

A second publication on geochemical modeling interpretation of experimental data was submitted to the top ranked journal Geochimica et Cosmochimica Acta, and is currently under peer review.

A third publication on the experimental data of Navajo sandstone was completed and submitted to the Journal of Greenhouse Gas Control for peer review.

In January 2008, the PI (Dr. Chen Zhu) gave presentations at the Lawrence Berkeley National Laboratory and Lawrence Livermore National Laboratory. Most in the audience are funded by DOE to work on various carbon sequestration programs. Presentations are also given at the annual convention of the American Association of Petroleum Geologist (2008), Seventh Annual Conference Carbon Capture \& Sequestration Conference (2008), Geological Society of America annual meeting (2008), and AAPG Eastern Section Meeting (2007). Because a large amount of experimental data were generated and have not been fully digested, some of our findings will be further analyzed and ideas will be refined. We will continue to communicate the results to the carbon sequestration community through open literature publications and presentations at national and international meetings with proper acknowledgement of this grant. 


\section{References Cited}

Bauluz, B., Peacor, D. R., and Ylagan, R. F., 2002. Transmission electron microscopy study of smectite illitization during hydrothermal alteration of a rhyolitic hyaloclastite from Ponza, Italy. Clays and Clay Minerals 50, 157-173.

Benezeth, P., Palmer, D. A., Anovitz, L. M., and Horita, J., 2007. Dawsonite synthesis and reevaluation of its thermodynamic properties from solubility measurements: Implications for mineral trapping of CO2. Geochimica Et Cosmochimica Acta 71, 4438-4455.

Blum, A. and Stillings, L., 1995. Feldspar dissolution kinetics. In: Brantley, S. L. (Ed.), Chemical Weathering Rates of Silicate Minerals. Mineralogical Society of America, Washington DC.

Bradley, R. S., 2001. Many citations support global warming trend. Science 292, 2011.

Busenberg, E. and Clemency, C. V., 1976. The dissolution kinetics of feldspars at $25^{\circ} \mathrm{C}$ and 1 atm $\mathrm{CO}_{2}$ partial pressure. Geochimica et Cosmochimica Acta 40, 41-49.

Carey, J. W., Lichtner, P. C., Rosen, E. P., Ziock, H. J., and Guthrie, G. D. J., 2003. Geochemical mechanisms of serpentine and olivine carbonationSecond annual conference on carbon sequestration, Alexandria, Virginia.

Celik, M., Karakaya, N., and Temel, A., 1999. Clay minerals in hydrothermally altered volcanic rocks, Eastern Pontides, Turkey. Clays and Clay Minerals 47, 708-717.

Crowley, T. J., 2000. Causes of climate change over the past 1000 years. Science 289, 270-277.

Cuadros, J. and Linares, J., 1996. Experimental kinetic study of the smectite-to-illite transformation. Geochimica et Cosmochimica Acta 60, 439-453.

DOE, 1999. Carbon Sequestration Research and Development. U.S. Department of Energy.

Drever, J. I. and Clow, D. W., 1995. Weathering rates in catchments. In: Brantley, S. L. (Ed.), Chemical Weathering Rates of Silicate Minerals. Mineralogical Society of America.

Duan, Z., Sun, R., Zhu, C., and Chou, I., 2006. An improved model for the calculation of CO2 solubility in aqueous solutions containing $\mathrm{Na}+, \mathrm{K}+, \mathrm{Ca} 2+, \mathrm{Mg} 2+, \mathrm{Cl}-$, and $\mathrm{SO} 42-$. Marine Chemistry 98, 131-139.

Dulaney, A. R., 1989. The geochemistry of the N-aquifer system, Navajo and Hopi Indian Reservations, Northeastern Arizona. Master thesis, 209p, Northern Arizona University.

Fu, Q., Lu, P., Konishi, H., Dilmore, R., Xu, H., Seyfried, W. E., Jr., and Zhu, C., 2008. Alkalifeldspar dissolution and secondary mineral precipitation in batch systems: 1 . New experiment data at $200^{\circ} \mathrm{C}$ and 300 bars. Chemical Geology. accepted September 2008.

Gunter, W. D., Perkins, E. H., and Hutcheon, I., 2000. Aquifer disposal of acid gases: modelling of water-rock reactions for trapping of acid wastes. Applied Geochemistry 15, 1085-1095.

Gunter, W. D., Wiwchar, B., and Perkins, E. H., 1997. Aquifer disposal of $\mathrm{CO}_{2}$-rich greenhouse gases: extension of the time scale of experiment for $\mathrm{CO} 2$-sequestering reactions by geochemical modeling. Mineralogy and Petrology 59, 121-140.

Haar, L., Gallagher, J. S., and Kell, G. S., 1984. NBS/NRC Steam Tables: Thermodynamic and Transport Properties and Computer Programs for Vapor and Liquid States of Water in SI Units. Hemisphere Publishing Corporation, New York, 320p.

Hammerstad, T., 2000. Carbon dioxide storage prized. www.statoil.com.

Harshbarger, J. W., Repenning, C. A., and Irwin, J. H., 1957. Stratigraphy of the Uppermost Triassic and the Jurassic Rocks of the Navajo Country. . U.S. Geological Survey Professional Paper 291. 
Hay, R. L., 1963. Zeolitic Weathering in Olduvai Gorge, Tanganyika. Geological Society of America Bulletin 74, 1281-1286.

Helgeson, H. C., 1968. Evaluation of irreversible reactions in geochemical processes involving minerals and aqueous solutions-1. Thermodynamic relations. Geochimica et Cosmochimica Acta 32, 853-877.

Helgeson, H. C., 1971. Kinetics of mass transfer among silicates and aqueous solutions. Geochimica et Cosmochimica Acta 35, 421-469.

Helgeson, H. C., 1979. Mass transfer among minerals and hydrothermal solutions. In: Barnes, H. L. (Ed.), Geochemistry of Hydrothermal Ore Deposits. John Wiley \& Sons, New York.

Helgeson, H. C., Garrels, R. M., and Mackenzie, F. T., 1969. Evaluation of irreversible reactions in geochemical processing involving minerals and aqueous solutions- II. Applications. Geochimica et Cosmochimica Acta 33, 455-481.

Hellevang, H., Aagaard, P., Oelkers, E. H., and Kvamme, B., 2005. Can dawsonite permanently trap $\mathrm{CO}_{2}$ ? Environmental Science \& Technology 39, 8281-8287.

Hellmann, R., Penisson, J.-M., Hervig, R. L., Thomassin, J.-H., and Abrioux, M.-F., 2003. An EFTEM/HRTEM high-resolution study of the near surface of labradorite feldspar altered at acid pH: evidence for interfacial dissolution-reprecipitation. Physics and Chemistry of Minerals 30, 192-197.

Hellmann, R., Penisson, J. M., Hervig, R. L., Thomassin, J. H., and Abrioux, M. F., 2004. Chemical alteration of feldspar: a comparative study using SIMS and HRTEM/EFTEM. Water-rock Interaction 11, Saratoga Springs, New York, 753-756, Saratoga Springs, New York.

Hemingway, B. S., Robie, R. A., and Apps, J. A., 1991. Revised values for the thermodynamic properties of boehmite, $\mathrm{AIO}(\mathrm{OH})$, and related species and phases in the system Al-H-O. American Mineralogist, 445-457.

Herzog, H., Drake, E., and Adams, E., 1997. Reuse, and Storage Technologies for Mitigating Global Climate Change.

Ho, P. C., Bianchi, H., Palmer, D. A., and Wood, R. H., 2000. Conductivity of dilute aqueous electrolyte solutions at high temperatures and pressures using a flow cell. Journal of Solution Chemistry 29, 217-235.

Holdren, G. R. and Berner, R. A., 1979. Mechanism of feldspar weathering-I. Experimental studies. Geochimica et Cosmochimica Acta 43, 1161-1171.

Holland, T. J. B. and Powell, R., 1998. An internally consistent thermodynamic data set for phases of petrological interest. Journal of Metamorphic Geology 16, 309-343.

Hovorka, S. D., Knox, P. R., Holtz, M. H., YEH, J. S., Fouad, K., and Sakurai, S., 2002. Sequestration pilot site in the texas gulf cosast, USAGSA annual meeting \& exposition abstracts with programs, Denver,Colorada.

Hower, J., Eslinger, E. V., Hower, M. E., and Perry, E. A., 1976. Mechanism of burial metamorphism of argillaceous sediments: Mineralogical and chemical evidence. Geological Society of America Bulletin 87, 725 -737.

Johnson, J. W. and Nitao, J. J., 2002. Reactive transport modelling of geologic CO2 sequestration at Sleipner. Proc. Sixth Intl. Conf. Greenhouse Gas Control Technologies (GHGT-6). Kyoto, Japan, Oct 1-4, 2002, v. 1, p. 327-332.

Johnson, J. W., Nitao, J. J., Steefel, C. I., and Knauss, K. G., 2001. Reactive transport modelling of geologic $\mathrm{CO}_{2}$ sequestration in saline aquifers: the influence of intra-aquifer shales and the relative effectiveness of structural, solubility, and mineral trapping during prograde 
and retrograde sequestration: Proc. First Natl. Conf. Carbon Seqn., Washington, DC, May $14-17,2001,60 \mathrm{p}$.

Johnson, J. W., Nitao, J. J., Steefel, C. I., and Knauss, K. G., 2002. Reactive transport modeling of geologic $\mathrm{CO}_{2}$ sequestration. GSA annual meeting \& exposition abstracts with programs. 34, 174-1.

Johnson, J. W., Oelkers, E. H., and Helgeson, H. C., 1992. SUPCRT92 - A software package for calculating the standard molal thermodynamic properties of minerals, gases, aqueous species, and reactions from 1-bar to 5000 -bar and $0^{\circ} \mathrm{C}$ to $1000^{\circ} \mathrm{C}$. Computers and Geosciences 18, 899-947.

Kaszuba, J. P., 2007. Dawsonite reactivity in geological carbon seqeustration. National Carbon Sequestration Conference.

Kaszuba, J. P., Janecky, D. R., and Snow, M. G., 2003. Carbon dioxide reaction processes in a model brine aquifer at $200^{\circ} \mathrm{C}$ and 200 bars: implications for geologic sequestration of carbon. Applied Geochemistry 18, 1065-1080.

Kaszuba, J. P., Janecky, D. R., and Snow, M. G., 2005. Experimental evaluation of mixed fluid reactions between supercritical carbon dioxide and $\mathrm{NaCl}$ brine: Relevance to the integrity of a geologic carbon repository. Chemical Geology 217, 277-293.

Keller, W. D., Reynolds, R. C., and Inoue, A., 1986. Morphology of clay minerals in the smectite-to-illite conversion series by scanning electron microscopy. Clays and Clay Minerals 34, 187-197.

Lagache, M., 1976. New data on the kinetics of the dissolution of alkali feldspars at $200^{\circ} \mathrm{C}$ in $\mathrm{CO}_{2}$ charged water. Geochimica et Cosmochimica Acta 40, 157-161.

Lasaga, A. C., 1998. Kinetic Theory in the Earth Sciences. Princeton University Press, New York.

Lee, M. and Parsons, I., 1995. Microtextural controls of weathering of perthitic alkali feldspars. Geochimica et Cosmochimica Acta 55, 4465-4488.

McCollom, T. M. and Shock, E. L., 1997. Geochemical constraints on chemolithoautotrophic metabolism by microorganisms in seafloor hydrothermal systems. Geochimica et Cosmochimica Acta 61, 4375-4391.

Moore, J., Adams, M., Allis, R., Lutz, S., and Rauzi, S., 2005. Mineralogical and geochemical consequences of the long-term presence of $\mathrm{CO} 2$ in natural reservoirs: An example from the Springerville-St. Johns Field, Arizona, and New Mexico, USA. Chem. Geol. 217, 365-385.

Nadeau, P. H., 1998. An experimental study of the effects of diagenetic clay minerals on reservoir sands. Clays and Clay Minerals 46, 18-26.

Nadeau, P. H., Peacor, D. R., Yan, J., and Hillier, S., 2002. I-S precipitation in pore space as the cause of geopressuring in Mesozoic mudstones, Egersund Basin, Norwegian Continental Shelf. American Mineralogist 87, 1580-1589.

Neasham, J. W., 1977. Applications of scanning electron microscopy to characterization of hydro carbon-braring rocks. Scanning Electron Microscopy 10, 101-108.

Nesbitt, H. W. and Skinner, W. M., 2001. Early development of Al, Ca, and Na compositional gradients in labradorite leached in $\mathrm{pH} 2 \mathrm{HCI}$ solutions. Geochimica et Cosmochimica Acta 65, 715-727.

NRC, 2003. Novel approaches to carbon management separation, capture, sequestration, and conversion to useful products workshop report. National Research council, Washington,DC. 
Nugent, M. A., Brantley, S. L., Pantano, C. G., and Maurice, P. A., 1998. The influence of natural mineral coatings on feldspar weathering. Nature 395, 588-591.

Parkhurst, D. L. and Appello, A. A. J., 1999. User's guide to PHREEQC (version 2)-a computer program for speciation, batch-reaction, one dimensional transport, and inverse geochemical modeling.Water-Resource Investigation Report. U.S. Geological Survey.

Perkins, E. H., Gunter, W. D., Hutcheon, I., Shevalier, M., Durocher, K., and Emberley, S., 2002. Geochemical modelling and monitoring of $\mathrm{CO}_{2}$ storage at the weyburn site, Saskatchewan, CanadaGSA annual meeting \& exposition abstracts with programs, Denver, Colorado.

Rafal'skiy, R. P., Prisyagina, N. I., and Kondrushin, I. B., 1990. Reaction of microcline-perthite with aqueous solutions at 150 and $250^{\circ} \mathrm{C}$. Geochemistry International 27, 56-66.

Robie, R. A. and Hemingway, B. S., 1995. Thermodynamic Properties of Minerals and Related Substances at 298.15 K and 1Bar (105 Pascals) Pressures and at Higher Temperatures. U.S. Geological Survey Bulletin 2131, 461p.

Seyfried, W. E., Jr., Janecky, D. R., and Berndt, M. E., 1987. Rocking autoclaves for hydrothermal experiments; II, The flexible reaction-cell system. In: Barnes, H. L. e. (Ed.), Hydrothermal Experimental Techniques. Wiley-Intescience.

Shock, E. L. and Helgeson, H. C., 1988. Calculation of the thermodynamic and transport properties of aqueous species at high pressures and temperatures: Correlation algorithms for ionic species and equation of state predictions to $5 \mathrm{~kb}$ and $1000^{\circ} \mathrm{C}$. Geochimica et Cosmochimica Acta 52, 2009-2036.

Shock, E. L., Helgeson, H. C., and Sverjensky, D. A., 1989. Calculations of the thermodynamic and transport properties of aqueous species at high pressures and temperatures: Standard partial molal properties of inorganic neutral species. Geochimica et Cosmochimica Acta 53, 2157-2183.

Shock, E. L. and Koretsky, C. M., 1995. Metal-Organic Complexes in Geochemical Processes Estimation of Standard Partial Molal Thermodynamic Properties of Aqueous Complexes between Metal-Cations and Monovalent Organic-Acid Ligands at High-Pressures and Temperatures. Geochimica Et Cosmochimica Acta 59, 1497-1532.

Shock, E. L., Oelkers, E. H., Sverjensky, D. A., Johnson, J. W., and Helgeson, H. C., 1992. Calculation of thermodynamic and transport properties of aqueous species at high pressures and temperatures. Effective electrostatic radii, dissociation constants and standard partial molal properties to $1000^{\circ} \mathrm{C}$ and $5 \mathrm{~kb}$. J. Chem. Soc. London, Faraday Transactions 88, 803-826.

Shock, E. L., Sassani, D. C., Willis, M., and Sverjensky, D. A., 1997. Inorganic species in geologic fluids: Correlations among standard molal thermodynamic properties of aqueous ions and hydroxide complexes. Geochimica et Cosmochimica Acta 61, 907-950.

Strazisar, B. R., Zhu, C., and Hedges, S. W., 2006. Preliminary modeling of the long-term fate of $\mathrm{CO}_{2}$ following injection into deep geological formations. Environmental Geosciences 13, $1-15$.

Sverjensky, D. A., Shock, E. L., and Helgeson, H. C., 1997. Prediction of the thermodynamic properties of aqueous metal complexes to 1000 degrees $\mathrm{C}$ and $5 \mathrm{~kb}$. Geochimica et Cosmochimica Acta 61, 1359-1412.

Tagirov, B. and Schott, J., 2001. Aluminum speciation in crustal fluids revisited. Geochimica et Cosmochimica Acta 65, 3965-3992. 
Wagman, D. D., Evans, W. H., Parker, V. B., Schumm, R. H., Halow, I., Bailey, S. M., Churney, K. L., and Nuttall, R. L., 1982. The NBS tables of chemical thermodynamic properties, selected values for inorganic and c1 and c2 organic substances in SI units. J. Phys. Chem. Ref. Data 11, supp. 2, 392p.

White, A. F., 1995. Chemical weathering of silicate minerals in soils. In: Brantley, S. L. (Ed.), Chemical Weathering Rates of Silicate Minerals. Mineralogical Society of America.

White, S. P., Allis, R. G., Moore, J., Chidsey, T., Morgan, C., Gwynn, W., and Adams, M., 2005. Simulation of reactive transport of injected $\mathrm{CO}_{2}$ on the Colorado Plateau, Utah, USA. Chem. Geol. 217, 387-405.

Wildenborg, A. F. B. and van der Meer, L. G. H., 2002. The use of oil, gas and coal fields as $\mathrm{CO}_{2}$ sinks.Intergovernmental Panel on Climate Change, Working Group III: Mitigation of Climate Change, Workshop on Carbon Dioxide Capture and Storage, Regina, Canada, pp. 61-78.

Wolery, T. J., 1978. Some chemical aspects of hydrothermal processes at mid-oceanic ridges -A theoretical study. I. Basalt-sea water reaction and chemical cycling between the oceanic crust and the oceans. II. Calculation of chemical equilibrium between aqueous solutions and minerals, Northwestern University, 263p.

$\mathrm{Xu}, \mathrm{T}$., Apps, J. A., and Pruess, K., 2003. Reactive geochemical transport simulation to study mineral trapping for $\mathrm{CO}_{2}$ disposal in deep arenaceous formations. J. Geophys. Res. 108(B2), 2071.

$\mathrm{Xu}, \mathrm{T} .$, Apps, J. A., and Pruess, K., 2004. Numerical simulation of $\mathrm{CO}_{2}$ disposal by mineral trapping in deep aquifers. Applied Geochemistry 19, 917-936.

Zerai, B., Saylor, B. Z., and Matisoff, G., 2006. Computer simulation of CO2 trapped through mineral precipitation in the Rose Run Sandstone, Ohio. Applied Geochemistry 21, 223240.

Zhu, C., 2005. In situ Feldspar Dissolution Rates in an Aquifer. Geochimica et Cosmochimica Acta 69, 1435-1453.

Zhu, C., Blum, A., and Veblen, D., 2004. Feldspar dissolution rates and clay precipitation in the Navajo aquifer at Black Mesa, Arizona, USA. In: Wanty, R. B. and Seal, R. R. I. Eds.)Proceedings of the Eleventh International Symposium on Water-Rock Interaction WRI-11. A.A. Balkema, Saratoga Springs, New York.

Zhu, C., Veblen, D. R., Blum, A. E., and Chipera, S. J., 2006. Naturally weathered feldspar surfaces in the Navajo Sandstone aquifer, Black Mesa, Arizona: Electron microscopic characterization. Geochimica et Cosmochimica Acta 70, 4600-4616. 


\section{Appendices}

A-1. Open literature publication in Chemical Geology

A-2. Manuscript submitted to Geochimica et Cosmochimica Acta

A-3. Manuscript submitted to Journal of Greenhouse Gas Control 


\title{
Coupled alkali-feldspar dissolution and secondary mineral precipitation in batch systems: 1 . New experiments at $200{ }^{\circ} \mathrm{C}$ and 300 bars
}

\author{
Qi Fu ${ }^{\text {a,* }}$, Peng Lu ${ }^{\text {b }}$, Hiromi Konishi ${ }^{\text {b,1 }}$, Robert Dilmore ${ }^{c}$, Huifang Xu ${ }^{\mathrm{d}}$, W.E. Seyfried Jr. ${ }^{\text {a }}$, Chen Zhu ${ }^{\mathrm{b}}$ \\ a Department of Geology and Geophysics, University of Minnesota, Minneapolis, MN 55455, USA \\ b Department of Geological Sciences, Indiana University, Bloomington, IN 47405, USA \\ c National Energy Technology Laboratory, U. S. Department of Energy, Pittsburgh, PA 15236, USA \\ d Department of Geology and Geophysics, University of Wisconsin-Madison, Madison, WI 53706, USA
}

\section{A R T I C L E I N F O}

\section{Article history:}

Received 18 February 2008

Received in revised form 15 September 2008

Accepted 16 September 2008

Available online xxxx

Editor: J. Fein

\section{Keywords:}

Feldspar

Kinetics

Dissolution

Precipitation

Secondary minerals

Mass transfer

\begin{abstract}
A B S T R A C T
Batch reactor experiments were conducted to assess perthitic alkali-feldspar dissolution and secondary mineral formation in an initially acidic fluid $(\mathrm{pH}=3.1)$ at $200{ }^{\circ} \mathrm{C}$ and 300 bars. Temporal evolution of fluid chemistry was monitored by major element analysis of in situ fluid samples. Solid reaction products were retrieved from two identical experiments terminated after 5 and 78 days. Scanning electron microscopy revealed dissolution features and significant secondary mineral coverage on feldspar surfaces. Boehmite and kaolinite were identified as secondary minerals by X-ray diffraction and transmission electron microscopy. Xray photoelectron spectroscopy analysis of alkali-feldspar surfaces before and after reaction showed a trend of increasing $\mathrm{Al} / \mathrm{Si}$ ratios and decreasing $\mathrm{K} / \mathrm{Al}$ ratios with reaction progress, consistent with the formation of boehmite and kaolinite.

Saturation indices of feldspars and secondary minerals suggest that albite dissolution occurred throughout the experiments, while K-feldspar exceeded saturation after $216 \mathrm{~h}$ of reaction. Reactions proceeded slowly and full equilibrium was not achieved, the relatively high temperature of the experiments notwithstanding. Thus, time series observations indicate continuous supersaturation with respect to boehmite and kaolinite, although the extent of this decreased with reaction progress as the driving force for albite dissolution decreased. The first experimental evidence of metastable co-existence of boehmite, kaolinite and alkali feldspar in the feldspar hydrolysis system is consistent with theoretical models of mineral dissolution/precipitation kinetics where the ratio of the secondary mineral precipitation rate constant to the rate constant of feldspar dissolution is well below unity. This has important implications for modeling the time-dependent evolution of feldspar dissolution and secondary mineral formation in natural systems.
\end{abstract}

(C) 2008 Elsevier B.V. All rights reserved.

\section{Introduction}

Silicate mineral dissolution and secondary mineral precipitation are integrated processes in chemical weathering and hydrothermal alteration of rocks. Numerous experiments have been conducted for measuring silicate mineral dissolution rates (Busenburg and Clemency, 1976; Holdren and Berner, 1979; Chou and Wollast, 1985; Knauss and Wolery, 1986; Nagy et al., 1991; Nagy and Lasaga, 1992; Burch et al., 1993; Gautier et al., 1994; Hellmann, 1994; Oelkers et al., 1994; Hellmann, 1995; Nagy, 1995; Stillings and Brantley, 1995; Brantley and Stillings, 1996). The primary focus

\footnotetext{
* Corresponding author. Tel.: +1 612624 9593; fax: +1 6126253819.

E-mail address: fuxx0033@umn.edu (Q.Fu).

Present address: Department of Geology and Geophysics, University of WisconsinMadison, Madison, WI 53706, USA.
}

of many of these studies, however, was to derive mineral dissolution rates from steady state chemical conditions. In such experiments, silicate minerals, mostly feldspars, are dissolved far from equilibrium and secondary mineral precipitation is avoided by adjusting the chemistry and rate of recirculation of the fluid phase. Results of these experiments have been enormously successful, providing a wealth of data on the rate and mechanism of mineral dissolution processes under a wide range of chemical and physical conditions.

Batch reactor experiments of feldspar hydrolysis, on the other hand, provide a different set of data, which address the broader context of congruency and incongruency, phase relations, mineral metastability, and interconnections between dissolution and precipitation reactions. Tremendous progress in our understanding of feldspar hydrolysis in closed systems has come from the seminal work by Helgeson and co-workers (Helgeson, 1968; Helgeson et al., 1969, 1970; Helgeson, 1971, 1972, 1974, 1979; Helgeson et al., 1984). While the first feldspar hydrolysis experiments conducted in batch 
reactors provided valuable information on the mechanism of feldspar dissolution, as summarized in Helgeson (1971) and Petrovic (1976), technological development of experimental design and apparatus has allowed the sampling of fluid co-existing with minerals at a wide range of temperatures and pressures (Seyfried et al., 1987). Furthermore, electron microscopy and surface analytical techniques have advanced significantly, which allow more accurate identification of secondary minerals, even when such phases exist on the nanometer size scale (Penn et al., 2001; Zhu et al., 2006).

Here we report results of alkali-feldspar dissolution experiments in well-mixed batch reactors that were performed at $200{ }^{\circ} \mathrm{C}$ and 300 bars in order to examine mineral dissolution and precipitation processes in moderately acidic fluids. Although dissolution reactions of single feldspars have been reported in the literature (Busenburg and Clemency, 1976; Holdren and Berner, 1979; Helgeson et al., 1984; Chou and Wollast, 1985; Knauss and Wolery, 1986; Wollast and Chou, 1992; Gautier et al., 1994; Hellmann, 1994; Oelkers et al., 1994; Hellmann, 1995; Stillings and Brantley, 1995; Brantley and Stillings, 1996; Hellmann and Tisserand, 2006), only a few experimental studies have been performed on feldspars with complex compositions (Morey and Fournier, 1961; Lagache, 1976; Rafal'skiy et al., 1990; Tsuchiya et al., 1995). The combination of time series monitoring of fluid chemistry and mineral analysis (scanning electron microscopy (SEM), high resolution transmission electron microscopy (HRTEM), X-ray diffraction (XRD), X-ray photoelectron spectroscopy (XPS), and electron microprobe analysis (EMPA)) at different reaction stages represents an insightful experimental strategy to assess geochemical controls on the temporal evolution of minerals and coexisting fluids. While this approach is relevant to mass transfer processes in a variety of natural and engineered hydrologic and hydrothermal rock-fluid systems, the experimental data are important in that they form a basis for evaluating a number of theories and hypotheses on the kinetics of water-rock interactions.

\section{Experiments}

Two batch experiments, with run times of 1872 h (78 days) and $120 \mathrm{~h}$ (5 days), involving perthitic alkali-feldspar dissolution in $\mathrm{K}$ bearing $(\sim 0.20 \mathrm{KCl} \mathrm{mol} / \mathrm{kg})$ fluid at $200{ }^{\circ} \mathrm{C}, 300$ bars were conducted at the University of Minnesota and National Energy Technology Laboratory (NETL), respectively. $40 \mathrm{~g} \mathrm{KCl}$ solution and $1.5 \mathrm{~g}$ alkalifeldspar were used for both experiments. Prior to the experiments, the starting fluid was acidified to $\mathrm{pH}=3.0$ by addition of dilute $\mathrm{HCl}$, so as to create initial conditions far from equilibrium.

"Orthoclase" crystals having an average size of $\sim 0.5 \mathrm{~cm}$ were obtained from WARD'S Natural Sciences Establishment. The crystals were ground with an agate mortar and pestle, and subsequently dry sieved to retain the size fraction between 50 and $100 \mu \mathrm{m}$. For the freshly ground material, there were a large number of submicron-tomicron size particles that adhered to the surface of large grains. To remove these particles, the feldspar sample was first ultrasonically "cleaned" in analytical grade acetone, and then repeatedly rinsed with deionized water, prior to drying at $105^{\circ} \mathrm{C}$.

A Beckman Coulter SA-3100 was used for BET surface area analysis of alkali-feldspar samples before experiments. The instrument was calibrated before and after measurements, using NIST reference material 1900, a silicon nitrite powder with surface area of $2.85 \mathrm{~m}^{2} / \mathrm{g}$. Multipoint $\mathrm{N}_{2}$ gas adsorption isotherms were measured to obtain the specific surface area of $0.13 \mathrm{~m}^{2} / \mathrm{g}( \pm 5 \%)$ for the alkali-feldspar reactant.

The alkali-feldspar and acidified $\mathrm{KCl}$ solution were loaded into a flexible $\mathrm{Au} / \mathrm{Ti}$ reaction cell and placed in a steel-alloy autoclave following procedures described in Seyfried et al. (1987). The reaction cell allows sampling of aqueous fluid from the ongoing reaction at constant temperature and pressure. Thus, internally filtered fluid samples could be recovered from the reaction cell any time during an experiment.

Fluid samples were analyzed for major dissolved components. Anion analyses were conducted on a Dionex ICS-2000 ion chromatography (IC) system composed of an AS 19 column (4 mm ID) and an ASRS self-regenerating suppressor ( $4 \mathrm{~mm}$ ID). $\mathrm{KOH}$ solution was used as the eluent at flow rate of $1 \mathrm{ml} / \mathrm{min}$. Gradient eluent concentrations were programmed as follows: $4 \mathrm{mM}$ for $30 \mathrm{~min}, 10 \mathrm{mM}$ for $30 \mathrm{~min}$ and $25 \mathrm{mM}$ for $15 \mathrm{~min}$. The column temperature and cell temperature were constant at $30{ }^{\circ} \mathrm{C}$. The injection volume of each sample was $50.0 \mu \mathrm{l}$. Uncertainties in reported concentrations were estimated to be within $\pm 1 \%$.

Major cation analyses were conducted on a Thermo Elemental PQ ExCell quadrupole inductively coupled plasma mass spectrometer (ICP-MS) with a simultaneous analog and pulse counting detector. System calibration was accomplished by using NIST traceable single or multi-element standard solutions. For each sample, standards and blanks were repeated 5 times to determine the mean and standard deviation for each selected elemental mass. All standards, blanks, and samples were atomized and introduced into a standard Meinhardt nebulizer by a free aspiration rate of approximately $1 \mathrm{ml} / \mathrm{min}$. All elements were measured on the most appropriate mass by peak hopping with dwell times of approximately $35 \mu$ ser mass and 25-50 mass sweeps per replicate. The clean matrix acid was used to flush the system for a minimum time of $65 \mathrm{~s}$ to prevent carryover between samples. Uncertainties for all elements were estimated to be within $\pm 1 \%$.

The $\mathrm{pH}$ of all fluid samples was measured at ambient laboratory conditions using a THERMO combination glass $\mathrm{pH} /$ reference electrode and Accumet AR-20 meter. Prior to measurement, the pH electrode was calibrated with NIST pH standard buffers, 4.0 and 7.0. Replicate measurements of fluid samples from the experiments indicate an uncertainty of the reported $\left.\mathrm{pH}_{(25}{ }^{\circ} \mathrm{C}\right)$ value of \pm 0.02 units.

Mineral products were retrieved from both experiments when the runs were terminated after 78 days and 5 days. A variety of microscopic and analytical techniques were used to characterize solid reactants and experimental products, including XRD, EMPA, SEM, HRTEM, and XPS. Powder XRD analysis was carried out using a PANalytical X'Pert PRO Theta-Theta multipurpose diffractometer, equipped with a $\mathrm{Cu}$ anode operated at $45 \mathrm{kV}$ and $40 \mathrm{~mA}$, a divergent beam monochromator, and an X'Celerator detector. The scanning angle $(2 \theta)$ ranged from 10.010 to $99.968^{\circ}$, with scan steps of $0.033^{\circ}$. Secondary minerals were analyzed on zero background quartz plate.

The chemical composition of alkali-feldspar lamellae (Table 1) was determined by wavelength dispersive EMPA using a CAMECA SX50. Operation accelerating voltage was $15 \mathrm{kV}$, while beam current and beam size were $15 \mathrm{nA}$ and $1 \mu \mathrm{m}$, respectively. The structural

\section{Table 1}

Electron microprobe analysis (EMPA) results ${ }^{\mathrm{a}}$ of Na-rich laminae, K-rich laminae and whole alkali-feldspar grains

\begin{tabular}{llrrrrrrr}
\hline & Oxide & \multicolumn{1}{c}{$\mathrm{SiO}_{2}$} & $\mathrm{Al}_{2} \mathrm{O}_{3}$ & $\mathrm{Na}_{2} \mathrm{O}$ & \multicolumn{1}{c}{$\mathrm{K}_{2} \mathrm{O}$} & $\mathrm{FeO}$ & $\mathrm{CaO}$ & Total \\
\hline Na-rich laminae & wt.\% & 68.20 & 20.45 & 10.49 & 0.18 & 0.09 & 0.83 & 100.22 \\
& S.D. & 0.03 & 0.05 & 0.18 & 0.06 & 0.03 & 0.04 & \\
& $N^{\mathrm{c}}$ & 2.96 & 1.04 & 0.95 & 0.01 & 0.00 & 0.04 & 5.00 \\
& S. D. & 0.00 & 0.00 & 0.02 & 0.00 & 0.00 & 0.00 & \\
K-rich laminae & w.\% & 63.69 & 18.95 & 1.66 & 13.82 & 0.05 & 0.00 & 98.16 \\
& S.D. & 0.53 & 0.25 & 0.42 & 0.87 & 0.04 & 0.00 & \\
& $N$ & 2.96 & 1.04 & 0.15 & 0.85 & 0.00 & 0.00 & 5.00 \\
& S.D. & 0.01 & 0.01 & 0.04 & 0.05 & 0.00 & 0.00 & \\
Alkali-feldspar & wt.\% & 64.71 & 19.91 & 3.17 & 12.21 & & & \\
& $N$ & 2.95 & 1.07 & 0.28 & 0.71 & & & \\
\hline
\end{tabular}

a Each result reflects the average value of 5-10 measurements.

b S.D. = Standard deviation.

$N=$ the number of cations per 8 oxygen atoms. 
formula for K-rich and Na-rich phases based on 8 oxygens is $\mathrm{K}_{0.85} \mathrm{Na}_{0.15} \mathrm{Al}_{1.04} \mathrm{Si}_{2.96} \mathrm{O}_{8}$ and $\mathrm{K}_{0.01} \mathrm{Na}_{0.95} \mathrm{Ca}_{0.04} \mathrm{Al}_{1.04} \mathrm{Si}_{2.96} \mathrm{O}_{8}$, respectively.

SEM analysis was conducted with a Quanta 400 Field Emission Gun (FEG). The Energy Dispersive X-ray Spectrometer (EDS) system has an EDAX thin window and CDU LEAP detector. The low energy X-ray detection with FEG provided high spatial resolution for microanalysis down to $\sim 0.1 \mu \mathrm{m}^{2}$.

A JEOL 1010 transmission electron microscope operated at $100 \mathrm{kV}$ and a JEOL 2100F FEG Scanning Transmission Electron Microscope (STEM) with attached X-ray EDS and Gatan Imaging Filtering (GIF) system were used for analysis of reaction products. Thus, a fraction of the reaction products was immersed in ethanol and ultrasonically treated for several minutes. A small aliquot of the resulting suspension was mounted on a strip of holey-carbon film supported by a standard $\mathrm{Cu}$ TEM grid, prior to air-drying for approximately $10 \mathrm{~min}$.

In addition to detailed examination of the fresh and reacted alkalifeldspar using microscopy, XPS was also used to determine the surface chemistry of the feldspar before and after hydrothermal reaction. XPS spectra of mineral reactant and products from the 78-day experiment were collected on a Physical Electronics 5400 instrument, with nonmonochromatic $\mathrm{Mg} \mathrm{K} \alpha$ as the X-ray source, operated at $300 \mathrm{~W}$. Similar analyses from the 5-day experiment were collected on a PHI 5600ci instrument. This instrument made use of monochromatic $\mathrm{Al} \mathrm{K \alpha}$ as the Xray source, operated at $400 \mathrm{~W}$. In both cases, mineral samples were embedded on double-sided adhesive tape, which was then fixed to the sample holder of the respective instruments. The samples were degassed at $10^{-7}$ Torr, before achieving operating vacuum at $5 \times 10^{-8}$ Torr. The analysis area was $1 \mathrm{~mm}$ by $1.414 \mathrm{~mm}$, while the photoelectron take-off angle was $45^{\circ}$. Survey scans ( $0-1200 \mathrm{eV}$ binding energy) were performed first to determine the near-surface composition of the samples, followed by multiple repetitive scans over the energy regions of interest: $\mathrm{Si}_{2 \mathrm{p}}, \mathrm{O}_{1 \mathrm{~s}}$, $\mathrm{K}_{2 \mathrm{p} 3 / 2}$ and $\mathrm{Al}_{2 \mathrm{p}}$. Charge shifting of the analyzed photoelectrons was corrected by referencing a coexisting $C_{1 s}$ peak to $285.0 \mathrm{eV}$. Surface compositions of elements of interest were determined by analysis of peak areas taking explicit account of element specific atomic sensitivity factors.

Equilibrium constants for aqueous speciation calculations of fluid samples from experiments were calculated using a modified version of SUPCRT92 (Johnson et al., 1992). This code takes explicit account of recent revisions in keeping with the modified HKF equations of state for aqueous species (Shock and Helgeson, 1988; Shock et al., 1997; Sverjensky et al., 1997). Thermodynamic data for Al-bearing aqueous species, however, were from Tagirov and Schott (2001), while experimental data from Ho et al. (2001), Ho et al. (2000), and Ho et al. (1994) were used for $\left.\mathrm{HCl}_{(\mathrm{aq})}\right)^{\circ}, \mathrm{KCl}_{(\mathrm{aq})}$, and $\mathrm{NaCl}_{(\mathrm{aq})}{ }^{\circ}$, respectively. In practice, calculations needed to assess mineral saturation states, $\mathrm{pH}_{\text {in }}$ situ) (see below), and derive ion-activity diagrams were performed using the EQ3/6 computer code (Wolery and Daveler, 1992). Standard state thermodynamic properties for all Al-bearing minerals were from Holland and Powell (1998).

\section{Results}

\subsection{Cations, anions and dissolved $\mathrm{SiO}_{2}$}

Time series changes in fluid chemistry from both experiments are listed in Table 2 and illustrated in Fig. 1. As anticipated from the relative abundances of fluid and mineral components used for the experiments, dissolved $\mathrm{Cl}^{-}$concentrations remained relatively constant. The concentration of dissolved $\mathrm{K}^{+}$, however, tended to decrease, although the extent of this represents a small fraction of that initially available in the fluid (200 $\mathrm{mmol} / \mathrm{kg})$.

Changes in dissolved concentrations of $\mathrm{Na}^{+}, \mathrm{Ca}^{2+}, \mathrm{Al}^{3+}$ and $\mathrm{SiO}_{2}$ during the 78-day experiment were significant as alkali-feldspar dissolution proceeded. For example, dissolved $\mathrm{SiO}_{2}$ increased slowly to

\section{Table 2}

Time-dependent changes in the composition of major dissolved constituents in aqueous fluid coexisting with alkali-feldspar at $200{ }^{\circ} \mathrm{C}$ and 300 bars

\begin{tabular}{|c|c|c|c|c|c|c|c|c|c|}
\hline \multirow{2}{*}{$\begin{array}{l}\text { Sample } \\
\#\end{array}$} & \multirow{2}{*}{$\frac{\text { Time }}{\mathrm{H}}$} & $\mathrm{Cl}^{-}$ & $\mathrm{K}^{+}$ & $\mathrm{SiO}_{2}$ & $\mathrm{Na}^{+}$ & $\mathrm{Ca}^{2+}$ & $\mathrm{Al}^{3+}$ & \multirow{2}{*}{$\frac{\mathrm{pH}}{25^{\circ} \mathrm{C}}$} & \multirow{2}{*}{$\frac{\text { In situ } \mathrm{pH}}{200^{\circ} \mathrm{C}}$} \\
\hline & & \multicolumn{6}{|c|}{$\mathrm{mmol} / \mathrm{kg}$} & & \\
\hline \multicolumn{10}{|c|}{ 78-day experiment } \\
\hline & 0 & 198.3 & 204.0 & - & - & 3.72 & - & 3.0 & 3.1 \\
\hline 1 & 24 & 197.5 & 202.8 & 0.31 & 0.42 & 0.12 & 0.01 & 3.2 & 3.3 \\
\hline 2 & 216 & 198.7 & 201.1 & 1.46 & 1.13 & 0.21 & 0.003 & 3.5 & 3.6 \\
\hline 3 & 456 & 196.8 & 197.8 & 1.70 & 2.04 & 0.43 & 0.08 & 4.1 & 3.7 \\
\hline 4 & 816 & 197.9 & 204.3 & 1.35 & 1.86 & 0.16 & 0.03 & 4.2 & 4.0 \\
\hline 5 & 1368 & 199.5 & 197.0 & 4.18 & 3.72 & 0.30 & 0.01 & 4.9 & 4.5 \\
\hline 6 & 1872 & 199.4 & 196.5 & 3.75 & 1.91 & 0.35 & 0.001 & 4.9 & 4.7 \\
\hline \multicolumn{10}{|c|}{ 5-day experiment } \\
\hline 1 & 120 & n.a. ${ }^{a}$ & n.a. & 1.31 & 0.88 & 0.35 & 0.005 & n.a. & n.a. \\
\hline
\end{tabular}

a n.a. = not available.

approximately $1.70 \mathrm{mmol} / \mathrm{kg}$ after $456 \mathrm{~h}$ of reaction, then, surprisingly, decreased to $1.35 \mathrm{mmol} / \mathrm{kg}$ during the next $360 \mathrm{~h}$ of reaction, before again increasing to $4.18 \mathrm{mmol} / \mathrm{kg}$ at $1368 \mathrm{~h}$. During the remaining $504 \mathrm{~h}$ of the experiment, dissolved $\mathrm{SiO}_{2}$ decreased by $0.43 \mathrm{mmol} / \mathrm{kg}$ to a final value of $3.75 \mathrm{mmol} / \mathrm{kg}$ (Table 2). Dissolved concentrations of $\mathrm{Na}^{+}$and $\mathrm{Ca}^{2+}$ generally tracked with $\mathrm{SiO}_{2}$, suggesting the possible involvement of non-stoichiometric dissolution of minor accessory components in albite in the moderately acidic fluids. $\mathrm{Al}^{3+}$ concentration decreased sharply during the first $216 \mathrm{~h}$, then increased to $0.08 \mathrm{mmol} / \mathrm{kg}$ by $456 \mathrm{~h}$ before decreasing gradually throughout the remainder of the experiment. Dissolved concentrations of $\mathrm{Na}^{+}, \mathrm{Ca}^{2+}$, $\mathrm{Al}^{3+}$ and $\mathrm{SiO}_{2}$ from the 5-day experiment at $120 \mathrm{~h}$ were largely consistent with changes in fluid chemistry of the 78-day experiment at a similar time of reaction (Fig. 1 ).

\section{2. $p H$}

It is well known from results of numerous studies of reaction kinetics of silicate minerals in aqueous fluids that $\mathrm{pH}$ plays a particularly important role in the rate of mineral dissolution/ precipitation processes. This is the case during the present study as well. To examine $\mathrm{pH}$ effects, the $\mathrm{pH}$ value measured for the fluid sample at ambient conditions $\left(25^{\circ} \mathrm{C}, 1\right.$ bar) (bench $\mathrm{pH}$ ) was recalculated at experimental conditions $\left(200{ }^{\circ} \mathrm{C}, 300\right.$ bars $)$ by taking account of the effect of temperature and pressure on the distribution of aqueous species. Accordingly, pH (in situ) was calculated for each sample taken during the course of experiments (Table 2). Owing to the relatively low experimental temperature, however, $\mathrm{pH}$ (in situ) was close to that measured, with an offset that ranged from approximately 0.1 to 0.4 units. During the 78-day experiment, $\mathrm{pH}$ values increased from 3.1 to 4.7 (Table 2).

\subsection{Characterization of solid reactants and products}

SEM photomicrographs of alkali-feldspar following the 78-day (Fig. 2A, B) and 5-day experiments (Fig. 2C, D) reveal channels and etch pits demonstrating dissolution heterogeneity, with albite lamellae preferentially dissolved. The presence of these mineral dissolution features was less obvious from results of the 5-day experiment.

Secondary minerals, with cross sectional diameter $(d)$ of less than $0.5 \mu \mathrm{m}$ and height $(h)$ of approximately $0.1 \mu \mathrm{m}$, covered approximately $20 \%$ of total alkali-feldspar surface from the 78-day experiment. Alteration products also exhibited hexagonal shape. In the 5-day experiment, however, secondary minerals covered much less $(\sim 5 \%)$ of feldspar surface (Fig. 2). In both cases, secondary minerals were evenly distributed on the feldspar surface, suggesting no structural inheritance from the alkali-feldspar precursor. Feldspar dissolution and 


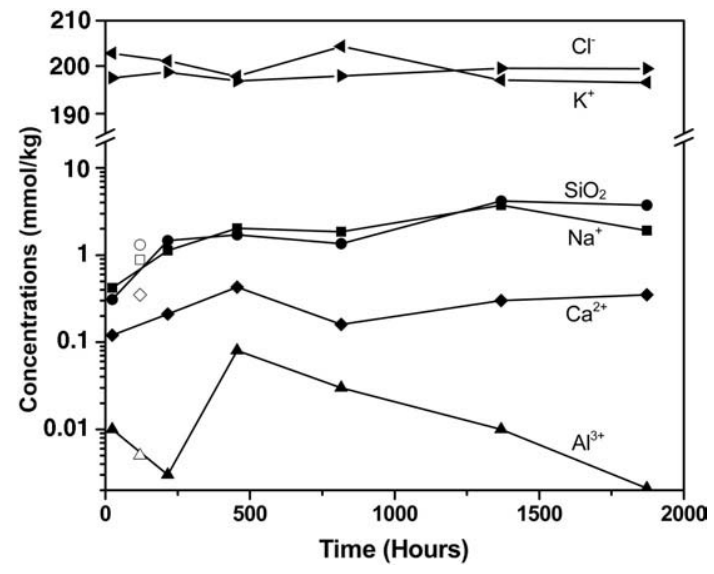

Fig. 1. Changes in the dissolved concentrations of selected aqueous constituents with time for the perthitic alkali-feldspar dissolution experiments at $200{ }^{\circ} \mathrm{C}$ and 300 bars. Dissolved concentrations of $\mathrm{K}^{+}, \mathrm{Cl}^{-}, \mathrm{Na}^{+}, \mathrm{Ca}^{2+}, \mathrm{Al}^{3+}$ and $\mathrm{SiO}_{2}$ for the 78-day experiment (solid symbols) and $\mathrm{Na}^{+}, \mathrm{Ca}^{2+}, \mathrm{Al}^{3+}$ and $\mathrm{SiO}_{2}$ for the 5 -day experiment (open symbols). Time series changes for $\mathrm{K}^{+}, \mathrm{Cl}^{-}$concentrations for the 5-day experiment are not available beyond the start of the experiment (Table 2).

secondary mineral formation are likely coupled in the overall mass transfer process.

XRD patterns of mineral products in both experiments showed the presence of kaolinite as well as boehmite (Fig. 3A, B). The high peak intensities of boehmite in the XRD patterns likely result from preferential orientation of boehmite, and are not directly proportional to abundance.

Due to relatively low magnification of the JEOL 1010 operated at low voltage $(100 \mathrm{kV})$, secondary mineral products (kaolinite and boehmite) from the 78-day experiment were manifest as a transparent phase with hexagonal shape and sizes of 200-300 nm (Fig. 4A). Selected area electron diffraction (SAED) patterns indicated that most alteration minerals are sheet silicates (Fig. 4B). The existence of boehmite crystals with rounded shapes, however, was confirmed by HRTEM observation with JEOL FEG 2100F (Fig. 4C). TEM images also showed "seesaw" edges of reacted alkali-feldspar from the experiment (Fig. 4D), suggesting preferential dissolution of Na lamellae, which is consistent with SEM observations. In the 5-day experiment, boehmite with distinctly sharp edges was observed on alkali-feldspar as the lone secondary mineral (Fig. 4E), which was confirmed by [010] SAED patterns, showing two dimensions for the $\mathrm{Al}$ octahedral structure (Fig. 4F). In contrast with boehmite from the 5-day experiment, boehmite following the 78-day experiment showed dissolution features characterized by more rounded grain boundaries (Fig. 4C).

Recently, Zhu et al. (2004a, 2006) observed an amorphous layer on naturally weathered feldspar, typically a few tens of nanometers thick. In the 78-day experiment, HRTEM observation also indicated that the alkali-feldspar grains were rimmed with an apparently amorphous layer (Fig. 4C). The amorphous nature of the edges was confirmed by the absence of electron diffraction pattern. It is still controversial whether an amorphous layer is caused by leaching (Nugent et al.,
A

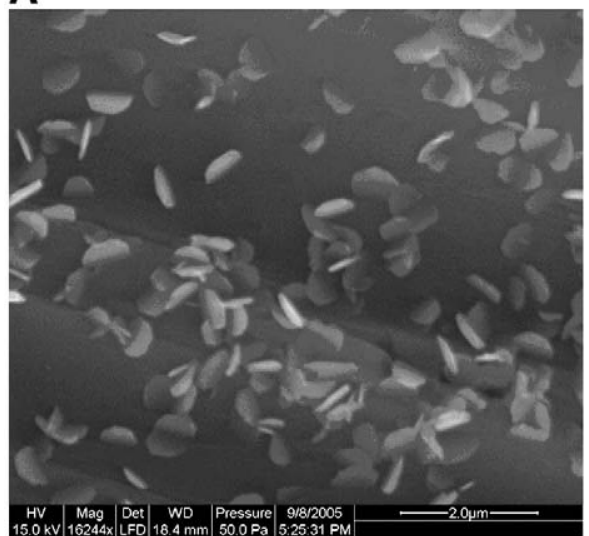

C

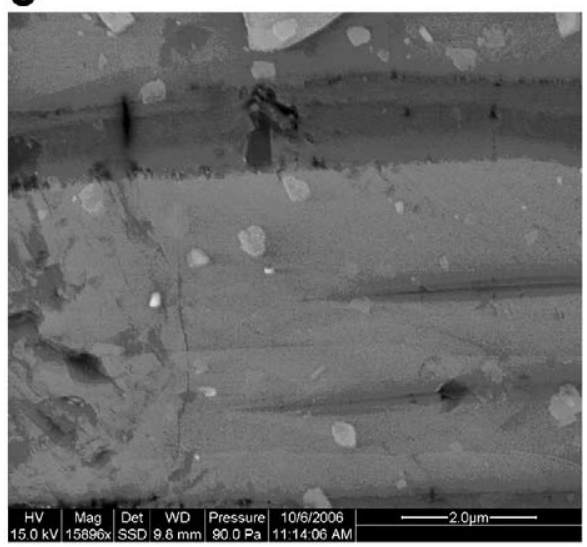

B

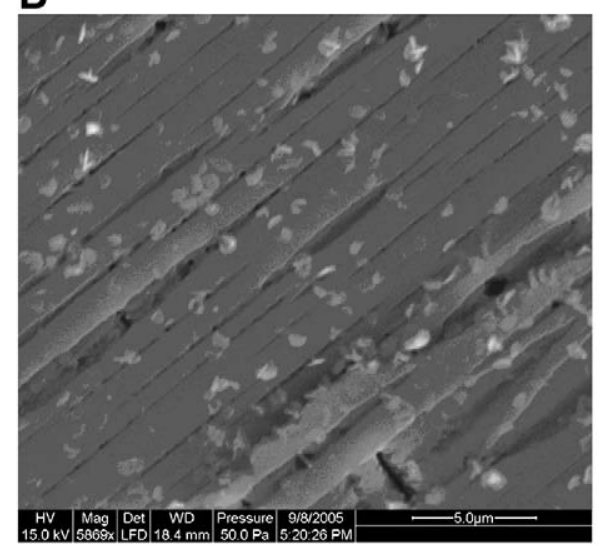

D

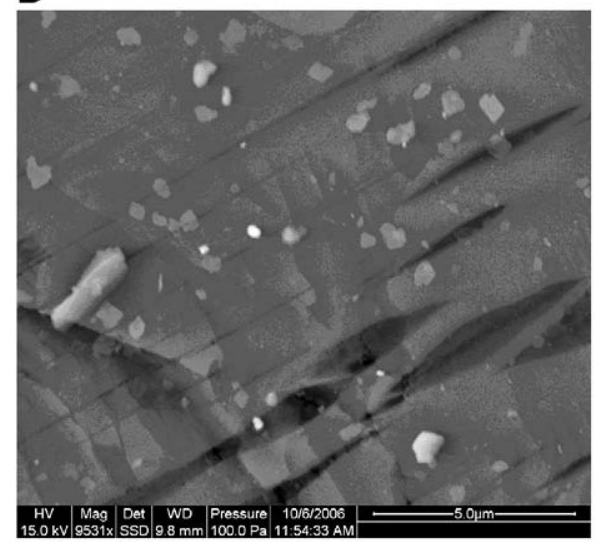

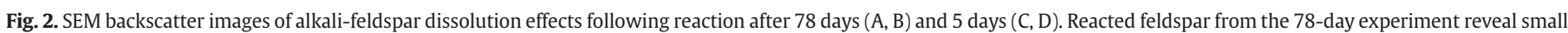

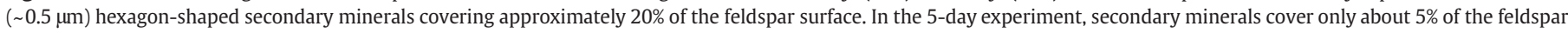

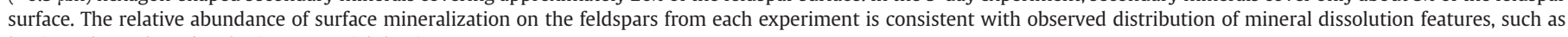
laminar channels and etch pits on Na-rich lamina. 
A

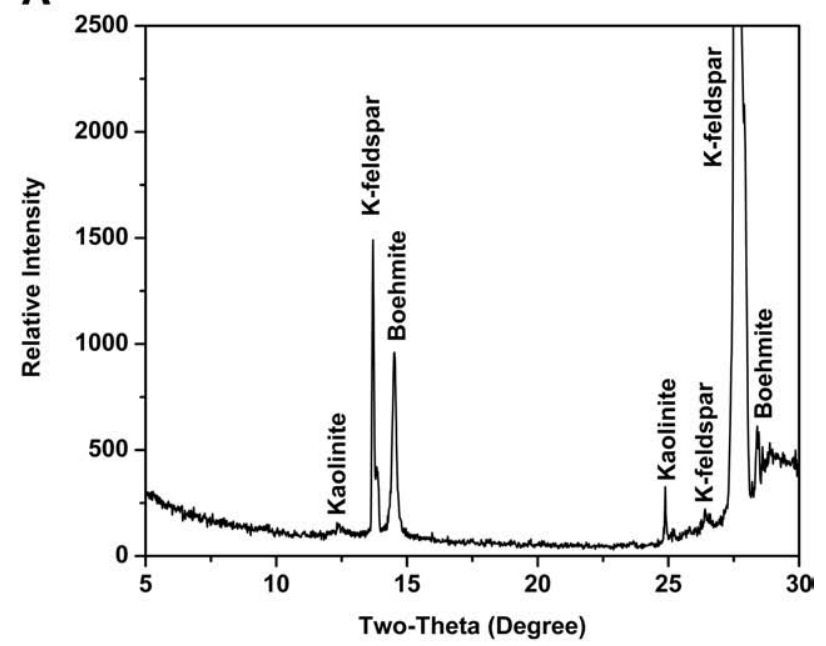

B

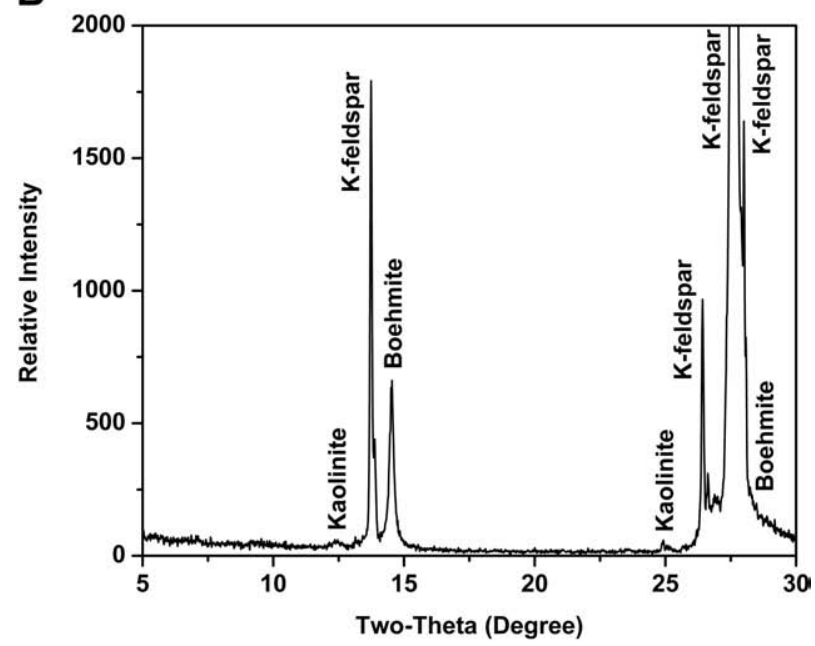

Fig. 3. X-ray diffraction patterns of mineral products following the 5-day experiment (A) and 78-day experiment (B). Kaolinite, boehmite, and K-feldspar were identified. The high peak intensity of boehmite is not a reflection of its abundance, but rather the result of preferential orientation.

1998; Nesbitt and Skinner, 2001) or is the result of silica reprecipitation effects (Hellmann et al., 2003, 2004).

Assuming that the majority of secondary minerals from the 78-day experiment are kaolinite (see below), we can estimate the abundance and surface area of this phase from dimensions determined from SEM examination. The surface area $\left(s_{\mathrm{kln}}\right)$ and volume $\left(v_{\mathrm{kln}}\right)$ of each kaolinite grain can be estimated geometrically assuming all crystals are hexagonal prisms, as follows:

$s_{\mathrm{kln}}=\frac{3 \sqrt{3}}{2}\left(\frac{d}{2}\right)^{2}$

$v_{\mathrm{kln}}=s_{\mathrm{kln}} \cdot h=\frac{3 \sqrt{3}}{2}\left(\frac{d}{2}\right)^{2} h$

Here we assume that the coverage $(x)$ of kaolinite is $~ 20 \%$ of total alkali-feldspar surface area (normalized surface area ( $\mathrm{SA}_{\text {alkali-feldspar }}$ ) times mass $\left(m_{\text {alkali-feldspar }}\right)$ ). The number $(i)$ of kaolinite grains produced by the end of the experiment is:

$i=\frac{x \cdot \mathrm{SA}_{\mathrm{alkali}-\mathrm{feldspar}} \cdot m_{\mathrm{alkali}-\mathrm{feldspar}}}{s_{\mathrm{kln}}}$.
The abundance of kaolinite $\left(m_{\mathrm{kln}}\right)$ can be calculated as follows:

$m_{\mathrm{kln}}=i \cdot v_{\mathrm{kln}} \cdot D_{\mathrm{kln}}=x \cdot h \cdot \mathrm{SA}_{\text {alkali-feldspar }} \cdot m_{\text {alkali-feldspar }} \cdot D_{\mathrm{kln}}$

where $D_{\text {kln }}$ is the density of kaolinite $\left(2.594 \mathrm{~g} / \mathrm{cm}^{3}\right)$. Thus, it follows that the normalized surface area of kaolinite is:

$\mathrm{SA}_{\mathrm{kln}}=\frac{x \cdot \mathrm{SA}_{\text {alkali-feldspar }} \cdot m_{\mathrm{alkali}-\mathrm{feldspar}}}{m_{\mathrm{kln}}}$

or

$\mathrm{SA}_{\mathrm{kln}}=\frac{1}{h \cdot D_{\mathrm{kln}}}$

Calculations indicate that at the end of the 78-day experiment, $10 \mathrm{mg}$ of kaolinite was produced, with a surface area of approximately $3.86 \mathrm{~m}^{2} / \mathrm{g}$.

XPS data for the alkali-feldspar before the 78-day experiment indicate $\mathrm{K} / \mathrm{Al}$ and $\mathrm{Al} / \mathrm{Si}$ mole ratios of 0.66 and 0.37 , respectively. These data are in good agreement with the surface chemistry of the fresh feldspar used for the 5-day experiment in spite of the fact that two different instruments were utilized to acquire the data (Table 3). Following the 78-day experiment, however, the $\mathrm{Al} / \mathrm{Si}$ mole ratio increased significantly to 0.57 , while $\mathrm{K} / \mathrm{Al}$ decreased to 0.37 . These data confirm the existence of secondary mineral phases, such as kaolinite and boehmite, where $\mathrm{Al}$ has a greater compositional percentage than for K-feldspar or albite. Results from the 5-day experiment also indicate an increase of $\mathrm{Al} / \mathrm{Si}$ mole ratio to 0.41 , while the $\mathrm{K} / \mathrm{Al}$ remained constant at 0.61 , which can best be accounted for by formation of aluminous secondary minerals, but in less abundance than for the 78-day experiment.

\section{Discussion}

\subsection{Albite dissolution}

Based on distribution of aqueous species calculations at experimental conditions, mineral saturation states during the experiments were determined (Table 4). The calculated saturation indices (SI, SI $=\log Q / K)$ indicate that throughout the experiments, the SI of albite is always negative, whereas the SI of K-feldspar becomes positive between 216 and $456 \mathrm{~h}$ of reaction (78-day experiment). Therefore, albite hydrolysis is predicted to occur throughout the experiment, while K-feldspar incrementally approaches saturation and then supersaturation. This is consistent with SEM and TEM observations of mineral products showing preferential dissolution of Na lamellae during the study (Figs. 2 and 4D), an observation consistent with results of earlier studies (Busenburg and Clemency, 1976; Lagache, 1976; Bevan and Savage, 1989; Rafal'skiy et al., 1990; Lee and Parsons, 1995; Tsuchiya et al., 1995).

\subsubsection{General compositional trend}

Albite hydrolysis can be illustrated by the following reaction:

$$
\begin{aligned}
& \text { Albite } \\
& \mathrm{NaAlSi}_{3} \mathrm{O}_{8}
\end{aligned}+\mathrm{H}^{+}+0.5 \mathrm{H}_{2} \mathrm{O}=0.5 \mathrm{Kaolinite}_{\mathrm{Al}_{2} \mathrm{Si}_{2} \mathrm{O}_{5}(\mathrm{OH})_{4}}^{\text {Ka }}+\mathrm{Na}^{+}+2 \mathrm{SiO}_{2}(\mathrm{aq})
$$

Thus, dissolution of albite releases $\mathrm{SiO}_{2}$ and $\mathrm{Na}^{+}$into solution by consuming $\mathrm{H}^{+}$. In a batch reactor, the concentrations of dissolved $\mathrm{SiO}_{2}$ and $\mathrm{Na}^{+}$will increase, while $\mathrm{H}^{+}$decreases. Accordingly, time series observations of the changes in the ratio of $\log a \mathrm{Na}^{+} / \mathrm{aH}^{+}$versus $\log$ $a \mathrm{SiO}_{2(\text { aq) }}$ provide a means to qualitatively assess mineral reactions within a broader context of congruency and incongruency involving phase relations in the $\mathrm{Na}_{2} \mathrm{O}-\mathrm{Al}_{2} \mathrm{O}_{3}-\mathrm{SiO}_{2}-\mathrm{H}_{2} \mathrm{O}-\mathrm{HCl}$ system (Fig. $5 \mathrm{~A}$ ).

Experimental data involving dissolution of numerous aluminosilicate minerals often reveal incongruency as reflected by the 
A

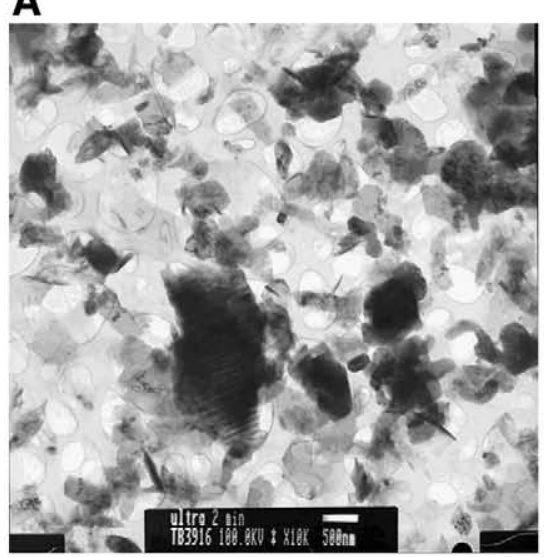

C

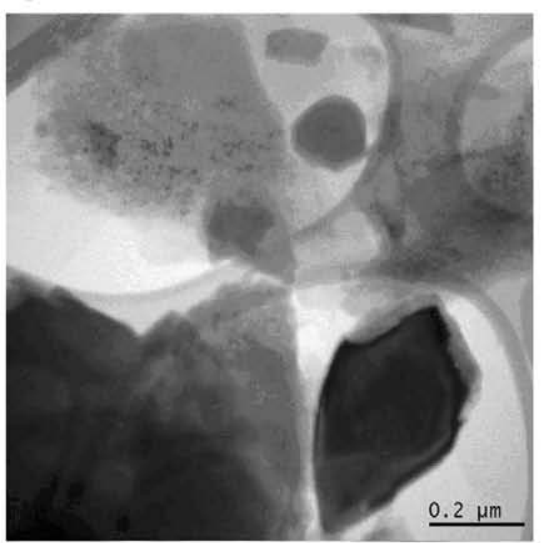

E

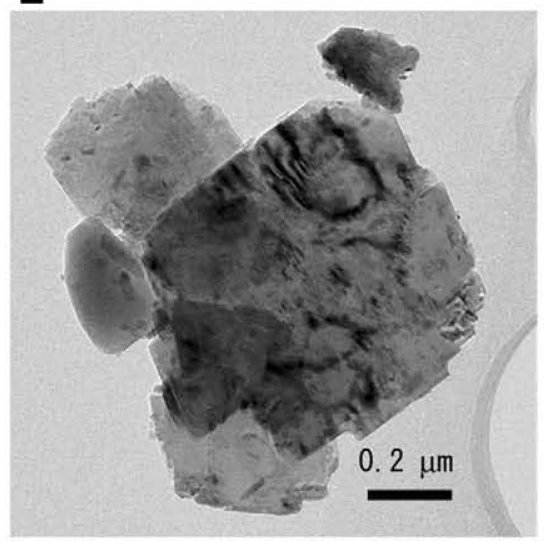

B

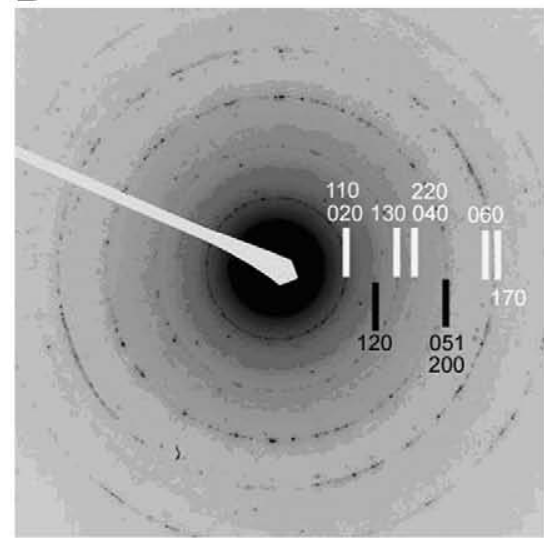

D

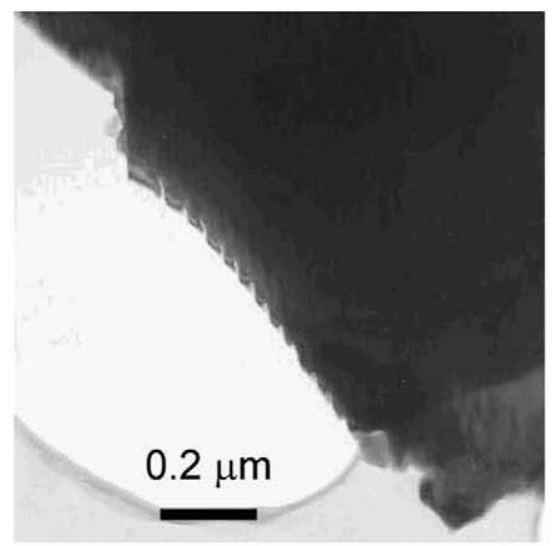

$\mathbf{F}$

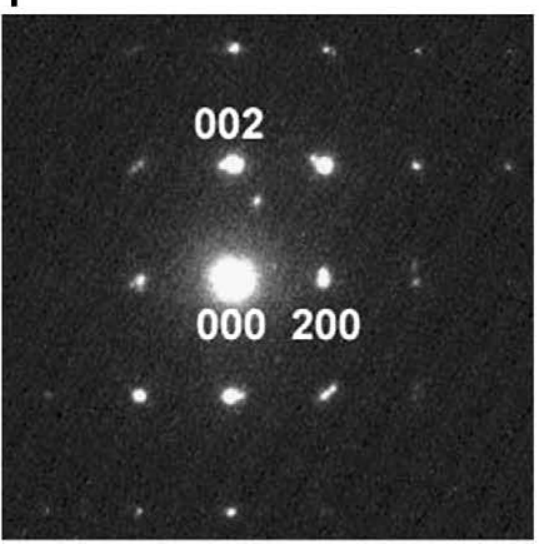

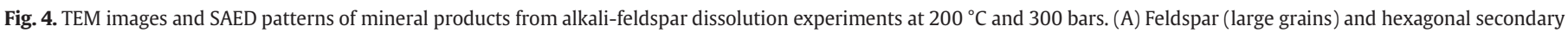

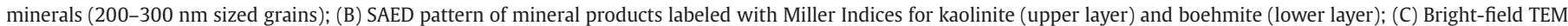

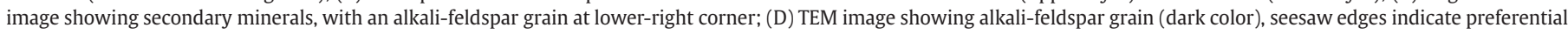

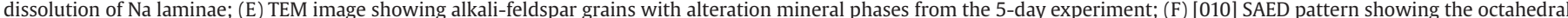

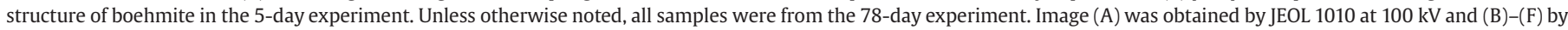
JEOL $2100 \mathrm{~F}$ at higher operating voltage.

nonstoichiometric release to solution of mineral components. This is most often caused by precipitation of secondary minerals or by preferential leaching of more reactive species in the primary mineral. The composition of the fluid coexisting with minerals undergoing dissolution will also affect the nonstoichiometric release of components (Amrhein and Suarez, 1988; Casey et al., 1988; Nesbitt and Muir, 1988; Hellmann et al., 1989, 1990; Inskeep et al., 1991; Nesbitt et al., 1991; Amrhein and Suarez, 1992; Alekseyev et al., 1993; Casey et al., 1993; Oxburgh et al., 1994; Stillings and Brantley, 1995; Gout et al., 1997; Brantley, 2003). The relatively acidic conditions (low $a \mathrm{Na}^{+} / a \mathrm{H}^{+}$) that characterized the starting fluid for the experiments, for example, initiated albite dissolution in the boehmite field of stability. Accordingly, early stage formation of boehmite is predictable (Fig. 5A), which can be illustrated as follows:

$$
\begin{aligned}
& \text { Albite } \\
& \mathrm{NaAlSi}_{3} \mathrm{O}_{8}
\end{aligned}+\mathrm{H}^{+}=\begin{aligned}
& \text { Boehmite } \\
& \mathrm{AlO}(\mathrm{OH})
\end{aligned}+\mathrm{Na}^{+}+3 \mathrm{SiO}_{2}(\mathrm{aq})
$$

Subsequent compositional changes in solution progressed slowly toward the kaolinite field of stability (Fig. 5A). Indeed, fluid composition revealed by samples 3 and 4 during the 78 day 
Table 3

XPS surface composition results ${ }^{\mathrm{a}}$ of alkali-feldspar from both experiments in comparison with theoretical values for K-feldspar and kaolinite

\begin{tabular}{|c|c|c|c|c|c|c|}
\hline & K & $\mathrm{Al}$ & 0 & $\mathrm{Si}$ & \multirow{2}{*}{$\frac{\mathrm{K} / \mathrm{Al}}{\text { Mole ratio }}$} & \multirow{2}{*}{$\frac{\mathrm{Al} / \mathrm{Si}}{\text { Mole ratio }}$} \\
\hline & \multicolumn{4}{|c|}{$\mathrm{mol} \%$} & & \\
\hline Starting alkali-feldspar ${ }^{\mathrm{b}}$ & 5.7 & 8.7 & 62.2 & 23.4 & 0.66 & 0.37 \\
\hline 78-day experiment product & 4.3 & 11.6 & 63.6 & 20.4 & 0.37 & 0.57 \\
\hline Starting alkali-feldsparc & 4.8 & 7.9 & 63.2 & 24.1 & 0.61 & 0.33 \\
\hline 5-day experiment product & 5.5 & 9.0 & 63.4 & 22.1 & 0.61 & 0.41 \\
\hline K-feldspar & 7.7 & 7.7 & 61.5 & 23.1 & 1 & 0.33 \\
\hline Kaolinite & - & 20.9 & 55.8 & 21.8 & - & 1 \\
\hline
\end{tabular}

a Each result reflects the average value of 4 measurements from different alkalifeldspar grains within the same sample.

b 78-day experiment.

5-day experiment.

experiment provide evidence for boehmite conversion to kaolinite as indicated by the decrease in dissolved silica, an overall process that can be illustrated as follows:

$\begin{aligned} & \text { Boehmite } \\ & \mathrm{AlO}(\mathrm{OH})\end{aligned}+0.5 \mathrm{H}_{2} \mathrm{O}+\mathrm{SiO}_{2}(\mathrm{aq})=0.5{ }_{\mathrm{Al}_{2} \mathrm{Si}_{2} \mathrm{O}_{5}(\mathrm{OH})_{4}}^{\mathrm{Kaolinite}}$

The calculated saturation indices for boehmite and kaolinite at 456 and 816 h of reaction, however, reflect supersaturation (Table 4). Apparently, the rate of albite dissolution is sufficient to maintain a level of supersaturation in spite of ongoing precipitation of both minerals, especially kaolinite.

As reactions proceed, compositional changes in the fluid (e.g., samples 5 and 6) indicate on-going dissolution of albite, which is likely accompanied by further replacement of boehmite by kaolinite, especially as increasing amounts of silica are dissolved. Thus, it is not surprising that the fluid $\mathrm{pH}$ increases (reactions (7) and (8)), although the rate of increase is surprisingly slow given the temperature of the experiment. That there is virtually no change in $a \mathrm{Na}^{+} / a \mathrm{H}^{+}$and only $0.43 \mathrm{mmol} / \mathrm{kg}$ decrease in dissolved $\mathrm{SiO}_{2}$ from sample intervals 5 to 6 (1369-1872 h of reaction) underscores the sluggishness of rates of mass transfer between metastable minerals (e.g., boehmite to kaolinite), even for high degrees of supersaturation ultimately caused by albite dissolution.

Prediction of reaction progress based on changes in fluid chemistry is generally consistent with mineral product analysis data. For example, in the 78-day experiment, XPS data indicate an increase in $\mathrm{Al} / \mathrm{Si}$ mole ratio from 0.37 to 0.57 and a decrease in $\mathrm{K} / \mathrm{Al}$ from 0.66 to 0.37 , consistent with greater coverage by kaolinite on alkali-feldspar surfaces. These data are consistent with SEM and HRTEM observations. Moreover, TEM images show that for the 78day experiment, boehmite takes on a rounded shape, which is consistent with constraints imposed by reaction (9). This is in contrast with the sharp edges of boehmite observed following the 5day experiment.

\subsubsection{Albite dissolution rate}

The lack of dissolved $\mathrm{Na}^{+}$in the fluid used for the experiments together with the apparent lack of formation of $\mathrm{Na}$ mineralization during the course of the experiments permits time series changes in dissolved $\mathrm{Na}^{+}$to serve as a constraint on the rate of albite dissolution. This approach is of course limited by the well known $\mathrm{Na}^{+} \Leftrightarrow \mathrm{H}_{3} \mathrm{O}^{+}$ exchange reaction on the feldspar surface at the initial stage of the reaction (e.g., Helgeson et al., 1984), but the exchanged amounts remain to be constant in evaluation of the time series data (Alekseyev et al., 1997). Our experimental data indicate significant and continuous increase in dissolved $\mathrm{Na}^{+}$during the early stages of the experiments, although both the rate and magnitude of $\mathrm{Na}^{+}$gain decreases appreciably with reaction progress, especially beyond $500 \mathrm{~h}$ of reaction (Table 2). The lessening of the $\mathrm{Na}^{+}$flux is likely caused by the gradually diminishing thermodynamic drive for albite dissolution.
Taking account of the rate of release of dissolved $\mathrm{Na}^{+}$during the first $456 \mathrm{~h}$ of reaction of the 78-day experiment (Table 2) suggests albite dissolution rate of approximately $5.0 \times 10^{-11} \mathrm{~mol} \mathrm{~s}^{-1}$. This value is in good agreement with the rate of albite dissolution determined by Hellmann (1994) for a similar temperature, albite surface area, and mineral (albite)-fluid saturation state.

The apparent decrease in the rate of albite dissolution with reaction progress results from changes in solution chemistry that affects the driving force for the reaction (Lasaga, 1981; Aagaard and Helgeson, 1982; Helgeson et al., 1984; Nagy and Lasaga, 1992). The increase in $\mathrm{pH}$ that occurs with reaction progress (reactions (7) and (8)) can induce changes in composition and microtopography of the mineral (albite) surface (reactive surface area, etch pits) (Holdren and Speyer, 1985; Brantley et al., 1986; Holdren and Speyer, 1987; Casey et al., 1988; Schott et al., 1989; Blum and Lasaga, 1991; Amrhein and Suarez, 1992; Brady and Walther, 1992; Wollast and Chou, 1992; Oelkers et al., 1994), further inhibiting albite dissolution kinetics.

\subsubsection{Coupled reaction processes}

Time $(t)$ dependent changes in dissolved $\mathrm{SiO}_{2}$ can be used effectively to assess rates of incremental reaction steps in the overall mineral dissolution-reprecipitation processes during the 78-day experiment, as follows:

$$
r=\frac{w \cdot \sum_{1}^{l} \frac{1}{c} \Delta m_{\mathrm{SiO}_{2(\mathrm{aq})}}}{t}
$$

where $r$ is the release/uptake rate of dissolved $\mathrm{SiO}_{2}, w$ is the mass of water in solution $(\mathrm{kg}), \Delta m_{\mathrm{SiO}_{2(\text { aa) }}}$ is the absolute value of $\mathrm{SiO}_{2}$ concentration change $(\mathrm{mol} / \mathrm{kg})$ for each mineral dissolution or precipitation reaction, $c$ is stoichiometric factor of $\mathrm{SiO}_{2}$ in the reaction, while $l$ is the number of simultaneous reactions considered at each stage of the experiment.

During the earliest stages of the experiment (Fig. 5A), reaction (8) is assumed to account for the release of dissolved $\mathrm{SiO}_{2}$. Therefore, the rate of release of $\mathrm{SiO}_{2}$ from albite not only provides a measure of the dissolution rate of this mineral, but also the rate of formation of boehmite. For example, the change in dissolved $\mathrm{SiO}_{2}$ during the first $456 \mathrm{~h}$ of reaction is $1.70 \mathrm{mmol} / \mathrm{kg}$, which when normalized to the mass of fluid actually present, yields $6.80 \times 10^{-5}$ mol. Accordingly, taking account of the stoichiometry depicted by reaction (8), the rates of albite dissolution and boehmite formation can be estimated to be $1.38 \times 10^{-11} \mathrm{~mol} \mathrm{~s}^{-1}$ (Table 5). Although the rate of albite dissolution estimated by this method differs from that estimated earlier from the rate of $\mathrm{Na}^{+}$release, the two numbers are actually in good agreement considering uncertainties in mineral surface areas and composition, analytical uncertainties, and uncertainties related to the assumed conservation of dissolved $\mathrm{Na}^{+}$and $\mathrm{SiO}_{2(\mathrm{aq})}$ at this stage in the overall reaction process.

\section{Table 4}

Changes of mineral saturation state $(\log Q / K)$ with time for alkali-feldspar dissolution experiments at $200{ }^{\circ} \mathrm{C}$ and 300 bars

\begin{tabular}{|c|c|c|c|c|c|c|}
\hline \multirow[t]{2}{*}{ Sample \# } & \multirow{2}{*}{$\frac{\text { Time }}{\mathrm{H}}$} & \multicolumn{5}{|l|}{ Minerals } \\
\hline & & K-feldspar & Albite & Boehmite & Kaolinite & Muscovite \\
\hline \multicolumn{7}{|c|}{ 78-day experiment } \\
\hline 1 & 24 & -2.82 & -6.85 & 1.17 & 1.27 & 1.60 \\
\hline 2 & 216 & -0.82 & -4.42 & 0.85 & 1.98 & 2.96 \\
\hline 3 & 456 & 0.96 & -2.38 & 2.34 & 5.10 & 7.73 \\
\hline 4 & 816 & 0.68 & -2.71 & 2.04 & 4.31 & 6.86 \\
\hline 5 & 1368 & 2.00 & -1.07 & 1.41 & 4.02 & 6.91 \\
\hline 6 & 1872 & 1.40 & -1.95 & 0.75 & 2.61 & 5.00 \\
\hline \multicolumn{7}{|c|}{ 5-day experiment } \\
\hline 1 & 120 & -1.14 & -4.84 & 0.87 & 1.93 & 2.69 \\
\hline
\end{tabular}


A
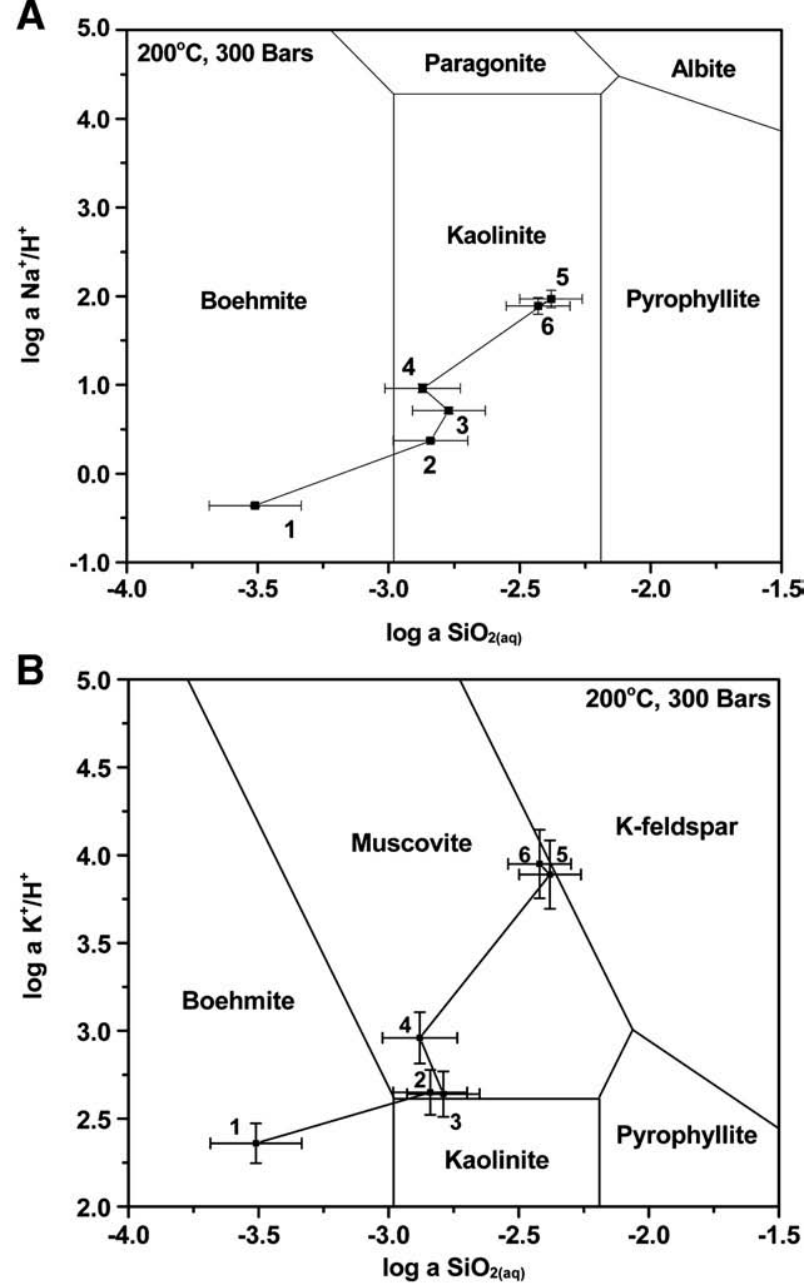

Fig. 5. Mineral phase diagrams in the $\mathrm{Na}_{2} \mathrm{O}-\mathrm{Al}_{2} \mathrm{O}_{3}-\mathrm{SiO}_{2}-\mathrm{H}_{2} \mathrm{O}-\mathrm{HCl}(\mathrm{A})$ and $\mathrm{K}_{2} \mathrm{O}-\mathrm{Al}_{2} \mathrm{O}_{3}-$ $\mathrm{SiO}_{2}-\mathrm{H}_{2} \mathrm{O}-\mathrm{HCl}$ (B) system at $200^{\circ} \mathrm{C}$ and 300 bars with experimental data showing time series change of $a \mathrm{Na}^{+} / a \mathrm{H}^{+}$and $a \mathrm{~K}^{+} / a \mathrm{H}^{+}$, respectively, with $a \mathrm{SiO}_{2}(\mathrm{aq})$ in alkali-feldspar dissolution experiment (78-day) at same conditions. The sizes of uncertainty bars for $y$ axis $\left(\log a \mathrm{Na}^{+} / a \mathrm{H}^{+}\right)$of samples 1-4 in (A) are smaller than the size of data symbols.

Using a similar approach for all reaction stages directly or indirectly contributing to the formation of kaolinite (Table 5), the mass of kaolinite formed throughout the experiment can be estimated to be approximately $11 \mathrm{mg}$. This value is similar to that estimated from SEM data, assuming all of the mineralization associated with the alkali-feldspar surface is kaolinite.

\subsection{K-feldspar dissolution and precipitation}

As shown above, K-feldspar was undersaturated before $456 \mathrm{~h}$ of reaction (Table 4). The dissolution of K-feldspar in moderately acidic aqueous fluid can be illustrated as follows:

$\begin{aligned} & \mathrm{K}-\text { feldspar } \\ & 3 \mathrm{KAlSi}_{3} \mathrm{O}_{8}\end{aligned}+2 \mathrm{H}^{+}=\begin{aligned} & \text { Muscovite } \\ & \mathrm{KAl}_{3} \mathrm{Si}_{3} \mathrm{O}_{10}(\mathrm{OH})_{2}\end{aligned}+2 \mathrm{~K}^{+}+6 \mathrm{SiO}_{2}(\mathrm{aq})$.

Accordingly, dissolution of $\mathrm{K}$-feldspar releases $\mathrm{SiO}_{2}$ and $\mathrm{K}^{+}$into solution by consuming $\mathrm{H}^{+}$until $\mathrm{K}$-feldspar-muscovite equilibrium is achieved. Owing to constraints imposed by temporal changes in fluid chemistry, data indicate that K-feldspar approached saturation and then supersaturation between 216 and $456 \mathrm{~h}$ of reaction, respectively (Table 4). Thus, subsequent to $456 \mathrm{~h}$ of reaction, K-feldspar dissolution is inhibited.
In the first $456 \mathrm{~h}$ of 78-day experiment, the relatively low fluid $\mathrm{pH}$ can be expected to enhance boehmite formation (Fig. 5B), as follows:

$\begin{aligned} & \mathrm{K}-\text { feldspar } \\ & \mathrm{KAlSi}_{3} \mathrm{O}_{8}\end{aligned}+\mathrm{H}^{+}=\begin{aligned} & \text { Boehmite } \\ & \mathrm{AlO}(\mathrm{OH})\end{aligned}+\mathrm{K}^{+}+3 \mathrm{SiO}_{2}(\mathrm{aq})$.

As emphasized previously, kaolinite was the dominant alteration mineral product to form during the 78-day experiment owing to the preferential reactivity of albite. Data indicate, however, a large $(-21.76 \mathrm{~kJ} / \mathrm{mol})$ thermodynamic drive to convert kaolinite to muscovite in a manner consistent with the following reaction:

$\underset{3 \mathrm{Al}_{2} \mathrm{Si}_{2} \mathrm{O}_{5}(\mathrm{OH})_{4}}{\text { Kaolinite }}+2 \mathrm{~K}^{+}=\frac{\text { Muscovite }}{2 \mathrm{KAl}_{3} \mathrm{Si}_{3} \mathrm{O}_{10}(\mathrm{OH})_{2}}+2 \mathrm{H}^{+}+3 \mathrm{H}_{2} \mathrm{O}$.

The end of the 78-day experiment did not achieve K-feldsparmuscovite-fluid equilibria. Instead, the system is at a metastable state as suggested by the coexistence of kaolinite and K-feldspar, and the apparent absence of muscovite in spite of a strong thermodynamic drive for its formation (Table 4). Similar observations have long been reported based on field and experimental studies of hydrothermal and diagenetic systems (Huang et al., 1986; Ehrenberg, 1991; Bjørlykke and Aagaard, 1992; Ehrenberg et al., 1993).

The experimental results by Huang et al. (1986) depicting conversion of albite to illite showed that the formation of illite occurred most effectively under near neutral $\mathrm{pH}$ conditions, while boehmite and kaolinite were formed in initially acidic solution. Moreover, kinetic modeling conducted by Berger et al. (1997) showed that the energy barrier for kaolinite conversion to illite is greater than $8.4 \mathrm{~kJ} / \mathrm{mol}$ at $120{ }^{\circ} \mathrm{C}$, which helps to explain kaolinite metastability. Similarly in the 78-day experiment, the relatively acidic fluid chemistry initiated albite dissolution in the boehmite stability field (Fig. 5A), which resulted in early formation of boehmite, followed by kaolinite. Although muscovite formation by reaction (13) is increasingly thermodynamically favored with reaction progress (Table 4), with Gibbs free energy of $-21.76 \mathrm{~kJ} / \mathrm{mol}$ at $1872 \mathrm{~h}$ of reaction, kaolinite persists, while muscovite or illite failed to form in detectable amounts.

Theoretical calculations (Berger et al., 1997) and experimental data (Huang et al., 1986) indicate that changes in fluid chemistry, such as consumption of $\mathrm{H}^{+}$or increase in $\mathrm{K}^{+}$, facilitate conversion of kaolinite to muscovite, which is consistent with the relatively high $a \mathrm{~K}^{+} / a \mathrm{H}^{+}$ values for muscovite stability (Table 4; Fig. 5B). Using a rate law and rate constant $\left(2.74 \times 10^{-12} \mathrm{~kg} \mathrm{~m}^{-2} \mathrm{~s}^{-1}\right)$ proposed by Chermak and Rimstidt (1990), which explicitly accounts for constraints imposed by fluid chemistry, we can obtain a provisional estimate of the conversion rate of kaolinite to muscovite. These data indicate that approximately 189 days beyond the time of sample 6 ( 78 days) would be required to convert all of the kaolinite $(10 \mathrm{mg})$ with an inferred surface area of $3.86 \mathrm{~m}^{2} / \mathrm{g}$ to muscovite (reaction (13)). The accuracy of this prediction is constrained by the fact that it is not possible to explicitly account for

Table 5

Reaction stages in alkali-feldspar dissolution experiment, and corresponding key reactions and corresponding mineral dissolution/precipitation rates ${ }^{\mathrm{a}}$

\begin{tabular}{|c|c|c|c|c|c|}
\hline \multirow[t]{2}{*}{ Stage } & \multirow[t]{2}{*}{ Samples } & \multirow{2}{*}{$\frac{\text { Time }}{\mathrm{H}}$} & \multirow[t]{2}{*}{ Key reactions } & \multicolumn{2}{|c|}{ Reaction rates $\left(\mathrm{mol} \mathrm{s}^{-1}\right)$} \\
\hline & & & & Dissolution & Precipitation \\
\hline 1 & $1-3$ & $0-456$ & $\begin{array}{l}\mathrm{NaAlSi}_{3} \mathrm{O}_{8}+\mathrm{H}^{+}=\mathrm{AlO}(\mathrm{OH})+ \\
\mathrm{Na}^{+}+3 \mathrm{SiO}_{2(\mathrm{aq})}\end{array}$ & $\begin{array}{l}1.38 \times 10^{-11} \\
(A b)\end{array}$ & $\begin{array}{l}1.38 \times 10^{-11} \\
(B m t)\end{array}$ \\
\hline 2 & $3-4$ & $457-816$ & $\begin{array}{l}\mathrm{AlO}(\mathrm{OH})+0.5 \mathrm{H}_{2} \mathrm{O}+\mathrm{SiO}_{2(\mathrm{aq})}= \\
0.5 \mathrm{Al}_{2} \mathrm{Si}_{2} \mathrm{O}_{5}(\mathrm{OH})_{4}\end{array}$ & $\begin{array}{l}1.08 \times 10^{-11} \\
(B m t)\end{array}$ & $\begin{array}{l}5.40 \times 10^{-12} \\
(K \ln )\end{array}$ \\
\hline 3 & $4-5$ & $817-1368$ & $\begin{array}{l}\mathrm{NaAlSi}_{3} \mathrm{O}_{8}+\mathrm{H}^{+}+0.5 \mathrm{H}_{2} \mathrm{O}= \\
0.5 \mathrm{Al}_{2} \mathrm{Si}_{2} \mathrm{O}_{5}(\mathrm{OH})_{4}+ \\
\mathrm{Na}^{+}+2 \mathrm{SiO}_{2(\mathrm{aq})}\end{array}$ & $\begin{array}{l}2.85 \times 10^{-11} \\
(A b)\end{array}$ & $\begin{array}{l}1.42 \times 10^{-11} \\
(\mathrm{Kln})\end{array}$ \\
\hline 4 & $5-6$ & 1369-1872 & $\begin{array}{l}\mathrm{AlO}(\mathrm{OH})+0.5 \mathrm{H}_{2} \mathrm{O}+\mathrm{SiO}_{2(\mathrm{aq})}= \\
0.5 \mathrm{Al}_{2} \mathrm{Si}_{2} \mathrm{O}_{5}(\mathrm{OH})_{4}\end{array}$ & $\begin{array}{l}9.48 \times 10^{-12} \\
(B m t)\end{array}$ & $\begin{array}{l}4.74 \times 10^{-12} \\
(K \ln )\end{array}$ \\
\hline
\end{tabular}

Ab: albite; Bmt: boehmite; Kln: kaolinite.

a The dissolution/precipitation rates were calculated based on the predominant reaction controlling dissolved $\mathrm{SiO}_{2}$ changes in each stage. 
the full effects of subsequent changes in fluid chemistry and effective surface area that will influence mineral dissolution (albite) and precipitation (muscovite) processes. A more serious limitation, however, involves the complete lack of data intrinsic to muscovite nucleation and growth. It is well known, for example, that the rate of mineral nucleation is controlled by interfacial energy, the collision frequency efficiency, temperature, as well as supersaturation (Nielsen, 1986). In the absence of these data, the provisional rate for kaolinite conversion to muscovite estimated above must be taken as a minimum value.

Between 216 and 456 h of reaction, K-feldspar became supersaturated. Other than alkali-feldspar microtextural control (Lee and Parsons, 1995), the high $\mathrm{K}^{+}$concentration of the starting fluid undoubtedly plays a role in the observed reaction path processes as well. For example, the high concentration of dissolved $\mathrm{K}^{+}$in the starting fluid ( $200 \mathrm{mmol} / \mathrm{kg}$ ), together with constraints imposed by the coexistence of two alkali feldspars, provide ample driving force for the reaction between these two feldspars to proceed as follows:

$\begin{aligned} & \text { Albite } \\ & \mathrm{NaAlSi}_{3} \mathrm{O}_{8}\end{aligned}+\mathrm{K}^{+}=\begin{aligned} & \mathrm{K}-\text { feldspar } \\ & \mathrm{KAlSi}_{3} \mathrm{O}_{8}\end{aligned}+\mathrm{Na}^{+}$

Calculations indicate that the Gibbs free energy change for the above reaction at $200{ }^{\circ} \mathrm{C}, 300$ bars varies from -31.67 to $-22.97 \mathrm{~kJ} / \mathrm{mol}$. Accordingly, as reactions proceed, the concentrations of dissolved $\mathrm{K}^{+}$ and $\mathrm{Na}^{+}$are predicted (and observed) to decrease and increase, respectively. In detail, however, the "cation exchange" reaction between albite and $\mathrm{K}$-feldspar is an exceedingly complex process, involving breakdown and rebuilding of $\mathrm{Si}-\mathrm{O}$ and $\mathrm{Al}-\mathrm{O}$ bonds (O'Neil and Taylor, 1967; O'Neil, 1977) and dissolution and precipitation with an abrupt discontinuity at the interface (Labotka et al., 2004). The possible rimming of K-feldspar on the albite component undoubtedly limits reaction rates and extent of mass transfer on the time scale of the experiment.

\subsection{Coupled dissolution and precipitation reaction kinetics}

In the absence of precipitation of muscovite/illite during the present experiments, the build up of solutes would provide a negative feedback on the rate of dissolution of the primary feldspars. This has important implications for the application of chemical kinetics to natural systems, as emphasized by Lasaga (1998). Lasaga (1998) showed a series of scenarios of possible reaction paths with different ratios of rate constants between feldspar and secondary clay mineral products. Indeed, results show that the dissolution rate of primary feldspar is an explicit function of the relative rates of all irreversible reactions in the system. In cases where the ratio of the reaction rate constant of secondary minerals to that of feldspar dissolution is small (as might be the case during the present experiment), the metastable coexistence of Al hydroxide and kaolinite grows significantly. At a sufficiently small value it is possible that three alteration phases including muscovite, could coexist with the primary feldspar. Thus, reaction path models based on assumptions of partial equilibria that necessarily entail formation of chemically complex secondary phases immediately upon saturation of the fluid with respect to these minerals will provide uncertain constraints on the chemical evolution of fluids and minerals in time and space in hydrologic and even hydrothermal systems.

\section{Conclusions}

Alkali-feldspar hydrolysis experiments using a well-mixed batch reactor allowed observations of time series in situ fluid chemistry at $200{ }^{\circ} \mathrm{C}$ and 300 bars to be integrated with the mineralogy and composition of reaction products retrieved after 5 and 78 days. Hydrolysis of the albite component of alkali-feldspar resulted in the formation of boehmite, and then kaolinite. SEM, HRTEM and XPS analyses of the surface of alkali-feldspar provide clear evidence for the preferential reaction of albite and coexistence of secondary mineralization involving both boehmite and kaolinite. The experimentally observed release of $\mathrm{Na}^{+}$and $\mathrm{SiO}_{2(\text { aq) }}$ during the earliest stages of reaction of the 78-day experiment (less than $500 \mathrm{~h}$ ) indicate a dissolution rate for albite in agreement with other studies when mineral surface area, temperature and saturation state effects are taken into account. The rate of albite dissolution becomes slower during late stages of reaction, likely due to the formation of secondary minerals on active sites on the albite surface and/or the gradually diminished thermodynamic drive for albite dissolution. The metastable existence of kaolinite results in part from intrinsically sluggish conversion of kaolinite to muscovite in moderately acidic fluids.

Traditionally, feldspar hydrolysis is treated with the assumption of partial equilibria between the secondary minerals and the aqueous solution. If this partial equilibrium is not observed, the reaction paths are different in terms of both aqueous solution chemistry and secondary mineral paragenesis (Lasaga, 1998). Our detailed mineralogical analysis showed that boehmite and kaolinite persisted metastably during the entire 78 days experiment, which provides the first experimental evidence to support early modeling illustrations (Steefel and van Cappellen, 1990; Lasaga, 1998). The time series solution chemistry data and calculated saturation indices are also more consistent with Lasaga's (1998) cases with slow clay precipitation kinetics than the partial equilibrium case. Slow secondary mineral reaction kinetics means strong coupling between dissolution and precipitation reactions, which is important in interpretation of field derived rates (Zhu et al., 2004a,b).

\section{Acknowledgments}

Material in this paper is based upon work supported by the U.S. Department of Energy under Award No. DE-FG26-04NT42125 to CZ and WES and partially by the National Science Foundation under Award No.'s EAR0423971 and EAR0509775 to CZ. Any opinions, findings, and conclusions or recommendations expressed in this material, however, are those of the authors and do not necessarily reflect the views of the United States Government or any agency thereof. We thank Rick Haasch and John Baltrus for assistances with XPS analyses that were carried out in the Center for Microanalysis of Materials, University of Illinois and the National Energy Technology Laboratory. We thank Rick Knurr at University of Minnesota for chemical analyses of fluid samples, and Kyle Jones at US EPA for BET surface analysis. We also thank Arndt Schimmelmann at Indiana University for helping with techniques in sample preparation protocols and Sheila Hedges at NETL for reading an earlier version of the manuscript. The paper greatly benefited from comments and suggestions made by John Kaszuba as well as comments from an anonymous reviewer and editor Jeremy Fein.

\section{References}

Aagaard, P., Helgeson, H.C., 1982. Thermodynamic and kinetic constraints on reaction rates among minerals and aqueous solutions: I. Theoretical considerations. American Journal of Science 282, 237-285.

Alekseyev, V.A., Prisyagina, N.I., Medvedeva, L.S., 1993. Rates of congruent dissolution of feldspars in acid and alkaline hydrothermal solutions. Geochemistry International $30,26-35$

Alekseyev, V.A., Medvedeva, L.S., Prisyagina, N.I., Meshalkin, S.S., Balabin, A.I., 1997. Change in the dissolution rates of alkali feldspars as a result of secondary mineral precipitation and approach to equilibrium. Geochimica et Cosmochimica Acta 61, 1125-1142.

Amrhein, C Suarez D.L 1988. The use of a surface complexation model to describe the kinetics of ligand-promoted dissolution of anorthite. Geochimica et Cosmochimica Acta 52, 2785-2793.

Amrhein, C., Suarez, D.L., 1992. Some factors affecting the dissolution kinetics of anorthite at $25{ }^{\circ} \mathrm{C}$. Geochimica et Cosmochimica Acta 56, 1815-1826.

Berger, G., Lacharpagne, J.-C., Velde, B., Beaufort, D., Lanson, B., 1997. Kinetic constraints on illitization reactions and the effects of organic diagenesis in sandstone/shale sequences. Applied Geochemistry 12, 23-35. 
Bevan, J., Savage, D., 1989. The effect of organic acids on the dissolution of K-feldspar under conditions relevant to burial diagenesis. Mineralogical Magazine 53, 415-425.

Bjørlykke, K., Aagaard, P., 1992. Clay minerals in North Sea sandstones. Origin, Diagenesis, and Petrophysics of Clay Minerals in Sandstones. SEPM Special Publication, vol. 47, pp. 65-80.

Blum, A.E., Lasaga, A.C., 1991. The role of surface speciation in the dissolution of albite. Geochimica et Cosmochimica Acta 55, 2193-2201.

Brady, P.V., Walther, J.V., 1992. Surface chemistry and silicate dissolution at elevated temperatures. American Journal of Science 292, 639-658.

Brantley, S.L., 2003. Reaction kinetics of primary rock-forming minerals under ambient conditions. In: Drever, J.I. (Ed.), Surface and Ground Water, Weathering, and Soils. Holland, H.D., Turekian, K.K. (Eds.), Treatise on Geochemistry, Vol. 5, Pergamon Press, Oxford, 73-117.

Brantley, S.L., Stillings, L.L., 1996. Feldspar dissolution at $25{ }^{\circ} \mathrm{C}$ and low pH. American Journal of Science 296, 101-127.

Brantley, S.L., Crane, R., Crerar, D.A., Hellman, R., Stallard, R., 1986. Dislocation etch pits in quartz. In: Davis, J., Hayes, K. (Eds.), Geochemical Processes at Mineral Surfaces. American Chemical Society, pp. 639-649.

Burch, T.E., Nagy, K.L., Lasaga, A.C., 1993. Free energy dependence of albite dissolution kinetics at $80^{\circ} \mathrm{C}$ and $\mathrm{pH}$ 8.8. Chemical Geology 105, 137-162.

Busenburg, E., Clemency, C.V., 1976. The dissolution kinetics of feldspars at $25{ }^{\circ} \mathrm{C}$ and $1 \mathrm{~atm}$ CO2, partial pressure. Geochimica et Cosmochimica Acta 40, 41-49.

Casey, W.H., Westrich, H.R., Arnold, G.W., 1988. Surface chemistry of labradorite feldspar reacted with aqueous solutions at $\mathrm{pH}=2,3$ and 12. Geochimica et Cosmochimica Acta 52, 2795-2807.

Casey, W.H., Westrich, H.R., Banfield, J.F., Ferruzzi, G., Arnold, G.W., 1993. Leaching and reconstruction at the surfaces of dissolving chain-silicate minerals. Nature 366, 253-256.

Chermak, J.A., Rimstidt, J.D., 1990. The hydrothermal transformation rate of kaolinite to muscovite/illite. Geochimica et Cosmochimica Acta 54, 2979-2990.

Chou, L., Wollast, R., 1985. Steady-state kinetics and dissolution mechanisms of albite. American Journal of Science 285, 963-993.

Ehrenberg, S.N., 1991. Kaolinized, potassium-leached zones at the contacts of the Garn Formation, Haltenbanken, mid-Norwegian continental shelf. Marine and Petroleum Geology 8, 250-269.

Ehrenberg, S.N., Aagaard, P., Wilson, M.J., Frazer, A.R., Duthie, D.M.L., 1993. Depthdependent transformation of kaolinite to dickite in sandstones of the Norwegian continental shelf. Clay Minerals 28, 325-352.

Gautier, J.M., Oelkers, E.H., Schott, J., 1994. Experimental study of K-feldspar dissolution rates as a function of chemical affinity at $150{ }^{\circ} \mathrm{C}$ and $\mathrm{pH} 9$. Geochimica et Cosmochimica Acta 58, 4549-4560.

Gout, R., Oelkers, E.H., Schott, J., Zwick, A., 1997. The surface chemistry and structure of acid-leached albite: new insights on the dissolution mechanisms of the alkali feldspars. Geochimica et Cosmochimica Acta 61, 3013-3018.

Helgeson, H.C., 1968. Evaluation of irreversible reactions in geochemical processes involving minerals and aqueous solutions - I. Thermodynamic relations. Geochimica et Cosmochimica Acta 32, 853-877.

Helgeson, H.C., 1971. Kinetics of mass transfer among silicates and aqueous solutions. Geochimica et Cosmochimica Acta 35, 421-469.

Helgeson, H.C., 1972. Kinetics of mass transfer among silicates and aqueous solutions: correction and clarification. Geochimica et Cosmochimica Acta 36, 1067-1070.

Helgeson, H.C., 1974. Chemical interaction of feldspar and aqueous solutions. In: MacKenzie, W.S., Zussman, J. (Eds.), The Feldspars. Crane, Russak and Co. Inc., New York.

Helgeson, H.C., 1979. Mass transfer among minerals and hydrothermal solutions. In: Barnes, H.L. (Ed.), Geochemistry of Hydrothermal Ore Deposits. John Wiley \& Sons, New York.

Helgeson, H.C., Garrels, R.M., Mackenzie, F.T., 1969. Evaluation of irreversible reactions in geochemical processing involving minerals and aqueous solutions - II. Applications. Geochimica et Cosmochimica Acta 33, 455-481.

Helgeson, H.C., Brown, T.H., Nigrini, A., Jones, T.A., 1970. Calculation of mass transfer in geochemical processes involving aqueous solutions. Geochimica et Cosmochimica Acta 34, 569-592.

Helgeson, H.C., Murphy, W.M., Aagaard, P., 1984. Thermodynamic and kinetic constraints on reaction rates among minerals and aqueous solutions: II. Rate constants, effective surface area, and the hydrolysis of feldspar. Geochimica et Cosmochimica Acta 48, 2405-2432.

Hellmann, R., 1994. The albite-water system: Part I. The kinetics of dissolution as a function of pH at 100, 200, and $300^{\circ} \mathrm{C}$. Geochimica et Cosmochimica Acta 58, 595-611.

Hellmann, R., 1995. The albite-water system: Part II. The time evolution of the stoichiometry of dissolution as a function of $\mathrm{pH}$ at 100,200 , and $300{ }^{\circ} \mathrm{C}$. Geochimica et Cosmochimica Acta 59, 1669-1697.

Hellmann, R., Tisserand, D., 2006. Dissolution kinetics as a function of the Gibbs free energy of reaction: an experimental study based on albite feldspar. Geochimica et Cosmochimica Acta 70, 364-383.

Hellmann, R., Crerar, D.A., Zhang, R., 1989. Albite feldspar hydrolysis to $300{ }^{\circ} \mathrm{C}$. Solid State Ionics 32/33, 314-329.

Hellmann, R., Eggleston, C.M., Hochella Jr., M.F., Crerar, D.A., 1990. The formation of leached layers on albite surfaces during dissolution under hydrothermal conditions. Geochimica et Cosmochimica Acta 54, 1267-1281.

Hellmann, R., Penisson, J.-M., Hervig, R.L., Thomassin, J.-H., Abrioux, M.-F., 2003. An EFTEM/HRTEM high-resolution study of the near surface of labradorite feldspar altered at acid $\mathrm{pH}$ : evidence for interfacial dissolution-reprecipitation. Physics and Chemistry of Minerals 30, 192-197.

Hellmann, R., Penisson, J.-M., Hervig, R.L., Thomassin, J.-H., Abrioux, M.-F, 2004 Chemical alteration of feldspar: a comparative study using SIMS and HRTEM/
EFTEM. In: Wanty, R.B., Seal, R.R. (Eds.), Proceedings of the 11th International Symposium on Water-Rock Interaction, Saratoga Springs, New York.

Ho, P.C., Palmer, D.A., Mesmer, R.E., 1994. Electrical conductivity measurements of aqueous sodium chloride solutions to $600{ }^{\circ} \mathrm{C}$ and $300 \mathrm{MPa}$. Journal of Solution Chemistry 23, 997-1018.

Ho, P.C., Bianchi, H., Palmer, D.A., Wood, R.H., 2000. Conductivity of dilute aqueous electrolyte solutions at high temperatures and pressures using a flow cell. Journal of Solution Chemistry 29, 217-235.

Ho, P.C., Palmer, D.A., Gruszkiewicz, M.S., 2001. Conductivity measurements of dilute aqueous $\mathrm{HCl}$ solutions to high temperatures and pressures using a flow-through cell. Journal of Physical Chemistry B 105, 1260-1266.

Holdren, G.R., Berner, R.A., 1979. Mechanism of feldspar weathering - I. Experimental studies. Geochimica et Cosmochimica Acta 43, 1161-1171.

Holdren, G.R., Speyer, P.M., 1985. pH dependent change in the rates and stoichiometry of dissolution of an alkali feldspar at room temperature. American Journal of Science 285, 994-1026.

Holdren, G.R., Speyer, P.M., 1987. Reaction rate-surface area relationships during the early stages of weathering. II. Data on eight additional feldspars. Geochimica et Cosmochimica Acta 51, 2311-2318.

Holland, T.J.B., Powell, R., 1998. An internally consistent thermodynamic data set for phases of petrological interest. Journal of Metamorphic Geology 16, 309-343.

Huang, W.L., Bishop, A.M., Brown, R.W., 1986. The effect of fluid/rock ratio on feldspar dissolution and illite formation under reservoir conditions. Clay Minerals 21, 585-602.

Inskeep, W.P., Nater, E.A., Bloom, P.R., Vandervoort, D.S., Erich, M.S., 1991. Characterization of laboratory weathered labradorite surfaces using X-ray photoelectron spectroscopy and transmission electron microscopy. Geochimica et Cosmochimica Acta 55, 787-800.

Johnson, J.W., Oelkers, E.H., Helgeson, H.C., 1992. SUPCRT92 - A software package for calculating the standard molal thermodynamic properties of minerals, gases, aqueous species, and reactions from 1 bar to 5000 bar and $0{ }^{\circ} \mathrm{C}$ to $1000{ }^{\circ} \mathrm{C}$. Computational Geosciences 18 (7), 899-947.

Knauss, K.G., Wolery, T.J., 1986. Dependence of albite dissolution kinetics on pH and time at $25^{\circ} \mathrm{C}$ and $70{ }^{\circ} \mathrm{C}$. Geochimica et Cosmochimica Acta 50, 2481-2497.

Labotka, T.C., Cole, D.R., Fayek, M., Riciputi, L.R., Stadermann, F.J., 2004. Coupled cation and oxygen-isotope exchange between alkali feldspar and aqueous chloride solution. American Mineralogist 89, 1822-1825.

Lagache, M., 1976. New data on the kinetics of the dissolution of alkali feldspars at $200{ }^{\circ} \mathrm{C}$ in $\mathrm{CO} 2$ charged water. Geochimica et Cosmochimica Acta 40, 157-161.

Lasaga, A.C., 1981. Transition state theory. In: Lasaga, A.C., Kirkpatrick, R.J. (Eds.) Kinetics of Geochemical Processes. Reviews in Mineralogy, vol. 8, pp. 135-169.

Lasaga, A.C., 1998. Kinetic Theory in the Earth Sciences. Princeton University Press, Princeton.

Lee, M.R., Parsons, I., 1995. Microtextural controls of weathering of perthitic alkali feldspars. Geochimica et Cosmochimica Acta 59, 4465-4488.

Morey, G.W., Fournier, R.O., 1961. The decomposition of microcline, albite, and nepheline in hot water. American Mineralogist 46, 688-699.

Nagy, K.L., 1995. Dissolution and precipitation kinetics of sheet silicates. In: White, A.F Brantley, S.L. (Eds.), Chemical Weathering Rates of Silicate Minerals, vol. 31. Mineralogical Society of America, Washington, DC, pp. 173-225.

Nagy, K.L., Lasaga, A.C., 1992. Dissolution and precipitation kinetics of gibbsite at $80{ }^{\circ} \mathrm{C}$ and $\mathrm{pH}$ 3: the dependence on solution saturation state. Geochimica et Cosmochimica Acta 56, 3093-3111

Nagy, K.L., Blum, A.E., Lasaga, A.C., 1991. Dissolution and precipitation kinetics of kaolinite at $80^{\circ} \mathrm{C}$ and $\mathrm{pH} 3$ : the dependence on solution saturation state. American Journal of Science 291, 649-686.

Nesbitt, H.W., Muir, I.J., 1988. SIMS depth profiles of weathered plagioclase and processes affecting dissolved $\mathrm{Al}$ and $\mathrm{Si}$ in some acidic soils. Nature 334, 336-338.

Nesbitt, H.W., Skinner, W.M., 2001. Early development of Al, Ca, and Na compositional gradients in labradorite leached in $\mathrm{pH} 2 \mathrm{HCl}$ solutions. Geochimica et Cosmochimica Acta 65, 715-727.

Nesbitt, H.W., Macrae, N.D., Shotyk, W., 1991. Congruent and incongruent dissolution of labradorite in dilute acidic salt solutions. The Journal of Geology 99, 429-442.

Nielsen, A.E., 1986. Mechanisms and rate laws in electrolyte crystal growth from aqueous solution. In: Davis, J.A., Hayes, K.F. (Eds.), Geochemical Processes at Mineral Surfaces. ACS symposium series, vol. 323, pp. 600-614.

Nugent, M.A., Brantley, S.L., Pantano, C.G., Maurice, P.A., 1998. The influence of natura mineral coatings on feldspar weathering. Nature 395, 588-591.

Oelkers, E.H., Schott, J., Devidal, J.-L., 1994. The effect of aluminum, pH, and chemical affinity on the rates of aluminosilicate dissolution reactions. Geochimica et Cosmochimica Acta 58, 2011-2024.

O'Neil, J.R., 1977. Stable isotopes in mineralogy. Physics and Chemistry of Minerals 2, 105-123.

O'Neil, J.R., Taylor Jr., H.P., 1967. The oxygen isotope and cation exchange chemistry of feldspars. American Mineralogist 52, 1414-1437.

Oxburgh, R., Drever, J.I., Sun, Y.-T., 1994. Mechanism of plagioclase dissolution in acid solution at $25^{\circ} \mathrm{C}$. Geochimica et Cosmochimica Acta 58, 661-669.

Penn, R.L., Zhu, C., Xu, H., Veblen, D.R., 2001. Iron oxide coatings on sand grains from the Atlantic coastal plain: high-resolution transmission electron microscopy characterization. Geology 29, 843-846.

Petrovic, R., 1976. Rate control in feldspar dissolution - II: the protective effects of precipitates. Geochimica et Cosmochimica Acta 40, 1509-1522.

Rafal'skiy, R.P., Prisyagina, N.I., Kondrushin, I.B., 1990. Reaction of microclineperthite with aqueous solutions at 150 and $250{ }^{\circ} \mathrm{C}$. Geochemistry International 27, 56-66.

Schott, J., Brantley, S., Crerar, D., Guy, C., Borcsik, M., Willaime, C., 1989. Dissolution kinetics of strained calcite. Geochimica et Cosmochimica Acta 53, 373-382. 
Seyfried Jr., W.E., Janecky, D.R., Berndt, M.E., 1987. Rocking autoclaves for hydrothermal experiments II: the flexible reaction cell system. In: Barnes, H.L., Ulmer, G.C. (Eds.), Hydrothermal Experimental Techniques. Wiley Interscience, pp. 216-240.

Shock, E.L., Helgeson, H.C., 1988. Calculation of the thermodynamic and transport properties of aqueous species at high temperatures and pressures: correlation algorithms for ionic species and equation of state predictions to $5 \mathrm{~kb}$ and $1000{ }^{\circ} \mathrm{C}$. Geochimica et Cosmochimica Acta 52, 2009-2036.

Shock, E.L., Sassani, C., Willis, M., Sverjensky, D.A., 1997. Inorganic species in geologic fluids: correlations among standard molal thermodynamic properties of aqueous ions and hydroxide complexes. Geochimica et Cosmochimica Acta 61, 907-950.

Steefel, C.I., van Cappellen, P., 1990. A new approach to modeling water-rock interaction: the role of precursors, nucleation, and Ostwald ripening. Geochimica et Cosmochimica Acta 54, 2657-2677.

Stillings, L.L. Brantley, S.L., 1995. Feldspar dissolution at $25{ }^{\circ} \mathrm{C}$ and $\mathrm{pH}$ 3: reaction stoichiometry and the effect of cations. Geochimica et Cosmochimica Acta 59, 1483-1496.

Sverjensky, D.A., Shock, E.L., Helgeson, H.C., 1997. Prediction of the thermodynamic properties of aqueous metal complexes to $1000{ }^{\circ} \mathrm{C}$ and $5 \mathrm{~kb}$. Geochimica et Cosmochimica Acta 61, 1359-1412.

Tagirov, B., Schott, J., 2001. Aluminum speciation in crustal fluids revisited. Geochimica et Cosmochimica Acta 65, 3965-3992.
Tsuchiya, N., Nakatsuka, K., Yamagishi, Y., 1995. Kinetics and modeling of alkali-feldspar dissolution in a hydrothermal acid solution. In: Khraka, Y.K., Chudaev, O.V. (Eds.), Proceedings of the 8th International Symposium on Water-Rock Interaction. A. A. Balkema, Rotterdam, pp. 161-164.

Wolery, T.J., Daveler, S.A., 1992. EQ6, a Computer Program for Reaction Path Modeling of Aqueous Geochemical Systems: Theoretical Manual, User's Guide, and Related Documentation (version 7.0) UCRL-MA-1 10662 PT IV, Lawrence Livermore National Laboratory, Livermore, CA. 337 pp.

Wollast, R., Chou, L., 1992. Surface reactions during the early stages of weathering of albite. Geochimica et Cosmochimica Acta 56, 3113-3121.

Zhu, C., Blum, A.E., Veblen, D.R., 2004a. Feldspar dissolution rates and clay precipitation in the Navajo aquifer at Black Mesa, Arizona, USA. In: Wanty, R.B., Seal, R.I. (Eds.), Proceedings of the 11th International Symposium on Water-Rock Interaction. A. A. Balkema, New York, pp. 895-899.

Zhu, C. Blum, A.E., Veblen, D.R., 2004b. A new hypothesis for the slow feldspar dissolution in groundwater aquifers. Geochimica et Cosmochimica Acta 68, A148.

Zhu, C., Veblen, D.R., Blum, A.E., Chipera, S.J., 2006. Naturally weathered feldspar surfaces in the Navajo Sandstone aquifer, Black Mesa, Arizona: electron microscopic characterization. Geochimica et Cosmochimica Acta 70, 4600-4616. 


\title{
Alkali Feldspar Dissolution and Secondary Mineral Precipitation in Batch Systems: Saturation States of Product Minerals and Reaction \\ Paths
}

\author{
Chen $\mathrm{Zhu}^{\dagger}$ and Peng $\mathrm{Lu}$ \\ Department of Geological Sciences, Indiana University, Bloomington, IN 47405, USA
}

${ }^{\dagger}$ To whom all correspondence may be addressed. Email: chenzhu@indiana.edu; phone: (812)856-1884

To be submitted to

Geochimica et Cosmochimica Acta 


\begin{abstract}
In order to evaluate the complex interplay between dissolution and precipitation reaction kinetics, we examined the hypothesis of partial equilibria between secondary mineral products and aqueous solutions in feldspar-water systems. Speciation and solubility geochemical modeling was used to compute the saturation indices (SI) for product minerals in batch feldspar dissolution experiments at elevated temperatures and pressures and to trace the reaction paths on activity-activity diagrams. The modeling results demonstrated: (1) the experimental aqueous solutions were supersaturated with respect to product minerals for almost the entire duration of the experiments; (2) the aqueous solution chemistry did not evolve along the phase boundaries but crossed the phase boundaries at oblique angles; and (3) the earlier precipitated product minerals did not dissolve but continued to precipitate even after the solution chemistry had evolved into the stability fields of minerals lower in the paragenesis sequence. These three lines of evidence signify that product mineral precipitation is a slow kinetic process and partial equilibria between aqueous solution and product minerals were not held. In contrast, the experimental evidences are consistent with the hypothesis of mineral dissolution/precipitation kinetics that the ratio of the secondary mineral precipitation rate constant to the rate constant of feldspar dissolution is well below unity (e.g., Zhu et al., 2004.. In: Wanty, R. B. and Seal, R. R. I. (Eds.), Water-Rock Interaction. A.A. Balkema, Saratoga Springs, New York. v. p. 895-899). In all batch experiments examined, the time of congruent feldspar dissolution was short and supersaturation with respect to the product minerals was reached within a short period of time. The experimental system progressed from a dissolution driven regime to a precipitation limited regime in a short order. The results of this study suggest a strong coupling and feedback between dissolution and precipitation reaction kinetics, which needs to be considered in the interpretation of field based
\end{abstract}


Zhu \& $\mathrm{Lu}$

dissolution rates.

\section{INTRODUCTION}

As pointed out by Drever (2004) in his foreword to the surficial geochemistry volume of the Treatise on Geochemistry, one fundamental assumption in geochemistry that has received relatively little attention since the initial proposal, is that partial equilibrium may exist among mineral products from the dissolution of the primary mineral (e.g., feldspar) and the aqueous solution (Helgeson, 1968; Helgeson et al., 1969; Helgeson, 1970; Helgeson et al., 1970; Helgeson, 1971; Helgeson, 1974; Helgeson and Murphy, 1983). The term "partial equilibrium" was used by Helgeson (1979) to describe the feldspar-water system as an example, in which all solutes are at equilibrium with each other and secondary minerals are at equilibrium with the aqueous solution but the aqueous solution is not at equilibrium with feldspar. As a consequence of partial equilibrium, mass transfer processes in silicate weathering systems is regarded as driven by irreversible dissolution of the primary mineral (Helgeson, 1979). A large body of literature on silicate weathering has focused on feldspar dissolution rates in soils and groundwater, with little references to the kinetics of product mineral precipitation (see reviews in Blum and Stillings, 1995; Drever and Clow, 1995; White and Brantley, 2003; Bricker et al., 2004). Over the years, it has been shown through numerical modeling of feldspar hydrolysis secondary mineral precipitation reactions, that if the partial equilibrium assumption does not hold, aqueous chemistry evolution, mineral paragenesis, and reaction rates can deviate significantly from the Helgeson classic reaction path model (Steefel and Van Cappellen, 1990; Lasaga et al., 1994; Lasaga, 1998; Zhu et al., 2004a; Ganor et al., 2007). However, to date, the partial equilibrium hypothesis has yet to be systematically tested. 
Zhu \& Lu

What has prompted us to re-examine this hypothesis proposed nearly half a century ago is its current relevance to the interpretation of the well known and extensively discussed apparent discrepancy between the field derived feldspar dissolution rates and those measured in the laboratory (Blum and Stillings, 1995; Drever and Clow, 1995), which currently is under intense and active research. In general, field derived feldspar dissolution rates are two to five orders of magnitude slower than laboratory measured rates (ibid). Note, however, that when comparing field and laboratory derived rates, one must be careful that the former represent bulk and effective rates and the latter are usually measured at conditions far from equilibrium (Zhu, 2005). Nevertheless, such a large discrepancy underscores our poor understanding of some the fundamental chemical and physical processes which control silicate reaction kinetics in nature.

One distinction that differentiates the field and laboratory conditions is that weathering product minerals are often intimately associated with the primary minerals in nature (Banfield and Eggleton, 1990; Banfield et al., 1991; Banfield and Barker, 1994; Zhu et al., 2006; Hereford et al., 2007). Conversely, in laboratory experiments, the precipitation of product minerals was often purposely suppressed. Recognizing the close association between the secondary minerals and primary mineral in the field, Zhu et al. (2004a) proposed a new hypothesis for explaining the laboratory-field discrepancy wherein the slow kinetics of secondary clay precipitation is the rate limiting step and thus controls the overall feldspar dissolution rate. Clay precipitation removes solutes from the aqueous solution, maintaining a condition of feldspar undersaturation, makes additional feldspar dissolution possible, but the slow clay precipitation (or smaller effective rate constants with respect to that for the dissolution reaction, see below) results in a steady state in which the aqueous solution is near equilibrium with feldspar. Therefore, slow clay precipitation could effectively reduce feldspar dissolution rates by orders of magnitude, in a fashion consistent 
Zhu \& Lu

with laboratory rates at conditions far from equilibrium, the control of dissolution rates by the Gibbs free energy of the reaction, and many field observations (Zhu et al., 2004a).

The potential control of slow clay precipitation on overall feldspar dissolution rates calls for rigorous testing of the above mentioned partial equilibrium hypothesis. Therefore, we have conducted a series of batch experiments of feldspar dissolution and secondary mineral precipitation at elevated temperatures and pressures (Fu et al., 2008). The new experiments are necessary because earlier studies, mostly conducted in the 1960s, typically did not (1) measure the aluminum concentrations that are necessary for saturation index evaluations; (2) analyze (or had the capacity to analyze with the techniques of the time) mineral products of nanometer size in great detail, or (3) take extra care to remove the fine particles on the feldspar surfaces that were later found to produce parabolic rate law artifacts (Holdren and Berner, 1979).

The present communication consists of geochemical modeling of the experimental results reported in Fu et al. (2008) as well as those in the literature (Alekseyev et al., 1997; Murakami et al., 1998) in the context of the partial equilibrium hypothesis and classic reaction path model. Although numerical reaction path modeling to match temporal evolution of aqueous solution chemistry and changes of the reaction rates could present more quantitative arguments in this study, the reaction path modeling would necessarily invoke the assumptions of reactive surface areas and the forms of rate laws, both of which are controversial. It is important to establish the evaluation of the partial equilibrium hypothesis without these assumptions.

\section{BACKGROUND}

To facilitate the discussions that follow, let us start with the classical reaction path model of feldspar hydrolysis (Helgeson, 1968; Helgeson et al., 1969; Helgeson, 1971; Helgeson, 1979), which states that: (1) dissolution of primary feldspar is the rate-limiting irreversible reaction and the driver of all processes in the system; 


\section{Zhu \& Lu}

(2) precipitation of all secondary minerals is instantaneous; (3) the aqueous solution is at equilibrium with or undersaturated with respect to all secondary minerals at all times; (4) fluid chemistry evolves along the boundaries of the mineral phases on equilibrium activity-activity diagrams (abbreviated as $a-a$ diagrams hereafter); and (5) secondary minerals dissolve and precipitate in a paragenesis sequence as aqueous chemistry evolves. This model has been described in nearly all geochemistry textbooks (see Anderson and Crerar, 1993; Krauskopf and Bird, 1995; Stumm and Morgan, 1996; Drever, 1997; Faure, 1998).

Consider the classic example of $\mathrm{K}$-feldspar (microcline) hydrolysis at $25^{\circ} \mathrm{C}$ and 1 bar in a closed system (Fig. 1a). Because it is out of equilibrium, feldspar dissolves in pure water (with a little $\mathrm{HCl}$ ) that initially contains essentially no $\mathrm{Si}, \mathrm{K}$, or Al. When the solution reaches point 1 on Fig. 1a, gibbsite forms and the solution is located in the gibbsite stability field. The aqueous solution has a saturation index (SI) of zero for gibbsite and is undersaturated with respect to kaolinite and muscovite. At point 2, kaolinite starts to precipitate. The coexistence of gibbsite and kaolinite buffers the activity of silica, and the fluid composition moves along the gibbsite-kaolinite boundary on the $a-a$ diagram. As feldspar continues to dissolve, gibbsite is converted to kaolinite. Along 2 to 3 , the saturation indices for both gibbsite and kaolinite are zero (at equilibrium) and for muscovite negative (undersaturated) (Fig. 1b). After all of the gibbsite is consumed, the fluid composition departs from the gibbsite-kaolinite boundary and traverses the kaolinite stability field toward microcline. Within the kaolinite stability field (point 4), the solution is undersaturated with respect to gibbsite $(\mathrm{SI}<0)$, saturated with respect to kaolinite $(\mathrm{SI}=0)$, and undersaturated with respect to muscovite (Fig. 1b). Between points 5 and 6, as $\mathrm{K}$ and $\mathrm{Si}$ concentrations increase, the solution reaches saturation with respect to muscovite, and muscovite starts to precipitate. The coexistence of muscovite and kaolinite buffers the activity ratio $\left(a \mathrm{~K}^{+} / a \mathrm{H}^{+}\right)$, and the fluid composition moves horizontally along the muscovite-kaolinite boundary (points 5,6). After all the kaolinite is consumed, the fluid composition departs from the kaolinite-muscovite boundary and evolves across the muscovite stability field towards K-feldspar. When the reaction path reaches point 7, quartz saturation is achieved. There are two different paths depending on whether quartz precipitates. If quartz precipitation is inhibited, the solution continues to evolve along the direction of point $6 \rightarrow$ point 7 , towards the Kfeldspar field. If quartz precipitates, the solution would evolve along the direction of point $7 \rightarrow$ point 8 , i.e., along the quartz saturation line (dashed line). In the second case, muscovite and quartz both precipitate because the solution is supersaturated with both muscovite and quartz. It is also possible, depending on the starting point, that the reaction path would not encounter the muscovite stability but would reach the microcline field through the 
$\mathrm{Zhu} \& \mathrm{Lu}$

kaolinite field or directly from the gibbsite field into muscovite field (Helgeson, 1979; Steinmann et al., 1994). While the $a-a$ diagrams depict the evolution of fluid chemistry (i.e., reaction path) in the feldspar-water system, the mineral abundance versus time diagram (Fig. 1c) depicts the sequential appearance and disappearance of gibbsite, kaolinite, muscovite, and quartz as the fluid moves from one stability field to another following the well known paragenesis sequence determined by thermodynamics.

However, Lasaga (1998) used different ratios of rate constants $k_{\mathrm{i}} / k_{\text {feld }}$, where $i$ stands for clay minerals gibbsite, kaolinite, or muscovite, and showed that reaction paths deviate from the classic reaction path model if the secondary minerals are not at equilibrium with the aqueous fluid. The deviations are manifested in two forms. First, the fluid chemistry no longer evolves along the mineral stability boundaries, but enters into another mineral stability field across the boundary at an oblique angle (hence, the reaction path is different from the classic reaction path model in terms of fluid chemistry). Second, the secondary minerals precipitated earlier no longer dissolve completely as fluid moves into the stability field of another mineral lower in the paragenesis sequence, but persist for a duration determined by the rate constant ratios. For example, some gibbsite persists when the solution chemistry is in the stability field of kaolinite. There may be a region of coexistence of gibbsite and kaolinite, and even a region of coexisting gibbsite, kaolinite, and muscovite. These regions become larger as the ratios of $k_{\mathrm{i}} / k_{\text {feld }}$ become smaller. Zhu et al. (2004a; 2004b) showed that when the $k_{\mathrm{i}} / k_{\text {feld }}$ (or more precisely the effective rate constants defined as $k^{*}=k \times$ surface area) are in $10^{-2}$ to $10^{-4}$, clay precipitation becomes the rate limiting step and a steady state persisted at which feldspar continues to dissolve near equilibrium at a much reduced rate due to the free energy effect. The term of "slow clay precipitation" in this communication refers to this scenario (i.e.,

$k_{i}^{*} / k_{\text {feld }}^{*}\langle\langle 1)$. However, these numerical predictions were intuitive and illustrative. The partial equilibrium hypothesis has not been tested experimentally or systematically.

\section{MODELING RESULTS}

In this paper, saturation indices (SI) for relevant minerals were calculated from the measured temperatures, pressures, and chemical compositions of experimental aqueous solutions. SI is defined as $\log (Q / K)$, where $Q$ denotes the activity quotient and $K$ the equilibrium 
constant (Zhu and Anderson, 2002, p. 45). Equilibrium activity-activity diagrams for mineral stability and phase relations were constructed to trace the evolution of the aqueous chemistry during the batch experiments. For all thermodynamic calculations, the standard states for the solids are defined as unit activity for pure end-member solids at the temperature and pressure of interest. The standard state for water is the unit activity of pure water. For aqueous species other than $\mathrm{H}_{2} \mathrm{O}$, the standard state is the unit activity of the species in a hypothetical one molal solution referenced to infinite dilution at the temperature and pressure of interest. Standard state thermodynamic properties for mineral end-members were taken from Holland and Powell (1998) except for boehmite (see Appendix A), for water from Haar et al. (1984), for Al-bearing aqueous species from Tagirov and Schott (2001), $\mathrm{KCl}^{\circ}{ }_{(\mathrm{aq})}$ from Ho et al. (2000), and all other aqueous species from Shock and Helgeson (1988), Shock et al. (1989), Shock et al. (1997), and Sverjensky et al. (1997) (Table 1a). The temperature and pressure dependences of thermodynamic properties for aqueous species, when applicable, were predicted using the parameters of the revised HKF equations of state for aqueous species (Helgeson et al., 1981; Tanger and Helgeson, 1988; Shock et al., 1992). Calculations of equilibrium constants were facilitated with a modified version of SUPCRT92 (Johnson et al., 1992) with the heat capacity function of Holland and Powell (1998) for minerals. Speciation and solubility calculations were aided with the computer code PHREeQC (Parkhurst and Appello, 1999) and EQ3/6 (Wolery, 1992) together with our own equilibrium constant databases for the programs with thermodynamic properties noted above. Activity coefficients for the charged aqueous species were calculated from the extended Debye-Hückel equation or B-dot equation fitted to mean salt $\mathrm{NaCl}$ activity coefficients (Helgeson et al., 1978; Oelkers and Helgeson, 1990).

In order to test whether the conclusions still stand when different sets of thermodynamic 
properties are used, SI values for primary minerals and product minerals were also calculated using three additional sets of thermodynamic properties for mineral end-members and aqueous species. These datasets are referred to A, B, and C in the following discussion, and their sources of thermodynamic properties are listed in Table $1 \mathrm{~b}$. The SI values calculated using these three datasets are presented as open symbols in Figs. 3, 5, 7, 9, 11, together with the baseline case ("BL" represented by solid symbols) described in the preceding paragraph. The equilibrium constants and calculated values of SI from these three datasets are shown in the Electronic Annex. Table 2 summarizes the batch experiments, for which geochemical modeling was carried out.

\subsection{Alkali Feldspar Dissolution and Clay Precipitation}

\subsubsection{Experimental Design and Results}

Two batch experiments for alkali feldspar dissolution in $\sim 0.20 \mathrm{~m} \mathrm{KCl}$ solution at an initial $\mathrm{pH}$ of 3.1 were conducted at $200{ }^{\circ} \mathrm{C}$ and 300 bars in a flexible $\mathrm{Au} / \mathrm{Ti}$ reaction cell, which was placed in a steel-alloy autoclave (Fu et al., 2008). X-ray diffraction (XRD) and electron microprobe analysis (EMPA) results show that the alkali feldspar sample was composed of 35\% low albite $\left(\mathrm{Ca}_{0.04} \mathrm{Na}_{0.95} \mathrm{~K}_{0.01} \mathrm{Al}_{1.04} \mathrm{Si}_{2.96} \mathrm{O}_{8}\right), 60 \%$ orthoclase $\left(\mathrm{K}_{0.85} \mathrm{Na}_{0.15} \mathrm{Al}_{1.04} \mathrm{Si}_{2.97} \mathrm{O}_{8}\right)$, and $5 \%$ quartz. A time series of in situ aqueous samples was analyzed for $\mathrm{Cl}, \mathrm{Si}, \mathrm{Al}, \mathrm{K}, \mathrm{Na}$, and $\mathrm{Ca}$ as well as trace elements. One experiment was terminated at the end of $120 \mathrm{~h}$, and the solids in the experiment were recovered for analysis. XRD and High Resolution Transmission Electron Microscopy (HRTEM) results showed boehmite and trace amount of kaolinite. Scanning Electron Microscopic (SEM) examination showed dissolution channels and the feldspar surfaces were covered with product minerals. The second experiment was terminated after $1872 \mathrm{~h}$. XRD of the solids detected boehmite and kaolinite, but no detectable muscovite. SEM images of the 
reaction products after the batch experiments showed that hexagonally shaped secondary minerals were present on the grains of alkali feldspars, but with no clear orientation or preferential sites on the feldspar surfaces. Laminar channels and etch pits on the surface of alkali feldspars indicated dissolution heterogeneity. The surface coverage of the secondary minerals was approximately $20 \%$.

\subsubsection{Reaction Paths and Mineral Saturation Indices}

The time evolution of aqueous chemistry in the system $\mathrm{Na}_{2} \mathrm{O}-\mathrm{K}_{2} \mathrm{O}-\left(\mathrm{Al}_{2} \mathrm{O}_{3}\right)-\mathrm{SiO}_{2}-\mathrm{H}_{2} \mathrm{O}-$ $\mathrm{HCl}$ system is traced on $a-a$ diagrams (Fig. 2). The parentheses on $\mathrm{Al}_{2} \mathrm{O}_{3}$ indicate that $\mathrm{Al}_{2} \mathrm{O}_{3}$ is used as the balancing component in writing reversible reactions for this system. Although three dimensional (3D) phase diagrams with axes of $\log a \mathrm{SiO}_{2}(\mathrm{aq})-\log \left(a \mathrm{~K}^{+} / a \mathrm{H}^{+}\right)-\log \left(a \mathrm{Na}^{+} / a \mathrm{H}^{+}\right)$ represent the reaction paths more realistically, the $3 \mathrm{D}$ diagrams in publications are difficult to view without the ability to rotate the axes. Therefore, although we constructed the 3D $a-a$ diagrams and used them for data analysis, we present the $a-a$ diagrams in two-dimensions (2D), which can be viewed as the $2 \mathrm{D}$ projection of the three dimensional diagrams on the plane that intersects zero on the third axis. Because this experiment is a $\mathrm{K}^{+}$-dominated system with respect to $\mathrm{Na}^{+}$, we present the $2 \mathrm{D} \log a \mathrm{SiO}_{2}(\mathrm{aq})-\log \left(a \mathrm{~K}^{+} / a \mathrm{H}^{+}\right) a-a$ diagrams, which approximately portray the phase relations pertaining to the experimental system. Microcline was used in place of orthoclase because thermodynamic properties for orthoclase are not available in the database of Holland and Powell (1998). To illustrate the temporal evolution of the system, we added time as the vertical axis in Fig. $2 b$.

The solution chemistry fell within the boehmite stability field after $24 \mathrm{~h}$. The $120 \mathrm{~h}$ sample showed that the aqueous fluid crossed the boehmite-kaolinite boundary and entered into the kaolinite stability field. Fluid chemistry fell in the muscovite stability field from 216 to 1872 
h, but muscovite was not detected in the products (Fu et al., 2008). Dissolution of the microcline should have stopped at $456 \mathrm{~h}$ because the microcline was supersaturated at this point (see below), but the fluid chemistry did not reach the microcline stability field even at the end of the experiment.

Although albite continued to dissolve in the experiment (Fu et al., 2008), the 2D log $a \mathrm{SiO}_{2}(\mathrm{aq})-\log \left(a \mathrm{Na}^{+} / a \mathrm{H}^{+}\right)$diagram is omitted here because it gives misleading projection that samples 3 to 7 fell within the kaolinite stability. In the 3D $a-a$ diagram (not shown), it is clear that these samples fell within the muscovite stability in this $\mathrm{K}^{+}$-dominated system.

SI values of the minerals of interest were calculated at each sampling time (Table 3). All sampled solutions were undersaturated with respect to albite (i.e., the major reactant), but the experimental solution changed from undersaturation with respect to microcline from 24 to $216 \mathrm{~h}$ to supersaturation at $456 \mathrm{~h}$. The solutions reached supersaturation with respect to boehmite, kaolinite, and muscovite at the earliest sampling time of $24 \mathrm{~h}$, and these phases continued to be supersaturated during the entire experiment (Fig. 3 and Table 3). Boehmite SI decreased slightly from 24 to $216 \mathrm{~h}$ coinciding with the fluid chemistry entries into the kaolinite field, increased to a maximum of 2.4 at $456 \mathrm{~h}$, and then decreased toward the end of the experiment. Kaolinite SI showed a maximum at $456 \mathrm{~h}$, and then decreased toward the end of the experiment.

The supersaturation of kaolinite and muscovite while the fluid chemistry is located in the boehmite stability field, and the supersaturation of boehmite while the fluid chemistry is located in the kaolinite and muscovite fields, indicate a departure from partial equilibrium between the aqueous solution and the secondary phases. Lasaga (1998) found muscovite supersaturation while the fluid is in the kaolinite field in the reaction path simulations that incorporated kinetics of secondary mineral dissolution and precipitation (see Discussion below). 
The solution was undersaturated with respect to paragonite from $24 \mathrm{~h}$ to $216 \mathrm{~h}$, but supersaturated from $456 \mathrm{~h}$ to $1872 \mathrm{~h}$ (Fig. 3 and Table 3 ) while the solution was located in the muscovite stability field. The sampled solutions were undersaturated with respect to quartz up to $816 \mathrm{~h}$, but close to equilibrium with quartz after $1368 \mathrm{~h}$ (Fig. 3 and Table 3 ).

The conclusion of supersaturation of product minerals for the baseline case (with solid symbols and connecting lines in Fig. 3) seems to sustain when different sets of thermodynamic properties are used (Fig. 3, open symbols and labeled as "A", "B", “C”, see Table 1b). In other words, the uncertainties of the thermodynamic properties for mineral end-members and aqueous species are not large enough to result in indications of opposite reaction directions for the experiments examined. To evaluate the baseline case further, the propagated errors in SI values were calculated for $95 \%$ confidence interval from the reported standard deviation of enthalpy of formation at $25^{\circ} \mathrm{C}$ alone (Hemingway et al., 1991; Holland and Powell, 1998).

The reaction path from sample at $816 \mathrm{~h}$ to samples at $1368 \mathrm{~h}$ and $1872 \mathrm{~h}$ requires the total consumption of boehmite in the partial equilibrium case. However, as noted earlier, the prolonged experiment did not show the disappearance of boehmite even though the solution chemistry had drastically departed from the boehmite field (Fig. 2b). In other words, the experimental data did not show sequential mineral dissolution and precipitation or paragenesis from boehmite to kaolinite to muscovite, as predicted by theoretical calculations assuming partial equilibrium between the product minerals and the aqueous solution with evolving chemistry. It should also be noted that the solution reached boehmite supersaturation very quickly after the experiment commenced (the earliest sampling time was $24 \mathrm{~h}$ after the experiment started). 


\subsection{Alkali Feldspar Dissolution and Clay Precipitation in $\mathrm{CO}_{2}$ Charged Systems}

\subsubsection{Experimental Design and Results}

These two batch experiments for alkali feldspar dissolution were similar in design to those presented in the preceding section. However, the experiments differed by adding $50 \mathrm{mM}$ $\mathrm{CO}_{2}$ into the experimental charge. One experiment was terminated at the end of $120 \mathrm{~h}$, and a second experiment was terminated after $648 \mathrm{~h}$. SEM images of the reaction products showed extensive dissolution features and secondary mineral coverage on feldspar grain surfaces. TEM study detected boehmite in samples after $120 \mathrm{~h}$ reaction, and XRD patterns indicated boehmite and muscovite in the $648 \mathrm{~h}$ sample. The fluid chemistry data are presented in Appendix B.

\subsubsection{Reaction Paths and Mineral Saturation Indices}

The reaction paths from these two batch experiments (Fig. 4) are different from those in the counterpart experiments without $\mathrm{CO}_{2}$ (cf. Fig. 2) because they started with a higher initial pH so that the kaolinite field was skipped. SI values of the minerals of interest are listed in Table 4. All sampled solutions were undersaturated with respect to albite, but the experimental solution changed from undersaturation with respect to microcline to supersaturation after $24 \mathrm{~h}$. As in the experiments without $\mathrm{CO}_{2}$, the solutions attained supersaturation with respect to boehmite, diaspore, kaolinite, and muscovite at the earliest sampling time of $24 \mathrm{~h}$, and these phases were supersaturated during the entire experiment (Fig. 5 and Table 4). The supersaturation of muscovite while the fluid chemistry has located in the boehmite stability field, and the supersaturation of boehmite while the fluid chemistry was located in the muscovite stability field are, again, indicative of a departure from partial equilibria between the aqueous solution and secondary phases (Lasaga, 1998). 
Similar to what Steinmann et al. (1994) illustrated in classroom exercises at room temperature, the fluid chemistry would be fixed at a point on the boehmite - muscovite boundary for the partial equilibrium case because the reaction

$$
\mathrm{AlOOH}+\mathrm{KAlSi}_{3} \mathrm{O}_{8} \rightarrow \mathrm{KAl}_{3} \mathrm{Si}_{3} \mathrm{O}_{10}(\mathrm{OH})_{2}
$$

does not change aqueous compositions of the system. However, the experimental data show that the aqueous fluid departed from the boehmite - muscovite boundary while boehmite was still observed at the end of the experiment. Apparently, partial equilibria were not observed.

\subsection{Anorthite Dissolution Batch Experiments}

\subsubsection{Experimental Design and Results}

Murakami et al. (1998) performed three series of batch experiments for anorthite $\left(\mathrm{An}_{95} \mathrm{Ab}_{5}\right)$ dissolution in $0.03 \mathrm{M}$ sodium acetate at 90,150 , and $210{ }^{\circ} \mathrm{C}$ with a room temperature initial $\mathrm{pH}$ of 4.56. Single crystals of anorthite were prepared by crushing. Experimental runs were from $72 \mathrm{~h}$ to $8520 \mathrm{~h}$. After the run, the reaction vessel was cooled to room temperature within $30 \mathrm{~min}$, and the aqueous solution was filtered with $0.22 \mu \mathrm{m}$ filters. Secondary minerals formed during the experiments were identified with XRD, SEM, and HRTEM. A sequence of secondary minerals, including boehmite, "modified boehmite" with silica, and kaolinite, was formed with increasing reaction time. Table 5 summarizes their reported experimental times when the different product minerals were observed.

\subsubsection{Reaction path and Mineral Saturation Indices}

The time evolution of Murakami et al.'s (1998) aqueous solution chemistry in the system CaO-Na2 $-\mathrm{O}-\left(\mathrm{Al}_{2} \mathrm{O}_{3}\right)-\mathrm{SiO}_{2}-\mathrm{H}_{2} \mathrm{O}-\mathrm{HCl}$-acetate was traced on the $a-a$ diagrams (Fig. 6). In all 
Zhu \& Lu

experiments, the solution chemistry quickly evolved from the boehmite stability field to the kaolinite stability field after 240,72 , and 72 hours, at 90,150 and $210{ }^{\circ} \mathrm{C}$, respectively. The solution chemistry stayed within the kaolinite field with little change for thousands more hours. This results in an almost vertical trend on the 3D $a-a-t$ diagrams (Fig. 6b). Murakami et al. (1998) found that boehmite and "modified boehmite" are the main product minerals from anorthite dissolution at 90,150 , and $210^{\circ} \mathrm{C}$. Kaolinite was found after 2328 hours' of experiment at $210{ }^{\circ} \mathrm{C}$, long after the solution chemistry had entered into the kaolinite stability field.

The solutions were supersaturated with respect to boehmite and kaolinite during the entire experiments at 90, 150, and $210{ }^{\circ} \mathrm{C}$ (Fig. 7 and Table 5). Kaolinite supersaturation occurred when the fluid chemistry was still located in the boehmite field. The solutions were undersaturated with respect to anorthite during the $90^{\circ} \mathrm{C}$ experiment, but changed from undersaturation to supersaturation at $150{ }^{\circ} \mathrm{C}$ after 240 hours, and $210{ }^{\circ} \mathrm{C}$ after 816 hours (Fig. 7 and Table 5). At 90 and $150{ }^{\circ} \mathrm{C}$, anorthite SI did not vary monotonically. There was an increase, and then a decrease with time, probably coincident with precipitation of product mineral(s). Murakami et al. (1998) believed that anorthite dissolution continued during the entire experiment as evidenced by the continued increase of $\mathrm{Ca}^{2+}$ concentrations. Therefore, the calculated SI $(>0)$ of anorthite in the experiments could result from uncertainties of thermodynamic properties for anorthite, which show an unusually large range in the literature (Arnórsson and Stefánsson, 1999). The experimental solutions were also supersaturated with respect to paragonite. The experimental solutions were close to quartz saturation at the end of the experiments.

\subsection{Sanidine and Albite Dissolution Experiments}

Alekseyev et al (1997) conducted two series of batch experiments. The first one was for sanidine $\left(\mathrm{KNa}_{0.03} \mathrm{Al}_{0.99} \mathrm{Si}_{3} \mathrm{O}_{8}\right)$ dissolution in $0.1 \mathrm{~m} \mathrm{NaHCO}_{3}$ solution and the second series for 
low albite $\left(\mathrm{Na}_{0.97} \mathrm{~K}_{0.02} \mathrm{AlSi}_{3.01} \mathrm{O}_{8}\right)$ dissolution in $0.1 \mathrm{~m} \mathrm{KHCO}_{3}$ solution, both at $300{ }^{\circ} \mathrm{C}$ and 88 bars (Alekseyev et al., 1997). The pH was buffered by the dissolved carbonate and bicarbonate to near 9. XRD and SEM results indicate that the secondary minerals formed for sanidine and albite dissolution were analcime $\left(\mathrm{NaAlSi}_{2} \mathrm{O}_{6} \cdot \mathrm{H}_{2} \mathrm{O}\right)($ after $\sim 7 \mathrm{~h})$ and sanidine (after $\left.\sim 16 \mathrm{~h}\right)$, respectively. Alekseyev et al. (1997) conducted detailed modeling analysis of their experimental data. They concluded that secondary mineral precipitation rates dominate the kinetics of incongruent dissolution. We examined their experimental results in the same manner as shown above for consistency, but our conclusions are similar to those of Alekseyev et al (1997).

\subsubsection{Sanidine Dissolution in $\mathrm{NaHCO}_{3}$ Solution}

The evolution of the aqueous solution chemistry during Alekseyev et al's (1997) experiments is depicted in the $a$ - $a$ diagrams for the $\mathrm{Na}_{2} \mathrm{O}-\mathrm{K}_{2} \mathrm{O}-\left(\mathrm{Al}_{2} \mathrm{O}_{3}\right)-\mathrm{SiO}_{2}-\mathrm{H}_{2} \mathrm{O}-\mathrm{CO}_{2}$ system, projected for the zero $\log \left(a \mathrm{~K}^{+} / a \mathrm{H}^{+}\right)$for the Na-dominated experimental system (Fig. 8). The solution chemistry evolved from the paragonite stability field to the analcime stability field after $0.25 \mathrm{~h}$. The solution stayed in the analcime stability field from 0.25 to $7 \mathrm{~h}$, and entered into the albite stability field and stayed there until the end of the experiment (16 h-1848 h) (Fig. 8d). Even though the solution chemistry fell in the albite stability field, albite was not detected with either XRD or SEM and was undersaturated (see below). Alekseyev et al. (1997) observed analcime precipitation from 16 to $1848 \mathrm{~h}$. Because both the $\mathrm{pH}$ of the solution was buffered around 9 and $\mathrm{Na}^{+}$was predominant, the $a \mathrm{Na}+/ a \mathrm{H}+$ ratios stayed nearly constant.

Saturation indices for minerals of interest were calculated for each experiment (Fig. 9 and Table 6). The solutions were undersaturated with respect to sanidine during the entire experiment (Fig. 9a and Table 6). The solutions were supersaturated with respect to analcime and albite 
during 7 to $72 \mathrm{~h}$ and 16 to $72 \mathrm{~h}$ reaction time, respectively. During the other time intervals, the solutions were undersaturated with respect to analcime and albite. The apparent conflict between calculated $<0$ SI values and the observation of continued analcime precipitation (Alekseyev et al., 1997) is puzzling, but could be related to uncertainties in the thermodynamic properties for analcime. As a member of the zeolite group, analcime may have a range of chemical compositions and structural details. Our calculated analcime SI values are within $\sim 0.2$ units of those calculated by Alekseyev et al. (1997) who used different thermodynamic properties but also showed negative SI while reporting analcime precipitation. However, it is clear from the experimental data that, although the experiments had progressed into the albite stability field, analcime is the mineral that was detected.

\subsubsection{Albite Sanidine Dissolution in $\mathrm{KHCO}_{3}$ Solution}

Activity-activity diagrams projected for the zero $\log \left(a \mathrm{Na}^{+} / a \mathrm{H}^{+}\right)$for this $\mathrm{K}$-dominated experimental system in the $\mathrm{K}_{2} \mathrm{O}-\mathrm{Na}_{2} \mathrm{O}-\left(\mathrm{Al}_{2} \mathrm{O}_{3}\right)-\mathrm{SiO}_{2}-\mathrm{H}_{2} \mathrm{O}-\mathrm{CO}_{2}$ system are shown in Fig. 10. The solution chemistry evolved from the muscovite stability field to the sanidine stability field after only $0.5 \mathrm{~h}$. For the next $16 \mathrm{~h}$, fluid chemistry moved horizontally in the sanidine field as the $\mathrm{pH}$ and $a \mathrm{~K}^{+}$(and hence their ratios) were buffered and silica activity increased with time. Thereafter, the fluid chemistry changed little from 16 to $848 \mathrm{~h}$ within the sanidine field, which is manifested on overlapping data points on the 2D diagram (Fig. 10a) and a straight vertical line on the 3D diagram (Fig. 10b). Alekseyev et al. (1997) observed that sanidine precipitated during this period of time.

The solutions were undersaturated with respect to albite during the entire experiment and supersaturated with respect to sanidine after $1.25 \mathrm{~h}$ (Table 7 and Fig. 11a,b), shortly after the 
solution chemistry entered into the sanidine field at $0.5 \mathrm{~h}$. Alekseyev et al. (1997) observed no sanidine precipitation during this time period, and their analysis showed that albite dissolution was congruent. The solution was undersaturated with respect to muscovite during the time ( $0-$ $0.5 \mathrm{~h}$ ) while the fluid composition was located in the muscovite stability field. After that, for the duration of the experiment, muscovite was either supersaturated $(7-48 \mathrm{~h}$ ) or undersaturated (all other times).

Alekseyev et al. (1997) concluded that slow precipitation of secondary minerals dominated the overall reactions in these two experimental series. The relatively higher temperature $\left(300{ }^{\circ} \mathrm{C}\right)$ in the experiments resulted in fast chemical evolution into the field of more stable phases, but a steady state was reached for the coupled dissolution - precipitation reactions (Fig. 8b, 10b), which prevailed during the majority of the experiments. Zhu et al. (2004a; 2004b) used reaction path modeling to show that such a steady state could be reached when the effective precipitation rate constants are much lower than the dissolution rate constants.

\section{DISCUSSION}

\subsection{Uncertainties of Thermodynamic Properties on Calculated Saturation Indices}

The calculated saturation states depend on the values of the standard state thermodynamic properties of both the minerals and aqueous species. Various internally consistent databases for thermodynamic properties for mineral species have been compiled (Helgeson et al., 1978; Berman, 1988; Berman, 1990; Robie and Hemingway, 1995; Holland and Powell, 1998). However, controversies and discrepancies still exist, particularly for the alumino-silicate minerals that are the primary focus of this study (see Pokrovskii and Helgeson, 1995; Arnórsson and Stefánsson, 1999). We chose to use the thermodynamic properties for mineral species from 
Holland and Powell (1998) because this database is internally consistent and it has incorporated recent experimental data as compared to other databases. Thermodynamic properties for boehmite are not available from the Holland and Powell (1998) database, and are discussed in Appendix A.

It is known that thermodynamic properties of minerals derived from calorimetric and phase equilibrium experiments rarely can predict experimental solubility results accurately (Sverjensky et al., 1991). The Holland and Powell thermodynamic properties for feldspars, kaolinite, and muscovite were derived from calorimetric and phase equilibrium measurements. However, Holland and Powell (1998) showed (their Fig. 2) that although the solubility data in the $\mathrm{K}_{2} \mathrm{O}-\mathrm{Al}_{2} \mathrm{O}_{3}-\mathrm{SiO}_{2}-\mathrm{H}_{2} \mathrm{O}-\mathrm{HCl}$ system reported by Sverjensky et al. (1991) were not used simultaneously together with phase equilibrium and calorimetric data in regressing thermodynamic properties for alumino-silicates, the off-sets of calculated phase stability fields from experimental data are small. This adds confidence to our calculated saturation indices for the $\mathrm{K}_{2} \mathrm{O}-\mathrm{Al}_{2} \mathrm{O}_{3}-\mathrm{SiO}_{2}-\mathrm{H}_{2} \mathrm{O}-\mathrm{HCl}$ system.

The boundaries of mineral stability fields are sensitive to the free energies used in the construction of $a-a$ diagrams (Zhu and Anderson, 2002). For example, a decrease of $1.2 \mathrm{~kJ} / \mathrm{mol}$ of the $\Delta G_{f}^{o}$ for boehmite would move the boehmite - kaolinite phase boundary to the right about 0.13 unit of $\log a \mathrm{SiO}_{2}(\mathrm{aq})$ in Fig $2 \mathrm{a}$. The adjusted $\Delta G_{f}^{o}$ value of $-919.6 \mathrm{~kJ} / \mathrm{mol}$ is still within the uncertainties of the $\Delta G_{f}^{o}$ values given by Hemingway et al. (1991) and McHale et al. (1997), and would fit to the kaolinite - boehmite phase equilibrium experiments by Hemley et al. (1980) better but fit the boehmite - andalusite phase equilibrium less well (see Appendix A). Likewise, the adjustment of $1.2 \mathrm{~kJ} / \mathrm{mol}$ to $\Delta G_{f}^{o}$ for boehmite would lead to an adjustment of $0.13 \mathrm{SI}$ units for boehmite, which, however, is insufficient to change the nature of boehmite supersaturation, 
as boehmite was one to two SI unit supersaturated in these sampled solutions (cf. Table 3). In other words, it would require an adjustment of $21.7 \mathrm{~kJ} / \mathrm{mol}$ to $\Delta G_{f}^{o}$ for boehmite to be at equilibrium with the aqueous solution at $456 \mathrm{~h}$ in Fu et al.'s (2008) experiments. This conclusion also applies to the alkali feldspar experiments with $\mathrm{CO}_{2}$ (Table 4) and experiments by Murakami et al. (1998), which show boehmite supersaturation from one to two SI units (cf. Table 5).

As discussed briefly earlier, to further test the validity of the conclusion that experimental solutions were supersaturated with respect to product minerals in the batch experiments that we have examined, we calculated saturation indices using different sets of thermodynamic properties for aqueous species and minerals, and different combinations of the two. The Electronic Annex of this paper shows the detailed results of these calculations. The conclusion of supersaturation of product minerals still holds for the batch experiments examined in this study. In other words, the calculated saturation states are valid with the known uncertainties of thermodynamic properties.

\subsection{Reaction Paths}

Lasaga (1998) showed, analytically, how the precipitation kinetics of secondary minerals is coupled to the rate of feldspar dissolution reaction. The kinetics of secondary mineral formation comes into play in the mass balance equations. Starting with the mass balance on $\mathrm{Al}$ and assuming the metastable coexistence of kaolinite and boehmite, we have,

$$
R_{\text {feld }}=\frac{-R_{b h m}-2 R_{k l n}}{\left[\sum_{j} \frac{d n_{A l_{j, a q}}}{d \xi}-1\right]}
$$


where $R_{\mathrm{i}}$ is the net rate ( $\left.d \xi / d t\right)$ of dissolution of feldspar, boehmite, and kaolinite $\left(R_{\mathrm{i}}<0\right.$ means precipitation). $n$ denotes the moles of $\mathrm{j}^{\text {th }} \mathrm{Al}$ aqueous species and $\xi$ the overall progress variable (Helgeson, 1968). Equation (1) is equivalent to Lasaga's (1998) Eqn. (1.235).

If we expand the net rate expression and divide the right hand side by $k_{\text {feld, }}$ we have,

$$
R_{\text {feld }}=\frac{-k_{\text {bhm }} / k_{\text {feld }} S_{\text {bhm }} f\left(\Delta G_{b h m}\right)-2 k_{k l n} / k_{\text {feld }} S_{k l n} f\left(\Delta G_{k l n}\right)}{\left[\sum_{j} \frac{d n_{\text {ll } l_{j, a q}}}{d \xi}-1\right] / k_{\text {feld }}}
$$

where $k_{\mathrm{i}}$ denotes the rate constant, $S_{\mathrm{i}}$ the surface area, and $\Delta G_{\mathrm{i}}$ the Gibbs free energy of the reactions. $f\left(\Delta G_{i}\right)$ signifies the relationship between rate and Gibbs free energy of reaction.

Equation (2) shows the inter-dependence between the rate constants of feldspar dissolution and those of boehmite and kaolinite precipitation. The net feldspar dissolution rate is a function of $k_{\mathrm{i}} / k_{\text {feld }}$ ratios. The smaller the $k_{\mathrm{i}} / k_{\text {feld }}$ ratio, the slower feldspar dissolves, provided that all other quantities are kept the same. In fact, the experiments discussed in Section 3 showed that secondary minerals were several SI units supersaturated. Zhu et al. (2004a; 2004b) explored the inter-connections numerically via reaction path modeling. When the effective rate constant ratios $k^{*}{ }_{i} / k_{\text {feld }}$ (defined as $k \times S$ ) are in $10^{-2}$ to $10^{-4}$, slow clay precipitation became the limiting step, and the net feldspar dissolution rates are orders of magnitude slower than that at conditions at far from equilibrium.

The batch experiment data and the modeling results shown in Section 3 of this communication are consistent with earlier numerical modeling predictions that secondary minerals are not at equilibrium with the fluid (Steefel and Van Cappellen, 1990; Lasaga, 1998). The slow-kinetic nature of secondary mineral precipitation was evident from both the fluid chemistry, which crossed the phase boundaries on the $a-a$ diagrams, and from mineral product analysis, which show persistent boehmite presence even after the fluid chemistry had evolved 
into the kaolinite and muscovite stability fields.

Moreover, the analysis of time series fluid chemistry and mineral products, as depicted in the 3D $a-a-t$ diagrams in this study, also revealed the temporal chemical evolution. Feldspar dissolution quickly resulted in the precipitation of a secondary mineral, and the coupling effects of dissolution - precipitation commenced from that point on. In other words, the time window for congruent feldspar dissolution is small in batch systems.

\subsection{Extrapolation to Natural Systems}

Natural systems differ from the laboratory experiments examined here mainly in two aspects. First, experimental results from batch systems cannot be applied directly to systems where advective and dispersive fluxes are significant. However, even in the case of fluid flow in a hydrological system flushed with fresh dilute water, the downstream water receives the solute fluxes from upstream, and the effects of supersaturation with respect to secondary minerals must be similar if the flow system has persisted for a while. These scenarios can be tested in a coupled reactive mass transport model in the future.

Second, laboratory experiments are brief on the scale of geological time. It is therefore necessary to examine samples from geological systems. Assessments of SI in the field are difficult, however, because of the absence or difficulty of aluminum analyses, the complex chemistry and structures of clay minerals, and the lack of internally consistent thermodynamic properties for clay minerals with such complex chemistry and structures. Nevertheless, Kwicklis (2004) calculated SI values of alumino-silicate minerals in the volcanic tuff aquifer in southern Nevada in the vicinity of Yucca Mountain. While the groundwaters there are undersaturated with respect to albite, they are supersaturated with respect to smectite and $\mathrm{Ca}$-clinoptilolite. The more meaningful aspect of his findings is probably the areal distribution of the SI values - the SI 
values increase four to five fold southward along the groundwater flow from the Yucca Mountain and Fortymile Wash area to the Amargosa desert. These solubility-speciation modeling exercises are marred by the general problems with $\mathrm{Al}$ analysis and clay mineral properties discussed above, and specifically by the assumption of equilibrium between kaolinite and groundwaters. Nevertheless, the southward increase of SI for smectite and Ca-clinoptilolite along the flow path appears to support Kwicklis's (2004) assertion that "silicate weathering reactions are providing ions to the groundwater faster than they can be removed by smectite precipitation."

\section{CONCLUDING REMARKS}

Feldspars comprise over $50 \%$ of the volume of the earth's crust. Establishing reliable rates for low-temperature feldspar dissolution is essential to quantify many basic geological and environmental processes. Among these are the functional relationship between silicate weathering and the global climate over geologic time (Berner and Berner, 1997), controls on surface and groundwater quality, global elemental cycling (Lasaga et al., 1994), the availability of inorganic nutrients in soils (Federer et al., 1989; Likens et al., 1998), impacts of acid mine drainage, neutralization of acid precipitation in watersheds (Drever and Clow, 1995), safety of nuclear waste repositories (Spycher et al., 2003), and geological carbon sequestration (White et al., 2003).

The pioneering work by Helgeson and co-workers (Helgeson, 1968; Helgeson et al., 1969; Helgeson and Murphy, 1983; Helgeson et al., 1984) to model feldspar hydrolysis as a process of coupled dissolution and precipitation reactions transformed the study of water-rock interactions into a quantitative science and opened up vast new fields of geochemistry in the following decades. The early model, however, assumed partial equilibria between the aqueous 
solution and the secondary phases. Although the assumption of partial equilibrium has been questioned in the intervening years (Steefel and Van Cappellen, 1990; Nagy and Lasaga, 1993; Small, 1993; Lasaga et al., 1994; Alekseyev et al., 1997; Lasaga, 1998; Zhu et al., 2004a; Price et al., 2005; Zhu, 2006; Ganor et al., 2007), until now there has never been a rigorous examination of this hypothesis. Here, we systematically analyzed our own feldspar hydrolysis batch experiments (Fu et al., 2008) and those in the literature. We find three lines of experimental evidence that contradicts the partial equilibrium hypothesis in the feldspar-water system: saturation indices, reaction paths, and secondary mineral paragenesis. However, we must emphasize that partial equilibria between secondary minerals and aqueous solutions may well exist for systems that involve rapidly precipitating secondary minerals (e.g., pyrite oxidation and precipitation of amorphous iron oxyhydroxides) or even for the feldspar-water system at higher temperatures and pressures.

In the feldspar-water system, the slow kinetics of secondary mineral precipitation results in close inter-dependence of the dissolution and precipitation reaction rates (Steefel and Van Cappellen, 1990; Lasaga et al., 1994; Alekseyev et al., 1997; Lasaga, 1998), which, if clay precipitation rate constants are sufficiently slower than feldspar dissolution rate constant, could rationalize the well-known discrepancy between field feldspar dissolution (bulk, effective) rates and rates measured in laboratory dissolution experiments at conditions far from equilibrium (Zhu et al., 2004a). Field studies often focused on the dissolution rates only. However, as seen in the batch experiments examined by this study, the congruent dissolution stage in the closed systems is short, probably a matter of hours at $90-210{ }^{\circ} \mathrm{C}$. A steady state or near steady state of aqueous chemistry for some constituents persisted as a consequence of the coupled dissolution and precipitation reactions. Zhu et al. (2004a) used a numerical reaction path model to show that 
such a steady state can result if the effective rate constants of clay precipitation are orders of magnitude smaller than those of feldspar. Note that although the reaction Gibbs free energy effect on dissolution rates is a widely cited reason to explain the field - laboratory rate discrepancy, there is a need of a control that such a state of proximity to equilibrium can be maintained in natural systems for prolonged time and over long distance. Slow clay precipitation may serve this role.

Clearly, interpretation of field based reaction rates needs to consider dissolution reactions within a network of dissolution - precipitation reactions. Future work should employ numerical modeling of reaction paths to match the experimental data and hence to quantitatively evaluate the inter-dependence of dissolution - precipitation reactions. However, the challenge is to measure precipitation rates and derive proper rate laws to describe precipitation processes. While the details may evolve over time (e.g., Al adsorption on feldspar surface as a retardation mechanism (Oelkers et al., 1994) and slow clay precipitation kinetics discussed here), the framework of modeling mass transfer in geological systems developed by Helgeson and coworkers will continue to serve as the foundation for rigorous and quantitative geochemical predictions.

Acknowledgments. This work is supported by the U.S. Department of Energy under Award No. DE-FG2604NT42125 and partially by the National Science Foundation under Award No. EAR0423971 and EAR0509775 to CZ. Any opinions, findings, and conclusions or recommendations expressed in this material, however, are those of the authors and do not necessarily reflect the views of the United States Government or any agency thereof. We thank Jim Brophy, Kurt Swingle, and Jeff Dick for review of the manuscript before submission. CZ also wishes to thank Bill Seyfried for his permission to include experiments in Sec 3.2 and Appendix B ahead of the publication of their joint research. We want to dedicate this work to Harold C. Helgeson, who passed away in May 2007. It is on his pioneering work that our efforts are based. 


\section{TABLES AND FIGURES}

Table 1a. Equilibrium constants used in this study (for the baseline case).

\begin{tabular}{|c|c|c|c|c|c|c|}
\hline Aqueous reactions & $\begin{array}{c}25^{\circ} \mathrm{C} \\
1 \mathrm{bar}\end{array}$ & $\begin{array}{c}90^{\circ} \mathrm{C} \\
1 \mathrm{bar}\end{array}$ & $\begin{array}{c}150^{\circ} \mathrm{C} \\
\text { Psat }\end{array}$ & $\begin{array}{c}210^{\circ} \mathrm{C} \\
\text { Psat }\end{array}$ & $\begin{array}{c}200{ }^{\circ} \mathrm{C} \\
300 \\
\text { bars }\end{array}$ & $\overline{\text { Ref }}$ \\
\hline$\overline{\mathrm{H}_{2} \mathrm{O}=\mathrm{OH}^{-}+\mathrm{H}^{+}}$ & -13.995 & -12.422 & -11.631 & -11.242 & -11.163 & $(1)$ \\
\hline $\mathrm{Al}^{3+}+\mathrm{H}_{2} \mathrm{O}=\mathrm{Al}(\mathrm{OH})^{2+}+\mathrm{H}^{+}$ & -4.964 & -3.248 & -2.129 & -1.265 & -1.446 & (2) \\
\hline $\mathrm{Al}^{3+}+2 \mathrm{H}_{2} \mathrm{O}=\mathrm{Al}(\mathrm{OH})_{2}^{+}+2 \mathrm{H}^{+}$ & -10.921 & -7.360 & -5.045 & -3.264 & -3.63 & (2) \\
\hline $\mathrm{Al}^{3+}+3 \mathrm{H}_{2} \mathrm{O}=\mathrm{Al}(\mathrm{OH})_{3}{ }^{\circ}+3 \mathrm{H}^{+}$ & -17.044 & -12.252 & -9.168 & -6.823 & -7.301 & (2) \\
\hline $\mathrm{Al}^{3+}+4 \mathrm{H}_{2} \mathrm{O}=\mathrm{Al}(\mathrm{OH})_{4}^{-}+4 \mathrm{H}^{+}$ & -22.851 & -17.299 & -13.747 & -11.086 & -11.572 & (2) \\
\hline $\mathrm{Al}^{3+}+\mathrm{Na}^{+}+4 \mathrm{H}_{2} \mathrm{O}=\mathrm{NaAl}(\mathrm{OH})_{4}{ }^{\circ}+4 \mathrm{H}^{+}$ & -22.90 & -16.941 & $|-13.097|$ & $-10.153 \mid$ & $|-10.748|$ & (2) \\
\hline $\mathrm{Al}^{3+}+\mathrm{SiO}_{2}{ }^{\mathrm{o}}+2 \mathrm{H}_{2} \mathrm{O}=\mathrm{AlH}_{3} \mathrm{SiO}_{4}{ }^{2+}+\mathrm{H}^{+}$ & -2.357 & -0.276 & 1.026 & 2.001 & 1.86 & (2) \\
\hline $\mathrm{Na}^{+}+\mathrm{H}_{2} \mathrm{O}=\mathrm{NaOH}^{\circ}+\mathrm{H}^{+}$ & -14.205 & -12.561 & $-11.642 \mid$ & -11.047 & -11.087 & (3) \\
\hline $\mathrm{SiO}_{2}{ }^{\circ}+\mathrm{H}_{2} \mathrm{O}=\mathrm{HSiO}_{3}{ }^{-}+\mathrm{H}^{+}$ & -9.585 & -9.016 & -8.802 & -8.860 & -8.707 & (3) \\
\hline $\mathrm{SiO}_{2}{ }^{\circ}+\mathrm{Na}^{+}+\mathrm{H}_{2} \mathrm{O}=\mathrm{NaHSiO}_{3}{ }^{\circ}+\mathrm{H}^{+}$ & -7.754 & -7.748 & -7.753 & -7.829 & $-7.767 \mid$ & (3) \\
\hline $\mathrm{Ca}^{2+}+\mathrm{H}_{2} \mathrm{O}=\mathrm{CaOH}^{+}+\mathrm{H}^{+}$ & -12.833 & -10.433 & -8.903 & -7.757 & -7.961 & (3) \\
\hline Acetate $^{-}+\mathrm{H}^{+}=$HAcetate $^{\circ}$ & 4.757 & 4.904 & 5.195 & 5.599 & & (4) \\
\hline Acetate $^{-}+\mathrm{Na}^{+}=\mathrm{NaAcetate}^{\circ}$ & -0.103 & 0.089 & 0.428 & 0.863 & & (5) \\
\hline 2 Acetate $^{-}+\mathrm{Na}^{+}=\mathrm{Na}(\text { Acetate })_{2}^{-}$ & -0.485 & -0.361 & 0.246 & 1.078 & & (5) \\
\hline Acetate $^{-}+\mathrm{Ca}^{2+}=\mathrm{CaAcetate}^{+}$ & 0.931 & 1.259 & 1.822 & 2.532 & & (5) \\
\hline 2 Acetate ${ }^{-}+\mathrm{Ca}^{2+}=\mathrm{Ca}(\text { Acetate })_{2}{ }^{\circ}$ & 1.40 & 1.937 & 3.013 & 4.398 & & (5) \\
\hline Acetate $^{-}+\mathrm{Al}^{3+}=\mathrm{Al}(\text { Acetate })^{2+}$ & 2.668 & 2.405 & 2.606 & 3.052 & & (5) \\
\hline 2 Acetate $^{-}+\mathrm{Al}^{3+}=\mathrm{Al}(\text { Acetate })_{2}^{+}$ & 5.27 & 4.322 & 4.429 & 5.083 & & (5) \\
\hline 3 Acetate $^{-}+\mathrm{Al}^{3+}=\mathrm{Al}(\text { Acetate })_{3}{ }^{\circ}$ & 7.169 & 5.296 & 5.138 & 5.878 & & (5) \\
\hline $\mathrm{K}^{+}+\mathrm{H}_{2} \mathrm{O}=\mathrm{KOH}^{\mathrm{o}}+\mathrm{H}^{+}$ & -14.439 & -12.584 & -11.551 & -10.885 & $\mid-10.939$ & (3) \\
\hline $\mathrm{Cl}^{-}+\mathrm{Ca}^{2+}=\mathrm{CaCl}^{+}$ & -0.292 & & & & 1.146 & (3) \\
\hline $2 \mathrm{Cl}^{-}+\mathrm{Ca}^{2+}=\mathrm{CaCl}_{2}{ }^{\circ}$ & -0.644 & & & & 0.672 & (3) \\
\hline $\mathrm{H}^{+}+\mathrm{Cl}^{-}=\mathrm{HCl}^{\circ}$ & -0.710 & & & & -0.15 & (6) \\
\hline $\mathrm{K}^{+}+\mathrm{Cl}^{-}=\mathrm{KCl}^{\circ}$ & & & & & 0.456 & (7) \\
\hline $\mathrm{Na}^{+}+\mathrm{Cl}^{-}=\mathrm{NaCl}^{\circ}$ & -0.777 & & & & 0.019 & (3) \\
\hline $\mathrm{HCO}_{3}^{-}+\mathrm{H}^{+}=\mathrm{CO}_{2}+\mathrm{H}_{2} \mathrm{O}$ & 6.345 & 6.343 & 6.724 & 7.305 & & (3) \\
\hline $\mathrm{HCO}_{3}{ }^{-}=\mathrm{CO}_{3}^{2-}+\mathrm{H}^{+}$ & -10.329 & -10.082 & -10.2 & -10.534 & & (3) \\
\hline \multicolumn{7}{|l|}{ Mineral dissolution reactions } \\
\hline $\mathrm{NaAlSi}_{3} \mathrm{O}_{8}($ Albite $)+4 \mathrm{H}^{+}=\mathrm{Al}^{3+}+\mathrm{Na}^{+}+3 \mathrm{SiO}_{2}{ }^{0}+2 \mathrm{H}_{2} \mathrm{O}$ & 2.065 & -0.057 & -1.713 & -3.02 & -2.508 & $(8)$ \\
\hline $\mathrm{NaAlSi}_{2} \mathrm{O}_{7} \mathrm{H}_{2}$ (Analcime) $+4 \mathrm{H}^{+}=\mathrm{Al}^{3+}+\mathrm{Na}^{+}+2 \mathrm{SiO}_{2}{ }^{\mathrm{o}}+3 \mathrm{H}_{2} \mathrm{O}$ & 6.391 & 3.464 & 1.417 & -0.155 & & $(8)$ \\
\hline $\mathrm{CaAl}_{2} \mathrm{Si}_{2} \mathrm{O}_{8}$ (Anorthite) $+8 \mathrm{H}^{+}=2 \mathrm{Al}^{3+}+\mathrm{Ca}^{2+}+4 \mathrm{H}_{2} \mathrm{O}+2 \mathrm{SiO}_{2}{ }^{\circ}$ & 23.68 & 14.260 & 7.819 & 2.739 & 4.042 & (8) \\
\hline $\mathrm{AlO}_{2} \mathrm{H}$ (Boehmite) $+3 \mathrm{H}^{+}=\mathrm{Al}^{3+}+2 \mathrm{H}_{2} \mathrm{O}$ & 7.610 & 4.023 & 1.660 & -.198 & .242 & (9) \\
\hline $\mathrm{AlO}_{2} \mathrm{H}$ (Diaspore) $+3 \mathrm{H}^{+}=\mathrm{Al}^{3+}+2 \mathrm{H}_{2} \mathrm{O}$ & 7.191 & 3.7 & 1.401 & -0.407 & 0.02 & (8) \\
\hline $\mathrm{Al}_{2} \mathrm{Si}_{2} \mathrm{O}_{5}(\mathrm{OH})_{4}$ (Kaolinite) $+6 \mathrm{H}^{+}=2 \mathrm{Al}^{3+}+2 \mathrm{SiO}_{2}{ }^{\circ}+5 \mathrm{H}_{2} \mathrm{O}$ & $4.501]$ & -0.254 & -3.535 & -6.119 & -5.354 & (8) \\
\hline $\mathrm{KAlSi}_{3} \mathrm{O}_{8}$ (Microcline) $+4 \mathrm{H}^{+}=\mathrm{Al}^{3+}+\mathrm{K}^{+}+3 \mathrm{SiO}_{2}{ }^{\mathrm{o}}+2 \mathrm{H}_{2} \mathrm{O}$ & -1.05 & -2.301 & -3.434 & -4.377 & -3.923 & (8) \\
\hline $\mathrm{KAl}_{3} \mathrm{Si}_{3} \mathrm{O}_{10}(\mathrm{OH})_{2}$ (Muscovite) $+10 \mathrm{H}^{+}=\mathrm{K}^{+}+3 \mathrm{Al}^{3+}+3 \mathrm{SiO}_{2}{ }^{\circ}+6 \mathrm{H}_{2} \mathrm{O}$ & 11.22 & 3.297 & -2.250 & -6.687 & -5.407 & (8) \\
\hline $\mathrm{NaAl}_{3} \mathrm{Si}_{3} \mathrm{O}_{10}(\mathrm{OH})_{2}$ (Paragonite) $+10 \mathrm{H}^{+}=\mathrm{Na}^{+}+3 \mathrm{Al}^{3+}+3 \mathrm{SiO}_{2}{ }^{\circ}+6 \mathrm{H}_{2} \mathrm{O}$ & 14.397 & 5.687 & -0.328 & -5.084 & -3.753 & (8) \\
\hline $\mathrm{Al}_{2} \mathrm{Si}_{4} \mathrm{O}_{10}(\mathrm{OH})_{2}$ (Pyrophyllite) $+6 \mathrm{H}^{+}=2 \mathrm{Al}^{3+}+4 \mathrm{H}_{2} \mathrm{O}+4 \mathrm{SiO}_{2}{ }^{\circ}$ & -1.724 & -5.394 & -8.234 & -10.549 & -9.733 & (8) \\
\hline $\mathrm{SiO}_{2}($ Quartz $)=\mathrm{SiO}_{2}{ }^{\circ}$ & -4.047 & -3.204 & -2.752 & -2.414 & -2.424 & (8) \\
\hline $\mathrm{KAlSi}_{3} \mathrm{O}_{8}$ (Sanidine) $+4 \mathrm{H}^{+}=\mathrm{Al}^{3+}+\mathrm{K}^{+}+3 \mathrm{SiO}_{2}{ }^{\circ}+2 \mathrm{H}_{2} \mathrm{O}$ & -0.002 & -1.571 & -2.911 & -4.009 & & (8) \\
\hline $\mathrm{KAlSiO}_{4}($ Kalsilite $)+4 \mathrm{H}^{+}=\mathrm{K}^{+}+\mathrm{Al}^{3+}+\mathrm{SiO}_{2}{ }^{\mathrm{o}}+2 \mathrm{H} 2 \mathrm{O}$ & 12.543 & & & & & (8) \\
\hline $\mathrm{NaAlSiO}_{4}$ (Nepheline) $+4 \mathrm{H}^{+}=\mathrm{K}^{+}+\mathrm{Al}^{3+}+\mathrm{SiO}_{2}{ }^{\circ}+2 \mathrm{H} 2 \mathrm{O}$ & 13.423 & & & & & (8) \\
\hline
\end{tabular}

(1) Haar et al. (1984); (2) Tagirov and Schott (2001); (3) Sverjensky et al. (1997); (4) Shock et al. (1995); (5) Shock and Koretsky (1993); (6) McCollom and Shock (1997); (7) Ho et al. (2000); (8) Holland and Powell (1998) for minerals and (1), (2), and (3) for aqueous species; (9) Hemingway et al. (1991) for boehmite. 
Table 1b. Different sets of thermodynamic properties for aqueous and mineral species for used calculations of saturation indices ${ }^{\S}$

\begin{tabular}{|c|c|c|c|c|}
\hline Notation & $\mathbf{A}$ & B & $\mathrm{C}$ & BL=baseline case \\
\hline & $\begin{array}{l}\text { Al-bearing species and } \\
\mathrm{NaOH}^{\circ} \text { from } \\
\text { Pokrovskii and } \\
\text { Heloeson }(1995)\end{array}$ & $\begin{array}{l}\text { Al-bearing species, } \\
\text { from Shock et al. } \\
\text { (1997); }\end{array}$ & $\begin{array}{l}\text { Al-bearing species, } \\
\text { from Shock et al. } \\
\text { (1997); }\end{array}$ & $\begin{array}{l}\text { Al-bearing species from } \\
\text { Tagirov and Schott } \\
(2001) ; \mathrm{KCl}^{\circ} \text { from Ho } \\
\text { et al }(2000) \text {. }\end{array}$ \\
\hline $\begin{array}{l}\text { Aqueous } \\
\text { species }\end{array}$ & $\begin{array}{l}\text { All other species from } \\
\text { Sverjensky et al. } \\
\text { (1997) and those } \\
\text { internally consistent to } \\
\text { Sverjensky et al. } \\
\text { (1997) in earlier } \\
\text { Helgeson and co- } \\
\text { workers' publications. }\end{array}$ & $\begin{array}{l}\text { All other species from } \\
\text { Sverjensky et al. (1997) } \\
\text { and those internally } \\
\text { consistent to } \\
\text { Sverjensky et al. (1997) } \\
\text { in earlier Helgeson and } \\
\text { co-workers' } \\
\text { publications. }\end{array}$ & $\begin{array}{l}\text { All other species } \\
\text { from Sverjensky et } \\
\text { al. (1997) and those } \\
\text { internally consistent } \\
\text { to Sverjensky et al. } \\
\text { (1997) in earlier } \\
\text { Helgeson and co- } \\
\text { workers' } \\
\text { publications. }\end{array}$ & $\begin{array}{l}\text { All other species from } \\
\text { Sverjensky et al. (1997) } \\
\text { and those internally } \\
\text { consistent to } \\
\text { Sverjensky et al. (1997) } \\
\text { in earlier Helgeson and } \\
\text { co-workers' } \\
\text { publications. }\end{array}$ \\
\hline Minerals & $\begin{array}{l}\text { Al oxyhydroxides from } \\
\text { Pokrovskii and } \\
\text { Helgeson (1995); all } \\
\text { others from Helgeson } \\
\text { et al. (1978) }\end{array}$ & Helgeson et al. (1978) & $\begin{array}{l}\text { Holland and Powell } \\
\text { (1998) }\end{array}$ & $\begin{array}{l}\text { Holland and Powell } \\
\text { (1998); Boehmite from } \\
\text { Hemingway et al. } \\
\text { (1991) }\end{array}$ \\
\hline
\end{tabular}

${ }^{\S}$ Equilibrium constants, corresponding to those listed in Table 1a for the baseline case, are listed in the Electronic Annex. 
Table 2. Summary of feldspar dissolution experiments used in this study

\begin{tabular}{|c|c|c|c|c|c|c|c|}
\hline Mineral Reactant & $\begin{array}{l}\mathrm{SA}^{(1)} \\
\left(\mathrm{m}^{2} / \mathrm{g}\right)\end{array}$ & $\begin{array}{l}\text { Initial } \\
\mathrm{pH}\end{array}$ & $\begin{array}{l}\text { Solution } \\
\text { Chemistry }\end{array}$ & $\begin{array}{l}\mathrm{T}^{\circ} \mathrm{C}, \mathrm{P} \\
\text { bar }^{(2)}\end{array}$ & $\begin{array}{l}\text { Reaction } \\
\text { time (hrs) }\end{array}$ & secondary minerals & Reference \\
\hline $\begin{array}{l}\text { Alkali-feldspar } \\
\text { (35\% low albite; } 60 \% \\
\text { orthoclase; } 5 \% \text { quartz) }\end{array}$ & 0.132 & 3.1 & $0.20 \mathrm{~m} \mathrm{KCl}$ & $\begin{array}{l}200 \\
300\end{array}$ & 1872 & Boehmite + Kaolinite & $\begin{array}{l}\text { Fu. et al. } \\
\text { (2008) }\end{array}$ \\
\hline $\begin{array}{l}\text { Alkali-feldspar } \\
\text { (35\% low albite; } 60 \% \\
\text { orthoclase; } 5 \% \text { quartz) }\end{array}$ & 0.132 & 4.0 & $\begin{array}{l}0.20 \mathrm{~m} \mathrm{KCl}+ \\
0.05 \mathrm{~m} \mathrm{CO}_{2}\end{array}$ & $\begin{array}{l}200 \\
300\end{array}$ & 648 & Boehmite + Kaolinite & Appendix B \\
\hline Anorthite & $\begin{array}{l}0.00333 \\
\left(\mathrm{~m}^{2} / \mathrm{L}\right)\end{array}$ & $\begin{array}{l}4.69 \\
4.97 \\
5.4\end{array}$ & $\begin{array}{l}0.3 \mathrm{~m} \mathrm{NaAc}+ \\
\mathrm{HAc}\end{array}$ & $\begin{array}{l}90 \\
150 \\
210\end{array}$ & $\begin{array}{l}8520 \\
2160 \\
3960\end{array}$ & $\begin{array}{l}\text { Bhm + Mod. } \mathrm{Bhm}^{(3)} \\
\text { Bhm + Mod. } \mathrm{Bhm}^{(3)} \\
\text { Bhm + Mod. } \mathrm{Bhm}^{(3)}+ \\
\text { Kaolinite }\end{array}$ & $\begin{array}{l}\text { Murakami et } \\
\text { al. (1998) }\end{array}$ \\
\hline $\begin{array}{l}\text { Low albite } \\
\text { Sanidine }\end{array}$ & $\begin{array}{l}0.12 \\
0.14\end{array}$ & 9.0 & $\begin{array}{l}0.1 \mathrm{~m} \mathrm{KHCO} 3 \\
0.1 \mathrm{~m} \mathrm{NaHCO}_{3}\end{array}$ & 300,88 & 1848 & $\begin{array}{l}\text { Sanidine } \\
\text { Analcime }\end{array}$ & $\begin{array}{l}\text { Alekseyev et } \\
\text { al. } \\
\text { (1997) }\end{array}$ \\
\hline
\end{tabular}

(1) SA stand for specific surface area; (2) $T^{\circ} \mathrm{C}, P$ bar refer temperature and pressure; (3) Bhm and Mod. Bhm refer to boehmite and modified boehmite, respectively, as reported in Murakami et al. (1998). 
Table 3. Mineral saturation indices at each sampling time in experiments for the alkali feldspar dissolution in $0.2 \mathrm{~m} \mathrm{KCl}$ solution at $200{ }^{\circ} \mathrm{C}$ and 300 bars $^{\dagger}$.

\begin{tabular}{|c|c|c|c|c|c|c|c|c|c|c|}
\hline Time (h) & In situ $\mathrm{pH}$ & Albite & Boehmite & Diaspore & Kaolinite & Microcline & Muscovite & Paragonite & Pyrophyllite & Quartz \\
\hline 24 & 3.3 & -6.80 & 1.23 & 1.45 & 1.30 & -2.75 & 1.67 & -2.62 & -1.30 & -1.07 \\
\hline (120) & 3.4 & -4.80 & 0.93 & 1.15 & 1.96 & -1.08 & 2.75 & -1.22 & 0.61 & -0.44 \\
\hline 216 & 3.6 & -4.37 & 0.90 & 1.13 & 2.01 & -0.75 & 3.02 & -0.83 & 0.75 & -0.39 \\
\hline 456 & 3.7 & -2.33 & 2.40 & 2.62 & 5.13 & 1.02 & 7.79 & 4.20 & 3.99 & -0.33 \\
\hline 816 & 4.0 & -2.66 & 2.11 & 2.33 & 4.34 & 0.75 & 6.93 & 3.28 & 3.02 & -0.43 \\
\hline 1368 & 4.5 & -1.02 & 1.47 & 1.69 & 4.05 & 2.07 & 6.98 & 3.65 & 3.71 & 0.06 \\
\hline (1872) & 4.8 & -2.36 & 0.26 & 0.48 & 1.53 & 1.02 & 3.50 & -0.12 & 1.09 & 0.01 \\
\hline
\end{tabular}

${ }^{\dagger}$ Solution chemistry data are from (Fu et al., 2008). The parentheses on time in the first column on left denote to the time that the experiment was terminated and solids were recovered for characterization. In situ $\mathrm{pH}$ was calculated from the speciation modeling.

Table 4. Mineral saturation indices at each sampling time in experiments for the alkali feldspar dissolution in $0.2 \mathrm{~m} \mathrm{KCl}$ and $0.05 \mathrm{~m} \mathrm{CO}_{2}$ solution at $200{ }^{\circ} \mathrm{C}$ and 300 bars $^{\dagger}$.

\begin{tabular}{|c|c|c|c|c|c|c|c|c|c|c|}
\hline Time (h) & In situ $\mathrm{pH}$ & Albite & Boehmite & Diaspore & Kaolinite & Microcline & Muscovite & Paragonite & Pyrophyllite & Quartz \\
\hline 24 & 4.9 & -5.13 & 1.18 & 1.40 & 1.43 & -0.88 & 3.44 & -1.04 & -0.96 & -0.96 \\
\hline (120) & 5.0 & -2.41 & 0.87 & 1.09 & 2.18 & 0.99 & 4.69 & 1.06 & 1.19 & -0.27 \\
\hline 144 & 5.1 & -2.85 & 1.00 & 1.22 & 2.42 & 1.16 & 5.13 & 0.88 & 1.38 & -0.29 \\
\hline 312 & 5.6 & -1.94 & 0.83 & 1.05 & 2.25 & 1.75 & 5.37 & 1.44 & 1.39 & -0.20 \\
\hline 480 & 5.7 & -1.22 & 1.21 & 1.43 & 3.05 & 2.30 & 6.68 & 2.93 & 2.23 & -0.18 \\
\hline (648) & 5.7 & -1.17 & 1.38 & 1.61 & 3.43 & 2.51 & 7.25 & 3.33 & 2.63 & -0.16 \\
\hline
\end{tabular}

${ }^{\dagger}$ See solution analytical data in Appendix B. The parentheses on time in the first column on left denote to the time that the experiment was terminated and solids were recovered for characterization. In situ $\mathrm{pH}$ was calculated from the speciation modeling. 
Table 5. Mineral saturation indices in the experiments for anorthite dissolution in $0.03 \mathrm{M} \mathrm{NaAc}$ and HAc solutions ${ }^{\dagger}$

\begin{tabular}{|c|c|c|c|c|c|c|c|c|c|c|c|c|}
\hline & T (h) & & $\begin{array}{r}\text { Prod } \\
\text { minera }\end{array}$ & & $\begin{array}{r}\mathrm{pH} \text { (in } \\
\text { situ) }\end{array}$ & albite & anorthite & boehmite & kaolinite & paragonite & pyrophyllite & quartz \\
\hline & 72 & $\mathrm{~b}$ & & & 4.71 & -4.88 & -7.02 & 2.54 & 3.68 & 2.55 & -0.88 & -1.65 \\
\hline & 240 & $\mathrm{~b}$ & & & 4.63 & -1.86 & -4.27 & 3.52 & 6.94 & 7.36 & 3.67 & -1.00 \\
\hline $90^{\circ} \mathrm{C}$ & 720 & $\mathrm{~b}$ & & & 4.67 & -0.11 & -1.33 & 3.61 & 8.25 & 9.37 & 6.13 & -0.43 \\
\hline $90 \mathrm{C}$ & 2160 & & $\mathrm{mb}$ & & 4.65 & -0.48 & -3.26 & 2.08 & 5.95 & 5.89 & 4.59 & -0.05 \\
\hline & 3816 & & $\mathrm{mb}$ & & 4.69 & 0.49 & -1.24 & 2.98 & 7.84 & 8.76 & 6.55 & -0.01 \\
\hline & 8520 & & $\mathrm{mb}$ & & 4.72 & 0.59 & -1.30 & 2.73 & 7.58 & 8.40 & 6.54 & 0.12 \\
\hline & 72 & $\mathrm{~b}$ & & & 4.98 & -2.73 & -3.78 & 1.23 & 2.20 & 1.67 & -0.21 & -0.80 \\
\hline $150^{\circ} \mathrm{C}$ & 240 & $\mathrm{~b}$ & & & 4.92 & 0.25 & 0.83 & 2.91 & 6.45 & 7.98 & 4.93 & -0.36 \\
\hline 1500 & 720 & & $\mathrm{mb}$ & & 4.93 & 1.02 & 1.72 & 3.02 & 7.11 & 8.98 & 6.02 & -0.14 \\
\hline & 2160 & & $\mathrm{mb}$ & & 4.99 & 0.48 & 0.13 & 1.88 & 5.21 & 6.19 & 4.50 & 0.05 \\
\hline & 72 & $\mathrm{~b}$ ? & & & 5.31 & -1.94 & -1.86 & 0.72 & 1.09 & 1.17 & -0.55 & -0.62 \\
\hline & 240 & & $\mathrm{mb}$ & & 5.30 & -0.71 & -0.19 & 1.19 & 2.54 & 3.33 & 1.41 & -0.37 \\
\hline $210^{\circ}$ & 816 & & $\mathrm{mb}$ & & 5.36 & -0.39 & 0.23 & 1.21 & 2.74 & 3.69 & 1.77 & -0.29 \\
\hline & 2328 & & $\mathrm{mb}$ & $\mathrm{k}$ & 5.36 & -0.14 & 0.37 & 1.08 & 2.73 & 3.67 & 2.02 & -0.16 \\
\hline & 3960 & & $\mathrm{mb}$ & $\mathrm{k}$ & 5.47 & 0.15 & 0.71 & 0.99 & 2.74 & 3.80 & 2.21 & -0.07 \\
\hline
\end{tabular}

${ }^{\dagger}$ Solution chemistry experimental data from Murakami et al. (1998); "Product minerals observed by Murakami et al. (1998) "b" stands for boehmite; "mb" for modified boehmite; " $\mathrm{k}$ " for kaolinite. In situ $\mathrm{pH}$ was calculated from the speciation modeling performed in this study. 
Table 6. Mineral saturation indices in each batch experiment for sanidine dissolution in $0.1 \mathrm{~m}$ $\mathrm{NaHCO}_{3}$ solution at $300{ }^{\circ} \mathrm{C}$ and 88 bars $^{\dagger}$

\begin{tabular}{|c|c|c|c|c|c|c|c|c|c|c|c|}
\hline $\mathrm{t}, \mathrm{h}$ & Sanidine & nalcime & Albite & Quartz & Boehmite & Kaolinite & Muscovite & Paragonite & Pyrophyllite & Kalsilite & Nepheline \\
\hline 0 & -4.66 & -2.14 & -2.86 & -1.29 & -2.37 & -7.01 & -7.52 & -6.22 & -9.44 & -4.71 & -2.12 \\
\hline 0.25 & -4.19 & -1.86 & -2.59 & -1.29 & -2.10 & -6.46 & -6.51 & -5.40 & -8.89 & -4.24 & -1.85 \\
\hline 0.5 & -3.45 & -1.42 & -1.95 & -1.09 & -2.04 & -5.95 & -5.66 & -4.64 & -8.00 & -3.89 & -1.60 \\
\hline 0.75 & -2.92 & -1.04 & -1.48 & -1.01 & -1.82 & -5.34 & -4.68 & -3.73 & -7.22 & -3.53 & -1.30 \\
\hline 1 & -2.41 & -0.72 & -1.04 & -0.88 & -1.76 & -4.96 & -4.04 & -3.16 & -6.58 & -3.27 & -1.11 \\
\hline 1.25 & -2.46 & -0.76 & -1.11 & -0.90 & -1.75 & -5.00 & -4.08 & -3.22 & -6.67 & -3.27 & -1.13 \\
\hline 1.5 & -2.18 & -0.59 & -0.88 & -0.85 & -1.70 & -4.77 & -3.69 & -2.88 & -6.32 & -3.11 & -1.02 \\
\hline 2 & -1.88 & -0.42 & -0.62 & -0.76 & -1.69 & -4.59 & -3.38 & -2.62 & -5.98 & -2.98 & -0.93 \\
\hline 2.5 & -1.97 & -0.48 & -0.7 & -0.79 & -1.70 & -4.66 & -3.48 & -2.71 & -6.09 & -3.01 & -0.96 \\
\hline 3 & -1.63 & -0.27 & -0.43 & -0.72 & -1.61 & -4.35 & -2.97 & -2.26 & -5.66 & -2.80 & -0.81 \\
\hline 3.5 & -1.64 & -0.28 & -0.45 & -0.74 & -1.60 & -4.36 & -2.96 & -2.26 & -5.69 & -2.79 & -0.81 \\
\hline 4 & -1.24 & -0.04 & -0.13 & -0.65 & -1.54 & -4.05 & -2.42 & -1.81 & -5.21 & -2.56 & -0.66 \\
\hline 5 & -1.09 & 0.04 & -0.02 & -0.63 & -1.49 & -3.92 & -2.18 & -1.61 & -5.04 & -2.45 & -0.60 \\
\hline 6 & -1.12 & -0.00 & -0.09 & -0.65 & -1.49 & -3.97 & -2.22 & -1.69 & -5.13 & -2.44 & -0.62 \\
\hline 7 & -1.05 & 0.02 & -0.03 & -0.61 & -1.54 & -3.99 & -2.25 & -1.72 & -5.08 & -2.45 & -0.63 \\
\hline \multicolumn{12}{|c|}{ Analcime started to precipitate } \\
\hline 16 & -0.57 & 0.33 & 0.38 & -0.51 & -1.44 & -3.58 & -1.58 & -1.11 & -4.46 & -2.18 & -0.44 \\
\hline 24 & -0.56 & 0.24 & 0.32 & -0.49 & -1.58 & -3.82 & -1.83 & -1.46 & -4.66 & -2.20 & -0.54 \\
\hline 48 & -0.53 & 0.21 & 0.27 & -0.50 & -1.59 & -3.87 & -1.83 & -1.52 & -4.73 & -2.15 & -0.56 \\
\hline 72 & -0.57 & 0.07 & 0.13 & -0.51 & -1.73 & -4.17 & -2.14 & -1.94 & -5.05 & -2.17 & -0.69 \\
\hline 120 & -0.66 & -0.11 & -0.04 & -0.50 & -1.96 & -4.59 & -2.69 & -2.57 & -5.45 & -2.29 & -0.88 \\
\hline 168 & -0.75 & -0.19 & -0.11 & -0.48 & -2.06 & -4.78 & -2.99 & -2.85 & -5.60 & -2.4 & -0.98 \\
\hline 216 & -0.57 & -0.02 & 0.06 & -0.49 & -1.88 & -4.42 & -2.45 & -2.31 & -5.25 & -2.22 & -0.80 \\
\hline 288 & -0.68 & -0.16 & -0.07 & -0.47 & -2.07 & -4.76 & -2.93 & -2.81 & -5.55 & -2.36 & -0.96 \\
\hline 360 & -0.73 & -0.33 & -0.20 & -0.44 & -2.31 & -5.18 & -3.45 & -3.42 & -5.91 & -2.47 & -1.16 \\
\hline 504 & -0.69 & -0.34 & -0.20 & -0.42 & -2.36 & -5.25 & -3.52 & -3.53 & -5.96 & -2.46 & -1.19 \\
\hline 672 & -0.86 & -0.52 & -0.40 & -0.45 & -2.50 & -5.58 & -3.97 & -4.01 & -6.33 & -2.59 & -1.34 \\
\hline 840 & -0.91 & -0.58 & -0.47 & -0.45 & -2.57 & -5.72 & -4.17 & -4.22 & -6.47 & -2.64 & -1.41 \\
\hline 1008 & -1.01 & -0.63 & -0.52 & -0.45 & -2.60 & -5.78 & -4.32 & -4.32 & -6.54 & -2.73 & -1.45 \\
\hline 1176 & -0.94 & -0.56 & -0.45 & -0.45 & -2.53 & -5.64 & -4.10 & -4.11 & -6.40 & -2.65 & -1.38 \\
\hline 1344 & -0.91 & -0.59 & -0.48 & -0.45 & -2.58 & -5.74 & -4.17 & -4.25 & -6.50 & -2.62 & -1.41 \\
\hline 1512 & -0.93 & -0.57 & -0.46 & -0.45 & -2.53 & -5.65 & -4.11 & -4.13 & -6.42 & -2.64 & -1.38 \\
\hline 1680 & -0.93 & -0.59 & -0.47 & -0.45 & -2.57 & -5.72 & -4.18 & -4.22 & -6.47 & -2.65 & -1.41 \\
\hline 1848 & -0.94 & -0.59 & -0.48 & -0.45 & -2.57 & -5.72 & -4.19 & -4.22 & -6.48 & -2.66 & -1.41 \\
\hline
\end{tabular}

${ }^{\dagger}$ Experiments conducted by Alekseyev et al. (1997). SI values were calculated in this study using their solution chemistry data. 
Table 7. Mineral saturation Indices in each batch experiment for albite dissolution in $0.1 \mathrm{~m}$ $\mathrm{KHCO}_{3}$ solution at $300{ }^{\circ} \mathrm{C}$ and 88 bars $^{\dagger}$

\begin{tabular}{|c|c|c|c|c|c|c|c|c|c|c|c|}
\hline $\mathrm{t}, \mathrm{h}$ & Albite & Sanidine & Microcline & Boehmite & Kaolinite & Muscovite & Paragonite & Pyrophyllite & Quartz & Kalsilite & Nepheline \\
\hline 0 & -7.50 & -4.08 & -3.89 & -2.49 & -8.49 & -7.17 & -11.1 & -12.2 & -1.92 & -2.87 & -5.50 \\
\hline 0.25 & -5.18 & -1.99 & -1.79 & -2.13 & -6.62 & -4.37 & -8.05 & -9.15 & -1.34 & -1.93 & -4.34 \\
\hline 0.5 & -4.09 & -0.99 & -0.79 & -1.86 & -5.59 & -2.83 & -6.43 & -7.64 & -1.09 & -1.43 & -3.74 \\
\hline 0.75 & -3.20 & -0.24 & -0.05 & -1.63 & -4.78 & -1.62 & -5.07 & -6.48 & -0.92 & -1.02 & -3.19 \\
\hline 1 & -3.15 & -0.21 & -0.02 & -1.64 & -4.78 & -1.60 & -5.03 & -6.45 & -0.91 & -1.02 & -3.17 \\
\hline 1.25 & -3.14 & -0.22 & -0.03 & -1.64 & -4.78 & -1.61 & -5.03 & -6.46 & -0.91 & -1.02 & -3.15 \\
\hline 1.5 & -2.61 & 0.23 & 0.43 & -1.51 & -4.30 & -0.9 & -4.24 & -5.76 & -0.8 & -0.79 & -2.85 \\
\hline 2 & -2.33 & 0.47 & 0.67 & -1.46 & -4.08 & -0.56 & -3.86 & -5.41 & -0.74 & -0.68 & -2.69 \\
\hline 2.5 & -2.37 & 0.45 & 0.64 & -1.48 & -4.12 & -0.63 & -3.95 & -5.45 & -0.74 & -0.7 & -2.73 \\
\hline 3 & -2.23 & 0.56 & 0.75 & -1.41 & -3.96 & -0.38 & -3.67 & -5.26 & -0.72 & -0.62 & -2.62 \\
\hline 3.5 & -2.19 & 0.55 & 0.75 & -1.45 & -4.00 & -0.45 & -3.69 & -5.29 & -0.71 & -0.64 & -2.60 \\
\hline 4 & -2.20 & 0.56 & 0.76 & -1.46 & -4.01 & -0.46 & -3.72 & -5.28 & -0.71 & -0.64 & -2.62 \\
\hline 5 & -1.88 & 0.84 & 1.03 & -1.36 & -3.70 & 0.00 & -3.21 & -4.85 & -0.65 & -0.49 & -2.42 \\
\hline 6 & -2.02 & 0.69 & 0.89 & -1.40 & -3.85 & -0.22 & -3.43 & -5.07 & -0.68 & -0.56 & -2.49 \\
\hline 7 & -1.81 & 0.88 & 1.08 & -1.36 & -3.67 & 0.04 & -3.14 & -4.8 & -0.63 & -0.48 & -2.38 \\
\hline 16 & -1.70 & 0.99 & 1.19 & -1.37 & -3.60 & 0.148 & -3.04 & -4.65 & -0.59 & -0.44 & -2.35 \\
\hline \multicolumn{12}{|c|}{ Sanidine started to precipitate } \\
\hline 24 & -1.63 & 1.06 & 1.25 & -1.35 & -3.54 & 0.24 & -2.94 & -4.55 & -0.58 & -0.41 & -2.31 \\
\hline 48 & -1.83 & 0.87 & 1.06 & -1.37 & -3.69 & 0.019 & -3.17 & -4.82 & -0.63 & -0.48 & -2.39 \\
\hline 72 & -1.93 & 0.77 & 0.96 & -1.40 & -3.80 & -0.15 & -3.34 & -4.98 & -0.66 & -0.54 & -2.44 \\
\hline 120 & -1.87 & 0.76 & 0.96 & -1.42 & -3.83 & -0.18 & -3.31 & -5 & -0.66 & -0.55 & -2.39 \\
\hline 168 & -1.79 & 0.86 & 1.05 & -1.42 & -3.76 & -0.09 & -3.23 & -4.87 & -0.62 & -0.52 & -2.37 \\
\hline 216 & -1.78 & 0.83 & 1.02 & -1.37 & -3.72 & -0.02 & -3.13 & -4.88 & -0.65 & -0.49 & -2.32 \\
\hline 288 & -1.69 & 0.84 & 1.03 & -1.39 & -3.75 & -0.06 & -3.09 & -4.89 & -0.64 & -0.5 & -2.25 \\
\hline 360 & -1.72 & 0.76 & 0.95 & -1.42 & -3.85 & -0.2 & -3.17 & -5.03 & -0.66 & -0.54 & -2.23 \\
\hline 504 & -1.55 & 0.72 & 0.92 & -1.45 & -3.93 & -0.3 & -3.07 & -5.13 & -0.67 & -0.56 & -2.05 \\
\hline 672 & -1.44 & 0.74 & 0.94 & -1.46 & -3.93 & -0.29 & -2.96 & -5.13 & -0.67 & -0.55 & -1.94 \\
\hline 840 & -1.40 & 0.67 & 0.86 & -1.51 & -4.07 & -0.48 & -3.04 & -5.29 & -0.68 & -0.59 & -1.88 \\
\hline 1008 & -1.51 & 0.50 & 0.69 & -1.52 & -4.20 & -0.65 & -3.15 & -5.55 & -0.74 & -0.64 & -1.86 \\
\hline 1176 & -1.44 & 0.55 & 0.74 & -1.50 & -4.15 & -0.57 & -3.06 & -5.47 & -0.73 & -0.61 & -1.81 \\
\hline 1344 & -1.44 & 0.49 & 0.68 & -1.56 & -4.28 & -0.74 & -3.17 & -5.62 & -0.74 & -0.65 & -1.79 \\
\hline 1512 & -1.43 & 0.50 & 0.70 & -1.54 & -4.24 & -0.69 & -3.13 & -5.58 & -0.74 & -0.64 & -1.79 \\
\hline 1680 & -1.46 & 0.43 & 0.62 & -1.57 & -4.35 & -0.83 & -3.22 & -5.72 & -0.76 & -0.68 & -1.78 \\
\hline 1848 & -1.43 & 0.47 & 0.67 & -1.56 & -4.30 & -0.76 & -3.16 & -5.65 & -0.75 & -0.65 & -1.77 \\
\hline
\end{tabular}

${ }^{\dagger}$ Experimental data from by Alekseyev et al. (1997). SI values were calculated in this study using their solution chemistry data. 

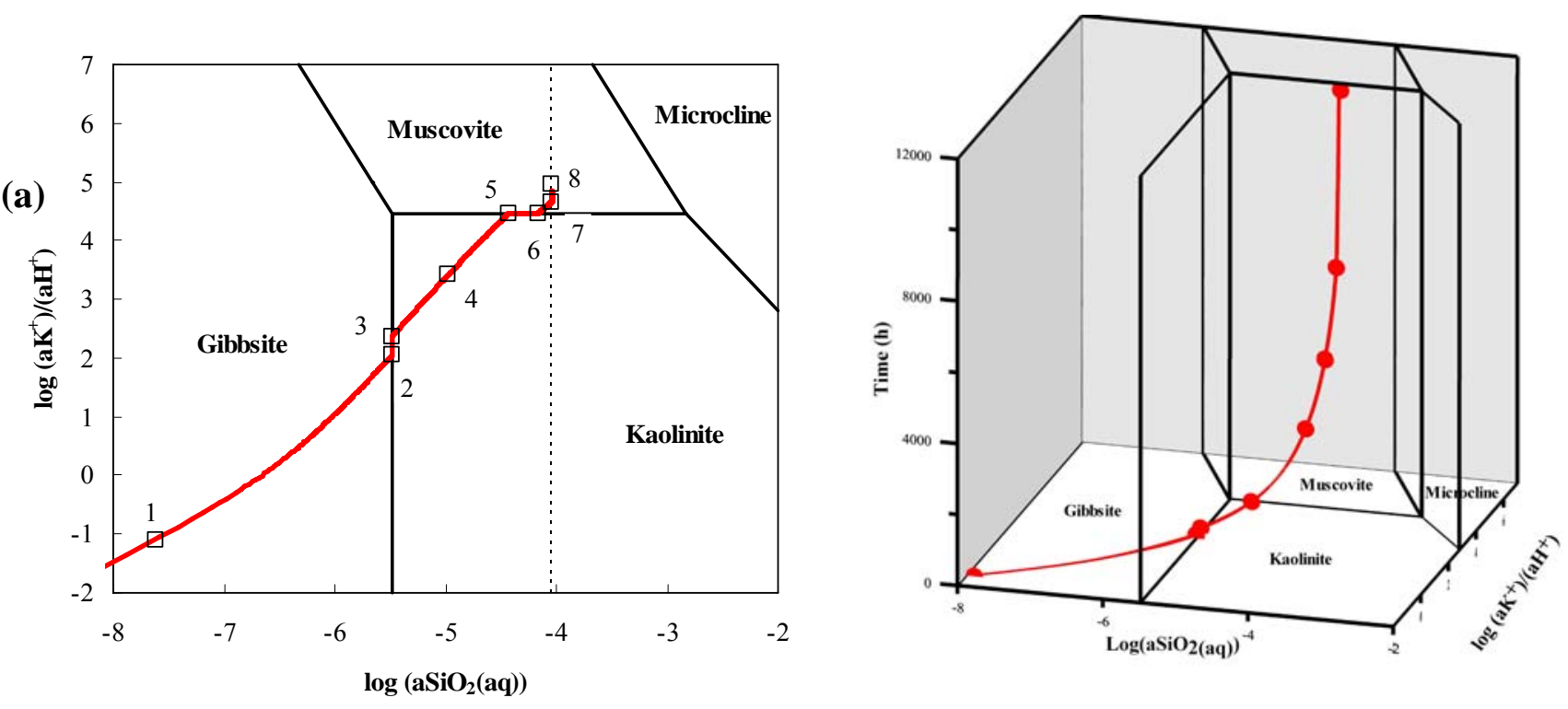

\begin{tabular}{crrrrrr}
\hline Point number & Time $(\mathrm{y})$ & \multicolumn{1}{c}{ Kaolinite } & Microcline & \multicolumn{1}{c}{ Muscovite } & \multicolumn{1}{l}{ Gibbsite } & \multicolumn{1}{c}{ Quartz } \\
\hline 1 & 0.002 & -4.21 & -15.04 & -11.85 & 0 & -3.54 \\
2 & 0.277 & 0 & -5.61 & -2.42 & 0 & -1.43 \\
3 & 0.404 & 0 & -5.29 & -2.10 & 0 & -1.43 \\
4 & 1.426 & 0 & -3.24 & -1.05 & -0.50 & -0.93 \\
5 & 6.133 & 0 & -1.08 & 0 & -1.05 & -0.38 \\
6 & 11.472 & 0 & -0.57 & 0 & -1.31 & -0.12 \\
7 & 18.395 & -0.12 & -0.20 & 0 & -1.49 & 0 \\
8 & 31.710 & -0.25 & -0.08 & 0 & -1.56 & 0 \\
\hline
\end{tabular}

(c)

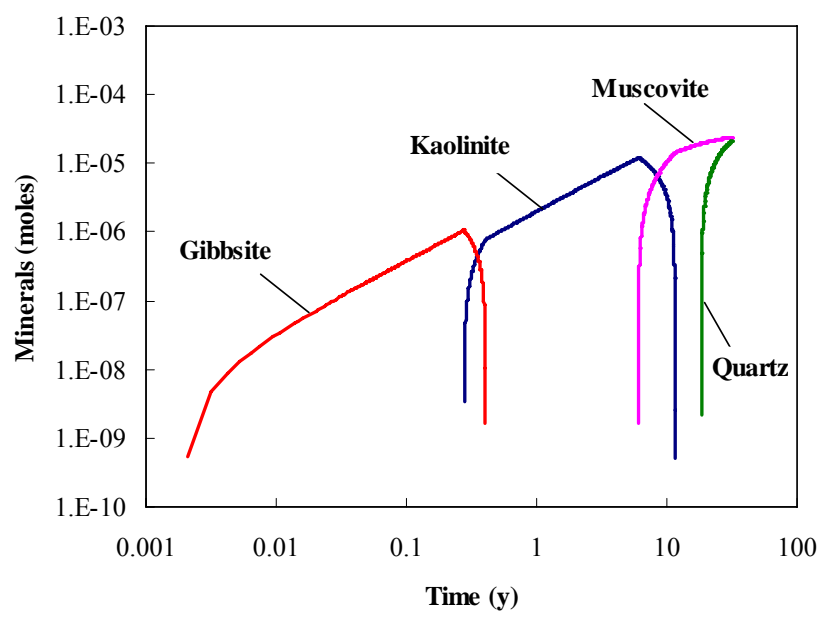

Fig. 1. Reaction path the dissolution of microcline in pure water at $25^{\circ} \mathrm{C}$. (a) equilibrium activity-activity diagram; (b) calculated mineral saturation indices; and (c) mineral abundance versus time. Thermodynamic data were from Table 1a, except for gibbsite (Robie and Hemingway, 1995). A linear rate law with a rate constant of $10^{-12} \mathrm{~mol} \mathrm{~m}^{-2} \mathrm{~s}^{-1}$ for microcline was used. 

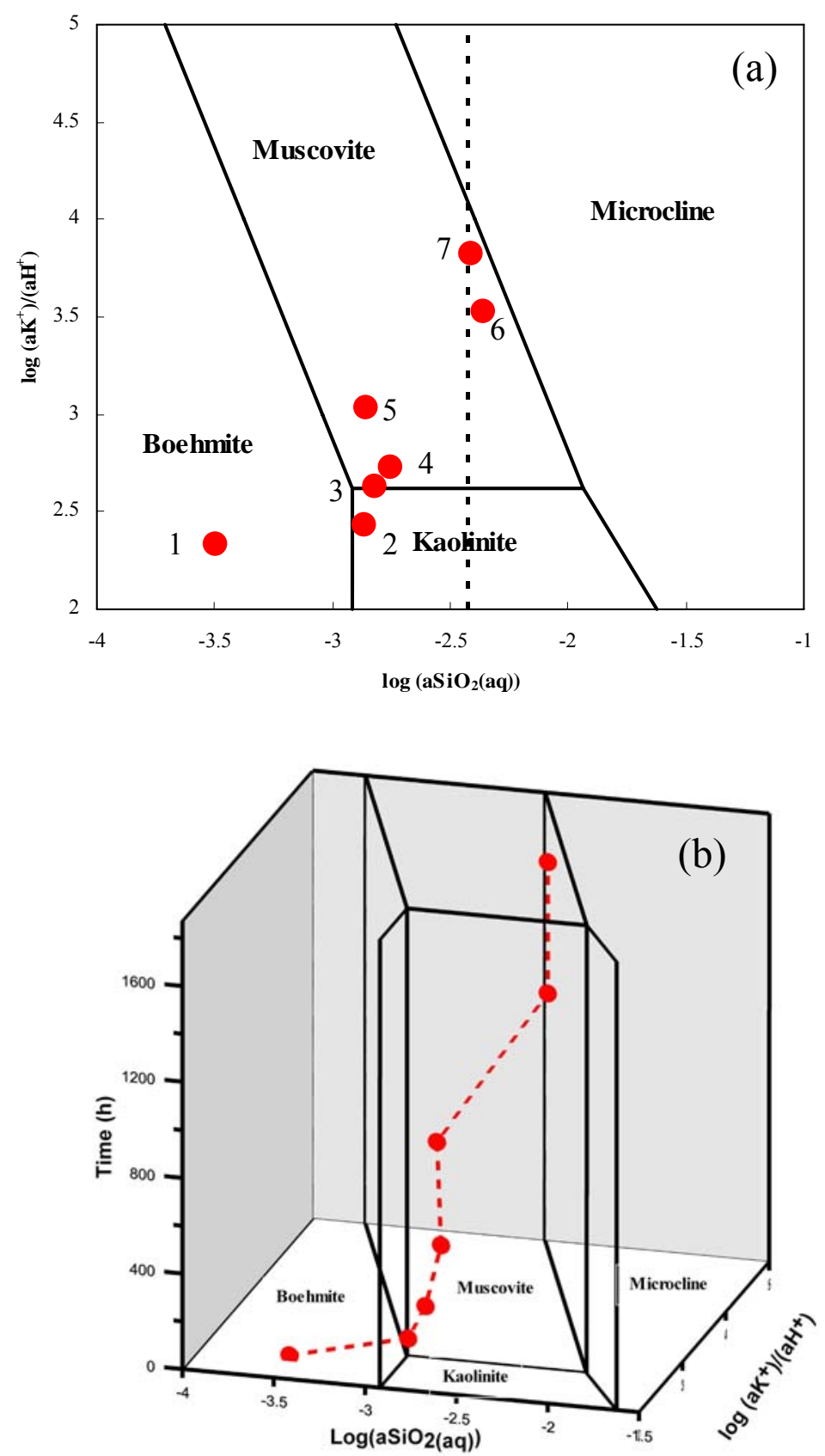

Fig. 2. Activity - activity diagrams showing the phase relations in the system $\mathrm{K}_{2} \mathrm{O}-\left(\mathrm{Al}_{2} \mathrm{O}_{3}\right)-\mathrm{SiO}_{2}$ $\mathrm{H}_{2} \mathrm{O}-\mathrm{HCl}$ at $200{ }^{\circ} \mathrm{C}$ and 300 bars. The dashed line in (a) denotes quartz saturation. Symbols represent experimental results of alkali feldspar dissolution in $0.2 \mathrm{~m} \mathrm{KCl}$ solution at $200{ }^{\circ} \mathrm{C}$ and 300 bars (Fu et al., 2008, see Sec. 3.1). The activity and activity ratios were obtained from speciation modeling of the experimental system $\mathrm{Na}_{2} \mathrm{O}-\mathrm{K}_{2} \mathrm{O}-\mathrm{Al}_{2} \mathrm{O}_{3}-\mathrm{SiO}_{2}-\mathrm{H}_{2} \mathrm{O}-\mathrm{HCl}$, based on the experimental solution chemistry data of $\mathrm{Fu}$ et al. (2008) and equilibrium constants listed in Table 1a. Points 1 through 7 represent experiment solutions at reaction time of 24, 120, 216, 456, 816, 1368, and $1872 \mathrm{~h}$, respectively. The red dashed line in (b) connecting experimental data is for visualization of fluid chemical evolution. 

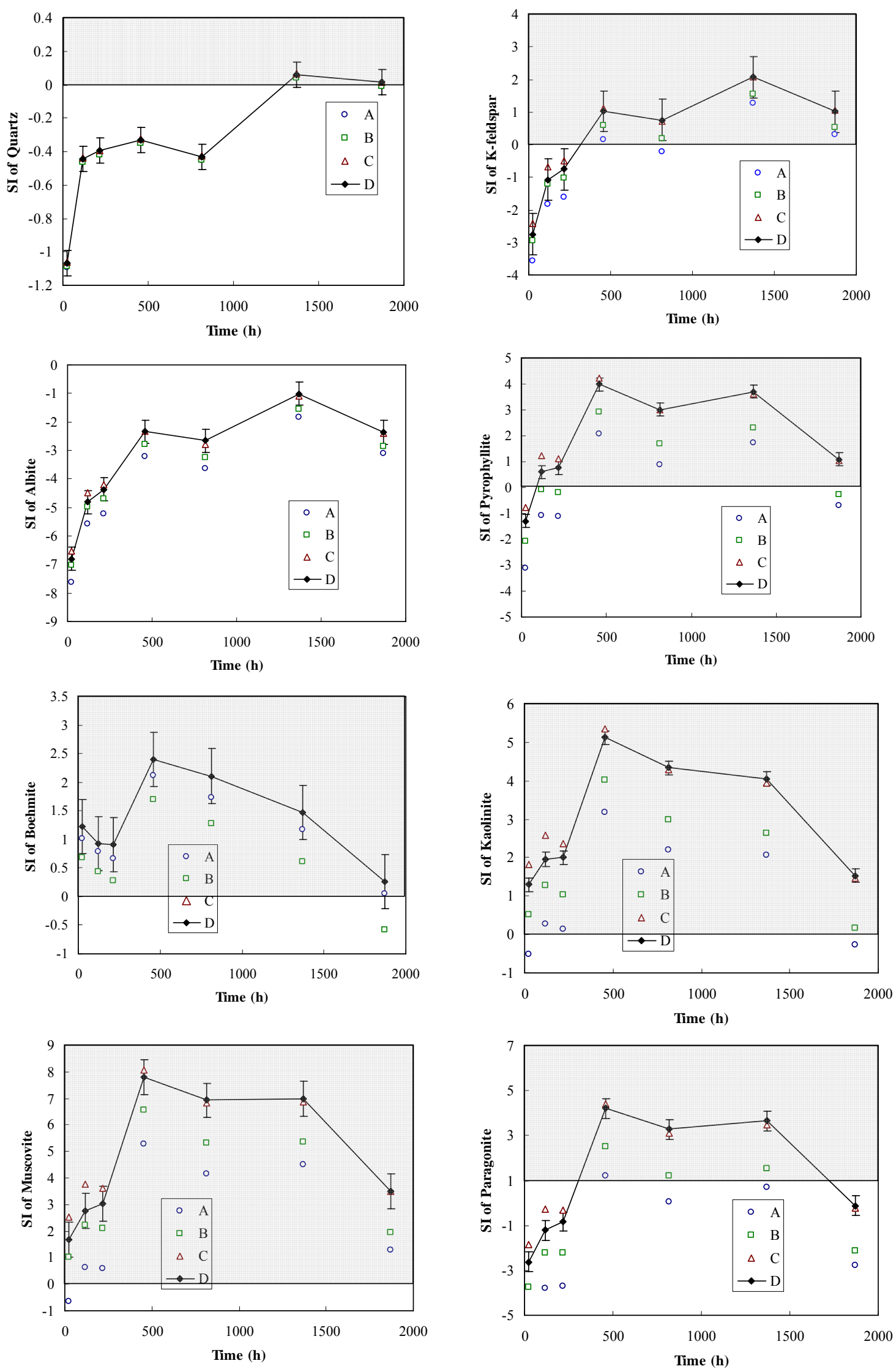
Fig. 3. Mineral saturation indices during the course of alkali feldspar dissolution in $0.2 \mathrm{~m} \mathrm{KCl}$ solution at $200{ }^{\circ} \mathrm{C}$ and 300 bars (Fu et al., 2008, see Sec. 3.1). "BL" (baseline case, Table 1a), and "A", "B", and "C" stand for calculated SI using thermodynamic datasets as described in Table $1 \mathrm{~b}$. Vertical errors bars represent the uncertainty from the $\Delta H_{f}^{o}$ at $25{ }^{\circ} \mathrm{C}$ alone. The gray shaded areas highlight mineral supersaturation. 

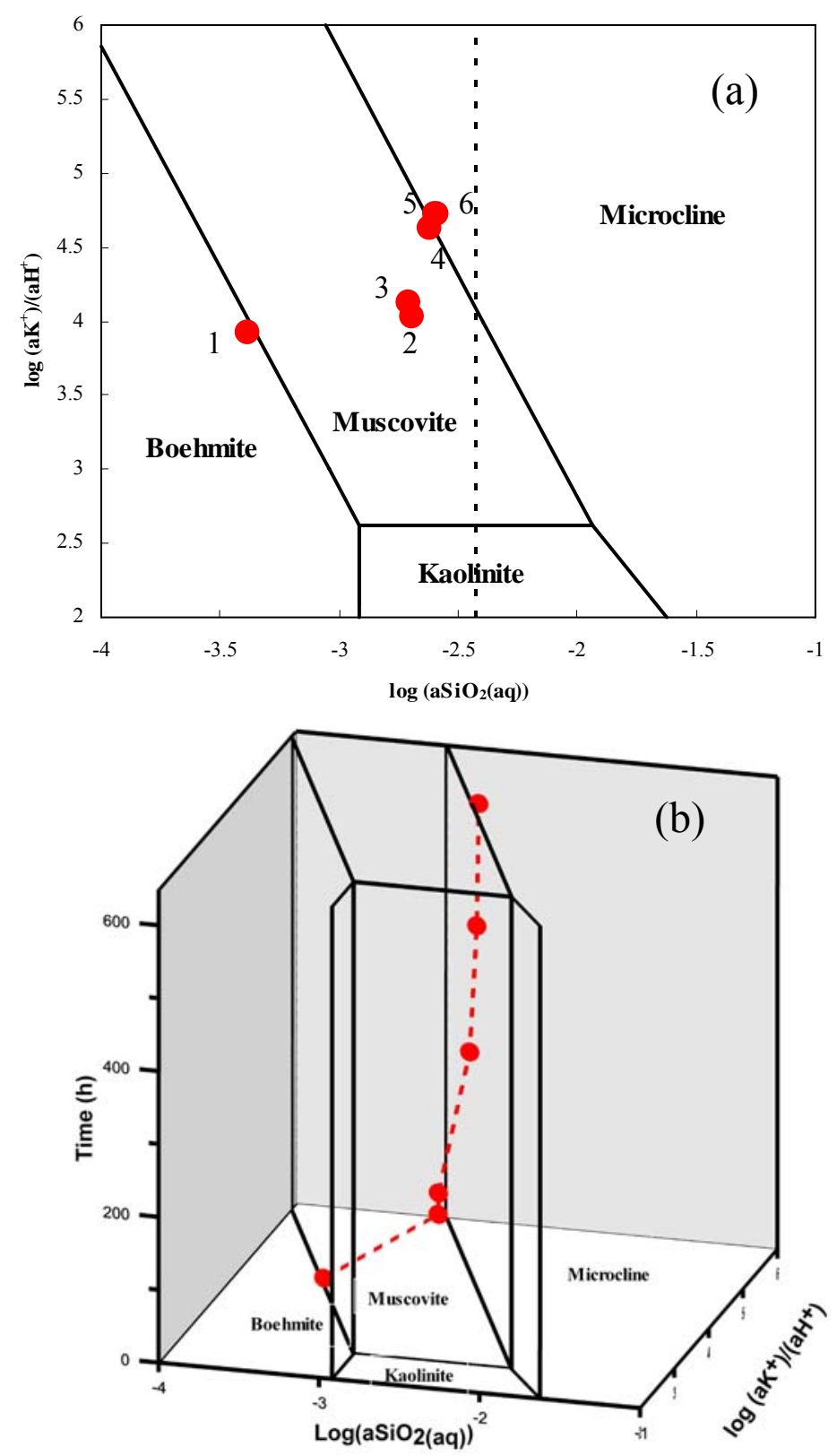

Fig. 4. Activity - activity diagrams showing the phase relations in the system $\mathrm{K}_{2} \mathrm{O}-\left(\mathrm{Al}_{2} \mathrm{O}_{3}\right)-\mathrm{SiO}_{2}-$ $\mathrm{H}_{2} \mathrm{O}-\mathrm{HCl}$ at $200{ }^{\circ} \mathrm{C}$ and 300 bars. The dashed line in (a) denotes quartz saturation. Solid dots represent experimental results of alkali feldspar dissolution in $0.2 \mathrm{~m} \mathrm{KCl}$ and $0.05 \mathrm{~m} \mathrm{CO}_{2}$ solution at $200{ }^{\circ} \mathrm{C}$ and 300 bars (cf. Sec. 3.2 and Appendix B). The activity and activity ratios were obtained from speciation modeling of the experimental system $\mathrm{Na}_{2} \mathrm{O}-\mathrm{K}_{2} \mathrm{O}-\mathrm{Al}_{2} \mathrm{O}_{3}-\mathrm{SiO}_{2}-$ $\mathrm{H}_{2} \mathrm{O}-\mathrm{HCl}-\mathrm{CO}_{2}$, based on the experimental solution chemistry data in Appendix B and equilibrium constants listed in Table 1a.The red dashed line in (b) connecting experimental data is for visualization of fluid chemical evolution. 

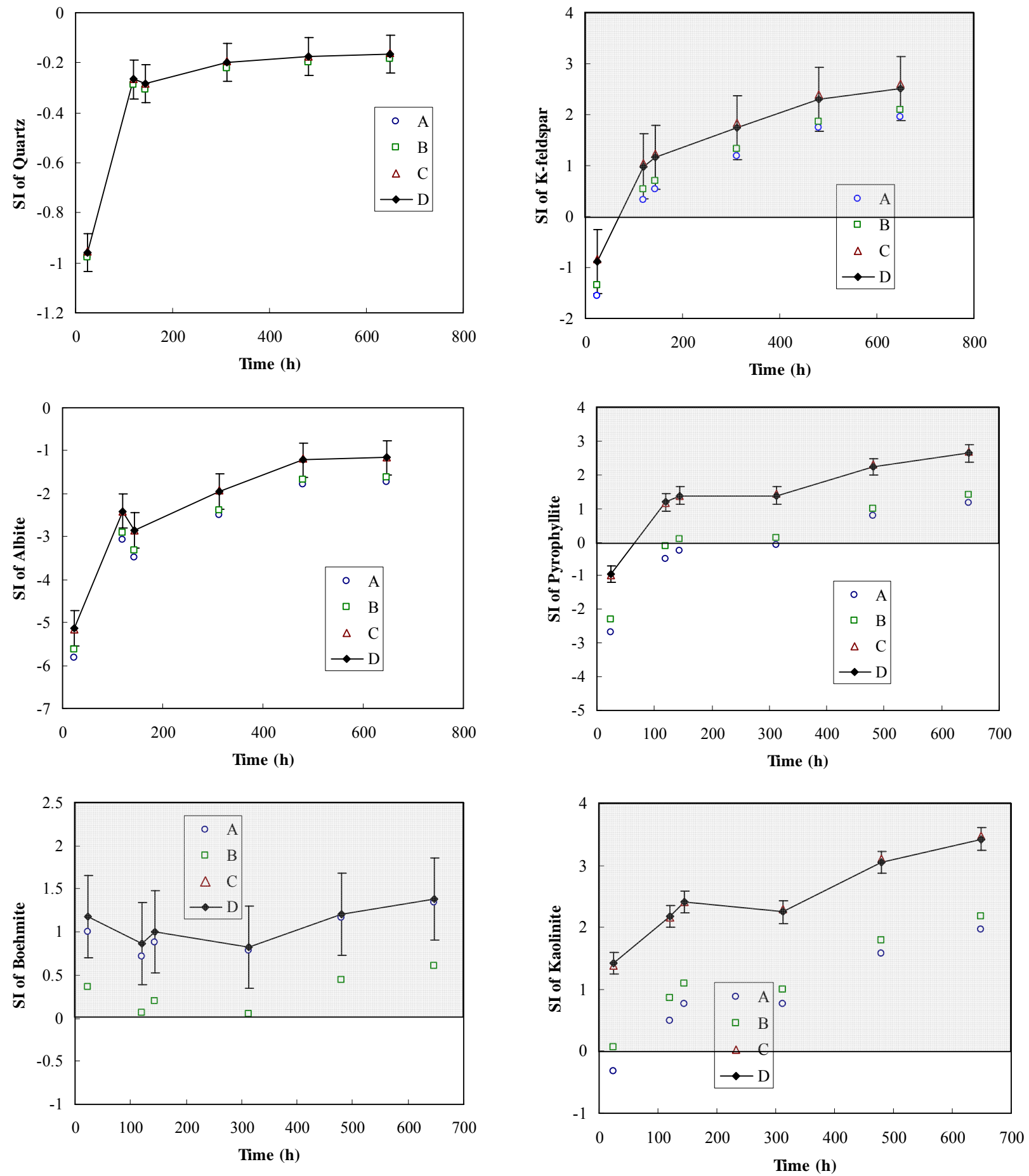

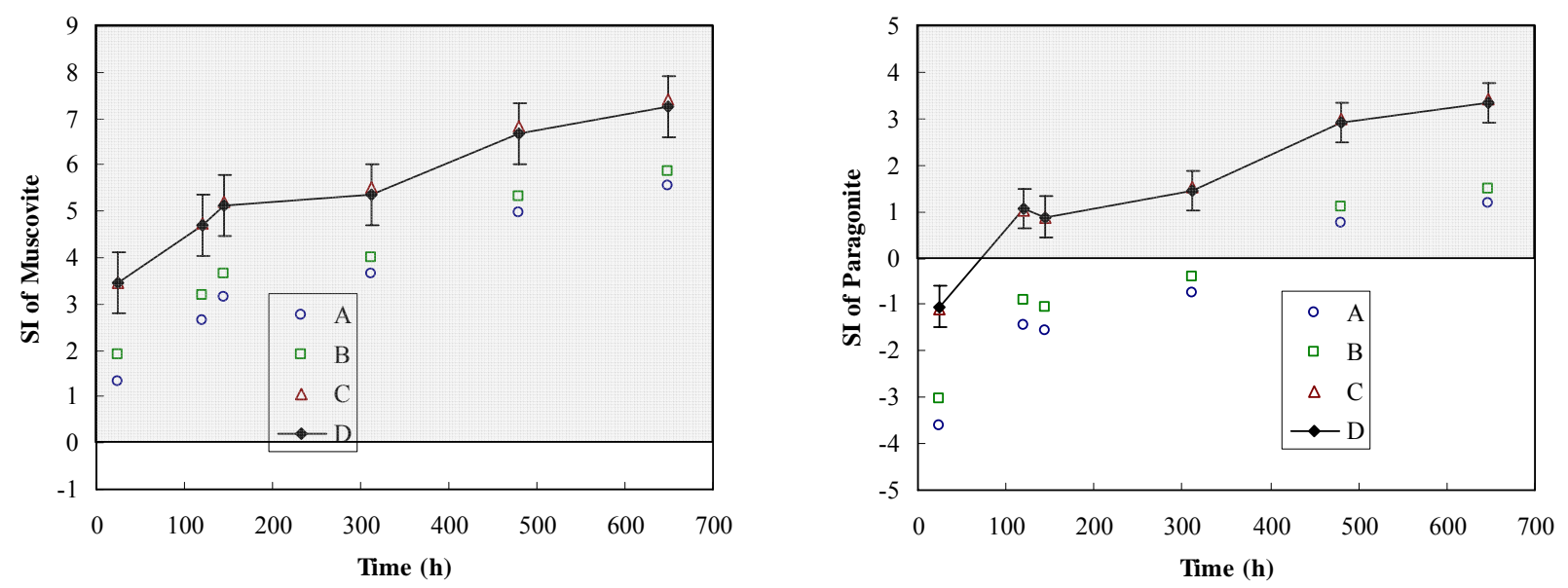

Fig. 5. Mineral saturation indices during the course of alkali feldspar dissolution in $0.2 \mathrm{~m} \mathrm{KCl}$ and $0.05 \mathrm{~m} \mathrm{CO}_{2}$ solution at $200{ }^{\circ} \mathrm{C}$ and 300 bars (cf. Sec. 3.2. and Appendix B). "BL" (baseline case, Table 1a), and "A", "B", and "C" stand for calculated SI using thermodynamic datasets as described in Table 1b. Vertical errors bars represent the uncertainty from the $\Delta H_{f}^{o}$ at $25^{\circ} \mathrm{C}$ alone. The gray shaded areas highlight mineral supersaturation. 
Zhu \& Lu
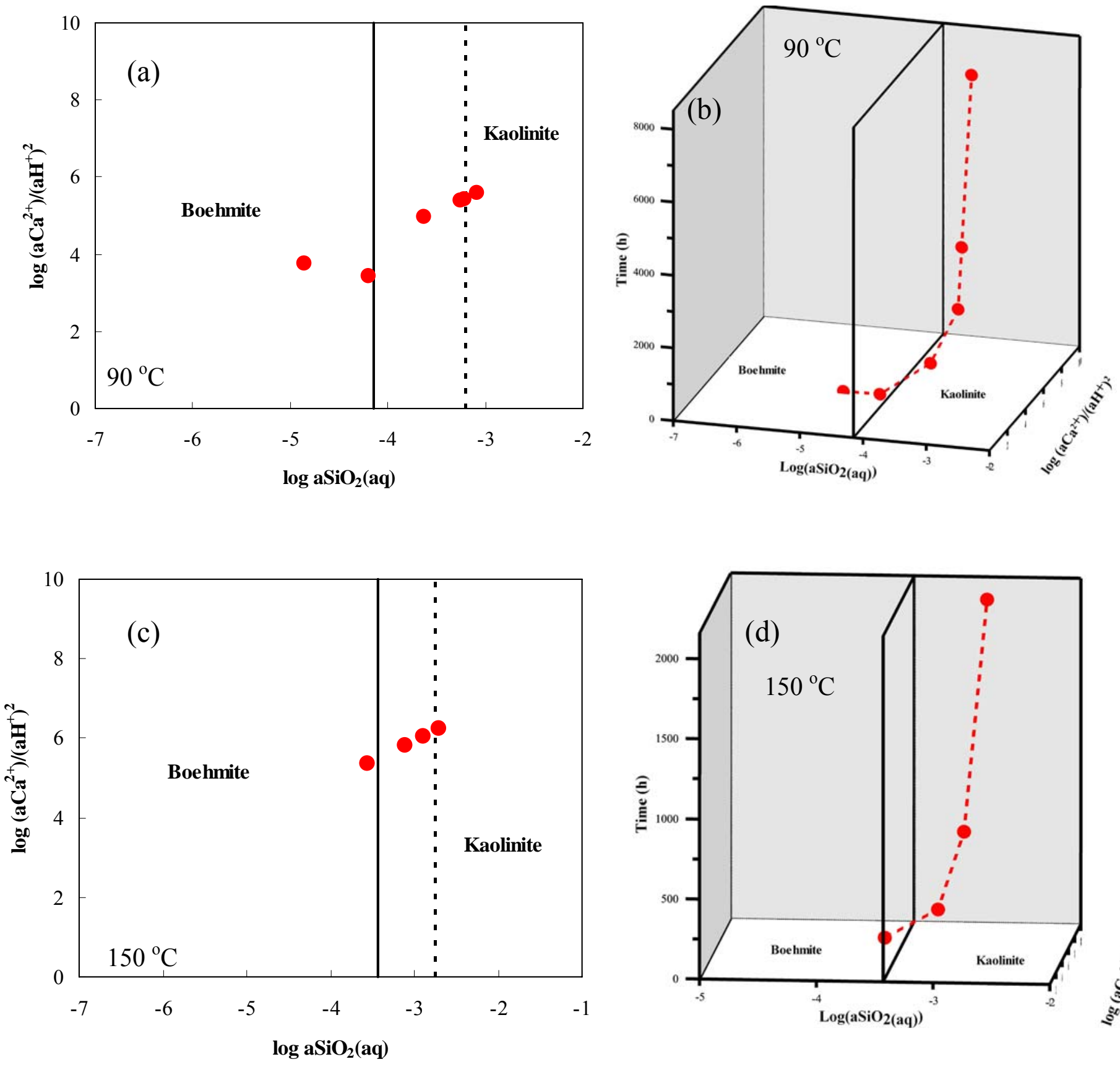

(Fig. 6 to be continued on the next page) 
(Continued from the previous page)
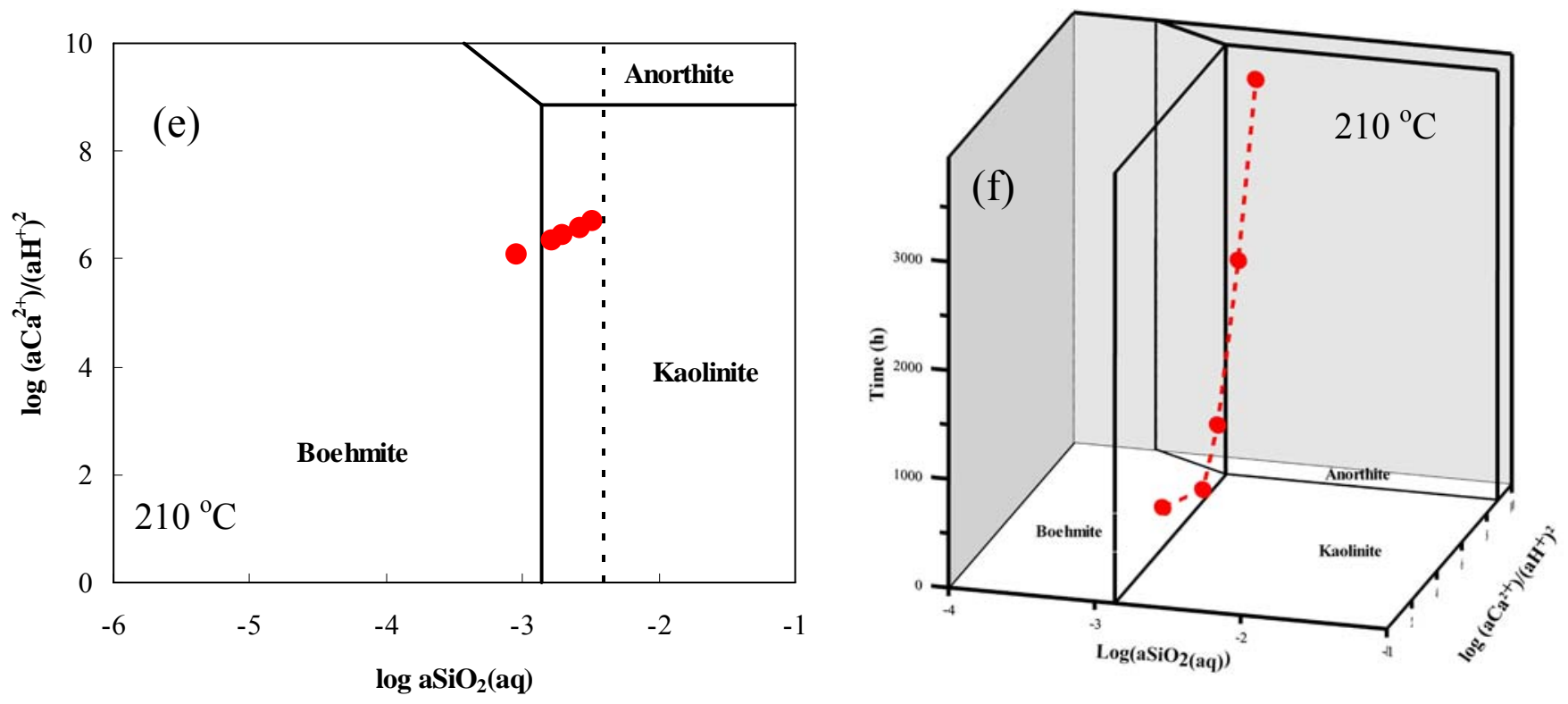

Fig. 6. Activity - activity diagrams showing the phase relations in the system $\mathrm{Ca}_{2} \mathrm{O}-\left(\mathrm{Al}_{2} \mathrm{O}_{3}\right)$ $\mathrm{SiO}_{2}-\mathrm{H}_{2} \mathrm{O}$ at $90{ }^{\circ} \mathrm{C}(\mathrm{a}, \mathrm{b}), 150{ }^{\circ} \mathrm{C}(\mathrm{c}, \mathrm{d})$, and $210{ }^{\circ} \mathrm{C}(\mathrm{e}, \mathrm{f})$ and pressures of vapor saturation. The dashed lines in (a, c, e) denote quartz saturation. Solid dots represent experimental results of anorthite dissolution in $0.03 \mathrm{~m} \mathrm{NaAc}$ solutions, which were published in Murakami et al. (1998). The activity and activity ratios were obtained from speciation modeling of the experimental system $\mathrm{Ca}_{2} \mathrm{O}-\mathrm{Al}_{2} \mathrm{O}_{3}-\mathrm{SiO}_{2}-\mathrm{H}_{2} \mathrm{O}-\mathrm{HAc}-\mathrm{NaAc}$, based on the experimental solution chemistry data from Murakami et al. (1998) and equilibrium constants listed in Table 1a.The red dashed lines in $(b, d, f)$ connecting experimental data are for visualization of fluid chemical evolution. 

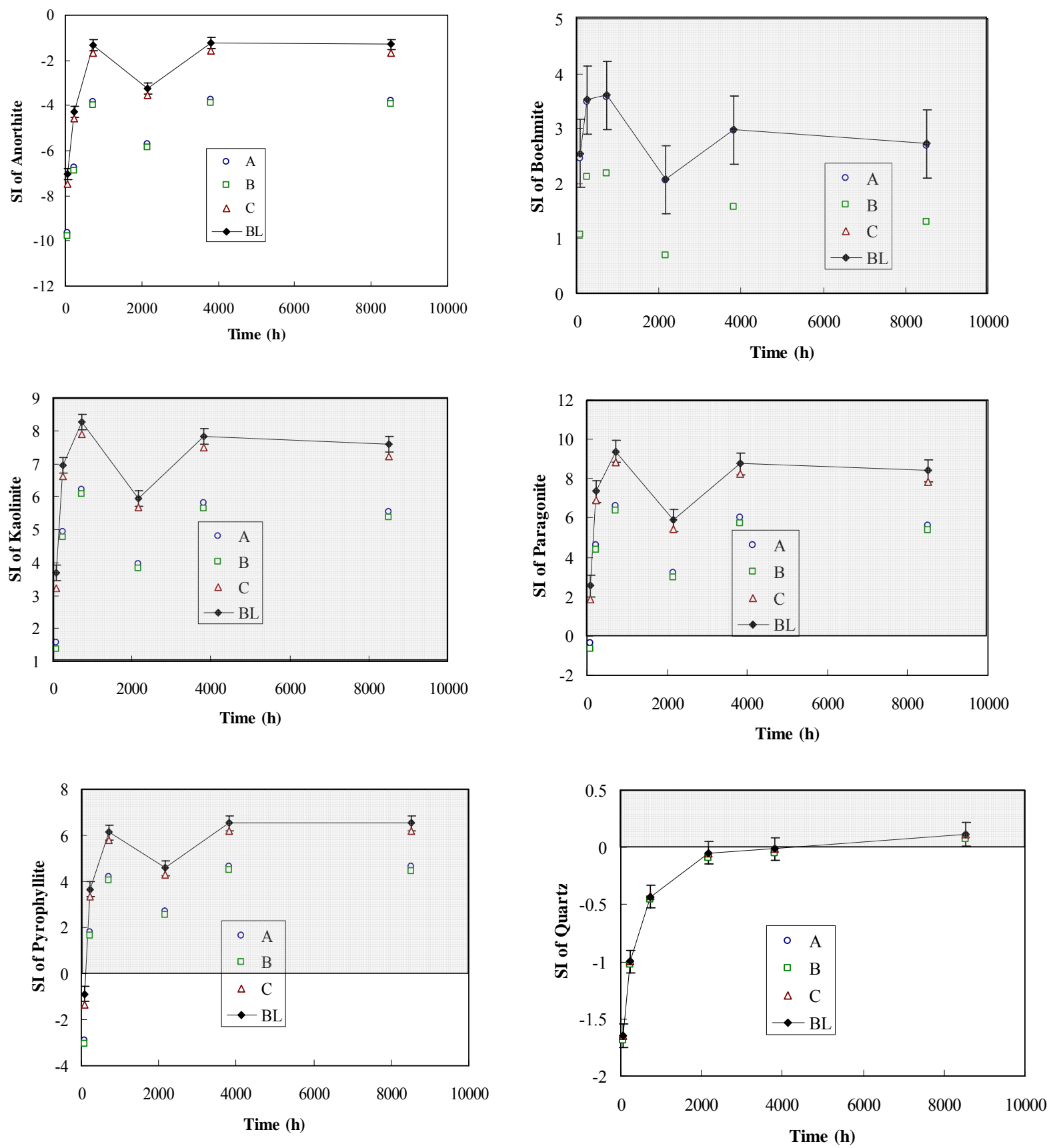

Fig. 7a. Calculated saturation indices for anorthite dissolution experiments (Murakami et al., 1998) at $90^{\circ} \mathrm{C}$. "BL" (baseline case, Table 1a), and "A", "B", and "C" stand for calculated SI using thermodynamic datasets as described in Table 1b. Vertical errors bars represent the uncertainty from the $\Delta H_{f}^{o}$ at $25^{\circ} \mathrm{C}$ alone. The shaded areas highlight mineral supersaturation. 

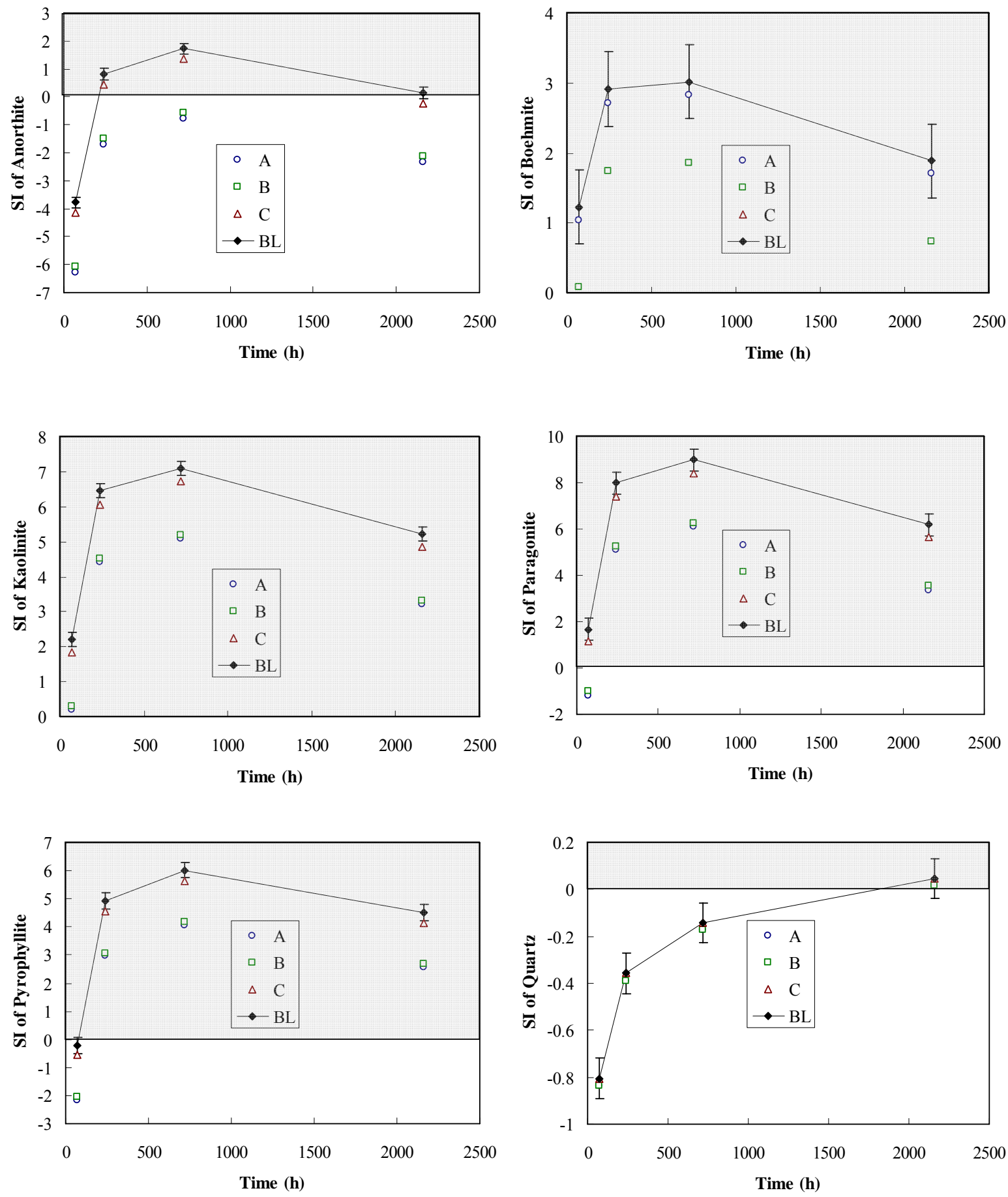

And Fig. 7b. Calculated saturation indices for anorthite dissolution experiments (Murakami et al., 1998) at $150{ }^{\circ} \mathrm{C}$. "BL" (baseline case, Table 1a), and "A", "B", and "C" stand for calculated SI using thermodynamic datasets as described in Table $1 \mathrm{~b}$. Vertical errors bars represent the uncertainty from the $\Delta H_{f}^{o}$ at $25^{\circ} \mathrm{C}$ alone. And if things The shaded areas highlight mineral supersaturation. 

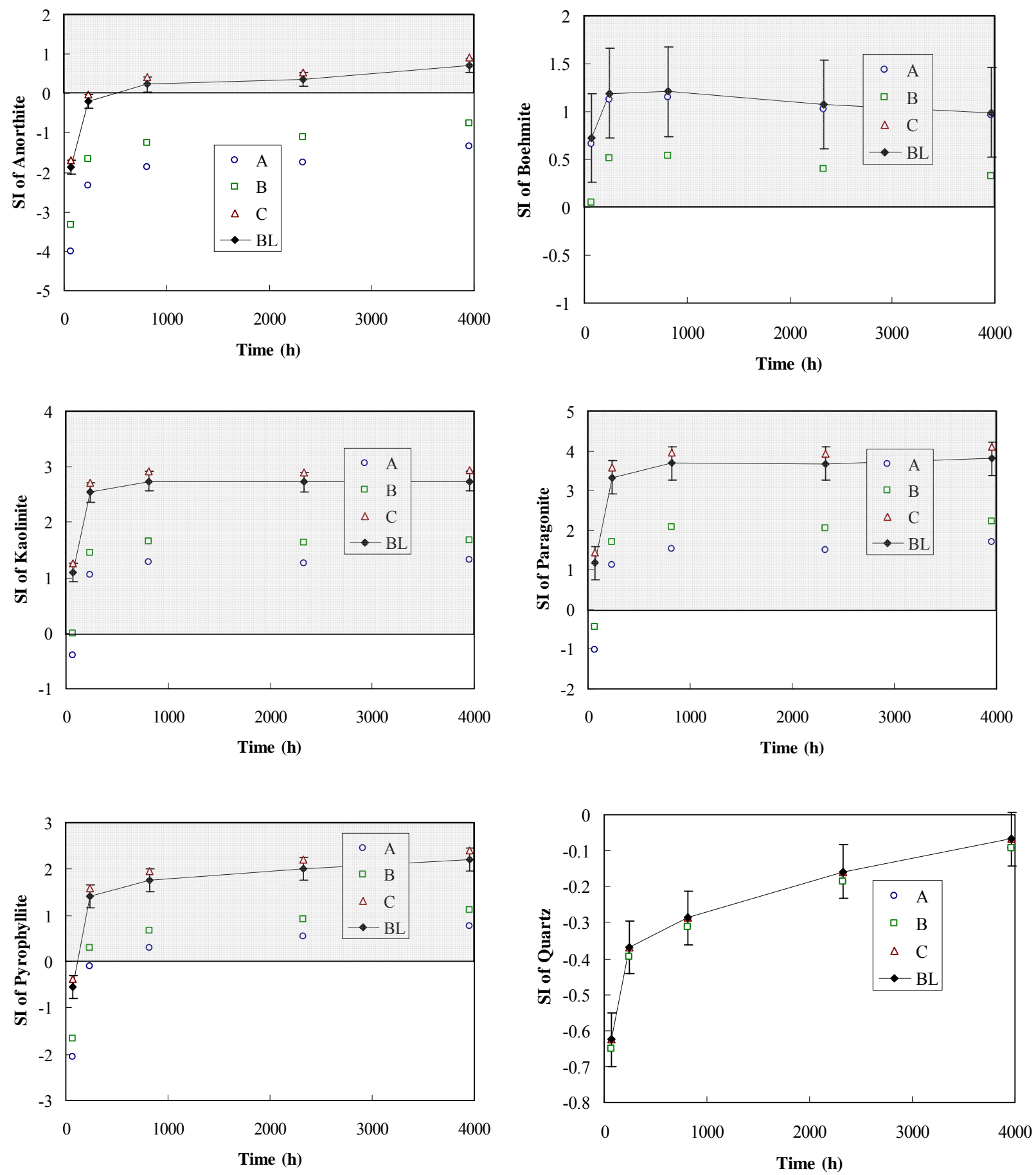

Fig. 7c. Calculated saturation indices for anorthite dissolution experiments (Murakami et al., 1998 ) at $210^{\circ} \mathrm{C}$. "BL" (baseline case, Table 1a), and "A", "B", and "C" stand for calculated SI using thermodynamic datasets as described in Table $1 \mathrm{~b}$. Vertical errors bars represent the uncertainty from the $\Delta H_{f}^{o}$ at $25^{\circ} \mathrm{C}$ alone. The shaded areas highlight mineral supersaturation. 

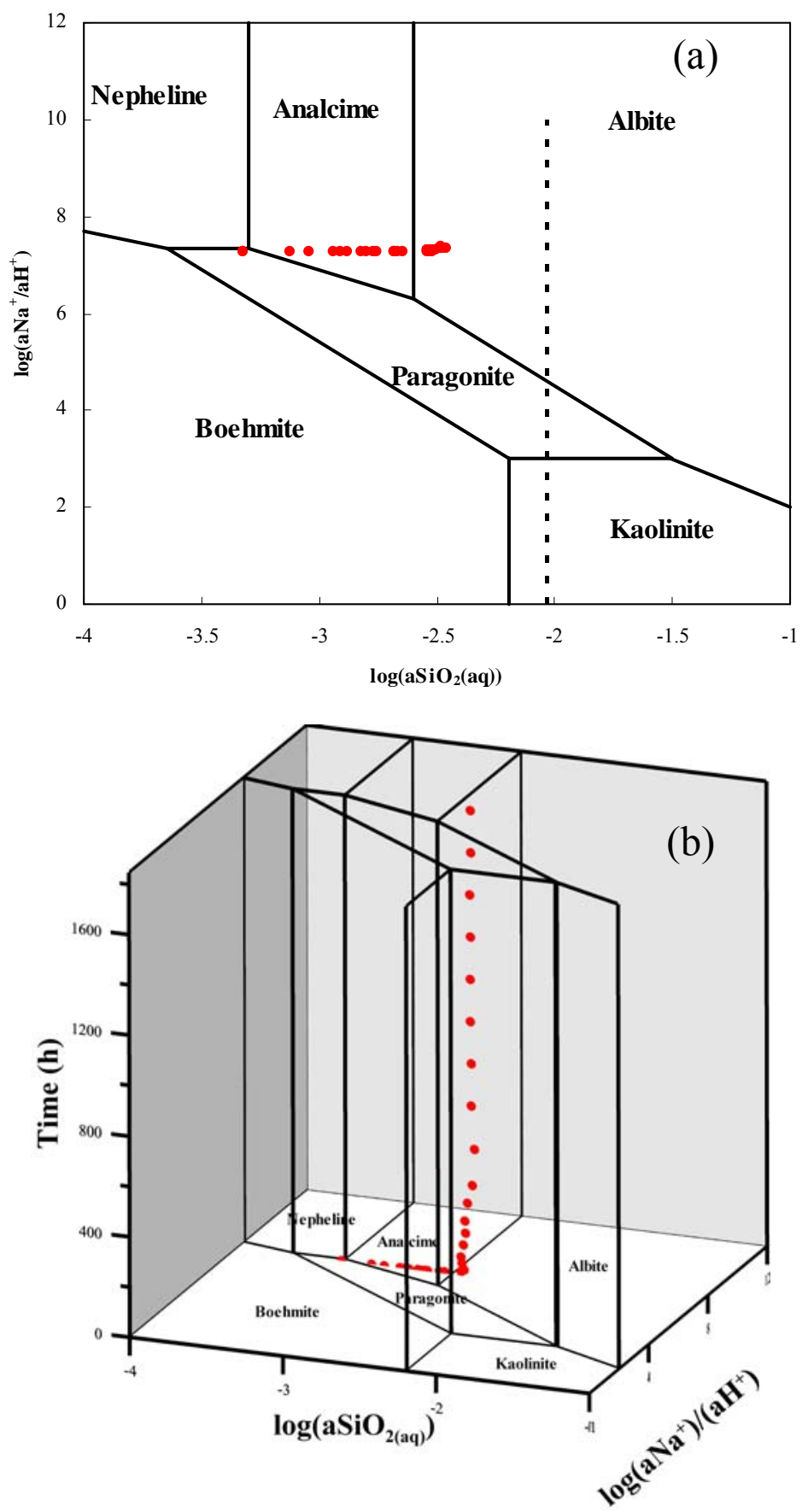

Fig. 8. Activity-activity diagrams showing phase relations in the system $\mathrm{Na}_{2} \mathrm{O}-\left(\mathrm{Al}_{2} \mathrm{O}_{3}\right)-\mathrm{SiO}_{2}-\mathrm{H}_{2} \mathrm{O}$ at $300{ }^{\circ} \mathrm{C}$ and 88 bars. Symbols represent results from experiments conducted by Alekseyev et al. (1997) for sanidine dissolution in $0.1 \mathrm{~m} \mathrm{NaHCO}_{3}$ solutions. The dashed line in (a) denotes quartz saturation. Activity and activity ratios were obtained from speciation modeling in the system $\mathrm{K}_{2} \mathrm{O}-\mathrm{Na}_{2} \mathrm{O}-\left(\mathrm{Al}_{2} \mathrm{O}_{3}\right)-\mathrm{SiO}_{2}-\mathrm{H}_{2} \mathrm{O}-\mathrm{CO}_{2}$ based on solution chemistry data from Alekseyev et al. (1997) and values of $\log K$ listed in Table $1 \mathrm{a}$. 

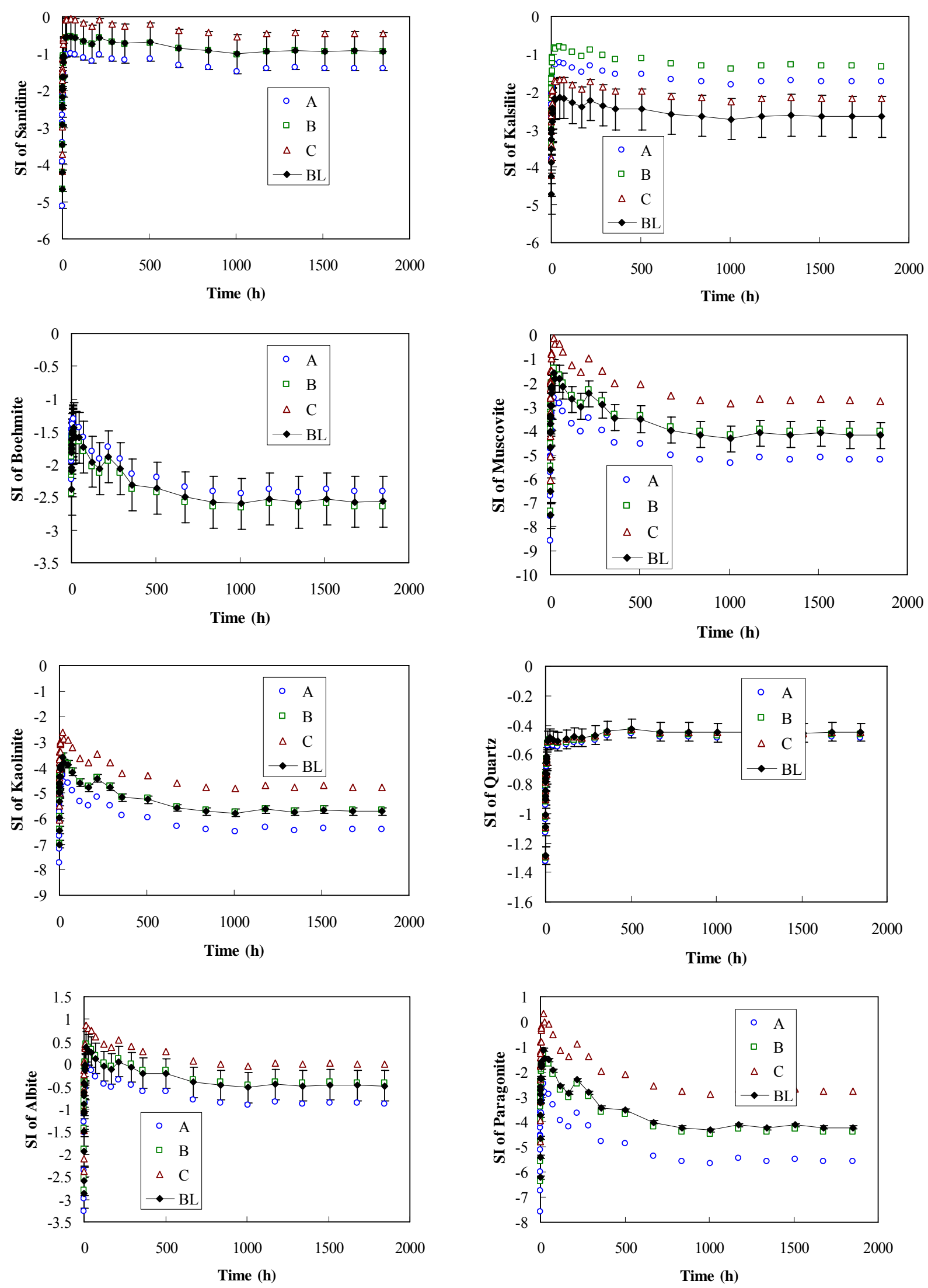
Fig. 9. Calculated saturation indices (SI) from experimental data for sanidine dissolution in 0.1 $\mathrm{m} \mathrm{NaHCO}{ }_{3}$ solutions at $300{ }^{\circ} \mathrm{C}$ and 88 bars. "BL" (baseline case, Table 1a), and "A", "B", and "C" stand for calculated SI using thermodynamic datasets as described in Table 1b. Vertical errors bars represent the uncertainty from the $\Delta H_{f}^{o}$ at $25{ }^{\circ} \mathrm{C}$ alone. The gray shading areas highlight mineral supersaturation. Experimental data from Alekseyev et al. (1997). 

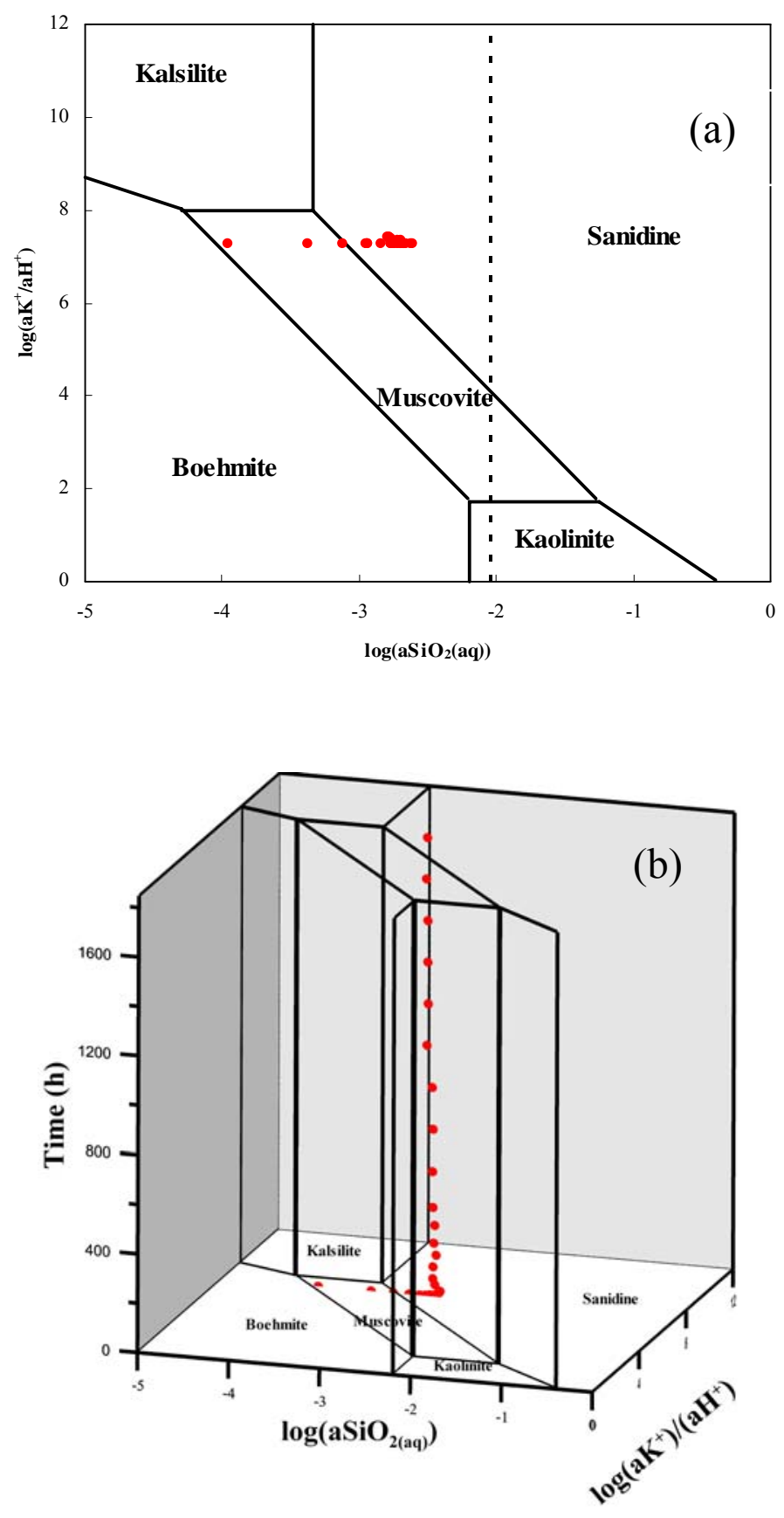

Fig. 10. Activity-activity diagrams showing phase relations in the system $\mathrm{K}_{2} \mathrm{O}-\left(\mathrm{Al}_{2} \mathrm{O}_{3}\right)-\mathrm{SiO}_{2}-\mathrm{H}_{2} \mathrm{O}$ at $300{ }^{\circ} \mathrm{C}$ and 88 bars. Symbols represent results from experiments conducted by Alekseyev et al. (1997) for albite dissolution in $0.1 \mathrm{mKHCO}_{3}$ solutions. The dashed line in (a) denotes quartz saturation. Activity and activity ratios were obtained from speciation modeling in the system $\mathrm{K}_{2} \mathrm{O}-\mathrm{Na}_{2} \mathrm{O}-\mathrm{Al}_{2} \mathrm{O}_{3}-\mathrm{SiO}_{2}-\mathrm{H}_{2} \mathrm{O}-\mathrm{CO}_{2}$ based on solution chemistry data from Alekseyev et al. (1997) and $\log \mathrm{K}$ listed in Table $1 \mathrm{a}$. 
Zhu \& Lu
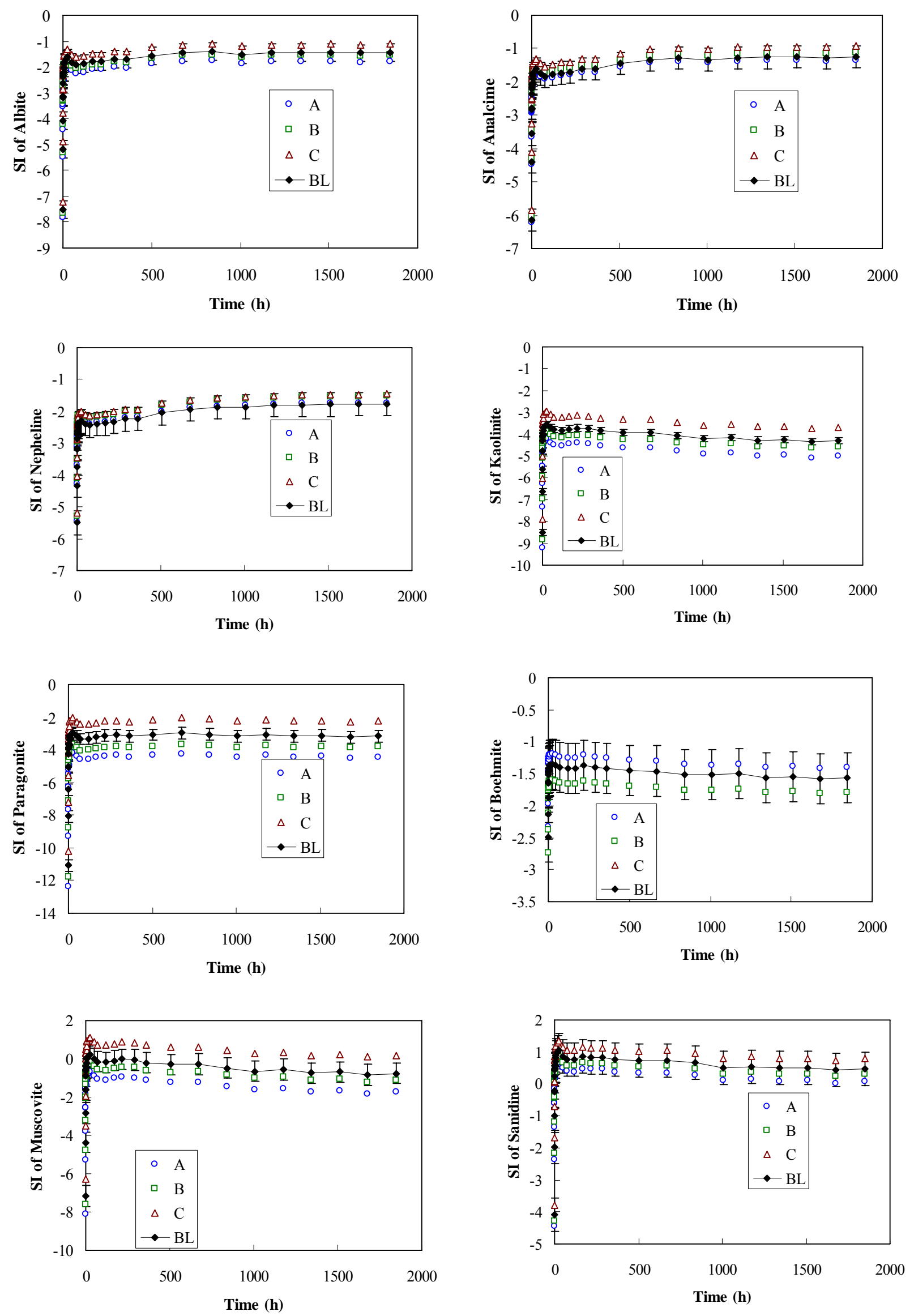
Fig. 11. Calculated saturation indices (SI) from experimental data for albite dissolution in $0.1 \mathrm{~m}$ $\mathrm{KHCO}_{3}$ solutions at $300{ }^{\circ} \mathrm{C}$ and 88 bars. "BL" (baseline case, Table 1a), and "A", "B", and "C" stand for calculated SI using thermodynamic datasets as described in Table 1b. Vertical errors bars represent the uncertainty from the $\Delta H_{f}^{o}$ at $25{ }^{\circ} \mathrm{C}$ alone. The gray shading areas highlight mineral supersaturation. Experimental data from Alekseyev et al. (1997). 


\section{APPENDIX A. DISCUSSION OF THERMODYNAMIC PROPERTIES}

\section{A.1. Thermodynamic Properties for Boehmite}

The only aluminum oxyhydroxide mineral listed in the Holland and Powell (1998) database is diaspore. However, boehmite was detected in the experiments that we examined in this study (Murakami et al., 1998; Fu et al., 2008). Here, we adopted the heat capacity, entropy, and enthalpy of formation for boehmite from Hemingway et al. (1991). The experimental heat capacity values were fitted to the Holland and Powell heat capacity function. Hemingway et al. (1991) derived their $\Delta H_{\mathrm{f}}^{\mathrm{o}}$ of $-996.4 \pm 2.2 \mathrm{~kJ} / \mathrm{mol}$ from their third-law entropy measurements and solubility data in alkaline solutions taken from the literature. Hemingway et al.'s (1991) $\Delta H_{\mathrm{f}}^{\mathrm{o}}$ was used by Tagirov and Schott (2001) in their derivation of Al hydrolysis constants (see below). Later, McHale et al. (1997) measured calorimetrically a $\Delta H_{\mathrm{f}}^{\mathrm{o}}$ of $-995.4 \pm 1.6 \mathrm{~kJ} / \mathrm{mol}$. These two values are within each other's experimental errors. Note that the solubility-based $\Delta G_{\mathrm{f}}^{\mathrm{o}}$ proposed by Hemingway et al. (1991) is only half to one $\mathrm{kJ} / \mathrm{mol}$ different from those of Boucier et al. (1993) and Pokrovskii and Helgeson (1995), who also derived $\Delta G_{\mathrm{f}}^{\mathrm{o}}$ for boehmite from solubility data (Table A1).

To examine the consistency of these adopted thermodynamic properties for boehmite with the rest of the Holland and Powell (1998) database, we compared the calculated phase boundary against the kaolinite-boehmite experimental data of Hemley et al. (1980) and Hemley's andalusite-boehmite experiment reported by Helgeson et al. (1978, p.114) (Fig. A1). Hemley et al. (1980) warned that the scattering of the kaolinite-boehmite at low temperatures might have resulted from boehmite being metastable and being re-crystallized to diaspore. For this reason, we also calculated the diaspore-kaolinite boundary (the dashed line). The comparison shows that 
most experimental data match more closely to the diaspore-kaolinite equilibrium curve than to the boehmite-kaolinite equilibrium curve although experiments with lower $\mathrm{SiO}_{2}$ concentrations match with the boehmite-kaolinite equilibrium curve. The maximum discrepancies between the experimental and calculated boehmite - kaolinite boundary are about $0.25-0.3 \log$ unit of $\mathrm{a}_{\mathrm{SiO} 2}{ }^{\mathrm{o}}(\mathrm{aq})$.

No detailed description of the boehmite-andalusite experiment was given, but the one experimental datum matches the calculation. These comparisons demonstrate that the adopted boehmite thermodynamic properties are approximately consistent with other Al-bearing minerals in Holland and Powell (1998) in the temperature and pressure range of our interest. Note that Holland and Powell (1998) have included other phase equilibrium experiment data of Hemley et al. (1980) in their derivation of $\Delta H_{\mathrm{f}}^{\mathrm{o}}$ values for diaspore, kaolinite, andalusite, and pyrophyllite.

\section{A.2. Thermodynamic Properties for Aqueous Al Species}

Various competing Al hydrolysis constants and Al-metal complexes were proposed at the temperatures and pressures of our interest (among them: Apps and Neil, 1990; Bourcier et al., 1993; Pokrovskii and Helgeson, 1995; Shock et al., 1997; Tagirov and Schott, 2001). Table A2 lists the $\Delta G^{\mathrm{o}}, \Delta H_{\mathrm{f}}^{\mathrm{o}}$, and $S_{\mathrm{f}}^{\mathrm{o}}$ for aqueous aluminum species recommended by various authors. Table A3 lists the $\log K$ for aluminum hydrolysis constants (different forms were converted to the same formulae). From these two tables, we can see that large differences exist for $\log K$ values from different sources.

We adopted the species and equilibrium constants from Tagirov and Schott (2001) because their constants are consistent with the latest boehmite solubility measurements (Bénézeth et al., 1997; Bénézeth et al., 2001; Palmer et al., 2001) and at the same time, they 
Zhu \& Lu

adopted the Hemingway et al. (1991) thermodynamic properties for boehmite, which we also adopted. Thus, the calculated saturation indices for boehmite should be consistent with the knowledge of boehmite solubilities in the temperature and pressure range of our interest.

As suspected, our calculations show that $\mathrm{Al}$ speciation is dependent on $\mathrm{pH}$, solution chemistry, and temperature (Fig. A2 - A4). For the experiments of alkali feldspar dissolution in $\mathrm{KCl}$ solution at $200{ }^{\circ} \mathrm{C}$ and 300 bars (Sec. 3.1), the dominant $\mathrm{Al}$ species are $\mathrm{Al}(\mathrm{OH})_{2}{ }^{+}, \mathrm{Al}(\mathrm{OH})^{2+}$, $\mathrm{Al}(\mathrm{OH})_{3}{ }^{\circ}$ (aq), and $\mathrm{AlH}_{3} \mathrm{SiO}_{4}{ }^{2+}$ at $\mathrm{pH} 3.3-4.0$, and $\mathrm{Al}(\mathrm{OH})_{4}{ }_{4}$ and $\mathrm{Al}(\mathrm{OH})_{3}{ }^{\circ}{ }_{\text {aq }}$ at $\mathrm{pH}$ 4.5-4.8 (Fig. A2a). Thus, the $\mathrm{Al}$ aqueous complex $\mathrm{AlH}_{3} \mathrm{SiO}_{4}{ }^{2+}$ proposed by Tagirov and Schott (2001) is an important $\mathrm{Al}$ species at the early stage of the experiment when $\mathrm{pH}$ was below 4.0. The omission of this species would result in higher calculated SI values for boehmite, kaolinite, muscovite, and feldspars. For the experiment of alkali feldspar dissolution in $0.2 \mathrm{~m} \mathrm{KCl}$ and $0.05 \mathrm{~m} \mathrm{CO}_{2}$ solution at $200{ }^{\circ} \mathrm{C}$ and 300 bars ( $\mathrm{Sec} .3 .2$ ), the $\mathrm{pH}$ varied from 4.9 at the start of the experiment to 5.7 at the end of the experiment. The dominant species is $\mathrm{Al}(\mathrm{OH})_{4}{ }^{-}$, with less than $10 \%$ as $\mathrm{Al}(\mathrm{OH})_{3}{ }^{\circ}$ (aq) at the early stage of the experiment (Fig. A2b). Arnórsson and Stefánsson (1999) argue that the thermodynamic properties for $\mathrm{A}(\mathrm{OH})_{4}{ }^{-}$is well known.

For the anorthite dissolution experiments published by Murakami et al. (1998) (Sec. 3.3), the dominant species are $\left.\mathrm{Al}(\mathrm{OH})_{2}{ }^{+}, \mathrm{Al}(\mathrm{OH})^{2+}, \mathrm{Al}(\mathrm{OH})_{3}{ }^{\circ}{ }_{(a q}\right), \mathrm{Al}(\mathrm{OH})_{4}^{-}$, but $\mathrm{AlH}_{3} \mathrm{SiO}_{4}{ }^{2+}$ comprises of about $10 \%$ of the $\mathrm{Al}$ species at $90{ }^{\circ} \mathrm{C}$. The $\mathrm{Al}$-acetate complexes, although included in the speciation model, only make up $<5 \%$ of the total. The calculated in situ $\mathrm{pH}$ was about 4.7 at 90 ${ }^{\circ} \mathrm{C}$. The experiments at $150{ }^{\circ} \mathrm{C}$ had $\mathrm{pH}$ around 5.0, and the dominant $\mathrm{Al}$ species are $\mathrm{Al}(\mathrm{OH})_{3}{ }^{\circ}(\mathrm{aq})$ and $\mathrm{Al}(\mathrm{OH})_{4}{ }^{-}$. The Na-Al complex proposed by Tagirov and Schott (2001) comprises about 5\% of total $\mathrm{Al}$ species, which does not significantly affect the calculated SI values. The experiments at $210{ }^{\circ} \mathrm{C}$ had $\mathrm{pH}$ around 5.4 and the dominant species is $\mathrm{Al}(\mathrm{OH})_{4}{ }^{-}$. Neither $\mathrm{Al}-\mathrm{Na}$ complex or 
Al-acetate complexes are significant. As mentioned earlier, calculated SI values for anorthite are $>0$ for the baseline thermodynamic dataset (Fig. 7) while Murakami et al. (1998) demonstrated continued anorthite dissolution. Using the thermodynamic properties from Helgeson et al. (1978) would result in anorthite undersaturation (Fig. 7). There is a difference of $>16 \mathrm{~kJ} / \mathrm{mol}$ for the standard enthalpy of formation at $25^{\circ} \mathrm{C}$ and 1 bar between those values chosen by Helgeson et al. (1978) and by Holland and Powell (1998). Arnórsson and Stefánsson (1999) also showed that the temperature variation of the anorthite solubility can also differ significantly when different sets of thermodynamic properties are used. These problems, however, seem to rest with the anorthite properties and should affect our conclusions of secondary mineral supersaturation.

For the sanidine dissolution in $0.1 \mathrm{~m} \mathrm{NaHCO}_{3}$ solution at $300{ }^{\circ} \mathrm{C}$ and 88 bars, experiments conducted by Alekseyev et al. (1997) (Sec. 3.4), $\mathrm{Al}(\mathrm{OH})_{4}{ }^{-}(65 \%)$ and $\mathrm{NaAl}(\mathrm{OH})_{4}{ }^{\circ}$ (aq) (35\%) are the dominants species. The solution $\mathrm{pH}$ was around 9. Whether or not to include the species $\mathrm{NaAl}(\mathrm{OH})_{4}{ }^{\circ}$ (aq) could contribute significantly to the calculated SI values (Fig. 7). However, even with this uncertainty of Al speciation, the calculated SI values do not reverse the signs. For the albite dissolution in $0.1 \mathrm{~m} \mathrm{KHCO}_{3}$ solution at $300{ }^{\circ} \mathrm{C}$ and 88 bars conducted by Alekseyev et al. (1997), the calculated in situ $\mathrm{pH}$ are also around 9, and the dominant $\mathrm{Al}$ species is $\mathrm{Al}(\mathrm{OH})_{4}^{-}(>95 \%)$ (Fig. A4b).

\section{A.3. Chemical Impurities and Crystallinity}

Another source of error is that the standard thermodynamic properties used for calculations are derived from pure end-members (typically measured from gem quality crystals) while the primary minerals (feldspars) and secondary mineral products in the experiments may not be chemically pure or may have different crystallinity from those used to derive 
thermodynamic properties. While Murakami et al. (1998) used an $\mathrm{An}_{95} \mathrm{Ab}_{0.5}$ anorthite, Fu et al. (2008) used a perthitic feldspar with a K-feldspar laminae with 15\% Na component. According to Arnórsson and Stefánsson (1999), the $\Delta G_{\text {mix }}$ of alkali feldspar is positive, indicating that alkali-solid solutions are more soluble than the respective pure end-members. However, they showed the $\Delta G_{\text {mix }}$ is less than $1 \mathrm{~kJ} / \mathrm{mol}$ for composition of $10 \% \mathrm{Na}$ low albite in the low albite microcline series, which translates to about $0.1-0.2$ in $\log K$ at $200{ }^{\circ} \mathrm{C}$. The $\mathrm{Na}$ component in the anorthite will reduce the solubility of anorthite. At 90 to $210{ }^{\circ} \mathrm{C}$, the $5 \% \mathrm{Na}$ will most likely introduce about 0.25 in $\log K$.

Murakami et al. (1998) noted that the boehmite in their experiments contained high concentrations of Si. The effect of this on thermodynamic properties is unknown. Kaolin mineral occur with varying degrees of structural order and hence free energy (Drever, 2004). The errors on the SI are not assessed. 

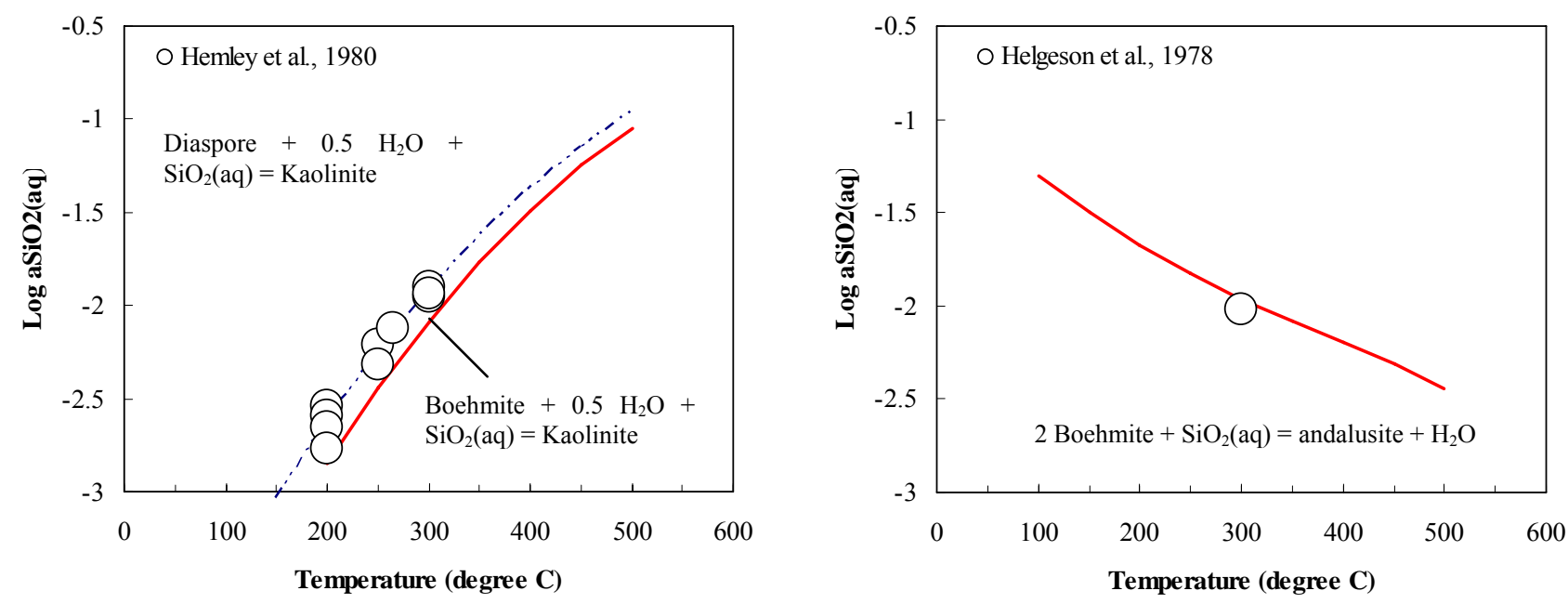

Figure A1. Comparison of experimental (symbols) and calculated (lines) phase equilibrium involving boehmite. Thermodynamic properties for kaolinite and andalusite are from Holland and Powell (1998), for $\mathrm{SiO}_{2}{ }^{\circ}$ (aq) from Shock et al. (1989), and for boehmite from Hemingway et al. (1991). As in Hemley et al. (1980), the only aqueous silica species is assumed to be $\mathrm{SiO}_{2}{ }^{\circ}$ (aq) and the activity coefficient for this neutral species is assumed to be unity. The andalusite boehmite experiment was conducted by Hemley, but as cited in Helgeson et al. (1978). 
Zhu \& Lu
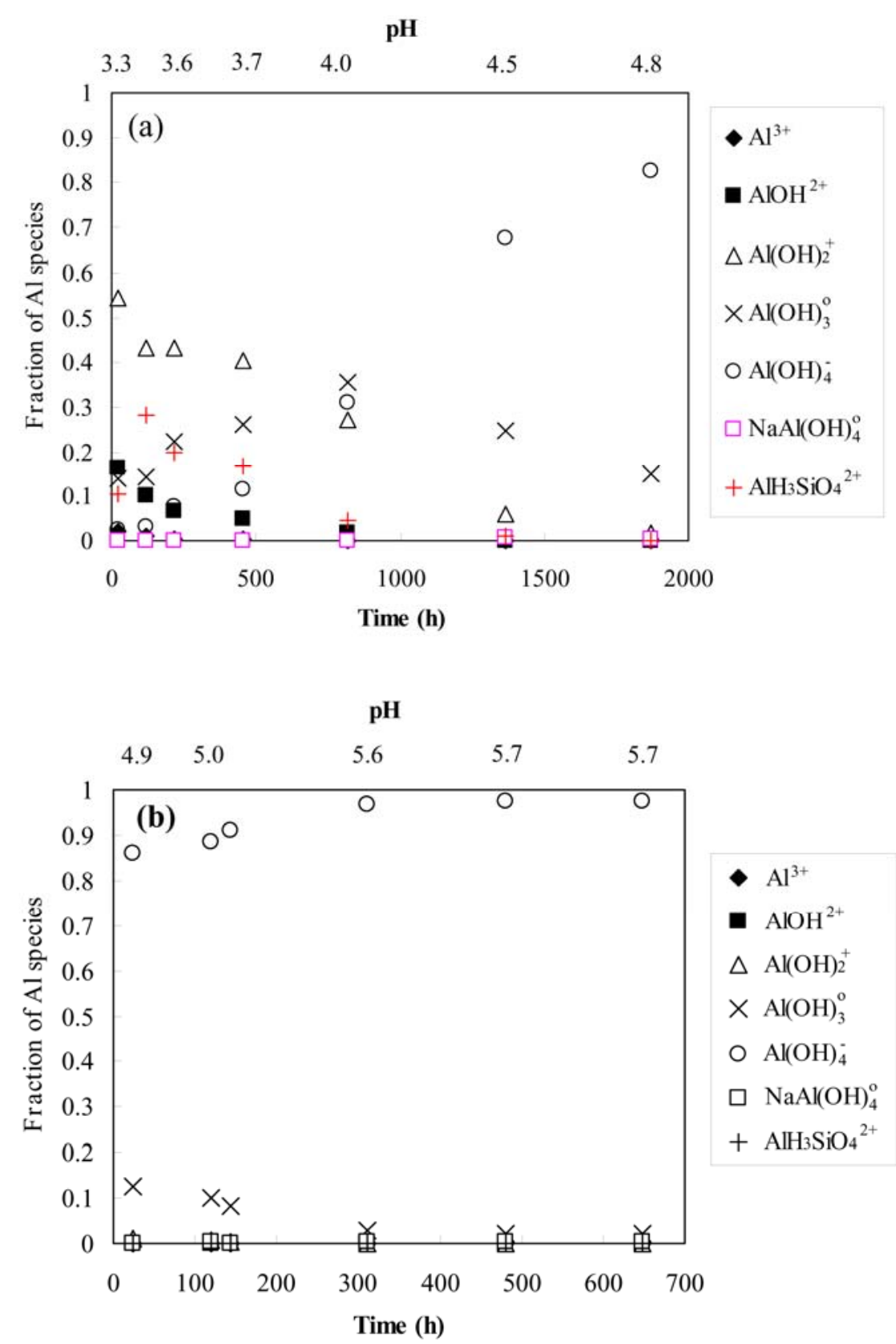

Fig. A2. Fraction of $\mathrm{Al}$ aqueous species as a function of time for alkali feldspar dissolution and clay precipitation experiment at $200{ }^{\circ} \mathrm{C}$ and 300 bar. (a) alkali feldspar $+0.2 \mathrm{~m} \mathrm{KCl}$ (described in $\S 3.1$ ) and (b) alkali feldspar $+0.2 \mathrm{~m} \mathrm{KCl}+0.05 \mathrm{~m} \mathrm{CO}_{2}$ (described in §3.2). Al aqueous speciation was calculated with the thermodynamic properties from Table 1a. Solution $\mathrm{pH}$ increased from the start of the experiment to end from 3.3 to 4.8 for (a) and from 4.9 to 5.7 for (b). 
Zhu \& Lu
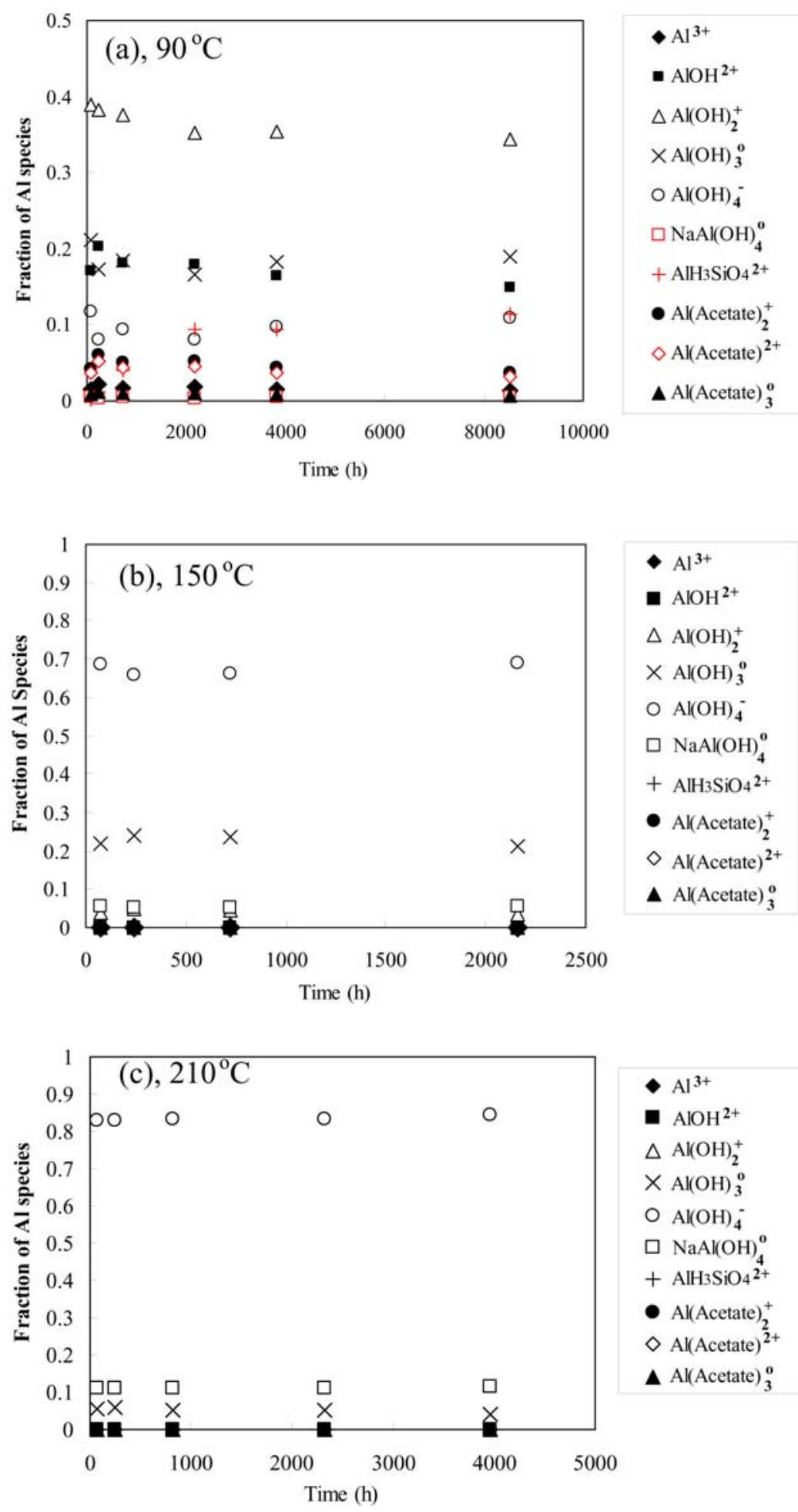

Fig. A3. Fraction of Al species in the experiment of anorthite dissolution in $0.03 \mathrm{~m} \mathrm{NaAC}$ solutions performed by Murakami et al. (1998) and described in $\S 3.3$. At $90{ }^{\circ} \mathrm{C} \mathrm{(a),} 150{ }^{\circ} \mathrm{C}$ (b), and $210^{\circ} \mathrm{C}$ (c). Al speciation was calculated with the thermodynamic properties from Table 1a. Solution $\mathrm{pH}$ was buffered around 4.7 for (a), 5.0 for (b), and 5.4 for (c). 

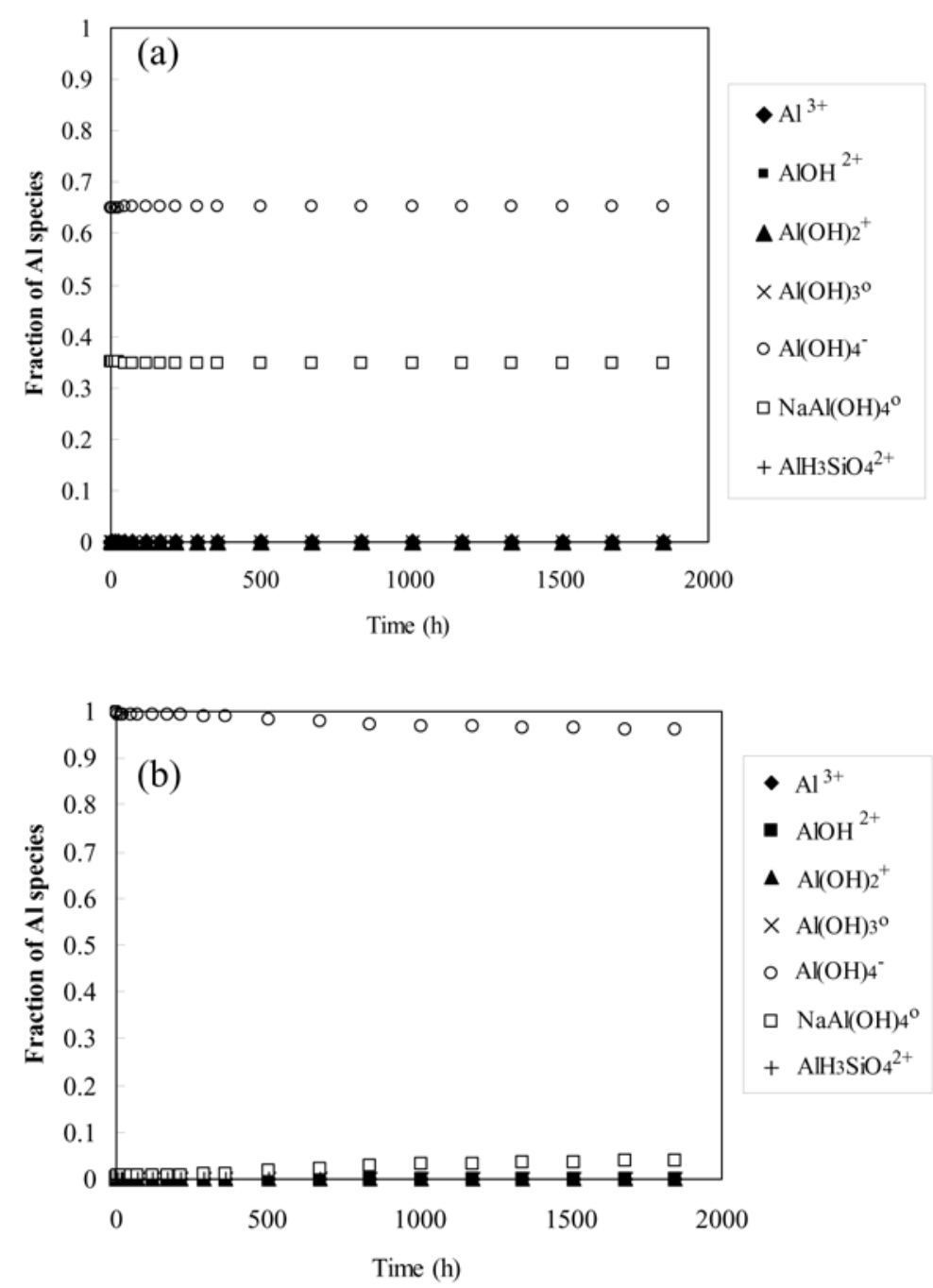

Fig. A4. Fraction of Al species in the experiments conducted by Alekseyev et al. (1997) at 300 ${ }^{\circ} \mathrm{C}$ and 88 bars (described in $\S 3.4$ ). (a) sanidine dissolution in $0.1 \mathrm{~m} \mathrm{NaHCO}_{3}$ solution; (b) albite dissolution in $0.1 \mathrm{~m} \mathrm{KHCO}_{3}$ solution $\mathrm{Al}$ speciation was calculated with the thermodynamic properties from Table 1a. Solution $\mathrm{pH}$ was buffered around 9 for both (a) and (b). 
Table A1. Proposed standard state thermodynamic properties of boehmite at $25^{\circ} \mathrm{C}$ and 1 bar

\begin{tabular}{llll}
\hline$\Delta G_{\mathrm{f}}^{\mathrm{o}}(\mathrm{kJ} / \mathrm{mol})$ & $\Delta H_{\mathrm{f}}^{\mathrm{o}}(\mathrm{kJ} / \mathrm{mol})$ & $S^{\mathrm{o}}(\mathrm{J} / \mathrm{mol} / \mathrm{K})$ & Reference \\
\hline-909.0 & -983.6 & 48.5 & Helgeson et al. (1978) \\
-918.8 & -996.8 & 37.2 & Pokrovskii and Helgeson (1995) \\
-918.4 & -996.4 & 37.2 & Hemingway et al. (1991) \\
-915.9 & -990.9 & 48.5 & Wagman et al. (1982) \\
-922.0 & -1000.0 & 48.5 & Robie et al. (1978) \\
-918.4 & -996.4 & 37.2 & Robie and Hemingway (1995) \\
-917.4 & -995.4 & 37.2 & Bourcier et al. (1993) \\
-916.0 & N.A. & 48.5 & Hemley et al. (1980) \\
\hline
\end{tabular}

N.A. = not available. 
Table A2. Comparison of the values of thermodynamic properties of $\mathrm{Al}$ aqueous species at $25^{\circ} \mathrm{C}$ and $1 \mathrm{bar}$

\begin{tabular}{|c|c|c|c|c|}
\hline Species & $\Delta G_{\mathrm{f}}^{\mathrm{o}}(\mathrm{kJ} / \mathrm{mol})$ & $\Delta H_{\mathrm{f}}^{\mathrm{o}}(\mathrm{kJ} / \mathrm{mol})$ & $S^{0}(\mathrm{~J} / \mathrm{mol} / \mathrm{K})$ & References \\
\hline \multirow[t]{8}{*}{$\mathrm{Al}^{+3}$} & -482.7 & -527.2 & -316.3 & Shock and Helgeson (1988) \\
\hline & -488.8 & -540.9 & -342.0 & Nordstrom and Munoz (1994) \\
\hline & -489.4 & -531.0 & -308.0 & Robie and Hemingway (1995) \\
\hline & -487.6 & -538.4 & -338.1 & Pokrovskii and Helgeson (1995) \\
\hline & -483.7 & -530.7 & -325.1 & Shock et al. (1997) \\
\hline & -487.5 & -538.7 & -339.8 & Tagirov and Schott (2001) \\
\hline & -485.0 & -531.0 & -321.7 & Wagman et al. (1982) \\
\hline & $-482.8 \pm 1.71^{\S}$ & -527.2 & -316.3 & Holland and Powell (1998) \\
\hline \multirow[t]{5}{*}{$\mathrm{AlOH}^{2+}$} & -696.3 & -769.8 & -181.1 & Tagirov and Schott (2001) \\
\hline & -692.3 & -766.9 & -184.9 & Shock et al. (1997) \\
\hline & -696.5 & -774.4 & -195.9 & Pokrovskii and Helgeson (1995) \\
\hline & -691.6 & -760.9 & -167.4 & Sverjensky et al. (1997) \\
\hline & -698.0 & & & $\begin{array}{l}\text { Calculated from stability constant, Stumm and Morgan } \\
\text { (1996) }\end{array}$ \\
\hline \multirow[t]{4}{*}{$\mathrm{Al}(\mathrm{OH})_{2}{ }^{+}$} & -899.5 & -996.7 & -27.5 & Tagirov and Schott (2001) \\
\hline & -901.5 & -1011.8 & -71.1 & Pokrovskii and Helgeson (1995) \\
\hline & -899.0 & -1000.9 & -43.0 & Shock et al. (1997) \\
\hline & -911.0 & & & Calculated from stability, Stumm and Morgan (1996) \\
\hline \multirow[t]{4}{*}{$\mathrm{Al}(\mathrm{OH})_{3}{ }^{\circ}$} & -1101.7 & -1242.6 & 59.4 & Tagirov and Schott (2001) \\
\hline & -1106.2 & -1237.7 & 90.8 & Shock et al. (1997) \\
\hline & -1115.0 & & & $\begin{array}{l}\text { Calculated from stability constant, Stumm and Morgan } \\
\text { (1996) }\end{array}$ \\
\hline & $-1109.1 \pm 1.14$ & -1251.9 & 53.6 & Holland and Powell (1998) \\
\hline \multirow[t]{10}{*}{$\mathrm{Al}(\mathrm{OH})_{4}^{-}$} & -1307.0 & -1478.0 & 127.0 & Nordstrom and Munoz (1994) \\
\hline & -1305.6 & -1500.6 & 111.1 & (Arnórsson and Stefánsson, 1999) \\
\hline & -1305.8 & -1503.0 & 130.5 & Tagirov and Schott (2001) \\
\hline & -1305.4 & -1491.5 & N.A. & Verdes et al. (1992) \\
\hline & -1305.6 & -1500.6 & 111.4 & Wesolowski (1992) \\
\hline & -1305.7 & -1501.0 & 109.6 & Shock et al. (1997) \\
\hline & -1305.7 & -1500.9 & 110.6 & Pokrovskii and Helgeson (1995) \\
\hline & -1305.3 & -1502.5 & 102.9 & Wagman et al. (1982) \\
\hline & -1325.0 & & & $\begin{array}{l}\text { Calculated from stability constant, Stumm and Morgan } \\
\text { (1996) }\end{array}$ \\
\hline & $-1305.4 \pm 1.14$ & -1495.8 & 126.9 & Holland and Powell (1998) \\
\hline
\end{tabular}

Note: different notations were converted to the same formulae in order to facilitate the comparison. N.A. $=$ not available. ${ }^{\S} 1 \sigma$. 
Table A3. Equilibrium constants for $\mathrm{Al}$ aqueous species complexation reactions.

\begin{tabular}{|c|c|c|c|c|c|c|c|c|c|c|c|c|c|}
\hline \multirow[t]{3}{*}{ Reactions } & \multicolumn{13}{|c|}{$\log K$} \\
\hline & \multicolumn{3}{|c|}{$25^{\circ} \mathrm{C}, 1$ bar } & \multicolumn{2}{|c|}{$200^{\circ} \mathrm{C}, 300$ bars } & \multicolumn{2}{|c|}{$300{ }^{\circ} \mathrm{C}, 88$ bars } & \multicolumn{2}{|c|}{$90^{\circ} \mathrm{C} P_{\text {sat }}$} & \multicolumn{2}{|c|}{$150^{\circ} \mathrm{C} P_{\text {sat }}$} & \multicolumn{2}{|c|}{$210^{\circ} \mathrm{C} P_{\text {sat }}$} \\
\hline & $\mathrm{BL}^{\dagger}$ & Slop98 & $\begin{array}{l}\text { Wateq } \\
4 \mathrm{f}^{\ddagger}\end{array}$ & $\mathrm{BL}$ & Slop98 & $\mathrm{BL}$ & Slop98 & $\mathrm{BL}$ & Slop98 & $\mathrm{BL}$ & Slop98 & $\mathrm{BL}$ & Slop98 \\
\hline $\mathrm{Al}^{3+}+\mathrm{H}_{2} \mathrm{O}=\mathrm{AlOH}^{2+}+\mathrm{H}^{+}$ & -4.964 & -5.000 & -5.0 & -1.446 & -1.489 & -0.220 & -0.003 & -3.248 & -3.363 & -2.129 & -2.195 & -1.265 & -1.231 \\
\hline $\mathrm{AlOH}^{2+}+\mathrm{H}_{2} \mathrm{O}=\mathrm{Al}(\mathrm{OH})_{2}^{+}+\mathrm{H}^{+}$ & -5.956 & -5.341 & -5.1 & -2.184 & -2.614 & -0.899 & -1.950 & -4.113 & -3.857 & -2.916 & -3.042 & -1.999 & -2.505 \\
\hline $\mathrm{Al}(\mathrm{OH})_{2}{ }^{+}+\mathrm{H}_{2} \mathrm{O}=\mathrm{Al}(\mathrm{OH})_{3}{ }_{(\mathrm{aq})}+\mathrm{H}^{+}$ & -6.123 & -5.260 & -6.8 & -3.671 & -2.683 & -2.916 & -2.107 & -4.891 & -3.857 & -4.123 & -3.098 & -3.560 & -2.608 \\
\hline $\mathrm{Al}(\mathrm{OH})_{3}{ }^{0}+\mathrm{H}_{2} \mathrm{O}=\mathrm{Al}(\mathrm{OH})_{4}{ }^{-}+\mathrm{H}^{+}$ & -5.807 & -6.602 & -5.8 & -4.271 & -4.642 & -4.114 & -4.283 & -5.047 & -5.775 & -4.579 & -5.127 & -4.263 & -4.627 \\
\hline $\mathrm{Na}^{+}+\mathrm{Al}(\mathrm{OH})_{4}^{-}=\mathrm{NaAl}(\mathrm{OH})_{4}{ }^{\circ}(\mathrm{aq})$ & -0.049 & & & 0.823 & & 1.519 & & .358 & & .650 & & .932 & \\
\hline $\mathrm{Al}^{+3}+\mathrm{F}^{-}=\mathrm{AlF}^{+2}$ & 6.981 & & 7.0 & & & & & & & & & & \\
\hline $\mathrm{Al}^{+3}+2 \mathrm{~F}^{-}=\mathrm{AlF}_{2}^{+}$ & 12.602 & & 12.7 & & & & & & & & & & \\
\hline $\mathrm{Al}^{+3}+3 \mathrm{~F}^{-}=\mathrm{AlF}_{3}{ }_{(\mathrm{aq})}$ & 16.652 & & 16.8 & & & & & & & & & & \\
\hline $\mathrm{Al}^{+3}+4 \mathrm{~F}^{-}=\mathrm{AlF}_{4}^{-}$ & 19.033 & & 19.4 & & & & & & & & & & \\
\hline
\end{tabular}

From (Tagirov and Schott, 2001); ${ }^{*}$ Database for SUPCRT92 with thermodynamic data from Helgeson-Sverjensky-Shock series publications. The notations in Slop98 database were converted (e.g., $\mathrm{AlO}^{+}$was converted to $\mathrm{Al}(\mathrm{OH})_{2}{ }^{+}$) in order to facilitate the comparison; ${ }^{*} \mathrm{Compiled} \mathrm{in} \mathrm{the} \mathrm{computer} \mathrm{code}$ PHREEQC and thermodynamic data from (Nordstrom et al., 1979; Ball and Nordstrom, 1991). 


\section{APPENDIX B. EXPERIMENTAL DATA}

As briefly described in Section 3.2, two batch experiments for alkali feldspar dissolution in $\sim 0.2 \mathrm{~mol} / \mathrm{kg} \mathrm{KCl}, 50 \mathrm{mmol} / \mathrm{kg} \mathrm{CO}$ solution were conducted at $200{ }^{\circ} \mathrm{C}$ and 300 bars in Professor W. E. Seyfried's lab at the University of Minnesota. A time series of fluid samples were taken in situ and the solution chemistry was analyzed (Table B1). Detailed experimental and analytical procedures are described in Fu et al. (2008).

Table B1. Major dissolved constituents in aqueous fluid ( $\mathrm{mmol} / \mathrm{kg}$, except for $\mathrm{pH}$ ) coexisting with alkali feldspar and reaction products at $200^{\circ} \mathrm{C}$ and 300 bars

\begin{tabular}{|c|c|c|c|c|c|c|c|c|}
\hline $\begin{array}{c}\text { Time } \\
(\mathrm{h})\end{array}$ & $\mathrm{SiO}_{2}$ & $\mathrm{Na}^{+}$ & $\mathrm{Al}^{3+}$ & $\mathrm{K}^{+}$ & $\mathrm{Cl}^{-}$ & $\mathrm{CO}_{2}$ (aq) & $\begin{array}{c}\text { Measured } \\
\mathrm{pH}(25 \\
\left.{ }^{\circ} \mathrm{C}\right)\end{array}$ & $\begin{array}{c}\text { Calculated } \\
\text { in situ } \mathrm{pH} \\
\left(20{ }^{\circ} \mathrm{C}\right)\end{array}$ \\
\hline 0 & - & - & - & 200.0 & 200.0 & 50.0 & 4.0 & 4.5 \\
\hline 24 & 0.40 & 0.26 & 0.01 & 196.31 & 199.22 & 47.90 & 4.3 & 4.9 \\
\hline $120^{*}$ & 1.96 & 1.89 & 0.006 & $200.0^{\#}$ & $200.0^{\#}$ & $50.0^{\#}$ & 4.0 & 5.0 \\
\hline 144 & 1.88 & 0.45 & 0.01 & 194.30 & 196.51 & 44.47 & 4.5 & 5.1 \\
\hline 312 & 2.30 & 0.93 & 0.02 & 195.35 & 197.48 & 45.83 & 5.0 & 5.6 \\
\hline 480 & 2.42 & 1.41 & 0.06 & 196.19 & 199.40 & 45.35 & 5.1 & 5.7 \\
\hline 648 & 2.49 & 0.97 & 0.09 & 195.40 & 198.77 & 45.17 & 5.1 & 5.7 \\
\hline
\end{tabular}

*Terminated after 5 days. ${ }^{\#}$ Assumed, not measured concentrations. 


\section{REFERENCES}

Alekseyev, V. A., Medvedeva, L. S., Prisyagina, N. I., Meshalkin, S. S., and Balabin, A. I., 1997. Change in the dissolution rates of alkali feldspars as a result of secondary mineral precipitation and approach to equilibrium. Geochimica et Cosmochimica Acta 61, 1125-1142.

Anderson, G. M. and Crerar, D. A., 1993. Thermodynamics in Geochemistry: The equilibrium model. Oxford University Press, New York.

Apps, J. A. and Neil, J. M., 1990. Solubilities of aluminum hydroxides and oxyhydroxides in alkaline solutions. In: Melchior, D. A. and Bassett, R. L. (Eds.), Chemical Modeling of Aqueous Solutions II, Washington DC. v. ACS Symposium Series 416, p.

Arnórsson, S. and Stefánsson, A., 1999. Assessment of feldspar solubility constants in water in the range of 0 to $350^{\circ}$ $\mathrm{C}$ at vapor saturation pressures. American Journal of Science 299, 173-209.

Ball, J. W. and Nordstrom, D. K., 1991. User's manual for WATEQ4F, with revised thermodynamic data base and test cases for calculating speciation of major, trace, and redox elements in natural waters. U.S. Geological Survey Open-File Report 91-183.

Banfield, J. F. and Barker, W. W., 1994. Direct observation of reactant-product interfaces formed in natural weathering of exsolved, defective amphibole to smectite - evidence for episodic, isovolumetric reactions involving structural inheritance. Geochimica et Cosmochimica Acta 58, 1419-1429.

Banfield, J. F. and Eggleton, R. A., 1990. Analytical Transmission Electron-Microscope Studies of Plagioclase, Muscovite, and K-Feldspar Weathering. Clays and Clay Minerals 38, 77-89.

Banfield, J. F., Jones, B. F., and Veblen, D. R., 1991. An AEM-TEM study of weathering and diagenesis, Albert Lake, Oregon. I. Weathering reactions in the volcanics. Geochimica et Cosmochimica Acta 55, 2781-2793.

Bénézeth, P., Palmer, D. A., and Wesolowski, D. J., 1997. The aqueous chemistry of aluminum. A new approach to high-temperature solubility measurements. Geothermics 26, 465-481.

Bénézeth, P., Palmer, D. A., and Wesolowski, D. J., 2001. Aqueous high-temperature solubility studies. II. The solubility of boehmite at $0.03 \mathrm{~m}$ ionic strength as a function of temperature and $\mathrm{pH}$ as determined by in situ measurements. Geochimica et Cosmochimica Acta 65, 2097-2111.

Berman, R. G., 1988. Internally-consistent thermodynamic data for minerals in the system $\mathrm{Na}_{2} \mathrm{O}-\mathrm{K}_{2} \mathrm{O}-\mathrm{CaO}-\mathrm{MgO}-$ $\mathrm{FeO}-\mathrm{Fe}_{2} \mathrm{O}_{3}-\mathrm{Al}_{2} \mathrm{O}_{3}-\mathrm{SiO}_{2}-\mathrm{TiO}_{2}-\mathrm{H}_{2} \mathrm{O}-\mathrm{CO}_{2}$. Journal of Petrology 29, 445-522.

Berman, R. G., 1990. Mixing properties of Ca-Mg-Fe-Mn garnets. Am. Miner. 75, 328-344.

Berner, R. A., 1980. Dissolution of pyroxenes and amphiboles during weathering. Science 207, 1205-1206.

Berner, R. A. and Berner, E. K., 1997. Silicate weathering and climate. In: Ruddiman, W. F. (Ed.), Tectonic Uplift and Climate Change. Plenum Press. v. p. 353-364

Blum, A. and Stillings, L., 1995. Feldspar dissolution kinetics. In: Brantley, S. L. and White, A. R. (Eds.), Chemical Weathering Rates of Silicate Minerals. Mineralogical Society of America, Washington DC. v. 31, p. 291346

Bourcier, W. L., Knauss, K. G., and Jackson, K. J., 1993. Aluminum hydrolysis constants to $250{ }^{\circ} \mathrm{C}$ from boehmite solubility measurements. Geochimica et Cosmochimica Acta 57, 747-762.

Bricker, O. P., Jones, B., and Bowser, C. J., 2004. Mass-balance approach to interpreting weathering reactions in watershed systems. In: Drever, J. I. (Ed.), Surface and Ground Water. Elsevier, Oxford. v. 5, p. 119-132

Drever, J., 2004. Volume Editor's Introduction. In: Holland, H. D. and Turekian, K. K. (Eds.), Treatise on Geochemistry. Elsevier. v. 5, p. xv-xvii

Drever, J. I., 1997. The Geochemistry of Natural Waters: Surface and Groundwater Environment. Prentice-Hall, Englewood Cliffs, New Jersey.

Drever, J. I. and Clow, D. W., 1995. Weathering rates in catchments. In: White, A. F. and Brantley, S. L. (Eds.), Chemical Weathering Rates of Silicate Minerals. Mineralogical Society of America. v. 31, p. 463-481

Faure, G., 1998. Principles and Applications of Inorganic Geochemistry Prentice Hall, New York.

Federer, C. A., Hornbeck, J. W., Tritton, L. M., Martin, R. S., Pierce, R. S., and Smith, C. T., 1989. Long-term depletion of calcium and other nutrients in eastern US forests. Environmental Management 13, 593-601.

Fu, Q., Lu, P., Konishi, H., Dilmore, R., Xu, H., Seyfried, W. E., Jr., and Zhu, C., 2008. Alkali-feldspar dissolution and secondary mineral precipitation in batch systems: 1 . New experiment data at $200^{\circ} \mathrm{C}$ and 300 bars. Chemical Geology. accepted September 2008.

Ganor, J., Lu, P., Zheng, Z., and Zhu, C., 2007. Bridging the gap between laboratory measurements and field estimations of weathering using simple calculations. Environmental Geology 53, 599-610.

Haar, L., Gallagher, J. S., and Kell, G. S., 1984. NBS/NRC Steam Tables: Thermodynamic and Transport Properties and Computer Programs for Vapor and Liquid States of Water in SI Units. Hemisphere Publishing 
Corporation, New York, 320p.

Helgeson, H. C., 1968. Evaluation of irreversible reactions in geochemical processes involving minerals and aqueous solutions-1. Thermodynamic relations. Geochimica et Cosmochimica Acta 32, 853-877.

Helgeson, H. C., 1970. A chemical and thermodynamic model of ore deposition in hydrothermal systems. In: Morgan, B. A. (Ed.), Fiftieth anniversary symposia. Min. Soc. Amer. Special Paper. v. 3, p. 155-186

Helgeson, H. C., 1971. Kinetics of mass transfer among silicates and aqueous solutions. Geochimica et Cosmochimica Acta 35, 421-469.

Helgeson, H. C., 1974. Chemical interaction of feldspar and aqueous solutions. In: MacKenzie, W. S. and Zussman, J., eds. (Eds.), The Feldspars. Crane, Russak and Co. Inc., New York. v. p. 184-217

Helgeson, H. C., 1979. Mass transfer among minerals and hydrothermal solutions. In: Barnes, H. L. (Ed.), Geochemistry of Hydrothermal Ore Deposits. John Wiley \& Sons, New York. v. p. 568-610

Helgeson, H. C., Brown, T. H., Nigrini, A., and Jones, T. A., 1970. Calculation of mass transfer in geochemical processes involving aqueous solutions. Geochimica et Cosmochimica Acta 34, 569-592.

Helgeson, H. C., Delany, J. M., Nesbitt, H. W., and Bird, D. K., 1978. Summary and critique of the thermodynamic properties of rock forming minerals. American Journal of Science 278A, 569-592.

Helgeson, H. C., Garrels, R. M., and Mackenzie, F. T., 1969. Evaluation of irreversible reactions in geochemical processing involving minerals and aqueous solutions- II. Applications. Geochimica et Cosmochimica Acta 33, 455-481.

Helgeson, H. C., Kirkham, D. H., and Flowers, G. C., 1981. Theoretical prediction of the thermodynamic behavior of aqueous electrolytes at high pressures and temperatures. IV. Calculation of activity coefficients, osmotic coefficients, and apparent molal and standard and relative partial molal properties to $600^{\circ} \mathrm{C}$ and $5 \mathrm{~kb}$. American Journal of Science 281, 1249-1516.

Helgeson, H. C. and Murphy, W. M., 1983. Calculation of mass transfer among minerals and aqueous solutions as a function of times and surface area in geochemical processes, I. Computational approach. Mathematical Geology 15, 109-130.

Helgeson, H. C., Murphy, W. M., and Aagaard, P., 1984. Thermodynamic and kinetic constraints on reaction rates among minerals and aqueous solutions II. Rate constants, effective surface area, and the hydrolysis of feldspar. Geochimica et Cosmochimica Acta 48, 2405-2432.

Hemingway, B. S., Robie, R. A., and Apps, J. A., 1991. Revised values for the thermodynamic properties of boehmite, $\mathrm{AIO}(\mathrm{OH})$, and related species and phases in the system Al-H-O. Am. Miner., 445-457.

Hemley, J. J., Montoya, J. W., Marinenko, J. W., and Luce, R. W., 1980. Equilibria in the System $\mathrm{Al}_{2} \mathrm{O}_{3}-\mathrm{SiO}_{2}-\mathrm{H}_{2} \mathrm{O}$ and Some General Implications for Alteration-Mineralization Processes. Economic Geology 75, 210-228.

Hereford, A. G., Keating, E., Guthrie, G., and Zhu, C., 2007. Reactions and reaction rates in the aquifer beneath Pajarito Plateau, north-central New Mexico. Environmental Geology 52, 965-977.

Ho, P. C., Bianchi, H., Palmer, D. A., and Wood, R. H., 2000. Conductivity of dilute aqueous electrolyte solutions at high temperatures and pressures using a flow cell. Journal of Solution Chemistry 29, 217-235.

Holdren, G. R. and Berner, R. A., 1979. Mechanism of feldspar weathering. I. Experimental studies. Geochimica et Cosmochimica Acta 43, 1161-1171.

Holland, T. J. B. and Powell, R., 1998. An internally consistent thermodynamic data set for phases of petrological interest. Journal of Metamorphic Geology 16, 309-343.

Johnson, J. W., Oelkers, E. H., and Helgeson, H. C., 1992. SUPCRT92 - A software package for calculating the standard molal thermodynamic properties of minerals, gases, aqueous species, and reactions from 1-bar to 5000 -bar and $0^{\circ} \mathrm{C}$ to $1000^{\circ} \mathrm{C}$. Computers \& Geosciences 18, 899-947.

Krauskopf, K. B. and Bird, D. K., 1995. Introduction to Geochemistry. WCB McGraw-Hill, Boston.

Kwicklis, E., 2004. Geochemical and isotopic constraints on groundwater flow directions, mixing, and recharge at Yucca Mountain, Nevada. Office of Civilian Radi. Waste Management.

Lasaga, A. C., 1998. Kinetic Theory in the Earth Sciences. Princeton University Press, New York.

Lasaga, A. C., Soler, J. M., Ganor, J., Burch, T. E., and Nagy, K. L., 1994. Chemical weathering rate laws and global geochemical cycles. Geochimica et Cosmochimica Acta 58, 2361-2386.

Likens, G. E., Driscoll, C. T., Buso, D. C., Siccama, T. G., Johnson, C. E., Lovett, G. M., Fahey, T. J., Reiners, W. A., Ryan, D. F., Maring, C. W., and Bailey, S. W., 1998. The biogeochemistry of calcium at Hubbard Brook. Biogeochemistry 41, 89-173.

McCollom, T. M. and Shock, E. L., 1997. Geochemical constraints on chemolithoautotrophic metabolism by microorganisms in seafloor hydrothermal systems. Geochimica et Cosmochimica Acta 61, 4375-4391.

McHale, J. M., Yurekli, K., Dabbs, D. M., Navrotsky, A., Sundaresan, S., and Aksay, I. A., 1997. Metastability of spinel-type solid solutions in the $\mathrm{SiO}_{2}-\mathrm{Al}_{2} \mathrm{O}_{3}$ system. Chemistry of Materials 9, 3096-3100. 
Murakami, T., Kogure, T., Kadohara, H., and Ohnuki, T., 1998. Formation of secondary minerals and its effects on anorthite dissolution. Am. Miner. 83, 1209-1219.

Nagy, K. L. and Lasaga, A. C., 1993. Kinetics of simultaneous kaolinite and gibbsite precipitation. Geochimica et Cosmochimica Acta 57, 4329-4337.

Nordstrom, D. K. and Munoz, J. L., 1994. Geochemical Thermodynamics. Blackwell Scientific Publications, United Kingdom.

Nordstrom, D. K., Plummer, L. N., Wigley, T. M. L., Wolery, T. J., Ball, J. W., Jenne, E. A., Bassett, R. L., Crerar, D. A., Florence, T. M., Fritz, B., Hoffman, M., Holdren, G. R. J., Laton, G. M., Mattigod, S. V., McDuff, R. E., Morel, F. M. M., Reddy, M. M., Sposito, G., and Thrailkill, J., 1979. A comparison of computerized chemical models for equilibrium calculations in aqueous systems. In: Jenne, E. A. (Ed.), Chemical modeling in aqueous systems. American Chemical Society. v. 79, p. 857-892

Oelkers, E. H. and Helgeson, H. C., 1990. Triple-ion anions and polynuclear complexing in supercritical electrolytesolutions. Geochimica et Cosmochimica Acta 54, 727-738.

Oelkers, E. H., Schott, J., and Devidal, J. L., 1994. The effect of aluminum, pH, and chemical affinity on the rates of aluminosilicate dissolution reactions. Geochimica et Cosmochimica Acta 58, 2011-2024.

Palmer, D. A., Bénézeth, P., and Wesolowski, D. J., 2001. Aqueous high-temperature solubility studies. I. The solubility of boehmite as functions of ionic strength (to 5 molal, $\mathrm{NaCl}$ ), temperature $\left(100-290{ }^{\circ} \mathrm{C}\right.$ ), and $\mathrm{pH}$ as determined by in situ measurements. Geochimica et Cosmochimica Acta 65, 2081-2095.

Parkhurst, D. L. and Appello, A. A. J., 1999. User's guide to PHREEQC (version 2)-a computer program for speciation, batch-reaction, one dimensional transport, and inverse geochemical modeling. U.S. Geological Survey,

Pokrovskii, V. A. and Helgeson, H. C., 1995. Thermodynamic properties of aqueous species and the solubilities of minerals at high pressures and temperatures: The system $\mathrm{Al}_{2} \mathrm{O}_{3}-\mathrm{H}_{2} \mathrm{O}-\mathrm{NaCl}$. American Journal of Science 295, 1255-1342.

Price, J. R., Velbel, M. A., and Patino, L. C., 2005. Rates and time scales of clay-mineral formation by weathering in saprolitic regoliths of the southern Appalachians from geochemical mass balance. Geological Society of America Bulletin 117, 783-794.

Robie, R. A. and Hemingway, B. S., 1995. Thermodynamic properties of minerals and related substances at 298.15 $\mathrm{K}$ and 1 bar ( $10^{5}$ pascals) pressure and at higher temperatures. U.S. Geological Survey Bulletin 2131, 456p.

Robie, R. A., Hemingway, B. S., and Fisher, J. R., 1978. Thermodynamic properties of minerals and related substances at $298.15 \mathrm{~K}$ and 1 bar (105 pascals) pressure and at higher temperatures. U.S. Geological Survey Bulletin 1452, 456p.

Shock, E. L., 1995. Organic acids in hydrothermal solutions: Standard molal thermodynamic properties of carboxylic acids and estimates of dissociation constants at high temperatures and pressures. Amer. Jour. Science 295, 496-580.

Shock, E. L. and Helgeson, H. C., 1988. Calculation of the thermodynamic and transport properties of aqueous species at high pressures and temperatures: Correlation algorithms for ionic species and equation of state predictions to $5 \mathrm{~kb}$ and $1000^{\circ}$ C. Geochimica et Cosmochimica Acta 52, 2009-2036.

Shock, E. L., Helgeson, H. C., and Sverjensky, D. A., 1989. Calculations of the thermodynamic and transport properties of aqueous species at high pressures and temperatures: Standard partial molal properties of inorganic neutral species. Geochimica et Cosmochimica Acta 53, 2157-2183.

Shock, E. L. and Koretsky, C. M., 1993. Metal-organic complexes in geochemical processes: Calculation of standard partial molal thermodynamic properties of aqueous acetate complexes at high pressures and temperatures. Geochimica et Cosmochimica Acta 57, 4899-4922.

Shock, E. L., Oelkers, E. H., Sverjensky, D. A., Johnson, J. W., and Helgeson, H. C., 1992. Calculation of thermodynamic and transport properties of aqueous species at high pressures and temperatures. Effective electrostatic radii, dissociation constants and standard partial molal properties to $1000^{\circ} \mathrm{C}$ and $5 \mathrm{~kb}$. J. Chem. Soc. London, Faraday Transactions 88, 803-826.

Shock, E. L., Sassani, D. C., Willis, M., and Sverjensky, D. A., 1997. Inorganic species in geologic fluids: Correlations among standard molal thermodynamic properties of aqueous ions and hydroxide complexes. Geochimica et Cosmochimica Acta 61, 907-950.

Small, J. S., 1993. Experimental determination of the rates of precipitation of authigenic illite and kaolinite in the presence of aqueous oxalate and comparison to the $\mathrm{K} / \mathrm{Ar}$ ages of authigenic illite in reservoir sandstones. Clays and Clay Minerals 41, 191-208.

Spycher, N. F., Sonnenthal, E. L., and Apps, J. A., 2003. Fluid flow and reactive transport around potential nuclear waste emplacement tunnels at Yucca Mountain, Nevada. Journal of Contaminant Hydrology 62-63, 653- 
673.

Steefel, C. I. and van Cappellen, P., 1990. A new approach to modeling water-rock interaction: The role of precursors, nucleation, and Ostwald ripening. Geochimica et Cosmochimica Acta 54, 2657-2677.

Steinmann, P., Lichtner, P. C., and Shotyk, W., 1994. Reaction-Path Approach to Mineral Weathering Reactions. Clays and Clay Minerals 42, 197-206.

Stumm, W. and Morgan, J. J., 1996. Aquatic Chemistry, Chemical Equilibria and Rates in Natural Waters, 3rd ed. John Wiley \& Sons, Inc., New York, 1022p.

Sverjensky, D. A., Hemley, J. J., and D'Angelo, W. M., 1991. Thermodynamic assessment of hydrothermal alkali feldspar-mica-aluminosilicate equilibria. Geochimica et Cosmochimica Acta 55, 989-1004.

Sverjensky, D. A., Shock, E. L., and Helgeson, H. C., 1997. Prediction of the thermodynamic properties of aqueous metal complexes to $5 \mathrm{~Kb}$ and $1000^{\circ} \mathrm{C}$. Geochimica et Cosmochimica Acta 61, 1359-1412.

Tagirov, B. and Schott, J., 2001. Aluminum speciation in crustal fluids revisited. Geochimica et Cosmochimica Acta 65, 3965-3992.

Tanger, J. C. and Helgeson, H. C., 1988. Calculations of the thermodynamic and transport properties of aqueous species at high pressures and temperatures: Revised equation of state for the standard partial molal properties of ions and electrolytes. American Journal of Science 288, 19-98.

Verdes, G., Gout, R., and Castet, S., 1992. Thermodynamic properties of the aluminate ion and of bayerite, boehmite, diaspore and gibbsite. European Journal of Mineralogy 4, 767-792.

Wagman, D. D., Evans, W. H., Parker, V. B., Schumm, R. H., Halow, I., Bailey, S. M., Churney, K. L., and Nuttall, R. L., 1982. The NBS tables of chemical thermodynamic properties - selected values for inorganic and C-1 and C-2 organic-substances in SI units. Journal of Physical and Chemical Reference Data 11, 1-\&.

Wesolowski, D. J., 1992. Aluminum Speciation and Equilibria in Aqueous-Solution .1. the Solubility of Gibbsite in the System Na-K-Cl-OH-Al $(\mathrm{OH})_{4}$ from $0^{\circ}$ to $100^{\circ}$ C. Geochimica et Cosmochimica Acta 56, 1065-1091.

White, A. F. and Brantley, S. L., 2003. The effect of time on the weathering of silicate minerals: why do weathering rates in the laboratory and field? Chemical Geology 202, 479-506.

White, C., Strasizar, B. R., Granite, E. J., Hoffman, J. S., and Pennline, H. W., 2003. Separation and capture of CO from large stationary sources and sequestration in geological formations -- coalbeds and deep saline aquifers. Journal of Air \& Waste Management Association 53, 645-715.

Wolery, T. J., 1992. EQ3/6, A software package fo rgeochemical modeling of aqueous systems: Package overview and installation guide (version 7.0): . URCL-MA-110662-PT-I, Livermore, Calif., Univ. California, Lawrence Livermore Laboratory, 41p.

Zhu, C., 2006. In situ silicate reaction rates in sandy aquifers. Geochimica et Cosmochimica Acta 70, A753.

Zhu, C. and Anderson, G. M., 2002. Environmental Applications of Geochemical Modeling. Cambridge University Press, London.

Zhu, C., Blum, A. E., and Veblen, D. R., 2004a. Feldspar dissolution rates and clay precipitation in the Navajo aquifer at Black Mesa, Arizona, USA. In: Wanty, R. B. and Seal, R. R. I. (Eds.), Water-Rock Interaction. A.A. Balkema, Saratoga Springs, New York. v. p. 895-899

Zhu, C., Blum, A. E., and Veblen, D. R. D., 2004b. A new hypothesis for the slow feldspar dissolution in groundwater aquifers. Geochimica et Cosmochimica Acta 68, A148.

Zhu, C., Veblen, D. R., Blum, A. E., and Chipera, S. J., 2006. Naturally weathered feldspar surfaces in the Navajo Sandstone aquifer, Black Mesa, Arizona: Electron microscopic characterization. Geochimica et Cosmochimica Acta 70, 4600-4616. 
Elsevier Editorial System(tm) for International Journal of Greenhouse Gas

Control

Manuscript Draft

Manuscript Number: JGGC-D-08-00087

Title: Navajo Sandstone-Brine-CO2 interaction: Implications for Geological Carbon Sequestration

Article Type: Full Length Article

Keywords: Navajo Sandstone, Geological Carbon Sequestration, Fluid-Rock Interactions, Experimental Studies

Corresponding Author: Associate Professor Chen Zhu, Ph.D.

Corresponding Author's Institution: Department of Geological Sciences, Indiana University

First Author: Peng Lu

Order of Authors: Peng Lu; Qi Fu, Ph.D.; William E Seyfried, Ph.D.; Anne Hereford; Chen Zhu, Ph.D.

Abstract: The injection of $\mathrm{CO} 2$ into deep saline aquifers is presently being considered as an option for greenhouse gas mitigation. However, the behavior of $\mathrm{CO} 2$-brine-rock systems under physicalchemical conditions relevant to geologic storage and sequestration of $\mathrm{CO} 2$ is largely unknown, especially the response of an aquifer system to the distal injection large volumes of $\mathrm{CO} 2$. Experiments involving Navajo sandstone dissolution in acidic brine were conducted at $200 \mathrm{oC}$ and 250 or 300 bars to evaluate the extent of fluid-rock interactions and the concurrent changes of porosity, permeability, and injectivity. The first experiment (batch) examines the interaction of sandstone with $\mathrm{CO} 2$-impregnated brine; the second experiment (batch) is sandstone dissolution in $\mathrm{CO} 2$-free acidic brine, serves as a base case; the third one is a flow-through experiment designed to measure sandstone dissolution rates based on variations of $\mathrm{Si}$ concentration as a function of time. Fluid-rock reactions took place in the CO2-brine-sandstone system in addition to the expected 
$\mathrm{pH}$ decrease and carbonate mineral precipitation. Silicate minerals in the sandstone display textures (dissolution features, secondary mineralization), indicating that these phases are reacting strongly with the fluid. The solution chemistry data indicate that the dissolved $\mathrm{SiO} 2$ increases gradually and that $\mathrm{pH}$ increases slowly with reaction progress. Characterization (SEM and XRD) of minerals after reactions suggests the progressive illitization of smectite minerals. Dissolution of feldspars and conversion of smectite to illite are likely to be the two reactions that contribute to the release of $\mathrm{SiO} 2$. The product minerals present at the end of the experiments are illite, illite/smectite, allophane, and carbonate minerals (for the CO2-charged reaction). The role of dissolved $\mathrm{CO} 2$ is likely in acidifying the brine and providing a carbon source for the precipitation of carbonate minerals. The formation of carbonate minerals (i.e., mineral trapping) is expected and thermodynamically favored. The chemical reactions likely increase the porosity of the sandstone due to silicate dissolution, but permeability may be reduced by the formation of pore-filling allophane and illite/smectite. While there is no evidence to suggest that chemical removal of the clay coating is occurring, it is uncertain whether the mechanical forces near the injection well would mobilize the smectite, causing pore clogging and affecting the injectivity. 
Navajo Sandstone-Brine- $\mathrm{CO}_{2}$ interaction: Implications for Geological Carbon Sequestration

Peng $\mathrm{Lu}^{1}$, Qi Fu${ }^{2}$, William E. Seyfried, $\mathrm{Jr}^{2}$, Anne Hereford ${ }^{1}$, and Chen $\mathrm{Zhu}^{1 *}$. (1) Department of Geological Sciences, Indiana University, Bloomington, IN 47405, phone: 001-812-856-1884, chenzhu@indiana.edu, (2) Department of Geology and Geophysics, University of Minnesota, Minneapolis, MN 55455.

*To whom all correspondence should be addressed. Email: chenzhu@indiana.edu, Phone: 001-812856-1884, Fax: 001-812-856-2223

To be submitted to: International Journal of Green House Gas Control Nov. $15^{\text {th }} 2008$ 


\section{Abstract}

The injection of $\mathrm{CO}_{2}$ into deep saline aquifers is presently being considered as an option for greenhouse gas mitigation. However, the behavior of $\mathrm{CO}_{2}$-brine-rock systems under physical-chemical conditions relevant to geologic storage and sequestration of $\mathrm{CO}_{2}$ is largely unknown, especially the response of an aquifer system to the distal injection large volumes of $\mathrm{CO}_{2}$. Experiments involving Navajo sandstone dissolution in acidic brine were conducted at 200 ${ }^{\circ} \mathrm{C}$ and 250 or 300 bars to evaluate the extent of fluid-rock interactions and the concurrent changes of porosity, permeability, and injectivity. The first experiment (batch) examines the interaction of sandstone with $\mathrm{CO}_{2}$-impregnated brine; the second experiment (batch) is sandstone dissolution in $\mathrm{CO}_{2}$-free acidic brine, serves as a base case; the third one is a flow-through experiment designed to measure sandstone dissolution rates based on variations of $\mathrm{Si}$ concentration as a function of time. Fluid-rock reactions took place in the $\mathrm{CO}_{2}$-brine-sandstone system in addition to the expected $\mathrm{pH}$ decrease and carbonate mineral precipitation. Silicate minerals in the sandstone display textures (dissolution features, secondary mineralization), indicating that these phases are reacting strongly with the fluid. The solution chemistry data indicate that the dissolved $\mathrm{SiO}_{2}$ increases gradually and that $\mathrm{pH}$ increases slowly with reaction progress. Characterization (SEM and XRD) of minerals after reactions suggests the progressive illitization of smectite minerals. Dissolution of feldspars and conversion of smectite to illite are likely to be the two reactions that contribute to the release of $\mathrm{SiO}_{2}$. The product minerals present at the end of the experiments are illite, illite/smectite, allophane, and carbonate minerals (for the $\mathrm{CO}_{2}$-charged reaction). The role of dissolved $\mathrm{CO}_{2}$ is likely in acidifying the brine and providing a carbon source for the precipitation of carbonate minerals. The formation of carbonate minerals (i.e., mineral trapping) is expected and thermodynamically favored. The chemical reactions 
likely increase the porosity of the sandstone due to silicate dissolution, but permeability may be reduced by the formation of pore-filling allophane and illite/smectite. While there is no evidence to suggest that chemical removal of the clay coating is occurring, it is uncertain whether the mechanical forces near the injection well would mobilize the smectite, causing pore clogging and affecting the injectivity.

Keywords: Navajo Sandstone, Geological Carbon Sequestration, Fluid-Rock Interactions, Experimental Studies 


\section{Introduction}

An ever-increasing amount of scientific evidence suggests that anthropogenic release of $\mathrm{CO}_{2}$ has led to a rise in global temperatures over the past several hundred years (BRANTLEY et al., 2001; CROWLEY, 2000). The injection of $\mathrm{CO}_{2}$ into deep saline aquifers is presently being evaluated as an option for greenhouse gas reduction (GALE, 2002). Currently, the U.S. Department of Energy (DOE) is conducting pilot $\mathrm{CO}_{2}$ injection tests to evaluate the feasibility of storing millions of tons of carbon dioxide in deep saline aquifers around the U.S. The Navajo Sandstone and its geological equivalent, the Nugget Sandstone, are two of the target aquifers. For example, the Nugget Sandstone saline formation was selected as the target for one of the large-volume injection tests by the Big Sky Carbon Sequestration Partnership (SPANGLER, 2007). The Jurassic Navajo/Nugget Sandstone has been identified as regionally extensive in the western US (LOOPE and ROWE, 2003), and is thus of significance for the success of sequestration in these regions.

From a capacity perspective, deep saline aquifers offer a very significant potential (GALE, 2002). However, considerable uncertainties exist because $\mathrm{CO}_{2}$ is reactive, in particular when dissolved in water. $\mathrm{CO}_{2}$ is likely to react with the sandstone, causing precipitation and dissolution of minerals, and changing the porosity, permeability and injectivity of the aquifer (e.g., Xu et al., 2004). The future success of $\mathrm{CO}_{2}$-injection tests is therefore partly dependent on how these reactions proceed under reservoir conditions. To date, the published literature has mainly focused on carbonate precipitation without regard to the reactivity of the host rock (e.g. Kaszuba et al., 2003; 2005). $\mathrm{CO}_{2}$-fluid-indigenous rock interactions within saline aquifers under reservoir 
temperature and pressure conditions have received little attention. Dissolution of silicate minerals in a brine and precipitation of carbonate are reported in limited numerical modeling studies that involve reaction kinetics (GUNTER et al., 2000; GUNTER et al., 1997; PERKINS and GUNTER, 1995) and experimental studies (GUNTER et al., 1997; KASZUBA et al., 2003; KASZUBA et al., 2005). The experimental studies mentioned above investigated geochemical reactions that occur within a supercritical $\mathrm{CO}_{2}$-brine-aquifer (or aquitard) system which could be imagined as an analog of a system close to an injection well. A month-long batch experiment at $105{ }^{\circ} \mathrm{C}$ and 90 bars yielded a large increase in alkalinity and small amounts of water-mineral reaction (GUNTER et al., 1997), whereas 32-77 day-long experiments at $200{ }^{\circ} \mathrm{C}$ and 200 bars resulted in silicate minerals (quartz, plagioclase, microcline and biotite) in the aquifer and the aquitard (an artificial analog) displaying textures (etch pits, mineralization) indicative of significant reaction. (Kaszuba et al., 2003; 2005) However, the following questions remained unanswered: What is the response of an aquifer system far away from an injection well dominated by ionic and dissolved $\mathrm{CO}_{2}(\mathrm{aq})$ ? Are there any new clay minerals formed and what is the stability of indigenous clay minerals - do they disappear by dissolution, transform into new minerals, or become free and mobile and tend to clog the pores? In addition, it is not at all clear from available data whether high $\mathrm{CO}_{2}$ concentrations in fluids (due to $\mathrm{CO}_{2}$-injection) act to catalyze or inhibit silicate mineral dissolution/secondary mineral precipitation processes. In this study, we conducted a series of $\mathrm{CO}_{2}$-Navajo Sandstone-brine interaction experiments, mimicking a system far away from the injection well, and evaluated the Navajo Sandstone saline aquifer responses to injection of $\mathrm{CO}_{2}$. Sandstone from drill core was used in the experiments to facilitate the 
investigation of stability of indigenous clay minerals. The study provides critical constraints that can serve as a basis to refine multiphase flow reactive-transport modeling of $\mathrm{CO}_{2}$ sequestration in saline aquifers.

\section{Material and Methods}

Experimental approach. A total of three hydrothermal experiments have been conducted to assess the primary mineral dissolution and secondary mineral precipitation kinetics and to test the feasibility of using the Navajo Sandstone saline aquifer for $\mathrm{CO}_{2}$ storage. The first batch experiment exposes the Navajo Sandstone to $\mathrm{CO}_{2}$-impregnant brine and assesses the mineral reactivity as it affects permeability, porosity, and permanent sequestration via precipitation of carbonates and dissolution/precipitation of silicates and clay. These data will provide input for further simulation studies and direct evidence for answering the question "is the Navajo Sandstone a viable formation for geologic carbon sequestration?" The second batch experiment dissolves the Navajo Sandstone in acidic brine without $\mathrm{CO}_{2}$ and serves as a base case to be compared with experiment \#1. Finally, a flow-through experiment (experiment \#3) is performed to measure the sandstone dissolution rates based on variations of Si concentration as a function of time. Our experimental pressures (250-300 bars) are similar to the pressure of the target formation studied by the Big Sky Carbon Sequestration Partnership (265.4 bars), but the experimental temperature is higher $\left(200^{\circ} \mathrm{C}\right)$ than that of the Big Sky study $\left(\sim 98^{\circ} \mathrm{C}\right)$. Our pressure and temperature conditions are comparable with those in Kuszuba et al. $(2003 ; 2005)$ 
(200 bars and $\left.200^{\circ} \mathrm{C}\right)$. Gunter et al. (1997) also used higher temperature $\left(105^{\circ} \mathrm{C}\right)$ than that of the corresponding aquifer $\left(54^{\circ} \mathrm{C}\right)$ because experiments at $54{ }^{\circ} \mathrm{C}$ did not produce observable reactions. The higher temperature in this study is necessary to accelerate the reactions to measurable rates in the laboratory. The higher temperature is justifiable because performance assessments are on the orders of thousands of years or longer (WILDENBORG and VAN DER MEER, 2002).

Experimental apparatus for batch experiments. The prepared sandstone particles were placed in a flexible gold reaction cell with detachable Ti closure, which was placed in a steel-alloy autoclave (SEYFRIED et al., 1987). This arrangement allows easy access to the reactants at the end of the experiment. More importantly, the flexible cell permits on-line sampling of the aqueous phase at constant temperature and pressure simply by adding water, in an amount equivalent to the sampled fluid, to the region surrounding the reaction cell. These experimental data are generally superior to those derived from samples collected after the reactors are cooled down because backward reactions may occur during cooling. The experiments using the flexible cell system were conducted at $200{ }^{\circ} \mathrm{C}$ and 300 bars.

Experimental apparatus for flow-through experiment. The flow-through dissolution experiment of the Navajo Sandstone was performed using a hydrothermal flow system. A fixed volume $(\sim 100 \mathrm{ml})$ Ti reactor represents the central unit of the flow system. It connects to a high-pressure fluid delivery system (Shimadzu 10A HPLC pump) that keeps the rate of fluid flow at pre-selected values. The outlet side of the reactor is connected to a computer-controlled regulating valve that serves to maintain the total pressure at fixed values. Temperature control is 
provided by a series of Watlow band heaters external to the Ti reactor. The reactor is also equipped with a magnetic stirrer (Parr Instrument, A1120HC), which allows reactants to remain suspended in the fluids during the experiment.

Materials. Reddish Navajo Sandstones were collected from N aquifer, Black Mesa, Arizona. The major mineral component of Navajo Sandstone is quartz, with $\sim 2 \%$ feldspars (DUlANEY, 1989; HARSHBARger et al., 1957; ZHU, 2005). A sandstone sample (MSE 136.5-137) is crushed and ground with an agate mortar and pestle, and then dry sieved to obtain the fraction between 50 and $100 \mu \mathrm{m}$. Ten grams of the resulting powder and $150 \mathrm{~mL}$ deionized water are placed into a $200-\mathrm{mL}$ polyethylene bottle and ultrasonic-cleaned with a sonic probe five times, for 10 minutes per treatment. The bottle is immersed into a water bath to keep cool when ultrasonicating. The supernatant is disposed of and the remaining solid is freeze-dried.

Analytical methods. Fluid samples taken from the reactor at regular intervals are analyzed for all major and some minor dissolved constituents. Dissolved cations are analyzed by inductively coupled plasma mass spectrometry (ICP-MS) while anions are analyzed by ion chromatography (IC). Reactants and products are characterized with X-ray diffraction (XRD, for phase identification) and SEM (for phase relationships and surface morphology).

XRD analyses are carried out using a Bruker D8 Advance diffractometer, equipped with a $\mathrm{Cu}$ anode at $20 \mathrm{kV}$ and $5 \mathrm{~mA}$, and with a SolX energy-dispersive detector. The scan parameters used are 2 to $70^{\circ} 2 \theta$, with a step size of $0.02^{\circ} 2 \theta$. The sample preparation method is called "slurry mount": reaction products are immersed in $20 \mathrm{~mL}$ deionized water in a plastic vessel (25 $\mathrm{mL}$ volume) and ultrasonicate three times for 15 minutes per treatment with 15 -minute breaks. 
After the final ultrasonication, the samples are allowed to settle overnight. Then, the suspension (clay with water) is carefully pipetted out, mounted onto a zero background quartz plate and air-dried. The mount-dry cycle is repeated to ensure we have enough materials for XRD analysis. SEM is conducted with a Quanta 400 Field Emission Gun (FEG). The equipped Energy Dispersive X-ray Spectrometer (EDS) system has an EDAX thin window and CDU LEAP detector. The low energy X-ray detection with FEG provided high spatial resolution for microanalysis down to $\sim 0.1 \mathrm{~mm}^{3}$ under optimum conditions.

\section{Results and Discussion}

Navajo sandstone before hydrothermal reactions. Detailed studies of untreated Navajo Sandstone were described in Zhu et al. (2006). XRD analysis of the bulk Navajo Sandstone shows $\sim 90 \%$ by weight quartz, with minor amounts of K-feldspar and smectite, and trace amounts of kaolinite and illite/mica (ZHU et al., 2006). Feldspar grains are covered with an inner layer of kaolin and an outer layer of smectite (ZHU et al., 2006). Smectite coatings occur not only on feldspar grains but also on quartz and Fe-Ti oxides (ZHU et al., 2006). X-ray diffraction results confirmed Zhu et al.'s (2006) findings that the clay coating on the Navajo Sandstone is mainly composed of smectite and kaolinite (Fig. 1).

Fig. 2 shows SEM microphotographs of the Navajo Sandstone after ultrasonication removed the clay coatings. These images are to be compared with the images after the experiments. After ultrasonication, the smectite coating is largely removed (Fig. 2). However, the kaolinite coating persists on the K-feldspar surface (Figs. 2b and 2c). 
Batch experiment 1: Navajo sandstone dissolution in $\mathrm{CO}_{2}$-impregnanted brine. The first Navajo Sandstone dissolution experiment is a batch experiment at $200{ }^{\circ} \mathrm{C}$ and 300 Bars and $\mathrm{pH} 4.1$ (measured at $25^{\circ} \mathrm{C}$ ). Four grams of Navajo sandstone were reacted with 40 grams 200 $\mathrm{mmol} / \mathrm{kg} \mathrm{KCl}$ solution in the presence of $20 \mathrm{mmol} / \mathrm{kg} \mathrm{CO}$ (aq). X-ray diffraction results (Fig. 1) indicate that our experiment produced secondary clay minerals after 552 hours of reaction. Hydrothermal reactions led to the illitization of smectite minerals (Fig. 1). The peak at 11-12 angstroms is illite/smectite. Illitization of smectite has been widely documented by XRD studies and continues to draw the attention of researchers all over the world. From the time of the pioneering study of Hower et al. (1976), there has been general agreement that illitization of smectite involves interstratified intermediates, with the proportion of illite in mixed-layer illite/smectite increasing as a function of increasing temperature, time and burial depth of basin sediments (e.g., BAULUZ et al., 2002; CUADros and LinARES, 1996). Kaolinite and allophane were also identified (Fig. 1). While kaolinite was present before the experiment, allophane was newly precipitated as a reaction product in the experiment. Allophane $\left(\mathrm{Al}_{2} \mathrm{Si}_{2} \mathrm{O}_{5} \cdot 3 \mathrm{H}_{2} \mathrm{O}\right)$ is a poorly crystallized hydrous aluminum silicate clay mineral and has a composition similar to kaolinite $\left(\mathrm{Al}_{2} \mathrm{Si}_{2} \mathrm{O}_{5}(\mathrm{OH})_{2}\right)$. Rhombohedra-shaped carbonate grains were occasionally found on quartz particles (Fig. 3f). However, there are not sufficient quantities of carbonate minerals to be successfully identified with XRD.

SEM images show that the morphology of the sandstone change during the course of the experiment. The reacted sandstone displays evidence of participating in fluid-rock interactions, which has also been observed in Kaszuba et al.(2003; 2005). Solution chemistry data (Si 
concentrations increase with time) suggests silicate dissolution (Table 1), although dissolution features on sandstones are not evident. Abundant clay minerals adhere to quartz and K-feldspars after the reaction and commonly bridge the pores. Product minerals observed with SEM are consistent with XRD results. Newly formed allophane aggregates fill the pores (Fig. 3a and 3c). These allophanes are poorly crystallized. XRD (Fig. 1) and SEM with X-ray microanalysis (SEM/EDS) analysis (Fig. 3d) confirm the identity of allophane. SEM observations confirmed the illtization of smectite. The morphologies range from the typical "corn-flake," "maple leaf," or "honeycomb" habit of smectite to the typical platy or scalloped (with curled points) habit of illite, as described by Keller et al. (1986). Elongated fabric, platy or ribbon-like illite/smectite is shown in Figs. 3a-3g. This morphology of illite/smectite has also been observed in Keller et al. (1986), Nadeau (1998), Nadeau et al. (2002), and Celik et al. (1999). Illite, as interwoven ribbons, is intimately associated with the smectite (Fig. 3g). The smectite and kaolinite coatings persisted on the K-feldspar grains, indicating that the chemical reactions did not remove the coatings (Fig. 3 h-j).

The solution chemistry results are presented in Tables 1 and 2. During the experiment, dissolved $\mathrm{K}^{+}$and $\mathrm{Cl}^{-}$concentrations remained relatively constant (Table 1). Dissolved $\mathrm{SiO}_{2}$ increased, reaching $2.20 \mathrm{mmol} / \mathrm{kg}$ by the end of experiment. The smectite-to-illite conversion generally consumes $\mathrm{K}^{+}$and releases $\mathrm{SiO}_{2}$ (CUADROS and LINARES, 1996). This conversion is likely to be a source of increased $\mathrm{SiO}_{2}$. Another source of $\mathrm{SiO}_{2}$ is dissolution of feldspars. Saturation index calculations indicate that the solution is undersaturated with respect to albite and anorthite during the entire course of the reaction (see below), suggesting the dissolution of 
plagioclase. The dissolved concentrations of $\mathrm{Mg}^{2+}$ and $\mathrm{Ca}^{2+}$ also increased with time. $\mathrm{Mg}^{2+}$ and $\mathrm{Ca}^{2+}$ are probably from $\mathrm{K}^{+}$cation exchange with $\mathrm{Mg}^{2+}$ and $\mathrm{Ca}^{2+}$ in smectite. There was only a slight decrease in dissolved $\mathrm{CO}_{2}$ concentration during the experiment (which suggests the formation of carbonates) while $\mathrm{pH}$ values increased slowly with reaction progress. Generally, the dissolved concentrations of most minor and trace elements approached steady-state values within the first 48 hours (Table 2). Fe, $\mathrm{Sr}$, and $\mathrm{Ba}$ are probably from $\mathrm{K}^{+}$cation exchange with $\mathrm{Fe}, \mathrm{Sr}$, and Ba in smectite.

The measured fluid chemistry and $\mathrm{pH}$, when considered alongside aqueous speciation distribution, and taking explicit account of mass balance, mass action and charge balance constraints, together with constraints imposed by the revised HKF equation of state, (JOHNSON et al., 1992; SHock and Helgeson, 1988; SHock et al., 1989; SHOcK et al., 1992; SHOCK et al., 1997) permit calculation of ion activities of dissolved species. Speciation-solubility calculations were facilitated with the geochemical modeling code PHREEQC. (PARKHURST and APPELLO, 1999) Thermodynamic data used in the speciation-solubility calculations are listed in Table 3.

Mineral saturation indices (SI) calculations (Table 4) show that the solution is supersaturated with respect to microcline and undersaturated with respect to albite during the entire course of the reaction; the solution changes from undersaturated (144 h) to supersaturated (336 h) back to undersaturated (552 h) with respect to anorthite; the solution is supersaturated with respect to calcite and magnesite and slightly undersaturated with respect to quartz. SI calculations indicate that the formation of carbonate minerals (e.g., calcite and magnesite) is thermodynamically favored. As for the clay minerals, the solution is supersaturated with respect to kaolinite and illite during the entire course of the reaction and changes from undersaturated to supersaturated with respect to beidellite-K (a type of smectite) and montmorillonite-K (a type of 
smectite) at $144 \mathrm{~h}$ and $336 \mathrm{~h}$, respectively.

Batch experiment 2: Navajo sandstone dissolution in acidic brine. The second Navajo Sandstone dissolution experiment is a batch experiment at $200{ }^{\circ} \mathrm{C}$ and 300 Bars without the presence of $\mathrm{CO}_{2}$ (aq). Four grams of Navajo sandstone are reacted with 40 grams $200 \mathrm{mmol} / \mathrm{kg}$ $\mathrm{KCl}$ solution at $\mathrm{pH} 2.8\left(25^{\circ} \mathrm{C}\right)$. The solution chemistry results are presented in Tables 5 and 6 . During the experiment, dissolved $\mathrm{K}^{+}$and $\mathrm{Cl}^{-}$concentrations remaine relatively constant (Table 5). Dissolved $\mathrm{SiO}_{2}$ continuously increases, reaching $4.93 \mathrm{mmol} / \mathrm{kg}$ at $696 \mathrm{~h}$ and then approaches steady-state. The sandstone dissolves much faster in this experiment than in Experiment \#1 because the initial $\mathrm{pH}$ of experiment $\# 2\left(2.8\right.$ at $\left.25^{\circ} \mathrm{C}\right)$ is much lower than that of experiment $\# 1$ (4.1 at $25{ }^{\circ} \mathrm{C}$ ). The release of $\mathrm{SiO}_{2}$ is possibly due to both dissolution of feldspars (albite, plagioclase, and anorthite; see SI calculations below) and the conversion of smectite to illite. Dissolved $\mathrm{Al}^{3+}$ reaches a maximum value of $0.14 \mathrm{mmol} / \mathrm{kg}$ at $24 \mathrm{~h}$ and decreases thereafter. The dissolved concentrations of $\mathrm{Mg}^{2+}$ and $\mathrm{Ca}^{2+}$ also increase with time. $\mathrm{Mg}^{2+}$ and $\mathrm{Ca}^{2+}$ are probably from $\mathrm{K}^{+}$cation exchange with $\mathrm{Mg}^{2+}$ and $\mathrm{Ca}^{2+}$ in smectite. $\mathrm{pH}$ values increase rapidly with reaction progress during the first $360 \mathrm{~h}$ and remain almost constant during the rest of the reaction time. Generally, the dissolved concentrations of most minor and trace elements approach steady-state values within the first 24 hours (Table 6). $\mathrm{Fe}, \mathrm{Sr}$ and $\mathrm{Ba}$ are probably from $\mathrm{K}^{+}$cation exchange with $\mathrm{Fe}, \mathrm{Sr}$ and $\mathrm{Ba}$ in smectite.

SEM images show that after reaction with acidic brine, the dissolution features are much more intensive than in experiment \#1. Although the surface of K-feldspar grains used as starting material have some rounded and angular pits (Fig. 2a), those observed on K-feldspar after reaction are more numerous and deep (Fig. 4h and 4i) and sometimes with dissolution features in the pits (Fig. 4i). The development of dissolution features (pits, steps and channels) shows that 
the dissolution is heterogeneous (e.g., Fig. 4e-i). The smectite coatings remain, indicating that the chemical reactions did not remove coatings (Fig. 4a). Abundant clay minerals adhere to quartz and K-feldspars after the reaction and stretch across pores and open fractures. The smooth, flaky illite/smectite fills the pore and bridges particles (e.g., Figs. 4c and 4d). Illite, as interwoven ribbons, displays intergrowth with the smectite (Fig. 4b). No carbonate minerals are found. Mineral saturation indices (SI) calculations (Table 7) show that the solution is supersaturated with respect to microcline and undersaturated with respect to albite during the entire course of the reaction; the solution changes from undersaturated (24 h) to slightly supersaturated (168 h) with respect to anorthite; the solution is supersaturated with respect to boehmite, muscovite, paragonite and pyrophyllite; slightly undersaturated (before $24 \mathrm{~h}$ ) to supersaturated with respect to quartz $(168 \mathrm{~h})$. As for the clay minerals, the solution is supersaturated with respect to kaolinite, illite, beidellite-K and montmorillonite-K during the entire course of the reaction.

Flow-through experiment: Navajo sandstone dissolution in acidic brine. The third Navajo Sandstone dissolution experiment is a flow-through experiment at $200{ }^{\circ} \mathrm{C}$ and 250 Bars. Five grams of Navajo sandstone are reacted with $200 \mathrm{mmol} / \mathrm{kg} \mathrm{KCl}$ fluid. The $\mathrm{KCl}$ fluid is acidified to $\mathrm{pH} 3.9$ before the experiment at ambient temperature and pressure by addition of dilute $\mathrm{HCl}$. The rate of fluid input is kept at $0.82 \mathrm{ml} / \mathrm{min}$ for the whole experiment of 23.5 hours. The results are presented in Table 8. During the experiment, dissolved $\mathrm{K}^{+}$and $\mathrm{Cl}^{-}$concentrations remain relatively constant (Table 8). The dissolved concentrations of $\mathrm{Si}$ and $\mathrm{Mg}$ approach steady-state values within the first 4 hours. $\mathrm{pH}$ values remained essentially the same with reaction progress.

SEM images show that after dissolution in a flow-through reactor, the dissolution features 
are less intensive than those in experiment \#2. The K-feldspar grains partially preserved the "three layer onion" structure of unreacted sandstones (see Fig. 5). Newly formed smectite/illite, observed in the products of experiment \#1 are also found (e.g., Figs. 5b, 5e, 5e, and 5f).

The Al concentrations are under the detection limit. Saturation states for aluminosilicates are thus unknown. The solution is also undersaturated with respect to quartz (Table 9).

Dissolution rate (as per mole of $\mathrm{Si}$ ) was calculated according to the following formula based on time-series Si concentrations:

$$
r=\frac{\left(C_{\text {out }}\right)\left(\vartheta_{0}\right)\left(10^{-6}\right)}{M \delta A}
$$

where $C_{\text {out }}$ is the output concentration of $\mathrm{Si}$ in $\mathrm{mg} / \mathrm{L}, \vartheta_{0}$ is the input flow rate in $\mathrm{ml} / \mathrm{s}, M$ is the atomic weight (g/mol) of $\mathrm{Si}, \delta$ is the stoichiometric coefficient of $\mathrm{Si}$ (set to 1 ), and $A$ is the total surface area in $\mathrm{m}^{2}$. The average dissolution rate is $6.85 \times 10^{-10} \mathrm{~mol} \mathrm{~m}^{-2} \mathrm{~s}^{-1}$ as per mole of Si (Table $10)$

Fate of $\mathrm{CO}_{2}$ and sandstone responses to $\mathrm{CO}_{2}$ injection. In experiment $\# 1$, the $\mathrm{CO}_{2}$ is mainly trapped in aqueous solution as carbonate species. Carbonate mineral precipitation is observed with SEM, and supported by calculated SI values, but the amount precipitated is small judging from the decrease of $\mathrm{CO}_{2}$ in solution chemistry data and absence in XRD patterns. However, in actual injection cases, the carbonate concentrations would be much higher and the reaction time would be in years to thousands of years. The formation of carbonate minerals (i.e., mineral trapping) is thus expected and thermodynamically favored.

The dissolution of silicates is likely to increase porosity, but permeability is probably inversely affected by the formation of clay minerals in the pore space. Open, interconnected pores lined with ribbons, coating grain surfaces and also bridging the pores between grains will create permeability barriers to fluid flow (e.g., Figs. 3a, 3b, 3c, 3e, 4c, 4d, and 5f). Neasham 
(1977) demonstrated that this clay texture severely reduces permeability without affecting porosity.

\section{Conclusions}

(1) Our experimental data show that the Navajo sandstone reacted strongly with $\mathrm{CO}_{2}$-impregnated brine. The lower the $\mathrm{pH}$, the more severe the reactions are in our experiments, regardless the $\mathrm{CO}_{2}$ concentrations. The role of dissolved $\mathrm{CO}_{2}$ is likely in acidifying the brine and providing a source for carbonate minerals. The $\mathrm{pH}$ values of the $\mathrm{CO}_{2}$-saturated brines under injection conditions (salinity, temperature, and pressure) are likely in the 2-3 range (SCHAEF and MCGRAIL, 2004). Therefore, the extent of reactions in the field would likely resemble our experiment with the most acidic brine (Experiment \#2). Although our experiments were conducted at a higher temperature than that in some field injection projects in order to expedite observable changes in the laboratory (GUNTER et al., 1997), the longer time frame that $\mathrm{CO}_{2}$-impregantaed brine interacts with sandstone and the lower $\mathrm{pH}$ in the actual injection case justify the conclusions that the reactions will be significant and possibly affect the injectivity.

(2) Increase of dissolved $\mathrm{SiO}_{2}$ and gradual increase of $\mathrm{pH}$ indicate that silicate mineral dissolutions are dominant reactions. Another source of $\mathrm{SiO}_{2}$ release is likely the conversion of smectite to illite.

(3) Hydrothermal reactions led to the progressive illitization of smectite minerals. The secondary mineral assemblage present at the end of the experiments was illite, illite/smectite, allophone, and carbonate minerals (for $\mathrm{CO}_{2}$-charged reaction). X-ray diffraction results were able to identify clay minerals that were not present before the reactions. SEM results are consistent with XRD results. SEM images show that newly formed, aggregated, allophane-like phases fill 
the pores. Illite is intergrown with the smectite. No carbonate minerals were identified in the $\mathrm{CO}_{2}$-free experiments.

(4) The chemical reactions likely increase the porosity of the sandstone due to silicate dissolution. However, permeability might be reduced by the precipitation of pore-filling allophane and illite/smectite. The smectite coatings remain on the sediment grains, indicating that the chemical reactions did not remove coatings. Zhu et al. (2006) found that the smectite coating in the Navajo Sandstone is easily removed by sonification in the laboratory. It is uncertain whether the mechanical forces near in the injection well would mobilize the smectite and cause pore clogging.

The experimental system in this paper mimics the long term $\mathrm{CO}_{2}$ interaction with a sandstone-based saline aquifer. Carbon dioxide injection into deep saline aquifers in sedimentary basins represents a huge potential for both $\mathrm{CO}_{2}$ storage and sequestration. The large volume of pore space available and long-term hydrodynamic trapping of $\mathrm{CO}_{2}(\mathrm{BACHU}$ et al., 1994) are optimal conditions for storage; with the formation of carbonate minerals (Kaszuba et al., 2003; 2005), the $\mathrm{CO}_{2}$ will be permanently trapped in the subsurface and returned to its place of origin (HITCHON et al., 1999). However, significant amount of water-rock interactions brings uncertainties to this potential option because water rock interactions may either enhance (increase the porosity/permeability) or decease (decrease the permeability and injectivity) the potential of the reservoir by dissolution of primary minerals, precipitation of secondary clay, and progressive evolution of clay. The experimental reactions provide initial constrains on mineral reactions that may impact the containment interface in moderate temperature brine aquifer systems with potential for carbon sequestration. 
Acknowledgments - Material in this paper is based upon work supported by the U.S. Department of Energy under Award No. DE-FG26-04NT42125 to CZ and WES. Any opinions, findings, and conclusions or recommendations expressed in this material, however, are those of the authors and do not necessarily reflect the views of the United States Government or any agency thereof. We thank Rick Knurr at University of Minnesota for chemical analyses of fluid samples.

\section{References}

Bachu, S., Gunter, W.D. and Perkins, E.H., 1994. Aquifer Disposal of $\mathrm{CO}_{2}$ - Hydrodynamic and Mineral Trapping. Energy Conversion and Management, 35(4): 269-279.

Bauluz, B., Peacor, D.R. and Ylagan, R.F., 2002. Transmission electron microscopy study of smectite illitization during hydrothermal alteration of a rhyolitic hyaloclastite from Ponza, Italy. Clays and Clay Minerals, 50(2): 157-173.

Brantley, S.L., Bau, M., Yau, S. and Alexander, B., 2001. Interpreting kinetics of groundwater-mineral interaction using major element, trace element, and isotopic tracers. Water-Rock Interaction, 10: 13-18.

Celik, M., Karakaya, N. and Temel, A., 1999. Clay minerals in hydrothermally altered volcanic rocks, Eastern Pontides, Turkey. Clays and Clay Minerals, 47(6): 708-717.

Crowley, T.J., 2000. Causes of climate change over the past 1000 years. Science, 289(5477): 270-277.

Cuadros, J. and Linares, J., 1996. Experimental kinetic study of the smectite-to-illite transformation. Geochimica et Cosmochimica Acta, 60(3): 439-453.

Dulaney, A.R., 1989. The geochemistry of the N-aquifer system, Navajo and Hopi Indian Reservations, Northeastern Arizona. Master thesis, 209p Thesis, Northern Arizona University, Flagstaff, Arizona.

Gale, J., 2002. Overview of $\mathrm{CO}_{2}$ emission sources, potential, transport and geographical distribution of storage possibilities., Intergovernmental Panel on Climate Change, Working Group III: Mitigation of Climate Change, Workshop on Carbon Dioxide Capture and Storage, Regina, Canada, pp.15-30.

Gunter, W.D., Perkins, E.H. and Hutcheon, I., 2000. Aquifer disposal of acid gases: modeling of water-rock reactions for trapping of acid wastes. Applied Geochemistry, 15(8): 1085-1095.

Gunter, W.D., Wiwchar, B. and Perkins, E.H., 1997. Aquifer disposal of $\mathrm{CO}_{2}$-rich greenhouse gases: extension of the time scale of experiment for $\mathrm{CO}_{2}$-sequestering reactions by geochemical modeling. Mineralogy and Petrology, 59: 121-140.

Harshbarger, J.W., Repenning, C.A. and Irwin, J.H., 1957. Stratigraphy of the Uppermost Triassic and the Jurassic Rocks of the Navajo Country. , U.S. Geological Survey Professional Paper 291.

Hitchon, B., Gunter, W.D., Gentzis, T. and Bailey, R.T., 1999. Sedimentary basins and greenhouse gases: a 
serendipitous association. Energy Conversion and Management, 40(8): 825-843.

Hower, J., Eslinger, E.V., Hower, M.E. and Perry, E.A., 1976. Mechanism of burial metamorphism of argillaceous sediments: Mineralogical and chemical evidence. Geological Society of America Bulletin, 87: 725 -737.

Johnson, J.W., Oelkers, E.H. and Helgeson, H.C., 1992. SUPCRT92 - A software package for calculating the standard molal thermodynamic properties of minerals, gases, aqueous species, and reactions from 1-bar to 5000-bar and $0^{\circ} \mathrm{C}$ to $1000^{\circ} \mathrm{C}$. Computers and Geosciences, 18(7): 899-947.

Kaszuba, J.P., Janecky, D.R. and Snow, M.G., 2003. Carbon dioxide reaction processes in a model brine aquifer at $200^{\circ} \mathrm{C}$ and 200 bars: implications for geologic sequestration of carbon. Applied Geochemistry, 18(7): 1065-1080.

Kaszuba, J.P., Janecky, D.R. and Snow, M.G., 2005. Experimental evaluation of mixed fluid reactions between supercritical carbon dioxide and $\mathrm{NaCl}$ brine: Relevance to the integrity of a geologic carbon repository. Chemical Geology, 217(3-4): 277-293.

Keller, W.D., Reynolds, R.C. and Inoue, A., 1986. Morphology of clay minerals in the smectite-to-illite conversion series by scanning electron microscopy. Clays and Clay Minerals, 34(2): 187-197.

Loope, D.B. and Rowe, C.M., 2003. Long-Lived Pluvial Episodes during Deposition of the Navajo Sandstone. . The Journal of Geology, 111: 223-232.

Nadeau, P.H., 1998. An experimental study of the effects of diagenetic clay minerals on reservoir sands. Clays and Clay Minerals, 46(1): 18-26.

Nadeau, P.H., Peacor, D.R., Yan, J. and Hillier, S., 2002. I-S precipitation in pore space as the cause of geopressuring in Mesozoic mudstones, Egersund Basin, Norwegian Continental Shelf. American Mineralogist, 87(11-12): 1580-1589.

Neasham, J.W., 1977. Applications of scanning electron microscopy to characterization of hydro carbon-braring rocks. Scanning Electron Microscopy, 10: 101-108.

Parkhurst, D.L. and Appello, A.A.J., 1999. User's guide to PHREEQC (version 2)-a computer program for speciation, batch-reaction, one dimensional transport, and inverse geochemical modeling. 99-4259, U.S. Geological Survey.

Perkins, E.H. and Gunter, W.D., 1995. Aquifer disposal of $\mathrm{CO}_{2}$-rich greenhouse gasses: modelling of water-rock reaction paths in a siliciclastic aquifer., Proceedings of the 8th international symposium on water-rock interaction, A.A. Balkema, Vladivostok, Russia, pp. 895-898.

Schaef, H.T. and McGrail, B.P., 2004. Direct measurements of $\mathrm{pH}$ and dissolved $\mathrm{CO}_{2}$ in $\mathrm{H}_{2} \mathrm{O}-\mathrm{CO}_{2}$ brine mixtures to supercritical conditions, AAPG Annual Meeting, Dallas, Texas.

Seyfried, W.E., Jr., Janecky, D.R. and Berndt, M.E., 1987. Rocking autoclaves for hydrothermal experiments; II, The flexible reaction-cell system. In: H.L.e. Barnes (Editor), Hydrothermal Experimental Techniques. Wiley-Intescience, pp. 216-239.

Shock, E.L. and Helgeson, H.C., 1988. Calculation of the thermodynamic and transport properties of aqueous species at high pressures and temperatures: Correlation algorithms for ionic species and equation of state predictions to $5 \mathrm{~kb}$ and $1000^{\circ} \mathrm{C}$. Geochimica et Cosmochimica Acta, 52: 2009-2036.

Shock, E.L., Helgeson, H.C. and Sverjensky, D.A., 1989. Calculations of the thermodynamic and transport properties of aqueous species at high pressures and temperatures: Standard partial molal properties of inorganic neutral species. Geochimica et Cosmochimica Acta, 53: 2157-2183.

Shock, E.L., Oelkers, E.H., Sverjensky, D.A., Johnson, J.W. and Helgeson, H.C., 1992. Calculation of 
thermodynamic and transport properties of aqueous species at high pressures and temperatures. Effective electrostatic radii, dissociation constants and standard partial molal properties to $1000^{\circ} \mathrm{C}$ and $5 \mathrm{~kb}$. J. Chem. Soc. London, Faraday Transactions, 88: 803-826.

Shock, E.L., Sassani, D.C., Willis, M. and Sverjensky, D.A., 1997. Inorganic species in geologic fluids: Correlations among standard molal thermodynamic properties of aqueous ions and hydroxide complexes. Geochimica et Cosmochimica Acta, 61(5): 907-950.

Spangler, L., 2007. Regional Characterization Activities and Large Volume Injection Test -Nugget Sandstone formation., Regional Carbon Sequestration Partnerships Initiative Review Meeting, Pittsburgh, Pennsylvania.

Wildenborg, A.F.B. and van der Meer, L.G.H., 2002. The use of oil, gas and coal fields as $\mathrm{CO}_{2}$ sinks., Intergovernmental Panel on Climate Change, Working Group III: Mitigation of Climate Change, Workshop on Carbon Dioxide Capture and Storage, Regina, Canada, pp. 61-78.

Xu, T., Apps, J.A. and Pruess, K., 2004. Numerical simulation to study mineral trapping for $\mathrm{CO}_{2}$ disposal in deep aquifers. Appl. Geochem., 19: 917-936

Zhu, C., 2005. In situ Feldspar Dissolution Rates in an Aquifer. Geochimica et Cosmochimica Acta, 69(6): 1435-1453.

Zhu, C., Veblen, D.R., Blum, A.E. and Chipera, S.J., 2006. Naturally weathered feldspar surfaces in the Navajo Sandstone aquifer, Black Mesa, Arizona: Electron microscopic characterization. Geochimica et Cosmochimica Acta, 70(18): 4600-4616. 


\section{FIGURE CAPTIONS}

Fig. 1. X-ray diffraction patterns of the clay fraction in Navajo Sandstone before (grey line) and after reactions with $\mathrm{CO}_{2}$-imprenanted brine (black line). Before reaction the clay fraction is mainly composed of smectite (with the (001) reflection between 14-15 angstroms) and kaolinite (K, ICDD: 14-164). The clays of the reacted sandstone shows an (001) reflection of 11-12 angstroms (illite/smectite), suggesting illitization of smectite due to hydrothermal reactions. Kaolinite and allophane were also identified. "I" Illite (ICDD: 29-1496), “A” Allophane (ICDD: 38-499), "I/S" illite/smectite.

Fig.2. (a) A K-feldspar particle image after sonication with a sonic probe. The K-feldspar is rounded with pitted surface topography. The identification of K-feldspar was confirmed by EDS; (b) Enlargement of one of the etch-pits outlined by the black box in (a), showing dissolution features. A kaolinite coating is visible to the right of the etch-pit; (c) Enlarged view of the kaolinite coating. The kaolinite is euhedral to semi-euhedral hexagonal platelets, with a size of $\sim$ $0.5 \mu \mathrm{m}$. These platelets are aggregated and well-oriented, but do not form a continuous cover. The basal plane always faces the feldspar surface; (d) A typical quartz particle after the ultrasonication treatment and before the dissolution experiment. The surface of the quartz is coated with incipient quartz overgrowth; (e) High resolution view of an area outlined by the black box in (d), showing incipient quartz overgrowth.

Fig.3. (a) SEM microphotograph shows a ribbon-like secondary mineral bridging two quartz 
particles and aggregated secondary minerals filling the pore between the quartz particles; (b) Enlarged view of the platy, flaky secondary mineral (approximately $8 \mu \mathrm{m}$ wide) shown in (a) with slightly scalloped, curled edges. This morphology looks similar to the reference illite shown in Keller et al. (1986). It is likely to be illite/smectite, with the chemical composition close to the illite end member; (c) Enlarged view of the aggregated secondary mineral. Poorly-crystallized allophane partly fills pores. Allophane has not been observed in the sandstone reactant and thus is newly formed; (d) EDS analysis yielding nearly equal peak heights of Si and Al suggests the minerals are probably allophane; (e) SEM microphotograph shows the smooth, flaky secondary mineral filling the pore and bridging two quartz particles. Similar morphology of illite/smectite was also shown in Keller et al. (1986), Nadeau (1998), Nadeau et al. (2002), and Celik et al. (1999); (f) SEM microphotograph shows rhombohedra-shaped secondary minerals (indicated by black arrows), approximately $1 \mu \mathrm{m}$ in size. These minerals are likely to be carbonates. However, it was difficult to confirm with EDS due to their small size. The flaky secondary mineral (approximately $3 \mu \mathrm{m}$ wide) to the left is illite/smectite; (g) SEM microphotograph shows secondary minerals on a quartz surface. The smooth, flaky secondary minerals (marked as " 1 " and "2") are illite/smectite. The interwoven ribbons feature is a typical morphology of illite (marked as " 3 "). The length of a single ribbon is about $2 \mu \mathrm{m}$. The existence of illite was confirmed by XRD (Figure 1); (h) SEM microphotograph shows a K-feldspar particle after reaction. A massive, webby smectite aggregate covers the right-hand part of the K-feldspar; (i) Enlarged view of an area outlined by the box in (h). Well-developed, highly crenulated smecite formed a thin, webby crust. The webby morphology is a common crystal habit of smectite. The 
morphology of the webby smectite is similar to that shown in Zhu et al. (2006), but it is much denser; (j) SEM microphotograph shows pore-filling kaolinite on a K-feldspar particle. The kaolinite particles are semi-euhedral platelets. These platelets are aggregated and well-oriented, but do not form a continuous cover. The basal plane always faces the feldspar surface.

Fig. 4. (a) SEM microphotograph shows secondary minerals on a quartz surface. The cornflake-shaped smectites at the upper part have a similar morphology to those in Zhu et al. (2006). These smectites possibly existed before the dissolution experiment. However, the smooth, flaky illite/smectite at the lower part is much larger and is possibly formed during the dissolution experiment. (b) SEM microphotograph shows secondary minerals on another quartz surface. The secondary minerals are likely to be illite (ribbons) intergrown with smectite, which suggests the progressive illitization of smectite; (c) SEM microphotograph shows secondary minerals (illite/smectite) filling the pore and bridging two quartz particles. Some smooth, flaky illite/smectite minerals are visible (indicated by arrows). These minerals are also likely to be newly formed; (d) Enlarged view of an area outlined by the black box in (c), showing one of the particle-bridging secondary minerals. The smooth, flaky mineral $(\sim 5 \mu \mathrm{m})$ is illite/smectite; (e) SEM microphotograph shows dissolution features on a K-feldspar particle; (f) SEM microphotograph shows dissolution features on a K-feldspar particle; (g) Close-up of dissolution features on the K-feldspar particle showed in (f). The feldspar has angular and prismatic features at the micron scale. Dissolution steps are visible along the c-axis of the cleavages and dissolution channels along the b-axis of the cleavages; (h) SEM microphotograph shows surface morphology 
of a K-feldspar particle after reaction; (i) Enlarged view of an area outlined by the black box in Fig. 39, showing dissolution feature in an etch pit.

Fig. 5. (a) SEM microphotograph shows the quartz surface after reaction. Secondary minerals (possibly illite) are visible; (b) Enlarged view of upper right corner of (a). The large smooth, flaky smectite/illite is possibly formed during the dissolution experiment; (c) SEM microphotograph shows the quartz surface after the hydrothermal experiment. Similar to Fig. 4a, the corn-flake-shaped smectites in the upper part have a similar morphology as those in Zhu et al. (2006). These smectites possibly existed before the hydrothermal reaction. However, the smooth, flaky smectite/illite at the lower part is much larger than authigenic smectite in the center of the image and possibly formed during the dissolution experiment; (d) SEM microphotograph shows the "three layer onion" described in Zhu et al. (2006). The grain is K-feldspar, and is coated with a layer of kaolinite. Smectite in turn covers kaolinite; (e) Close-up of the smectite shown in (d). The smooth, flaky, slightly crenulated smectite/illite at the lower part is much larger than authigenic smectite shown in this image and is possibly formed during the dissolution experiment; (f) The smooth, flaky illite/smectite with scalloped, curled edges is much larger than authigenic smectite shown in this image and is possibly formed during the dissolution experiment. 


\section{TABLES}

Table 1. Time-dependent changes in the composition of major dissolved species in $\mathrm{CO}_{2}$-bearing aqueous fluid coexisting with Navajo sandstone at $200{ }^{\circ} \mathrm{C}$ and 300 bars. The overall analytical error for dissolved species is $\pm 5 \%$.

\begin{tabular}{|c|c|c|c|c|c|c|c|c|c|c|c|c|}
\hline Sample & $\begin{array}{l}\text { Time } \\
\text { (h) }\end{array}$ & $\mathrm{K}^{+}$ & $\mathrm{SiO}_{2}$ & $\mathrm{Al}^{3+}$ & $\mathrm{Na}^{+}$ & $\begin{array}{c}\mathrm{Mg}^{2+} \\
(\mathrm{mmol} /\end{array}$ & $\begin{array}{l}\mathrm{Ca}^{2+} \\
\mathrm{kg})\end{array}$ & $\mathrm{Cl}^{-}$ & $\mathrm{SO}_{4}^{2-}$ & $\mathrm{CO}_{2}(\mathrm{aq})$ & $25^{\circ} \mathrm{C}$ & $\begin{array}{l}\mathrm{oH} \\
\text { In-situ* }\end{array}$ \\
\hline starting & 0 & 197.26 & - & - & 0.17 & - & - & 200.77 & 0.04 & 20 & 4.1 & 4.4 \\
\hline$\# 1$ & 48 & 195.00 & 0.89 & 0.01 & 0.26 & 0.09 & 0.29 & 193.33 & 0.16 & 9.2 & 7 & .2 \\
\hline$\# 2$ & 144 & 190.42 & 1.70 & 0.01 & 0.08 & 0.11 & 0.26 & 197.76 & 0.05 & & 4.8 & 5.4 \\
\hline$\# 3$ & 336 & 193.32 & 2.03 & 0.10 & 0.14 & 0.17 & 0.34 & 192.38 & - & 19.5 & 4.9 & 5.3 \\
\hline \#4 & 552 & 199.60 & 2.20 & 0.02 & 0.05 & 0.19 & 0.33 & 193.66 & 0.18 & 19.6 & 4.9 & 5.6 \\
\hline
\end{tabular}

In-situ $\mathrm{pH}$ is calculated from distribution of aqueous species calculations at the temperature and pressure of the experiment using constraints imposed by major element concentrations and $\mathrm{pH}$ values measured at $25^{\circ} \mathrm{C}$.

Table 2. Time-dependent changes in the composition of minor and trace dissolved species in $\mathrm{CO}_{2}$-bearing aqueous fluid coexisting with Navajo Sandstone at $200{ }^{\circ} \mathrm{C}$ and 300 bars. The overall analytical error for concentration measurements is $\pm 5 \%$.

\begin{tabular}{cccccccccccccc}
\hline Sample & $\begin{array}{c}\text { Time } \\
(\mathrm{h})\end{array}$ & $\mathrm{Li}$ & $\mathrm{Cr}$ & $\mathrm{Fe}$ & $\mathrm{Mn}$ & $\mathrm{Co}$ & $\begin{array}{c}\mathrm{Ni} \\
(\mathrm{Cu})\end{array}$ & $\mathrm{Zn}$ & $\mathrm{Rb}$ & $\mathrm{Sr}$ & $\mathrm{Cs}$ & $\mathrm{Ba}$ \\
\hline Starting & 0 & - & - & - & - & - & - & 0.10 & 0.24 & 0.29 & 0.01 & 0.01 & 0.01 \\
$\# 1$ & 48 & - & - & 1.70 & 0.09 & 0.01 & - & 0.06 & 0.32 & 0.27 & 0.36 & 0.01 & 0.22 \\
$\# 2$ & 144 & - & - & - & 0.08 & - & - & 0.13 & 0.20 & 0.27 & 0.36 & 0.01 & 0.30 \\
$\# 3$ & 336 & 0.04 & 0.01 & 6.63 & 0.13 & 0.01 & 0.25 & 0.27 & 0.38 & 0.43 & 0.36 & 0.08 & 0.25 \\
$\# 4$ & 552 & 0.05 & - & 0.67 & 0.12 & - & 0.18 & 0.09 & 0.17 & 0.32 & 0.35 & 0.02 & 0.24 \\
\hline
\end{tabular}


Table 3. Thermodynamic data used in this report, calculated with the computer code of SUPCRT92 (JOHNSON et al., 1992).

\begin{tabular}{|c|c|c|c|c|}
\hline Aqueous reactions & $\begin{array}{l}\log \mathrm{K} \\
25^{\circ} \mathrm{C}\end{array}$ & $\begin{array}{c}\log \mathrm{K} \\
200^{\circ} \mathrm{C} 300 \mathrm{bar}\end{array}$ & $\begin{array}{c}\log \mathrm{K} \\
200^{\circ} \mathrm{C} 250 \text { bar }\end{array}$ & Ref \\
\hline 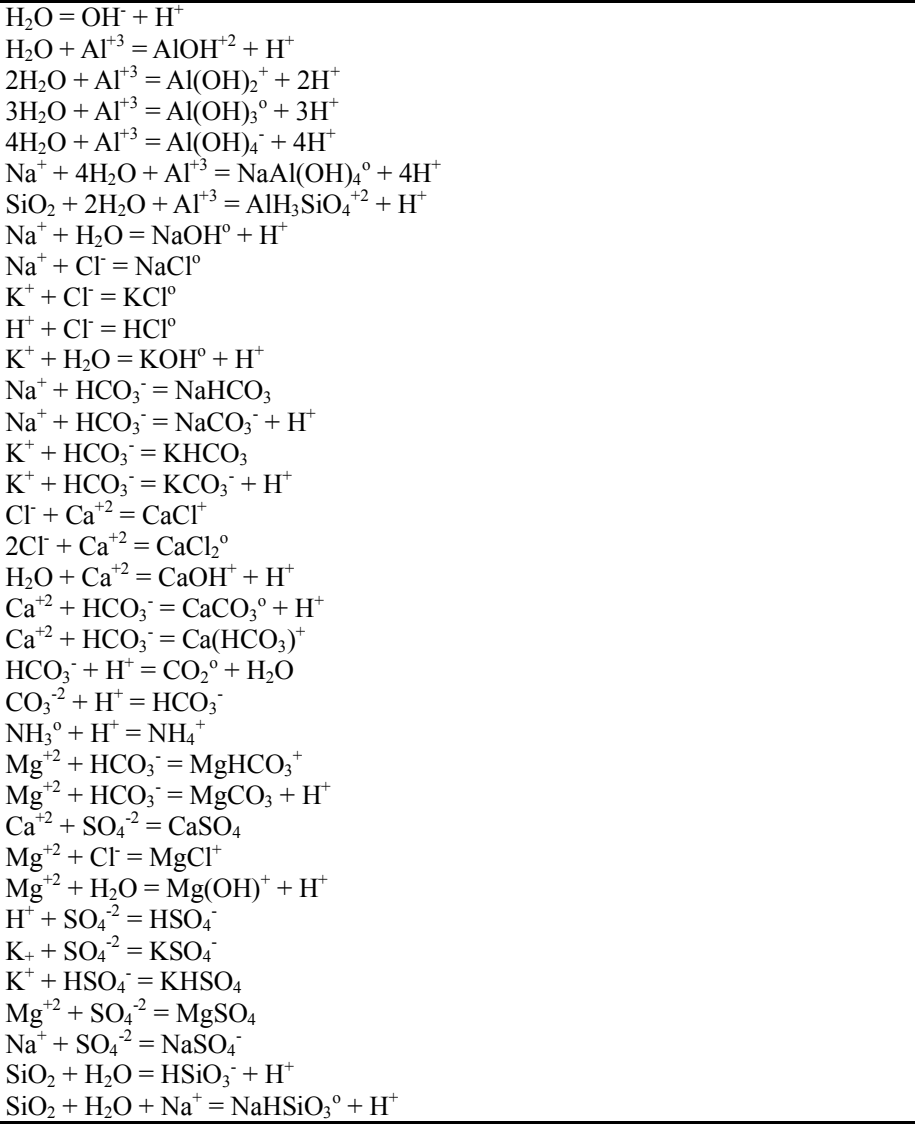 & $\begin{array}{c}-13.995 \\
-4.964 \\
-10.921 \\
-17.044 \\
-22.851 \\
-22.9 \\
-2.357 \\
-14.205 \\
-0.777 \\
\\
-0.710 \\
-14.439 \\
0.1541 \\
-9.8144 \\
0.1541 \\
-9.8144 \\
-0.292 \\
-0.644 \\
-12.833 \\
-7.002 \\
1.047 \\
6.345 \\
10.329 \\
9.241 \\
1.036 \\
-7.35 \\
2.111 \\
-0.135 \\
-11.682 \\
1.979 \\
0.88 \\
-3.474 \\
2.23 \\
0.7 \\
-9.585 \\
-7.754 \\
\end{array}$ & 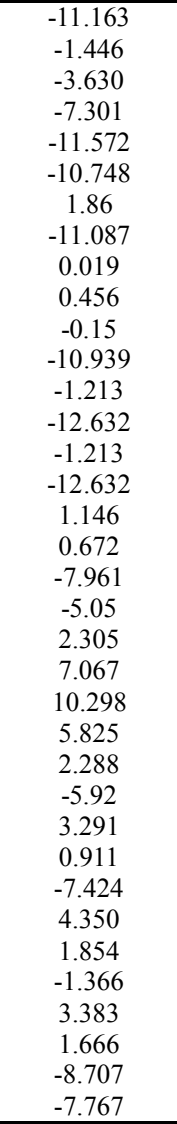 & $\begin{array}{c}-11.183 \\
-1.438 \\
-3.614 \\
-7.281 \\
-11.557 \\
-10.724 \\
1.858 \\
-11.095 \\
.031 \\
0.464 \\
-0.15 \\
-10.946\end{array}$ & $\begin{array}{l}(1) \\
(2) \\
(2) \\
(2) \\
(2) \\
(2) \\
(2) \\
(3) \\
(4) \\
(5) \\
(6) \\
(3) \\
(7) \\
(7) \\
(8) \\
(8) \\
(4) \\
(4) \\
(3) \\
(3) \\
(4) \\
(3) \\
(3) \\
(3) \\
(9) \\
(4) \\
(3) \\
(4) \\
(4) \\
(4) \\
(4) \\
(4) \\
(4) \\
(4) \\
(4) \\
(4)\end{array}$ \\
\hline \multicolumn{5}{|l|}{ Mineral reactions } \\
\hline 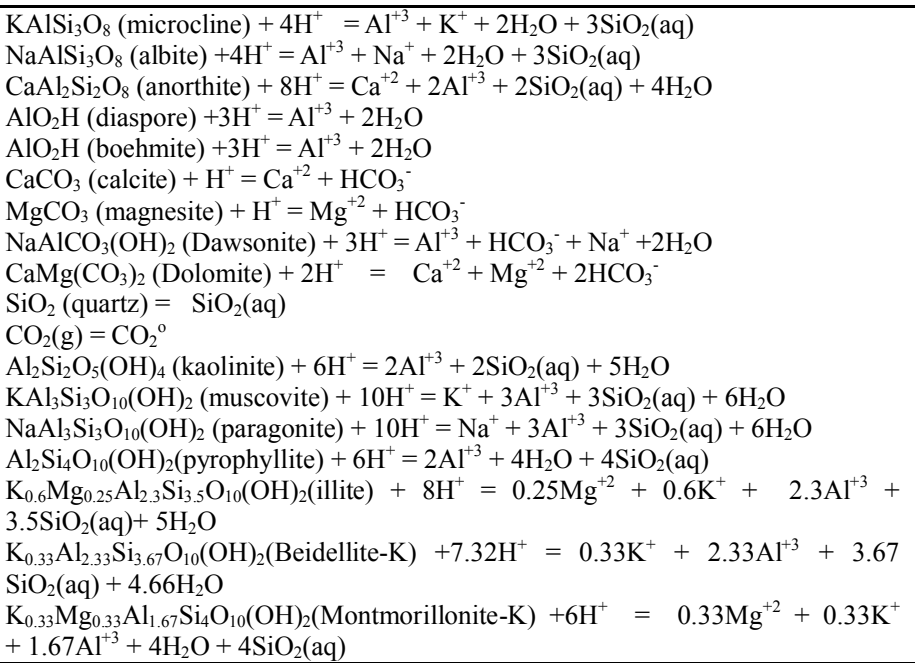 & $\begin{array}{c}-1.050 \\
2.065 \\
23.68 \\
7.191 \\
7.595 \\
1.816 \\
2.29 \\
4.3464 \\
3.240 \\
-4.047 \\
-1.473 \\
4.501 \\
11.22 \\
14.397 \\
-1.724 \\
9.0260 \\
5.252\end{array}$ & $\begin{array}{c}-3.923 \\
-2.508 \\
4.042 \\
0.02 \\
0.242 \\
-0.438 \\
-1.066 \\
-0.4756 \\
-2.018 \\
-2.424 \\
-2.132 \\
-5.354 \\
-5.407 \\
-3.753 \\
-9.733 \\
-4.6120 \\
-6.559 \\
-5.766\end{array}$ & $\begin{array}{l}-0.4756 \\
-2.431 \\
-5.415 \\
-5.506 \\
-3.852 \\
-9.809 \\
-4.6120 \\
-6.644 \\
-5.839\end{array}$ & $\begin{array}{l}(10) \\
(10) \\
(10) \\
(10) \\
(11) \\
(10) \\
(10) \\
(12) \\
(10) \\
(10) \\
(10) \\
(10) \\
(10) \\
(10) \\
(10) \\
(13) \\
(10)\end{array}$ \\
\hline
\end{tabular}

(1) Haar et al.(1984); (2) Tagirov and Schott (2001); (3) Shock et al. (1997); (4) Sverjensky et al. (1997); (5) Ho et al., (2000); (6) McCollom and Shock (1997); (7)Wagman et al. (1982), $200{ }^{\circ} \mathrm{C}, \mathrm{P}_{\text {sat }}$; (8) Assumed $\log \mathrm{K}$ as same as Na species; (9) Shock and Koretsky (1995); (10) Holland and Powell (1998); (11) Hemingway et al. (1991) for boehmite; (12) Robie and Hemingway (1995), $200{ }^{\circ} \mathrm{C}, \mathrm{P}_{\text {sat }}$; (13) Wolery (1978), $200{ }^{\circ} \mathrm{C}, \mathrm{P}_{\text {sat }}$. 
Table 4. Saturation indices calculation for experiment \#1.

\begin{tabular}{lrrrr}
\hline Minerals & $48(\mathrm{~h})$ & $144(\mathrm{~h})$ & $336(\mathrm{~h})$ & $552(\mathrm{~h})$ \\
\hline Quartz & -0.61 & -0.33 & -0.25 & -0.22 \\
Microcline & 0.19 & 1.04 & 2.27 & 1.70 \\
Albite & -4.05 & -3.71 & -2.24 & -3.27 \\
Diaspore & 1.13 & 0.94 & 2.04 & 1.05 \\
Boehmite & 0.91 & 0.72 & 1.82 & 0.83 \\
Kaolinite & 1.58 & 1.77 & 4.11 & 2.21 \\
Muscovite & 3.98 & 4.45 & 7.87 & 5.33 \\
Paragonite & -0.51 & -0.54 & 3.12 & 0.12 \\
Pyrophyllite & -0.10 & 0.65 & 3.14 & 1.31 \\
Calcite & 7.78 & 8.14 & 8.05 & 8.62 \\
Anorthite & -1.87 & -1.33 & 0.93 & -0.40 \\
Magnesite & 7.95 & 8.45 & 8.43 & 9.06 \\
Illite & 0.54 & 1.33 & 4.06 & 2.26 \\
Beidellite-K & -0.50 & 0.15 & 2.96 & 0.89 \\
Montmorillonite-K & -1.25 & -0.21 & 1.89 & 0.69 \\
\hline
\end{tabular}

Table 5. Time-dependent changes in the composition of major dissolved species in aqueous fluid coexisting with Navajo sandstone at $200{ }^{\circ} \mathrm{C}$ and 300 bars. The overall analytical error for dissolved species is $\pm 5 \%$.

\begin{tabular}{|c|c|c|c|c|c|c|c|c|c|c|}
\hline Sample & Time & $\mathrm{K}^{+}$ & $\mathrm{SiO}_{2}$ & $\mathrm{Al}^{+3}$ & $\mathrm{Na}^{+}$ & $\mathrm{Mg}^{2+}$ & $\mathrm{Ca}^{2+}$ & $\mathrm{Cl}^{-}$ & \multicolumn{2}{|c|}{$\mathrm{pH}$} \\
\hline & (h) & \multicolumn{7}{|c|}{$(\mathrm{mmol} / \mathrm{kg})$} & $25^{\circ} \mathrm{C}$ & In-situ* \\
\hline starting & 0 & 203.86 & - & - & 0.11 & - & - & 188.25 & 2.8 & 2.9 \\
\hline$\# 1$ & 24 & 197.28 & 1.63 & 0.14 & 1.42 & 0.77 & 1.15 & 184.91 & 3.6 & 3.4 \\
\hline$\# 2$ & 168 & 200.07 & 4.00 & 0.03 & 0.14 & 1.03 & 1.17 & 182.93 & 4.6 & 4.1 \\
\hline$\# 3$ & 360 & 193.05 & 4.55 & 0.02 & 0.21 & 1.01 & 1.20 & 202.32 & 4.9 & 4.3 \\
\hline$\# 4$ & 696 & 208.74 & 4.93 & 0.02 & 0.30 & 1.36 & 1.28 & 200.96 & 5.0 & 4.3 \\
\hline$\# 5$ & 1392 & 198.67 & 4.49 & 0.02 & 0.24 & 0.86 & 1.09 & 198.78 & 5.1 & 4.2 \\
\hline
\end{tabular}

*In-situ $\mathrm{pH}$ is calculated from distribution of aqueous species calculations at the temperature and pressure of the experiment using constraints imposed by major element concentrations and $\mathrm{pH}$ values measured at $25^{\circ} \mathrm{C}$. 
Table 6. Time-dependent changes in the composition of minor and trace dissolved species in aqueous fluid coexisting with Navajo sandstone at $200{ }^{\circ} \mathrm{C}$ and 300 bars. The overall analytical error for concentration measurements is $\pm 5 \%$.

\begin{tabular}{ccccccccccccc}
\hline Sample & $\mathrm{Li}$ & $\mathrm{Cr}$ & $\mathrm{Fe}$ & $\mathrm{Mn}$ & $\mathrm{Co}$ & $\begin{array}{c}\mathrm{Ni} \\
(\mathrm{ppm})\end{array}$ & $\mathrm{Cu}$ & $\mathrm{Zn}$ & $\mathrm{Rb}$ & $\mathrm{Sr}$ & $\mathrm{Cs}$ & $\mathrm{Ba}$ \\
\hline Starting & - & - & - & - & - & - & - & 0.04 & 0.12 & 0.01 & 0.01 & 0.04 \\
$\# 1$ & - & - & 1.57 & 0.94 & - & - & 6.07 & 0.52 & 0.12 & 0.54 & 0.01 & 0.41 \\
$\# 2$ & - & - & 0.10 & 0.75 & - & 0.09 & 0.10 & 0.20 & 0.13 & 0.54 & 0.01 & 0.30 \\
$\# 3$ & 0.10 & - & 0.12 & 0.37 & 0.02 & 0.21 & 0.14 & 0.06 & 0.14 & 0.53 & 0.01 & 0.30 \\
$\# 4$ & - & - & 0.34 & 0.28 & - & - & 0.11 & 0.05 & 0.18 & 0.56 & 0.02 & 0.45 \\
$\# 5$ & 0.24 & - & 0.27 & 0.28 & - & - & 0.2 & 0.32 & 0.15 & 0.55 & 0.01 & 0.35 \\
\hline
\end{tabular}

Table 7. Saturation indices calculation.

\begin{tabular}{lrrrrr}
\hline Minerals & $24(\mathrm{~h})$ & $168(\mathrm{~h})$ & $360(\mathrm{~h})$ & $696(\mathrm{~h})$ & $1392(\mathrm{~h})$ \\
\hline Quartz & -0.36 & 0.04 & 0.10 & 0.14 & 0.09 \\
Microcline & 0.59 & 2.24 & 2.38 & 2.51 & 2.30 \\
Albite & -2.92 & -2.29 & -1.96 & -1.70 & -1.99 \\
Diaspore & 2.57 & 2.30 & 2.09 & 2.09 & 2.12 \\
Boehmite & 2.35 & 2.08 & 1.87 & 1.87 & 1.89 \\
Kaolinite & 4.97 & 5.24 & 4.92 & 4.99 & 4.96 \\
Muscovite & 7.25 & 8.37 & 8.08 & 8.21 & 8.05 \\
Paragonite & 3.50 & 3.60 & 3.51 & 3.76 & 3.53 \\
Pyrophyllite & 3.78 & 4.86 & 4.65 & 4.79 & 4.68 \\
Anorthite & -1.49 & 0.18 & 0.29 & 0.36 & 0.08 \\
Illite & 2.99 & 4.59 & 4.50 & 4.67 & 4.42 \\
Beidellite-K & 3.18 & 4.27 & 4.04 & 4.17 & 4.05 \\
Montmorillonite-K & 0.69 & 2.59 & 2.65 & 2.83 & 2.55 \\
\hline
\end{tabular}


Table 8. Time-dependent changes in the composition of major dissolved species in aqueous fluid coexisting with Navajo sandstone at $200{ }^{\circ} \mathrm{C}$ and 250 bars. The overall analytical error for dissolved species is $\pm 5 \%$.

\begin{tabular}{|c|c|c|c|c|c|c|c|c|c|c|}
\hline Sample & $\begin{array}{l}\text { Time } \\
\text { (hours) }\end{array}$ & $\overline{\mathrm{K}^{+}}$ & $\mathrm{SiO}_{2}$ & $\mathrm{Al}^{3}$ & $\begin{array}{c}\mathrm{Na}^{+} \\
\mathrm{amol} / \mathrm{l}\end{array}$ & $\begin{array}{l}\mathrm{Mg}^{2+} \\
\mathrm{g})\end{array}$ & $\mathrm{Ca}^{2+}$ & $\mathrm{Cl}^{-}$ & $25^{\circ} \mathrm{C}$ & $\begin{array}{l}\text { In } \\
\text { In-situ* }\end{array}$ \\
\hline$\# 1$ & 0.5 & 196.35 & 0.02 & - & 0.22 & 0.01 & 0.02 & 201.43 & 5.2 & 5.2 \\
\hline$\# 2$ & 4 & 209.45 & 0.26 & - & 0.02 & 0.04 & - & 198.79 & 5.3 & 5.2 \\
\hline$\# 3$ & 13 & 207.01 & 0.24 & - & 0.05 & 0.03 & 0.01 & 197.34 & 5.3 & 5.2 \\
\hline$\# 4$ & 23.5 & 204.83 & 0.18 & - & 0.30 & 0.05 & 0.02 & 196.78 & 5.5 & 5.3 \\
\hline
\end{tabular}

*In-situ $\mathrm{pH}$ is calculated from distribution of aqueous species calculations at the temperature and pressure of the experiment using constraints imposed by major element concentrations and $\mathrm{pH}$ values measured at $25^{\circ} \mathrm{C}$.

Table 9. Saturation indices calculation.

\begin{tabular}{lcrrr}
\hline Minerals & $0.5(\mathrm{~h})$ & $4(\mathrm{~h})$ & $13(\mathrm{~h})$ & $23.5(\mathrm{~h})$ \\
\hline Quartz & -2.25 & -1.14 & -1.17 & -1.30 \\
\hline
\end{tabular}

Table 10. Dissolution rates of Navajo sandstone in the experiment with flow-through apparatus at $200{ }^{\circ} \mathrm{C}$ and 250 bars. The total surface area of 5 gram Navajo sandstone is assumed to be $3.5 \mathrm{~m}^{2}$. The input flow rate is $0.82 \mathrm{ml} / \mathrm{min}$.

\begin{tabular}{cc}
\hline Sample & Dissolution Rate $\left(\mathrm{mol} \mathrm{m}^{-2} \mathrm{~s}^{-1}\right)^{*}$ \\
\hline$\# 1$ & $7.81 \times 10^{-11}$ \\
$\# 2$ & $1.02 \times 10^{-9}$ \\
$\# 3$ & $9.37 \times 10^{-10}$ \\
$\# 4$ & $7.03 \times 10^{-10}$ \\
\hline Average & $6.85 \times 10^{-10}$ \\
\hline
\end{tabular}

* As per mole of $\mathrm{Si}$ 
Figure

\section{FIGURES}

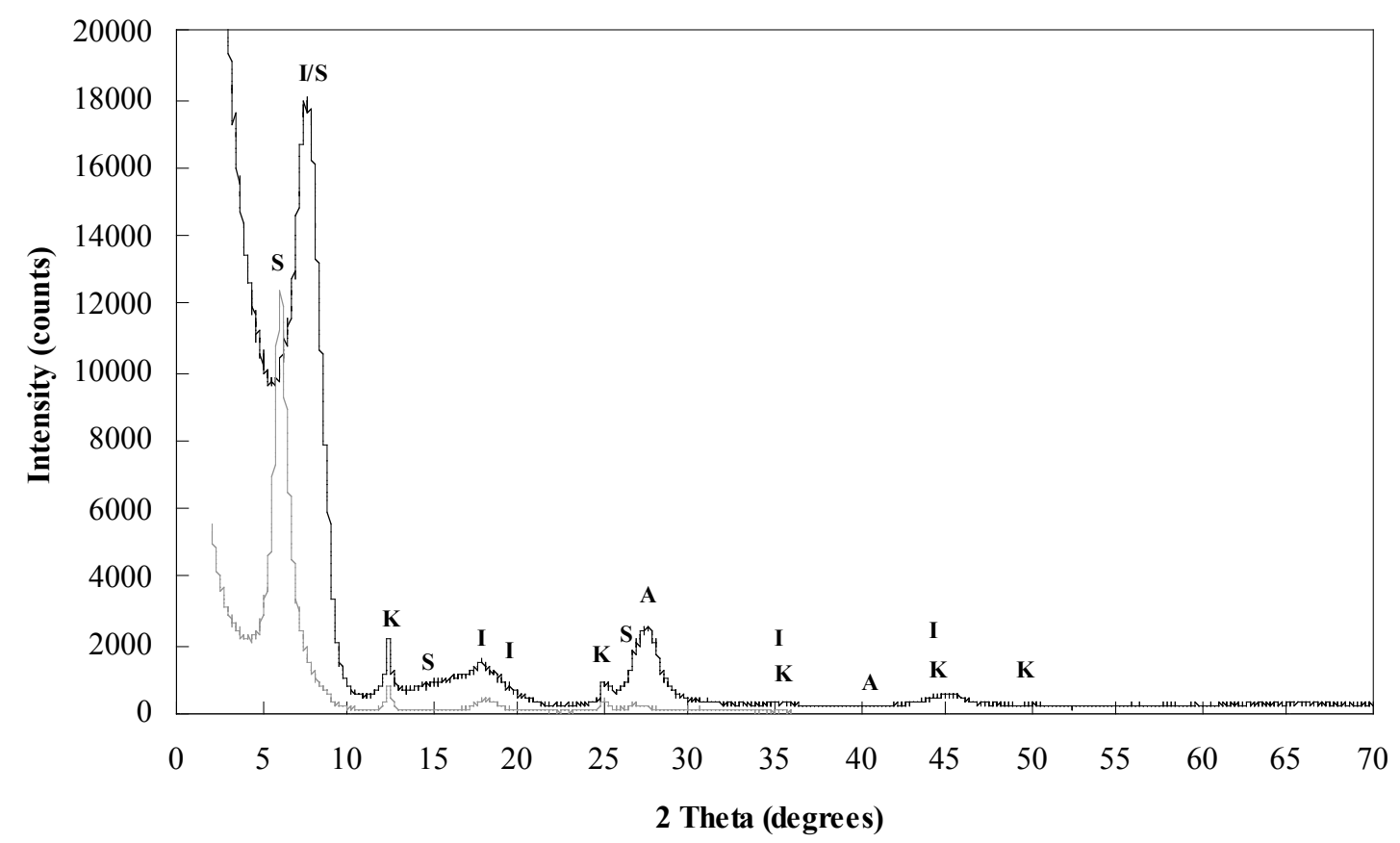

Fig. 1. 

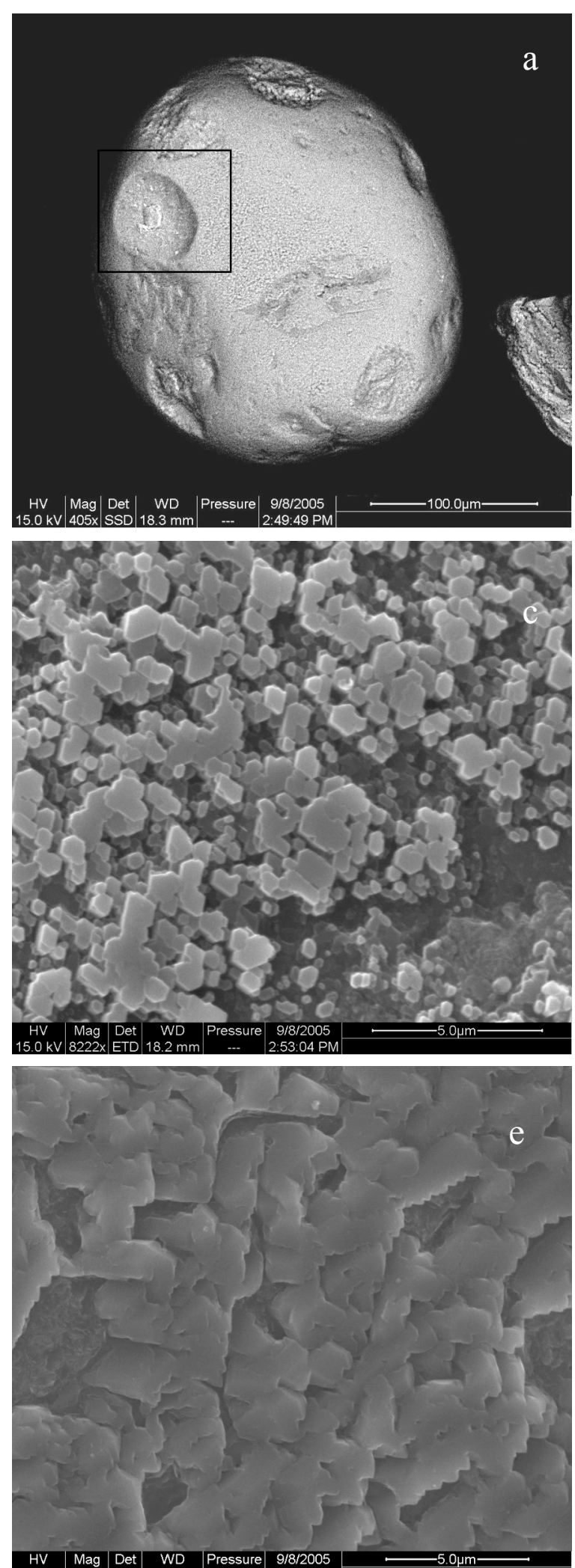

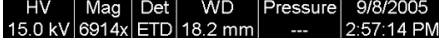

Fig. 2.
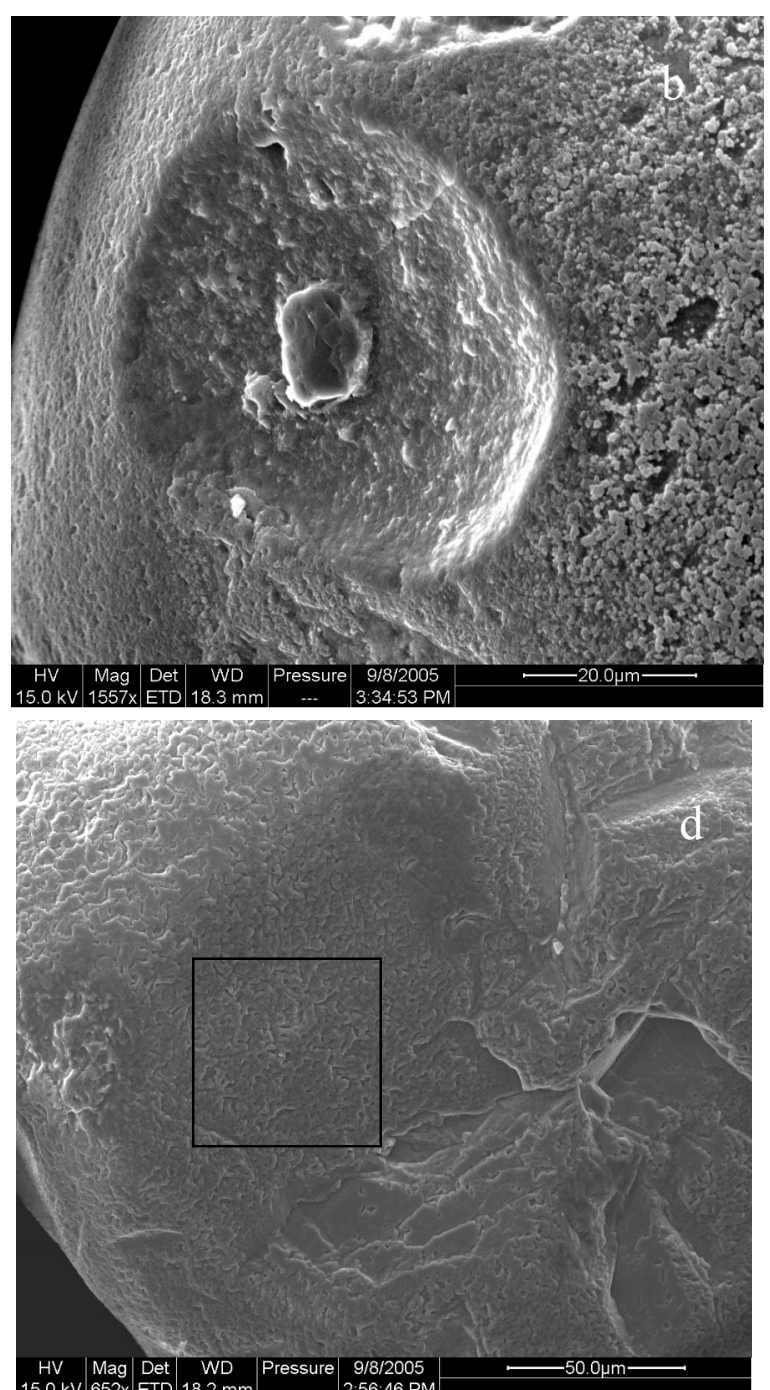

$-57<4$ म5: 

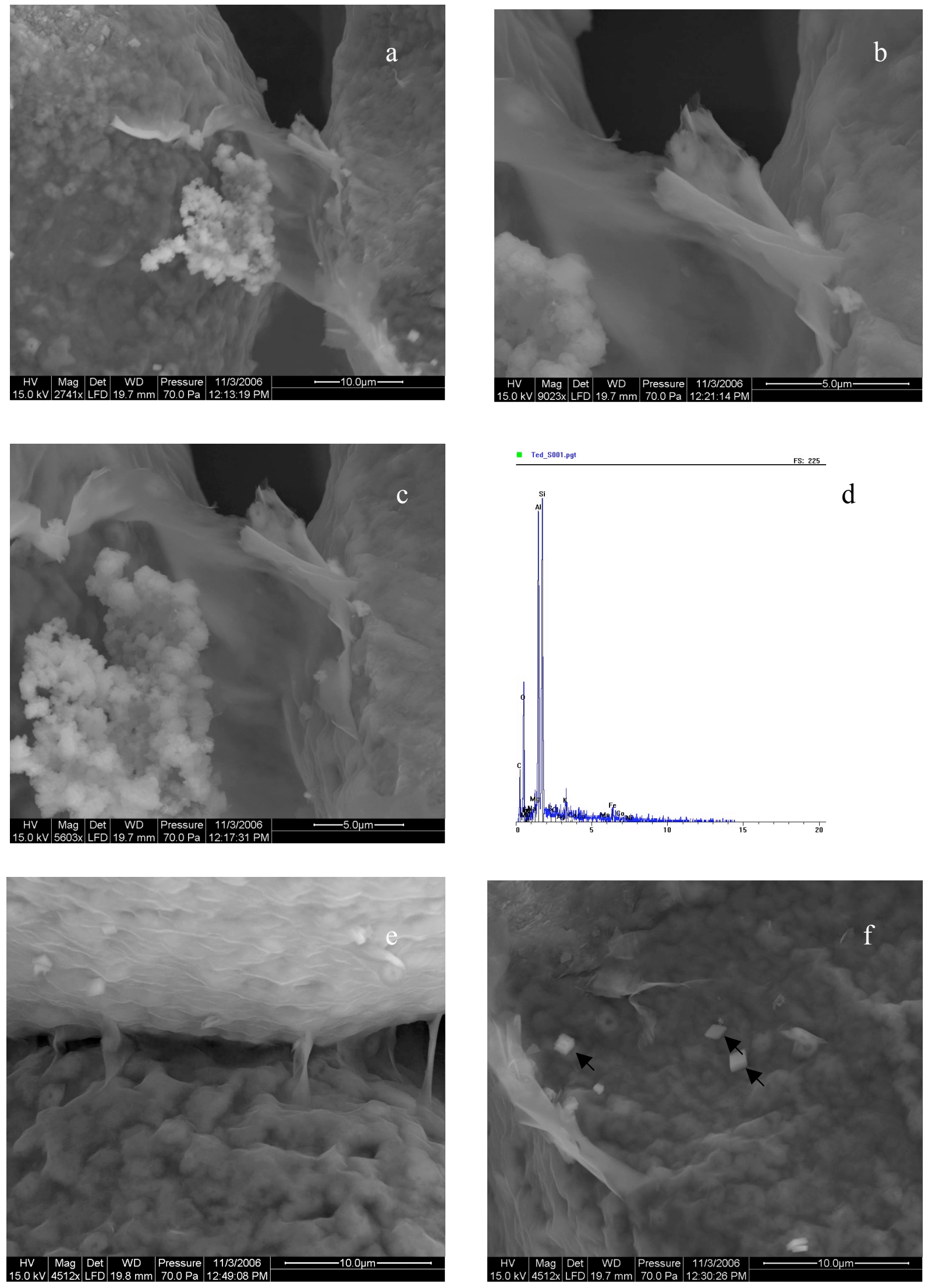

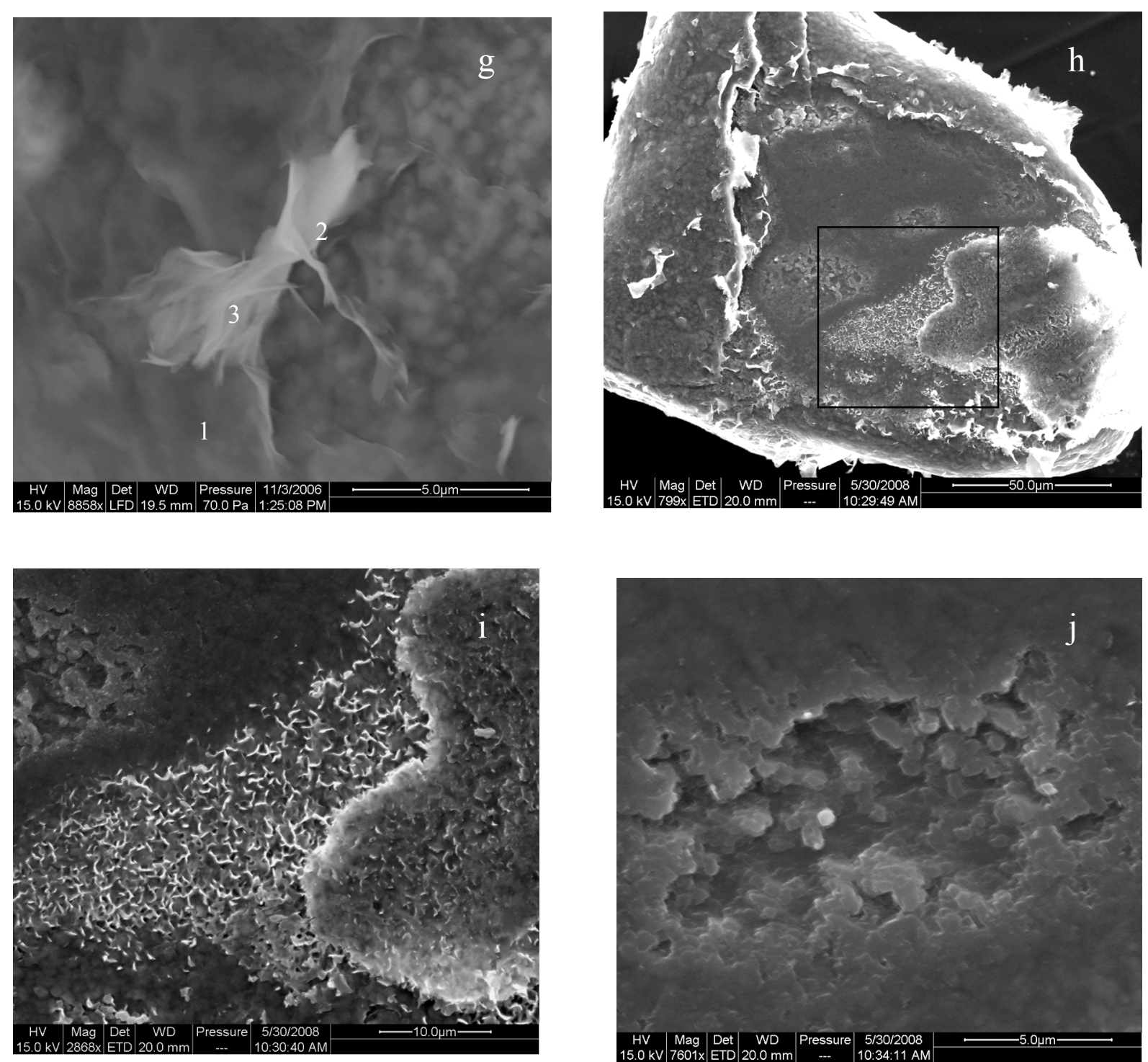

Fig.3. 

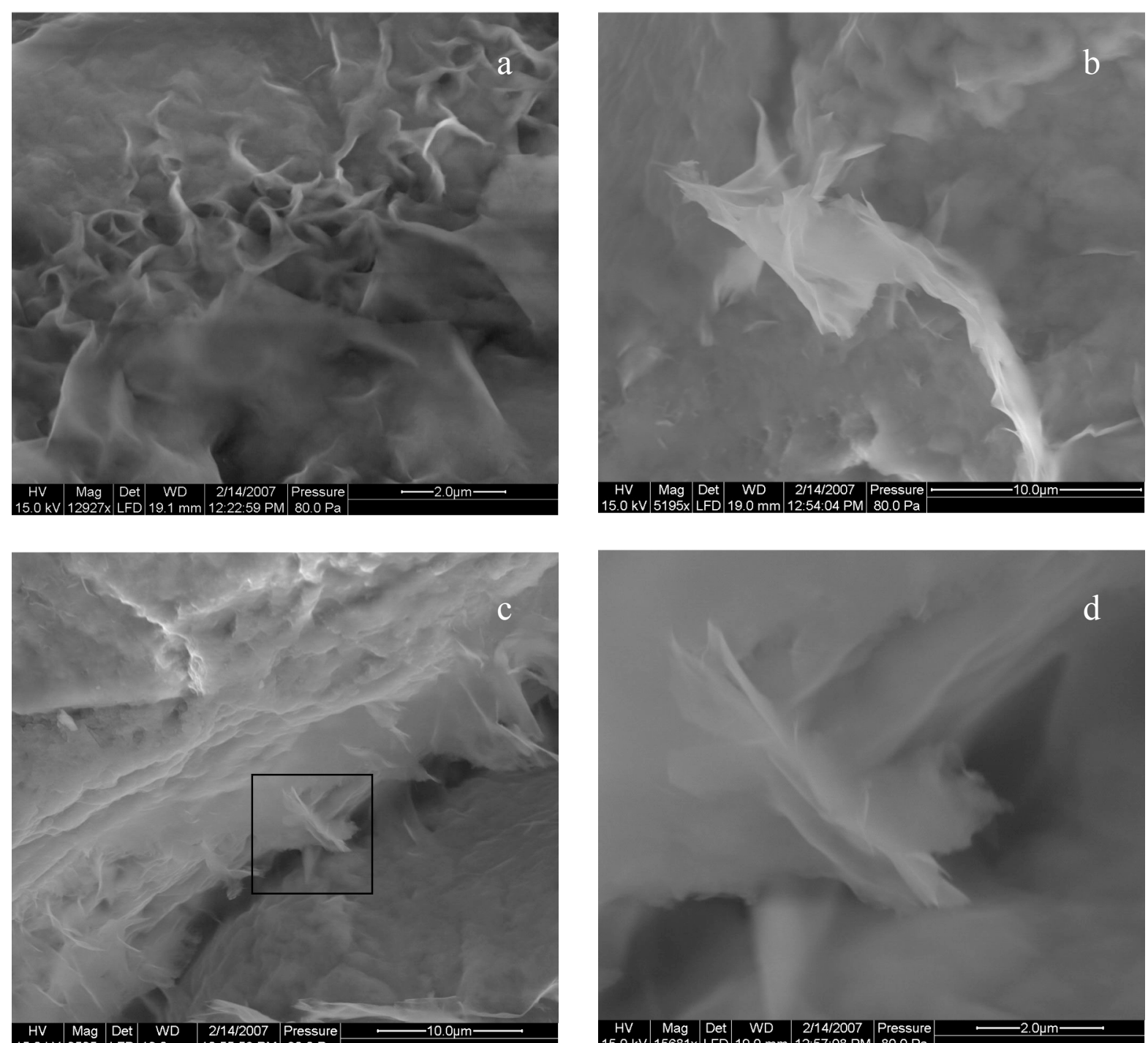

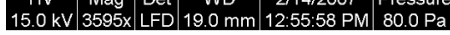
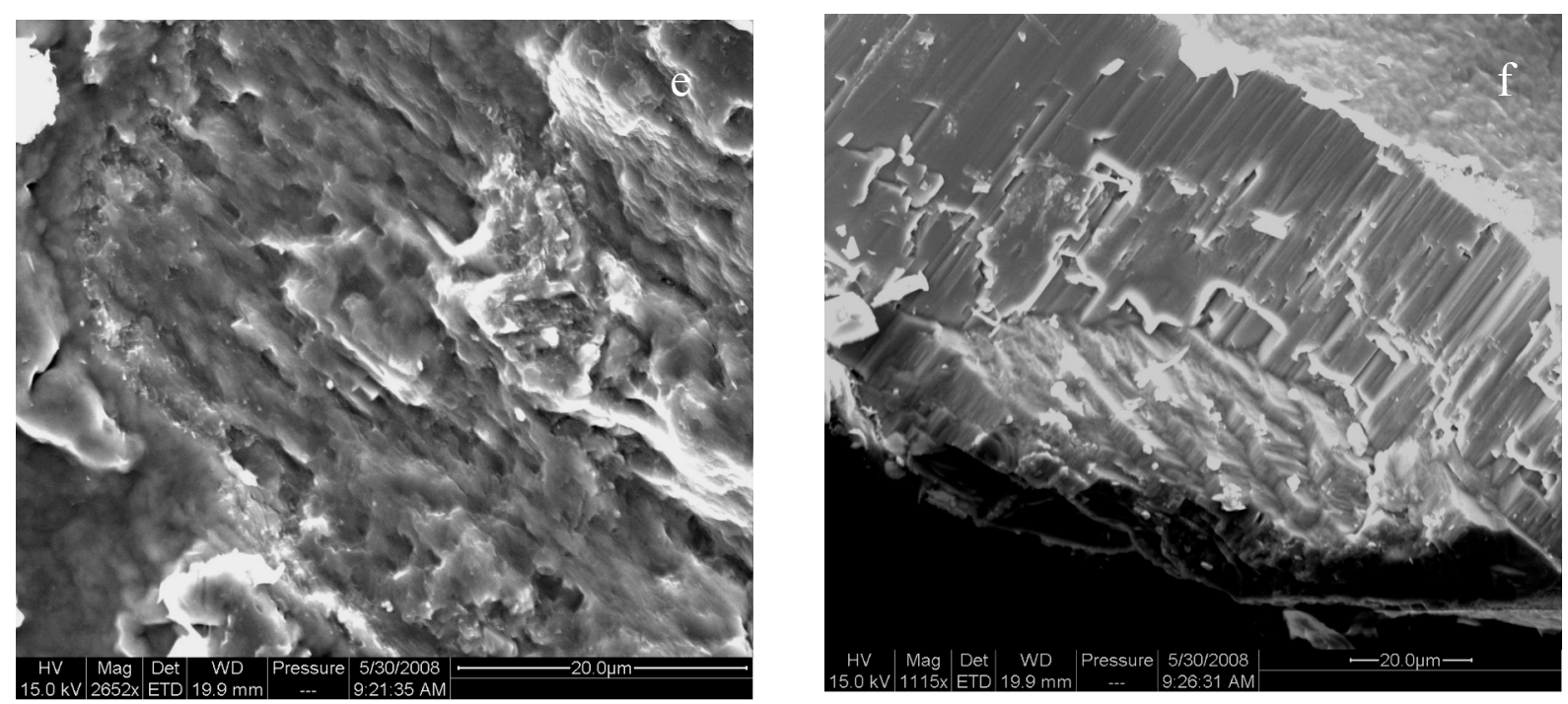

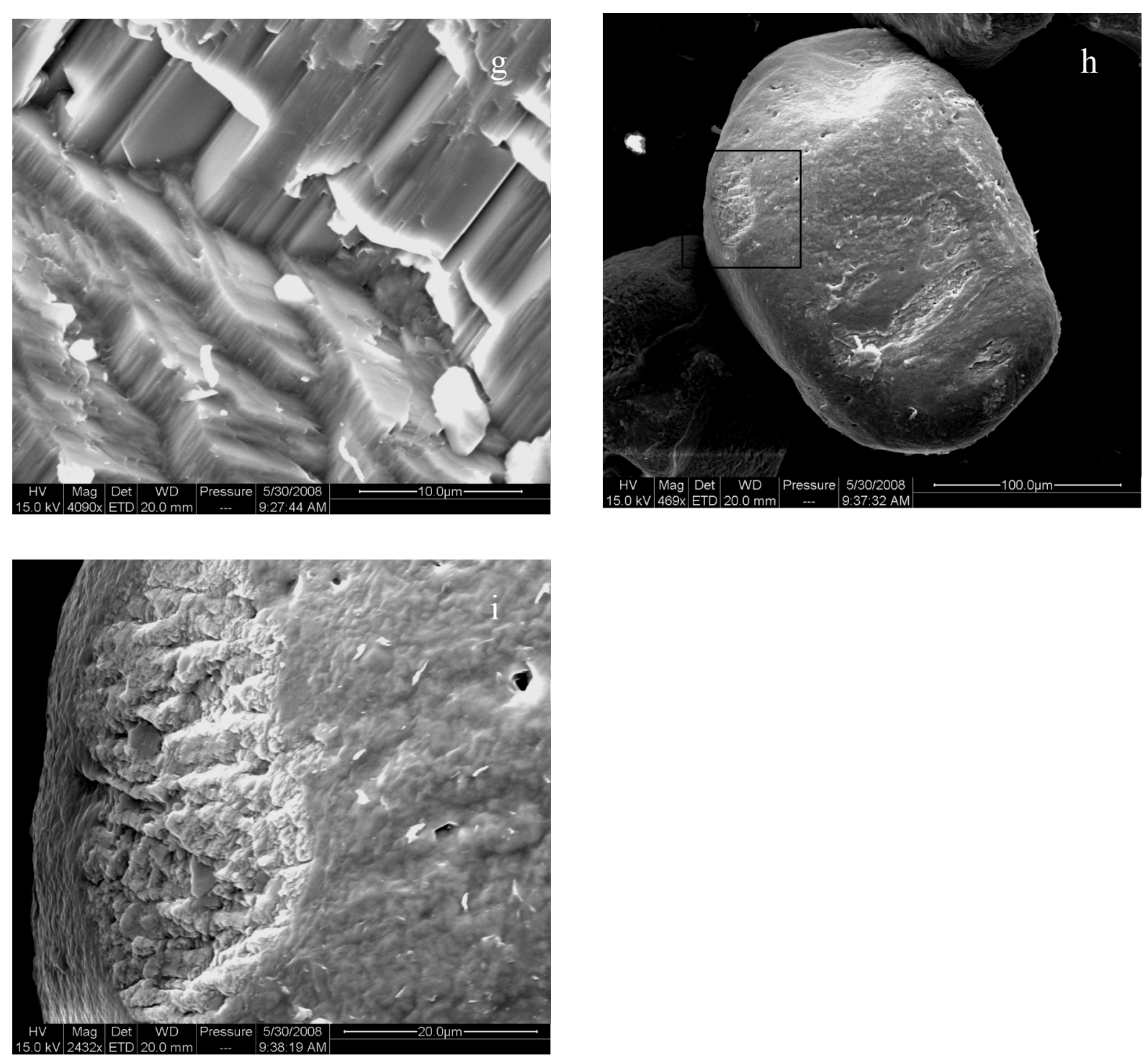

Fig. 4. 

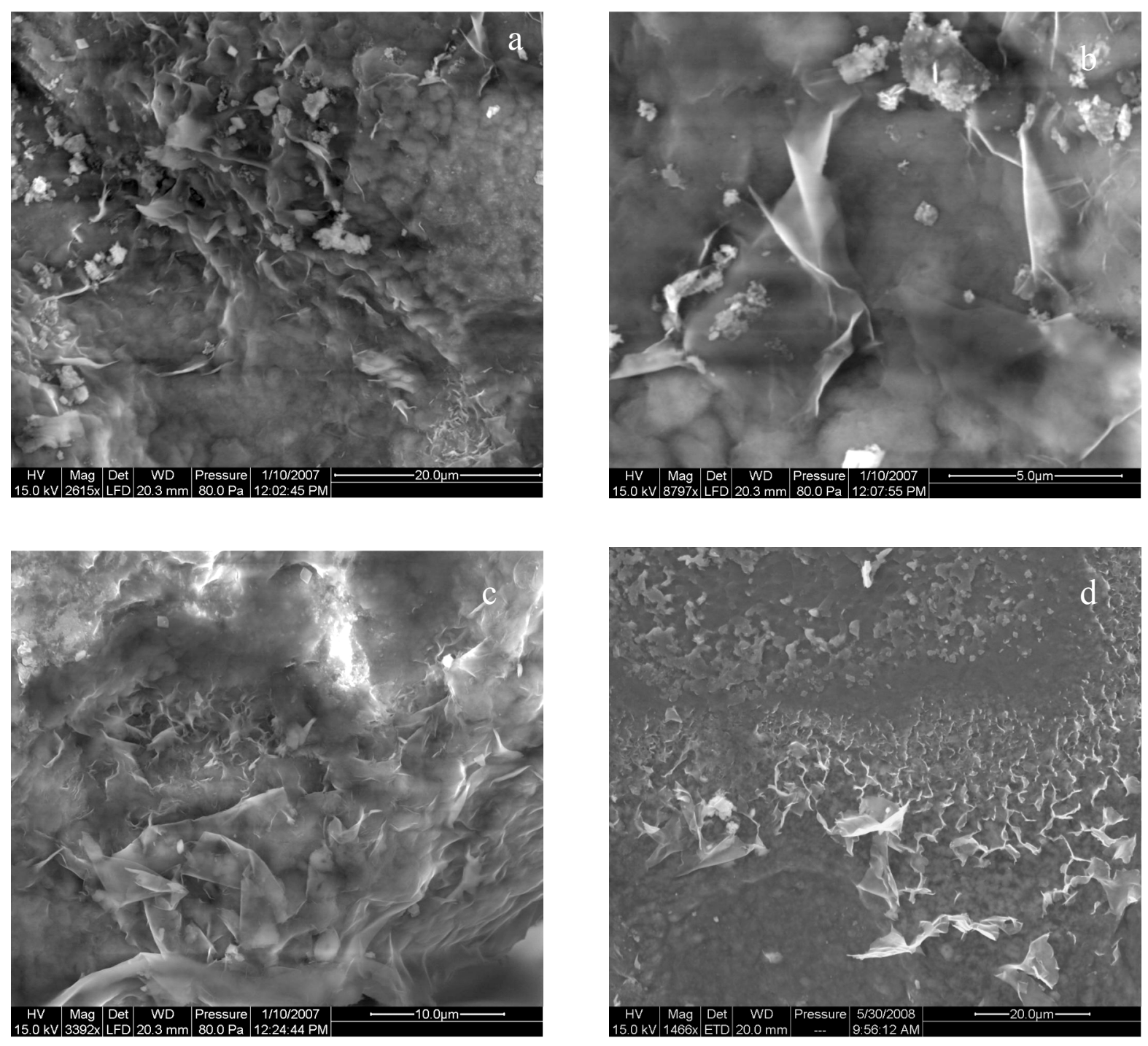

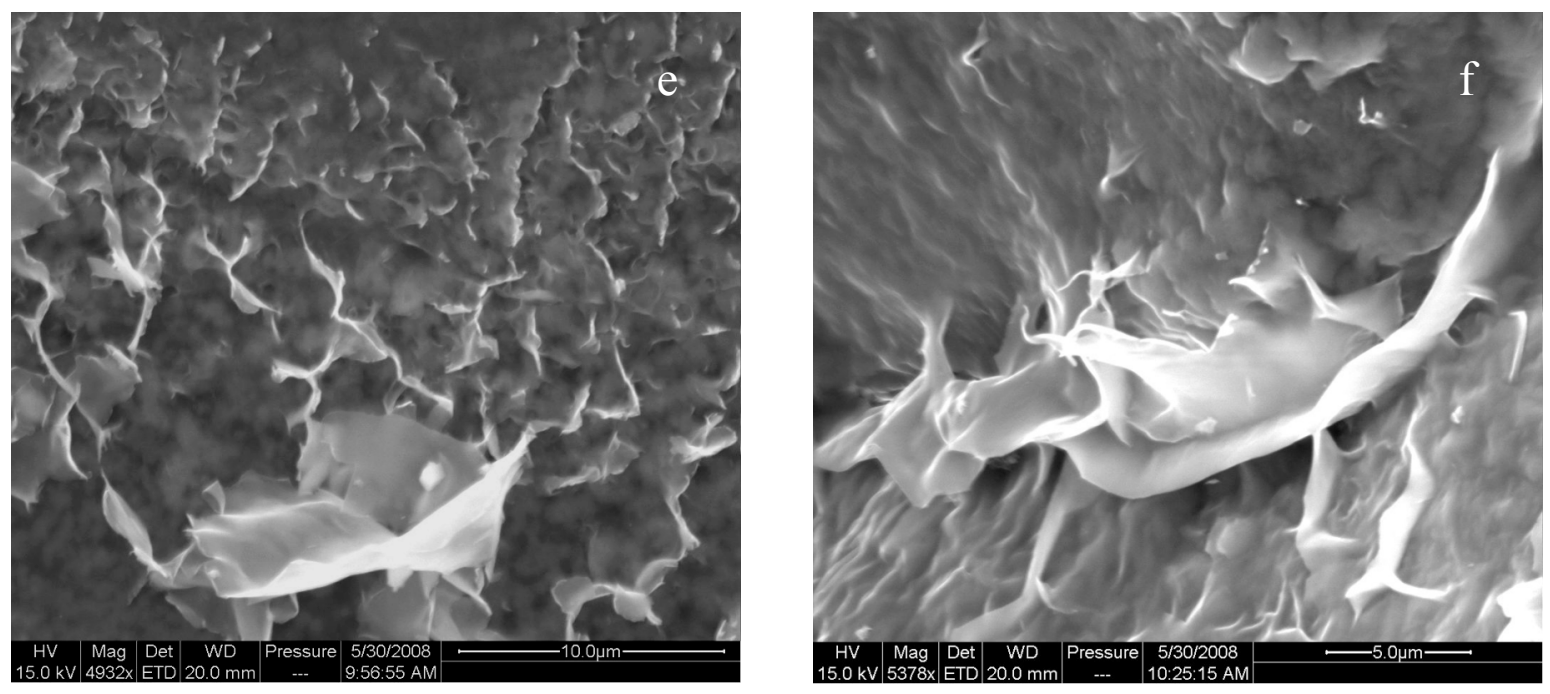

Fig. 5. 